PROGRAMA DE DOCTORADO EN INVESTIGACIÓN TRANSDISCIPLINAR EN EDUCACIÓN

TESIS DOCTORAL:

\title{
MUSICOTERAPIA BASADA EN TÉCNICAS DE MÚSICA E IMAGEN (MI) COMO INTERVENCIÓN EN CASOS DE NIÑOS CON Y SIN DIAGNÓSTICO DE TRASTORNO POR DÉFICIT DE ATENCIÓN/HIPERACTIVIDAD (TDAH): UN ENFOQUE MIXTO
}

\author{
Presentada por Alberto Acebes de Pablo \\ para optar al grado de \\ Doctor por la Universidad de Valladolid
}

Dirigida por:

Dra. Andrea Giráldez Hayes

Dr. Andrés Palacios Picos 





\section{AGRADECIMIENTOS}

El desarrollo de la presente tesis doctoral ha supuesto recorrer un camino que en varias ocasiones no ha sido nada sencillo, y estoy seguro de que no podría haberlo logrado sin la ayuda y soporte de todas y cada una de las personas a las que voy a mencionar en estas palabras de agradecimiento.

En primer lugar, me gustaría agradecer todo el apoyo y acompañamiento que me han brindado en todo momento mis directores de tesis: Andrea Giráldez y Andrés Palacios. Me habéis ayudado siempre, aportándome confianza y tranquilidad, mostrando vuestra capacidad de escucha, vuestra sensibilidad y atención, tanto en las situaciones complicadas como en los momentos de impulso y lucidez.

Andrea, gracias por confiar en mí desde que terminé la carrera, no solo para acompañarme en el proceso de desarrollo de mi Trabajo Fin de Máster, sino también en el proceso de construcción de todo este camino que ha terminado tomando la forma de tesis doctoral. Y, lo más importante, gracias por escucharme y darme tanto apoyo en uno de los momentos que fueron más complicados para mí a lo largo de este trabajo. Nunca olvidaré tu ayuda, soporte y tu empatía en ese instante. Gracias.

Andrés, gracias por estar siempre ahí, en todo momento, para lo bueno y para lo malo. Siempre he sabido que tenías un abrazo para darme en los malos momentos, y un chascarrillo para reírnos en los buenos momentos y celebrar las buenas noticias. Hemos pasado horas hablando sobre la tesis y al fin hemos llegado al final del camino. Gracias.

En segundo lugar, me gustaría agradecer a las personas responsables de que esta investigación haya sido posible, que son todos los participantes que han formado parte del estudio: madres, padres, niños, niñas y tutoras. No hace falta que diga que nutrís cada página de este documento. Juntos vivimos un proceso en el que reímos, jugamos, lloramos, escuchamos, dibujamos, hablamos... En definitiva, nos acompañamos. Por cuestión de protección de vuestros datos, no puedo mencionar a nadie, pero sabéis perfectamente lo agradecido que me siento por vuestro interés y buena disposición, desde el comienzo hasta el final de la investigación.

Me gustaría continuar con dos personas que para mí han sido maestros, mentores y supervisores, y que ahora se han transformado en dos de las personas más importantes en mi vida. Jim Borling y Montserrat Gimeno, que han sido quienes me han guiado y formado en la especialización en el Modelo Bonny de Imagen Guiada con Música, de un modo tan profesional y cuidadoso. 
Jim, I have no words to describe all the things you have done for me since the first time we met. I feel so grateful for every moment I spent learning from you and sharing good moments. Meeting you has changed my life and that of many other people. You are always there to help us in different ways. I appreciate that and it means a lot to me. Thanks for the trust you have on me. I hope we can see each other again, as soon as this situation allows us to travel again. Mentor, trainer, spiritual father, friend. Thanks for everything.

Montse, hemos vivido muchísimas cosas juntos, no solo en la formación, sino en mi viaje a Estados Unidos y en algún que otro congreso. Cosas maravillosas, y situaciones complicadas que nos han hecho aprender y apreciar más los pequeños detalles y los buenos momentos que la vida nos brinda. Te agradezco de corazón tu confianza en mí y cada cosa que has hecho por mí, y me alegro enormemente de que tengamos una relación tan cercana y honesta. Mentora, formadora, madre espiritual, amiga. Gracias por todo.

Continuando con las personas pertenecientes al ámbito académico, tengo mucho que agradecer a todos mis compañeros de la Facultad de Educación de Segovia, con quienes tantos momentos buenos he compartido desde hace ya la friolera de seis años (diez, si cuento mi tiempo como estudiante).

David Carabias, que ha pasado de ser profesor en la carrera y tutor de TFG a convertirse en compañero y, sin dudarlo, amigo. Gracias por nuestras conversaciones, cargadas siempre de sensibilidad, compañerismo y, en muchas ocasiones, risas. Siempre has tenido unas palabras que ofrecerme cuando surgían momentos de estrés o complicación respecto a la tesis y otros temas. En este punto no puedo por menos que agradecer a tu compañera de vida, Luisa Moreno, por razones similares. Como compañera de universidad y amiga, también hemos compartido muchas conversaciones sobre el desarrollo de la tesis y la dificultad de la construcción de la carrera docente, así que con cada paso que doy me acuerdo de ello y me siento orgulloso. Gracias a ambos por vuestra confianza en mí. Recuerdos a Lula.

Mis queridas compañeras de departamento: Mao Cortón e Inés Monreal. Hemos compartido cantidad de cosas a lo largo de estos años de docencia. Os estoy enormemente agradecido por confiar en mí para este proceso, y feliz de seguir contribuyendo al desarrollo de las asignaturas de música y a la formación de futuros maestros y maestras junto a vosotras, con la sensibilidad y cariño que os caracteriza. Gracias de corazón.

Miriam Sonlleva, Raúl Barba, Suyapa Martínez, Carlos Sanz. Gracias por nuestras incansables y divertidas conversaciones. Miriam, siempre dispuesta a ayudarnos en todo lo que sea posible. Te desvives por los demás y por ello 
te estoy enormemente agradecido, no solo como tu amigo sino como persona que se preocupa de hacer de este mundo un lugar mejor. Tú contribuyes a ello cada día. Raúl y Carlos, siempre capaces de sacarnos una sonrisa aun cuando la situación no sea nada alentadora. Suyapa, que se preocupa por el mundo y por el bienestar de las personas (nosotros los primeros). Gracias amigos y amigas, de corazón.

Juan Carlos Manrique, que me ha acompañado en el despacho de decanato en los momentos de incertidumbre y bloqueo que han surgido, junto con Andrés Palacios. Me has dado confianza y energía que sin duda necesitaba en esos momentos para poder seguir avanzando. Gracias de corazón.

Nuestra gran Antonieta. Una de las personas más profesionales y competentes que conozco. Empleas todo tu esfuerzo y empeño en hacer las cosas bien, en ayudar en todo lo que te sea posible. Haces que lo que puede parecer difícil sea fácil, y además siempre con un chascarrillo que nos ayuda a echarnos unas risas. Gracias por todo tu trabajo.

Ruth Pinedo, por tantas y buenas conversaciones que hemos tenido, que me han aportado alegría y serenidad. Luis Torrego, por todo tu acompañamiento y guía respecto a gran cantidad de cosas. Ana Maroto, por sacarme siempre una sonrisa y darme tranquilidad cuando hay algún problema. Víctor, Roberto, Darío, Alfonso, Mercedes, Cristina Gil, Cristina Vallés, Marian, Belén, Matías, Rosendo. Algún compañero que me pueda dejar y ruego que me disculpe. Gracias a todos. Os tengo muy presentes.

Entrando más en el terreno personal, la primera persona en la que pienso es Elena López García, mi pareja y compañera de vida. No sé cómo describir en pocas palabras todo lo que me has apoyado y ayudado durante estos últimos meses de travesía en mi tesis doctoral en los que tantos momentos de estrés y ansiedad ha habido. Eres de esas personas que no necesitan pensar qué tienen que decir para echar una mano, porque solo tu presencia, junto con tu gran corazón, ayuda y reconforta. Estoy feliz de que nuestras vidas se hayan entrelazado. Gracias por todo, por cada momento a tu lado. Gracias de corazón.

Y el primer grupo de personas que me viene a la cabeza es, sin duda, mi familia. Mi padre José Luis Acebes (Sievo), mi madre Charo de Pablo (Sieva), mi hermano Dani. Sievo y Sieva, habéis cuidado de nosotros siempre, desde el minuto uno de nuestra vida, y seguís haciéndolo aun en nuestra etapa adulta. Sievo, siempre tienes algún buen consejo que dar o alguna recomendación acertada que hacer, y siempre estás disponible para ayudarnos en todo lo que te sea posible. De ti tengo la profesionalidad, la seriedad y la responsabilidad de cuidado hacia mí y hacia los demás. Sieva, tienes la maravillosa 
capacidad de hacer sonreír siempre, sea cual sea la circunstancia. De ti tengo la amabilidad, la buena educación y el cariño hacia otras personas. Hermano, eres una de las pocas personas que me sigue demostrando constantemente que es posible ser mejor persona y mejor profesional solo con intentarlo de forma auténtica y constante, haciendo todo lo posible cada día y poniendo todo el empeño en una buena actitud ante la vida. Y aquí entra en juego tu compañera de vida, María, que sintoniza contigo en esta actitud y en el deseo de hacer del mundo un lugar mejor con vuestro trabajo cada día. Gracias a los cuatro por todo.

A continuación, lo que podría considerar sin duda como mi segunda familia: el grupo de formación en el Modelo Bonny de Imagen Guiada con Música, compañeras y compañeros que hicieron de esta formación un espacio de confianza, honestidad, seguridad y comprensión. No hace falta que explique todo lo que hemos vivido juntos durante estos años de camino que hemos recorrido juntos. Sois algo especial para mí. Sé que formáis parte de mi vida de forma auténtica e imprescindible. Sigamos construyendo y compartiendo el camino de crecimiento personal y profesional. Gracias por estar siempre ahí, Familia.

No puedo dejarme a mis compañeros del Máster de Musicoterapia, que también me acompañaron en el proceso de elaboración de esta tesis doctoral. A lo largo de los años que pasamos en el máster compartimos una gran cantidad de vivencias y de experiencias. Guardo muy buen recuerdo y os tengo muy presentes. Helena, has pasado de ser compañera de máster a ser una de mis mejores amigas, co-terapeuta en las sesiones de Musicoterapia, vicepresidenta en la Asociación para el Desarrollo y la Investigación de la Musicoterapia (ADIMTE) y, sin duda, una gran profesional con la que sé que puedo y podré contar siempre. Gracias por todo, de corazón.

Mis mejores amigos: Jimy, Javi, David, Elena, Canario, Dan. Estáis y estoy deseando terminar la tesis para que podamos pasar más tiempo juntos. Ya casi está conseguido. Gracias por vuestro apoyo y vuestra presencia siempre.

Toda la gente con la que he recorrido camino en relación con la música, por medio de la Asociación Cultural Alborada Musical en Cantalejo: el lugar de donde vengo. Celia y Diana, me habéis acompañado en infinidad de conversaciones sobre mi tesis, y me habéis ayudado siempre. Gracias. Andrés, Mario, Álex, Eva, Javier San Inocente, Javier Sanz, Raúl, Curro, David, Víctor, Manu. Hemos vivido cantidad de experiencias juntos, y habéis estado presentes en muchos de mis momentos de fragilidad, dándome soporte e impulso en todo momento. Gracias.

Repito y quiero que quede claro: nada de esto habría sido posible sin vosotros. Gracias de corazón. 




\section{RESUMEN}

El principal objetivo de la presente tesis doctoral es estudiar el empleo de un método de Musicoterapia basado en técnicas de música e imagen (MI) como intervención en casos de niños con y sin diagnóstico de Trastorno por Déficit de Atención/Hiperactividad (TDAH). Esta intervención se plantea como una forma de contribuir a la mejora de los procesos de inclusión educativa y social de niños con este diagnóstico y al desarrollo de la capacidad de gestión emocional tanto suya como de los niños sin este diagnóstico.

El método de investigación empleado se fundamenta en un enfoque mixto, $y$ más en concreto en un Diseño de Triangulación Concurrente (DITRIAC). Se contó con la colaboración de nueve niños participantes, de los cuales cinco tienen diagnóstico de TDAH y cuatro no. Las principales técnicas cualitativas de obtención de información fueron la entrevista semiestructurada, realizada a los padres y las madres de los niños participantes, antes y después del estudio, la observación participante, junto con el diario de investigación, en el que se plasmó de forma reflexiva lo acontecido durante el proceso de desarrollo de las sesiones de Musicoterapia, y los dibujos o mandalas resultantes de las sesiones, como evidencias visuales. Por su parte, los instrumentos cuantitativos de recogida de datos fueron la escala de evaluación de conductas de TDAH (EDAH) y una escala de observación de desarrollo emocional (EODE).

Para el análisis de contenido de los datos cualitativos se siguieron las fases de categorización, condensación e interpretación de significado. Para el análisis de datos cuantitativos se realizó la prueba no paramétrica de Wilcoxon, con el objetivo de valorar si los cambios producidos después de haber realizado la intervención son estadísticamente significativos para un nivel de confianza del 5\%. Una vez llevado a cabo este análisis de datos paralelo, ambos puntos de vista (cualitativo y cuantitativo) fueron comparados, siguiendo el diseño de enfoque mixto empleado, con el fin de valorar el grado de alcance de los objetivos e hipótesis planteados.

Los resultados reflejan que se ha producido un incremento significativo de la competencia emocional de todos los niños participantes en lo referido a las capacidades de conciencia emocional, regulación emocional, autonomía emocional, competencia social y competencia de vida y bienestar, así como una disminución significativa de la muestra de conductas características en casos de TDAH: hiperactividad e impulsividad, déficit de atención y trastorno de conducta.

Palabras clave: Trastorno por Déficit de Atención/Hiperactividad (TDAH), Musicoterapia, Imagen Guiada con Música (GIM), Música e Imagen (MI), Educación Emocional, Educación Inclusiva. 



\section{ABSTRACT}

The main aim of this doctoral thesis is to study the use of a music therapy method based on music and imagery (MI) techniques, as an intervention for children with and without diagnosed Attention-Deficit/Hyperactivity Disorder (ADHD). The intervention is used to improve processes of educational and social inclusion for children with an ADHD diagnosis, and the capacity for emotional regulation in both sets of patients (with and without the diagnosis).

The research methodology employed is based on a mixed method - more specifically, the Concurrent Triangulation Design (CTD). Nine children took part in the study, five of whom were diagnosed with ADHD and four were not. The main qualitative techniques used to collect information were: semi-structured interviews with the children's parents, both before and after the study; and participant observation along with an investigation log, containing reflections on occurrences during the process of the music therapy sessions, and the drawings or mandalas the children produced in the sessions, as visual evidence. Meanwhile, the quantitative instruments used were the ADHD behavioural rating scale (EDAH) and an emotional development scale (EODE).

The steps followed in analysing the content of the qualitative data were categorisation, condensation and interpretation of meaning. The non-parametric signed-rank Wilcoxon test was applied in analysing the quantitative data, to assess whether the changes brought about after the intervention were statistically significant for a confidence level of 5\%. Following this parallel data analysis, the two standpoints (qualitative and quantitative) were compared, in keeping with the mixed method design, to assess the degree to which the objectives and hypotheses had been realised.

The results reflect a significant increase in the emotional competence of all the children who took part, in terms of emotional awareness, emotional independence, social skills, life skills and wellbeing, and a significant decrease in the characteristic behaviours exhibited in cases of ADHD: hyperactivity and impulsivity, attention deficit and behavioural disorder.

\section{Keywords:}

Attention Deficit/Hyperactivity Disorder (ADHD); Music therapy; Guided Imagery and Music (GIM); Music and Imagery (MI); Emotional Education; Inclusive Education. 





\section{ÍNDICE DE CONTENIDOS}

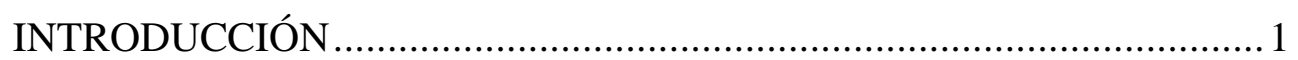

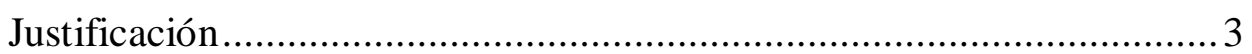

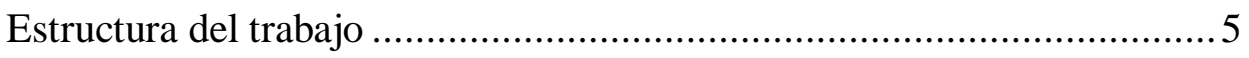

Consideraciones previas a la lectura de esta tesis doctoral .................... 8

CAPÍTULO I. HACIA UNA EDUCACIÓN INCLUSIVA ...................... 11

1. De la exclusión a la inclusión. Del alumnado con discapacidad a la diversidad educativa................................................................... 13

1.1. Asumir la diversidad como oportunidad de cambio ................... 17

1.2. Principios de la Educación Inclusiva .......................................... 19

2. Respuesta educativa ante la diversidad ........................................... 21

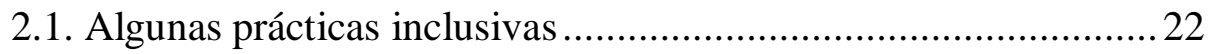

CAPÍTULO II. EL TRASTORNO POR DÉFICIT DE

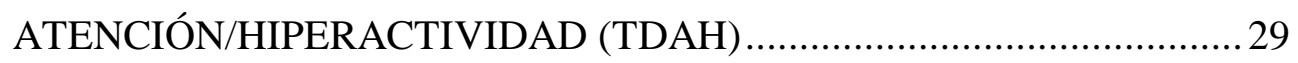

1. Aproximación conceptual y características básicas ............................ 31

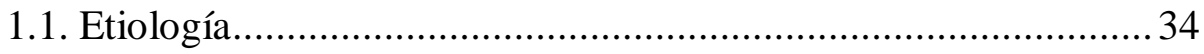

1.2. No solo niños inquietos o inatentos: aspectos positivos del TDAH

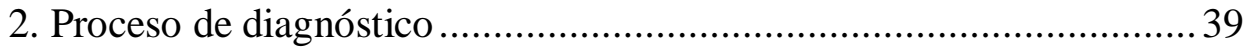

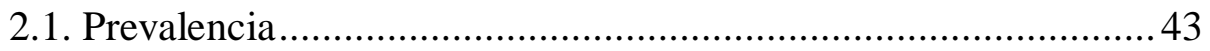

3. Formas de intervención .................................................................... 45

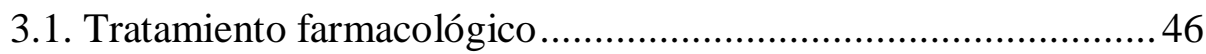

3.2. Medidas no farmacológicas ................................................... 48

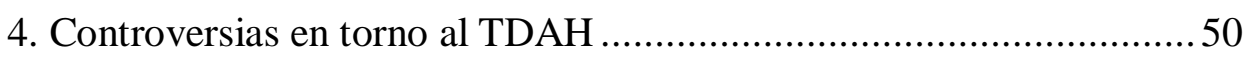

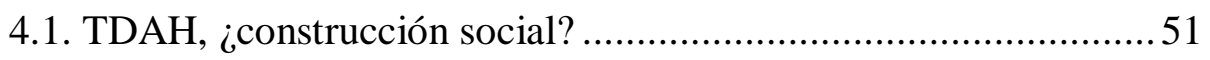

4.2. En relación con el número de diagnósticos ..................................54

4.3. Respecto a la medicación farmacológica...................................56

4.3.1. Terapias complementarias como intervención para el TDAH 


\section{CAPÍTULO III. LA MUSICOTERAPIA COMO INTERVENCIÓN NO}

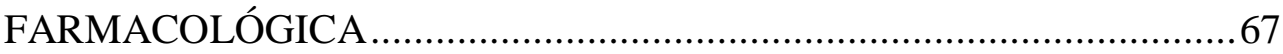

1. Fundamentos teóricos de la Musicoterapia ………………………......69

1.1. Perspectiva histórica ....................................................................69

1.2. Fundamentos biológicos ...........................................................

1.3. Fundamentos psicológicos ...........................................................

2. La Musicoterapia como disciplina .....................................................76

2.1. Aproximación conceptual y características básicas .......................76

2.1.1. El papel del musicoterapeuta...............................................78

2.1.2. El papel de la música .......................................................... 80

2.1.3. Clasificación de métodos de trabajo en Musicoterapia...........82

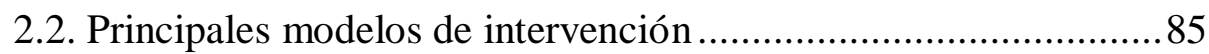

2.2.1. El Modelo Bonny de Imagen Guiada con Música (BMGIM) 85

2.2.2. El Modelo Nordoff-Robbins .................................................90

2.2.3. La Musicoterapia Analítica ....................................................92

2.2.4. El Modelo Benenzon ...........................................................94

2.2.5. El Modelo Conductista ………………………………...........96

3. Musicoterapia en el ámbito educativo ..................................................

3.1. Musicoterapia y necesidades educativas especiales .....................100

3.2. Musicoterapia y TDAH ……………………………................ 103

\section{CAPÍTULO IV. CARACTERÍSTICAS DE LA INTERVENCIÓN} MUSICOTERAPÉUTICA: TÉCNICAS DE MÚSICA E IMAGEN (MI) 107

1. Fundamentación del método de Musicoterapia empleado para la

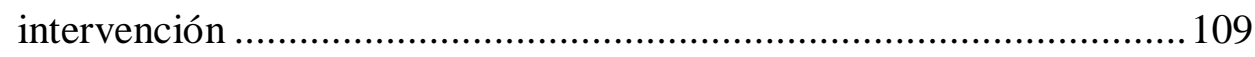

1.1. Adaptaciones del BMGIM......................................................109

1.1.1. Aplicación de GIM en niños ...............................................113

1.2. Delimitación entre GIM y otras técnicas de Musicoterapia

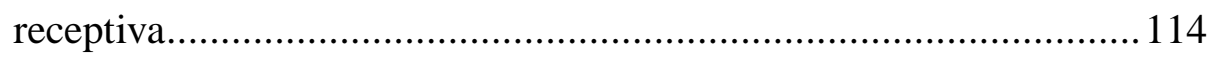

1.3. Música, emociones y estados de ánimo ………………………....116

1.4. El papel del cuerpo en GIM .....................................................122

1.5. Utilidad del mandala como objeto proyectivo .............................124 
2. Implicaciones para el TDAH y descripción del método de

1. Introducción

2. Principios de la investigación

2.1. Paradigma de la investigación

2.2. La utilidad del enfoque mixto: Diseño de Triangulación

Concurrente (DITRIAC)

2.2.1. Perspectiva cuantitativa: diseño longitudinal 138

2.2.2. Perspectiva cualitativa: estudio de casos múltiples 139

3. Objeto de estudio

3.1. Objetivos

3.2. Hipótesis

4. Diseño metodológico 142

4.1. Contextualización. 142

4.2. Descripción de los participantes 143

4.3. Técnicas e instrumentos de recogida de datos 146

4.3.1. Instrumentos cuantitativos de recogida de datos. 146 4.3.1.1. Escala Evaluación del Trastorno por Déficit de Atención con Hiperactividad (EDAH) 146 4.3.1.2. Escala de observación del desarrollo emocional para ciclo inicial 147

4.3.2. Técnicas cualitativas de obtención de información..... 148

4.3.2.1. Entrevista semiestructurada 148

4.3.2.2. Observación participante y diario de campo 149

4.3.2.3. Material audiovisual y fotografías 151

4.4. Proceso de análisis de datos 151

4.4.1. Análisis de los datos cuantitativos. 151

4.4.2. Análisis de la información textual cualitativa 152 
4.4.2.1. Proceso de codificación o categorización del significado

4.4.2.1. Fases de condensación e interpretación del significado 154

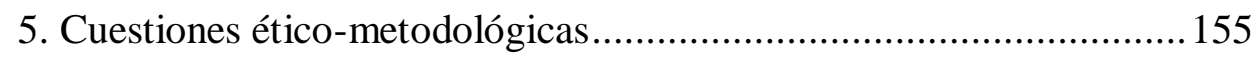

6. Criterios de validez, fiabilidad y triangulación.............................. 159

CAPÍTULO VI. ANÁLISIS DE LOS DATOS .................................... 163

1. Repercusión de la intervención a nivel emocional........................... 166

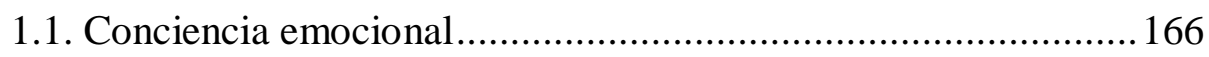

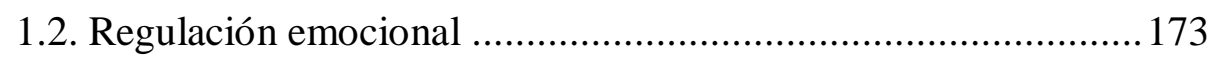

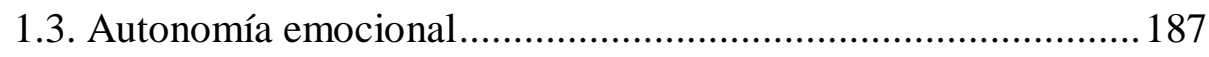

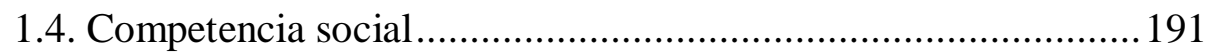

1.5. Competencia de vida y bienestar............................................ 197

2. Repercusión de la intervención respecto a las características propias del

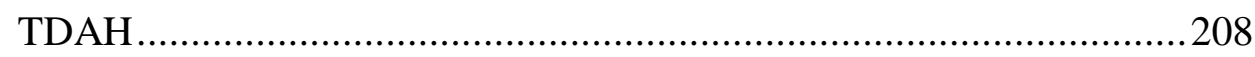

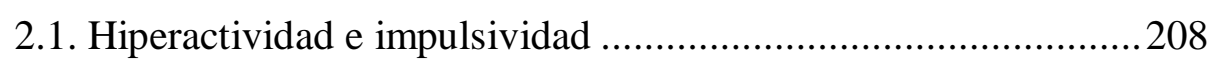

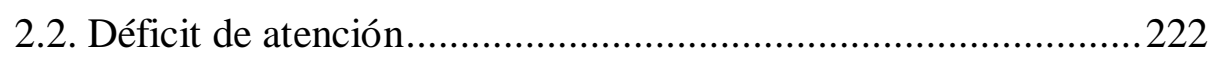

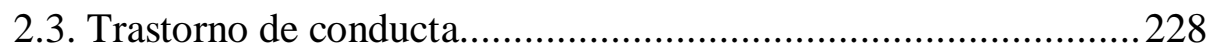

\section{CAPÍTULO VII. DISCUSIÓN DE LOS RESULTADOS DE}

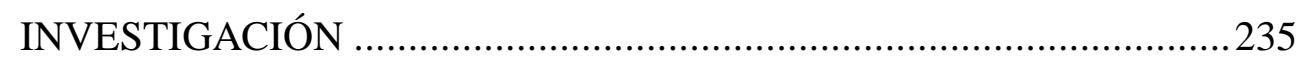

1. Repercusión de la intervención musicoterapéutica a nivel emocional

2. Repercusión de la intervención musicoterapéutica respecto a las características propias del TDAH.

3. Las técnicas de música e imagen como método de intervención para niños con y sin diagnóstico de TDAH 
1. Emotional impact of Music Therapy …............................................ 247

2. Impact of Music Therapy on the distinguishing traits of ADHD ...... 248

3. Music and imagery techniques as a method of intervention for children with and without an ADHD diagnosis ............................................. 250

CAPÍTULO VII. CONCLUSIONES.................................................. 253

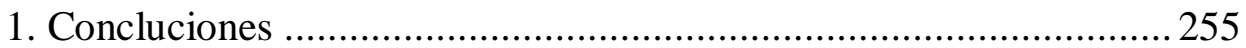

1.1. Contraste de las hipótesis del estudio ..................................... 255

1.1.1. Contraste de la Hipótesis 1 del estudio ............................. 255

1.1.2. Contraste de la Hipótesis 2 del estudio ............................. 256

1.2. Conclusiones relacionadas con los objetivos del estudio .......... 257

2. Limitaciones y futuras líneas de trabajo......................................... 260

2.1. Ampliación del alcance de los resultados cuantitativos ............ 260

2.2. Profundización en la información cualitativa emergente ........... 261

2.3. Continuar investigando: Musicoterapia y TDAH ..................... 263

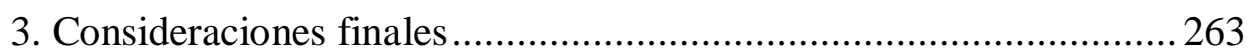

CHAPTER VIII. CONCLUSIONS ................................................. 269

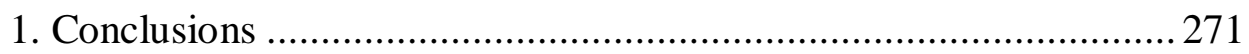

1.1. Assessment of study hypotheses .......................................... 271

1.1.1. Assessment of study Hypothesis 1 ................................... 271

1.1.2. Assessment of study Hypothesis 2 ................................ 272

1.2. Conclusions regarding the study objectives ........................... 273

2. Limitations and avenues for future research ................................ 275

2.1. Extending the scope of the quantitative results........................ 275

2.2. Delving deeper into the emerging qualitative information......... 275

2.3. Further investigation: Music therapy and ADHD ..................... 277

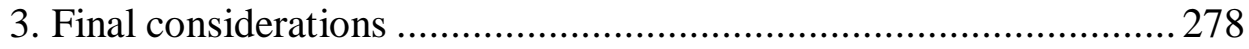

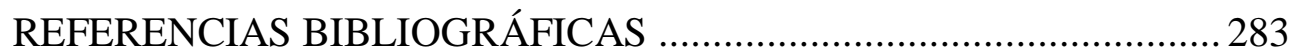





\section{ÍNDICE DE TABLAS}

Tabla 1. Fases de evolución de leyes educativas en España ....................................14

Tabla 2. Fases del protocolo de coordinación para TDAH (JCyL) ........................40

Tabla 3. Criterios diagnósticos para el TDAH..................................................41

Tabla 4. Diagnóstico y prevalencia media de TDAH a nivel internacional ...........44

Tabla 5. Efectos biológicos de la Musicoterapia ...................................................72

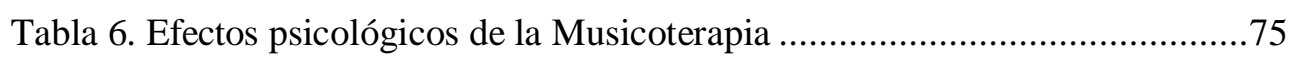

Tabla 7. Factores que determinan en terapia el modo de empleo de la música ......81

Tabla 8. Métodos activos empleados en Musicoterapia .........................................83

Tabla 9. Distribución de Fellows por países según la AMI ....................................90

Tabla 10. Musicoterapia para discapacidades o trastornos ....................................102

Tabla 11. Métodos de Musicoterapia empleados en el tratamiento del TDAH ....105

Tabla 12. Distinciones entre el Modelo Bonny de Imagen Guiada con Música (BMGIM) y las técnicas Relajación de Música e Imagen (MIR) y Viaje de

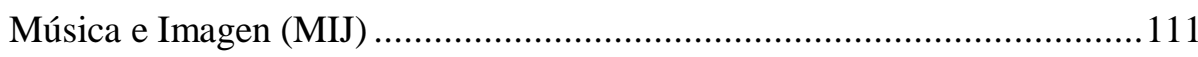

Tabla 13. Ítems de la escala EDAH distribuidos por factores .............................147

Tabla 14. Bloques de la escala de observación del desarrollo emocional .............148

Tabla 15. Categorías elaboradas antes del comienzo del trabajo de campo ..........153

Tabla 16. Categoría cualitativa para el análisis textual de conciencia emocional.166

Tabla 17. Conciencia emocional antes y después de la intervención 167

Tabla 18. Punto de vista del investigador y de las familias respecto a la conciencia emocional después de la intervención. 172

Tabla 19. Categoría cualitativa para el análisis textual de regulación emocional.173

Tabla 20. Regulación emocional antes y después de la intervención. 174

Tabla 21. Punto de vista del investigador y de las familias respecto a la regulación emocional después de la intervención. 186

Tabla 22. Categoría cualitativa para el análisis textual de autonomía emocional.187

Tabla 23. Autonomía emocional antes y después de la intervención... 188

Tabla 24. Punto de vista del investigador y de las familias respecto a la autonomía emocional después de la intervención. 190

Tabla 25. Categoría cualitativa para el análisis textual de competencia social.....191

Tabla 26. Competencia social antes y después de la intervención. 192

Tabla 27. Punto de vista del investigador y de las familias respecto a la competencia social después de la intervención 196 
Tabla 28. Categoría cualitativa para el análisis textual de competencia de vida y bienestar 197

Tabla 29. Competencia de vida y bienestar antes y después de la intervención... 198

Tabla 30. Punto de vista del investigador y de las familias respecto a la competencia de vida y bienestar después de la intervención ........................201

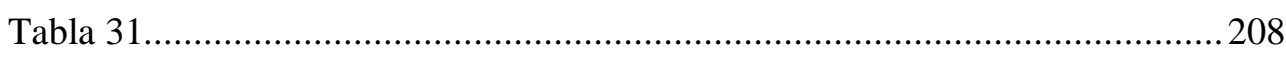

Tabla 32. Hiperactividad e impulsividad antes y después de la intervención ......209

Tabla 33. Punto de vista del investigador y de las tutoras respecto a la hiperactividad e impulsividad después de la intervención ..........................221

Tabla 34. Categoría cualitativa para el análisis textual de inatención...................222

Tabla 35. Inatención antes y después de la intervención......................................223

Tabla 36. Punto de vista del investigador y de las tutoras respecto a la inatención después de la intervención ....................................................................227

Tabla 37. Categoría cualitativa para el análisis textual de trastorno de conducta. 228

Tabla 38. Trastorno de conducta antes y después de la intervención....................229

Tabla 39. Punto de vista del investigador y de las tutoras respecto a trastorno de

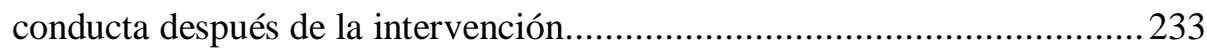

Tabla 40. Categorías emergentes durante la fase de obtención de información ...262

Table 41. Categories that emerged during the information-gathering stage 277 


\section{ÍNDICE DE FIGURAS}

Figura 1. Formación de la identidad profesional del musicoterapeuta....................80

Figura 2. Representación de identidades sonoras y estados de la mente. ...............96

Figura 3. Beneficios de la música en educación. ...............................................99

Figura 4. Diseño de triangulación concurrente (DITRIAC). ...............................138

Figura 5. Extracto de un ejemplo de condensación del significado. ..................... 154

Figura 6. Mandala de A, Sesión 1. 09/03/2017................................................... 168

Figura 7. Mandala de N, Sesión 2. 15/03/2017............................................... 170

Figura 8. Mandala de N, Sesión 5. 04/04/2017................................................... 170

Figura 9. Mandala de I1, Sesión 2. 16/03/2017. ................................................... 171

Figura 10. Mandala de D2, Sesión 4. 30/03/2017 .................................................. 175

Figura 11. Mandala de A, Sesión 7. 04/05/2017................................................176

Figura 12. Mandala de A, Sesión 6. 20/04/2017.................................................178

Figura 13. Mandala de I1, Sesión 5. 06/04/2017 ...............................................180

Figura 14. Mandala de N, Sesión 3. 22/03/2017................................................ 181

Figura 15. Mandala de M, Sesión 4. 30/03/2017................................................183

Figura 16. Mandala de M, Sesión 2. 16/03/2017.............................................. 185

Figura 17. Mandala de N, Sesión 6. 11/04/2017..................................................189

Figura 18. Mandala de F, Sesión 3. 20/03/2017. ................................................193

Figura 19. Mandala de Y, Sesión 2. 16/03/2017....................................................199

Figura 20. Mandala de Y, Sesión 3. 23/03/2017...............................................199

Figura 21. Mandala de Y, Sesión 12. 08/06/2017...........................................200

Figura 22. Mandala de D2, Sesión 11. 01/06/2017 ...........................................203

Figura 23. Mandala de J2, Sesión 5. 04/04/2017...............................................204

Figura 24. Mandala de I1, Sesión 6. 20/04/2017 .............................................205

Figura 25. Mandala de N, Sesión 1. 08/03/2017.................................................207

Figura 26. Mandala de F, Sesión 1. 06/03/2017. ..............................................210

Figura 27. Mandala de F, Sesión 2. 13/03/2017. .................................................212

Figura 28. Mandala de F, Sesión 2. 13/03/2017. ..................................................212

Figura 29. Mandala de F, Sesión 4. 27/03/2017. .............................................213

Figura 30. Mandala de J1, Sesión 1. 09/03/2017...............................................216

Figura 31. Mandala de J1, Sesión 1. 09/03/2017..............................................217

Figura 32. Mandala de J2, Sesión 3. 21/03/2017.............................................226 





\section{ÍNDICE DE ANEXOS}

Anexo I. Documento informativo para las familias.

Anexo II. Escala de evaluación de conductas de TDAH (EDAH)

Anexo III. Datos recogidos mediante la escala EDAH.

Anexo IV. Datos recogidos mediante la escala EODE.

Anexo V. Transcripción de las entrevistas previas a la intervención.

Anexo VI. Transcripción de las entrevistas finales.

Anexo VII. Diario de investigación.

Anexo VIII. Informe de análisis cualitativo por categorías (ATLAS.ti).

Anexo IX. Documento de consentimiento informado.

Los anexos pueden ser consultados a través del siguiente código QR:

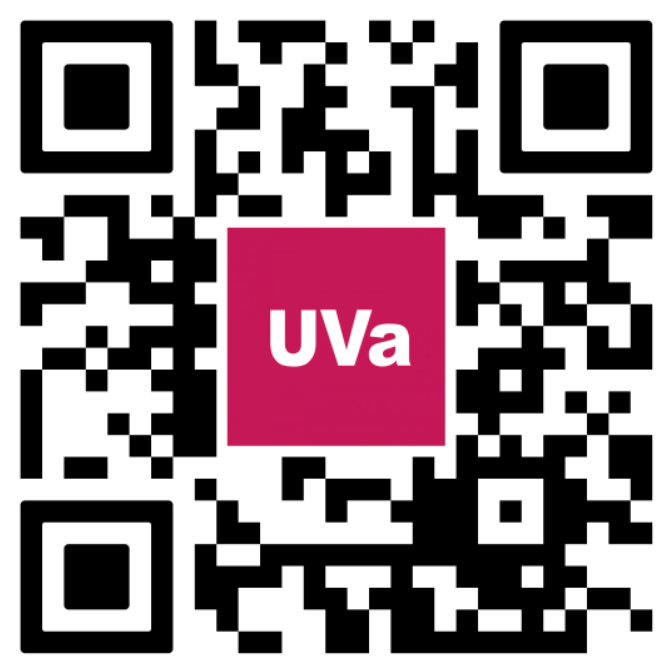





\section{INTRODUCCIÓN}

Los niños que han sido amados y cuidados tienen una fe maravillosa en que el mundo es un lugar seguro para ellos y pueden contar con los demás para que les provean apoyo físico, emocional e intelectual y les ayuden a crecer y madurar. La confianza que tienen en otros, y por lo tanto en sí mismos, les permite aprender lo que necesitan para la vida.

Pearson, 1992

La educadora y escritora americana Carol S. Pearson escribió de forma continuada en relación a los procesos de crianza y educación saludables, basados en el amor, la protección y la seguridad, y estudió aquellos que no lo son para encontrar formas de mejorar estas situaciones y ayudar a las personas. Este extracto de su libro Despertando los héroes interiores ilustra, de esta forma, el comienzo de esta tesis doctoral, en la que este pensamiento está latente de forma constante.

La sociedad en la que vivimos es cada vez más dinámica y diversa. Cada día nos encontramos con infinidad de estímulos, nuevas opciones de ocio y entretenimiento e infinidad de fuentes de información a las que podemos acceder. Esto, sumado a una mayor y creciente presencia de dispositivos electrónicos y un aumento de la ubicuidad de redes inalámbricas y la conectividad, contribuye a que el día a día de las personas se viva de forma artificial y esté más centrado en las redes sociales, la distracción y la evasión (a menudo a través de contenidos superfluos) que en mantener la atención en el cuidado hacia uno mismo y hacia su entorno.

Este contexto también está teñido de una cotidianeidad en la que a menudo es inevitable prestar más atención a las obligaciones laborales y académicas que a las necesidades emocionales que puedan surgir en el día a día. En relación con los procesos de crianza, de forma inconsciente esto repercute en que se espere que los niños se adapten a las necesidades de la sociedad y de la vida de los adultos, que cumplan con excelencia con los requisitos establecidos o que se comporten de forma exquisita en un mundo que en ocasiones parece haber olvidado la esencia emocional del ser humano.

Dentro de este contexto, actualmente el Trastorno por Déficit de Atención/Hiperactividad (TDAH) está clasificado como uno de los trastornos del neurodesarrollo más comunes entre la población infantil y juvenil. Son varios los autores que hablan de la posibilidad de que lo que ha aumentado tanto el número de diagnósticos a lo largo de los últimos años puede estar relacionado con los cambios sociales que se han producido, la constante estimulación tecnológica con la que ya nos hemos acostumbrado a vivir o, simplemente, con 
el hecho de que cada vez tengamos menos tiempo que dedicar de forma saludable a la gestión emocional y a los procesos de relación social. De hecho, como también veremos más adelante, resulta curioso encontrarnos con que muchos de los casos con este diagnóstico provienen de familias desestructuradas en las que no se ha provisto de un entorno adecuado de seguridad y cuidado, por lo que a menudo son niños en situación de adopción o acogida.

Por otra parte, cabe señalar que el COVID-19, junto con la situación de pandemia y crisis económica, social y sanitaria que ha originado a nivel mundial, ha llegado a nuestras vidas para agitar el estado de bienestar en el que estábamos acostumbrados a vivir y, con ello, a zarandear nuestra estabilidad y equilibrio emocionales: situaciones de confinamiento, la necesidad de un distanciamiento social constante, las restricciones de movilidad y una gran pérdida de vidas humanas. Todo lo que hemos vivido en estos meses nos ha llevado, inevitablemente, a un estado de mayor aislamiento social, a vivir procesos de duelo o situaciones de estrés y ansiedad difíciles de sostener, y otras circunstancias, que han repercutido en el detrimento de nuestra capacidad de gestión emocional y nuestras habilidades para establecer y mantener relaciones sociales saludables.

De forma inevitable, hoy en día este tipo de situaciones se están viviendo en los colegios, afectando a niños y niñas que conviven a diario con protocolos constantes de contención y medidas de seguridad ante el COVID-19. Probablemente esto, como se ha dicho, origine ocasional o continuamente situaciones de estrés, incomodidad o conflicto en las que una buena capacidad de gestión emocional puede ayudar a mejorar las relaciones entre iguales, el ambiente de aula y los procesos de enseñanza-aprendizaje.

Es por todo lo expuesto que esta tesis doctoral pretende poner en valor la importancia del desarrollo de la capacidad de gestión emocional, el cuidado personal y el trabajo en la mejora de las habilidades sociales, en pos de una educación y una sociedad más concienciada, responsable y respetuosa.

Con todo ello, en este trabajo se presenta la Musicoterapia y, en concreto, el empleo de técnicas específicas de música e imagen (MI), como una forma de intervención que puede ayudar a los niños a mejorar su capacidad de conciencia y de regulación emocional en diferentes ámbitos y contextos. La Musicoterapia ayuda a las personas, entre otras cosas, a aumentar su nivel de autoconocimiento por medio de la conexión y expresión emocional mediante el empleo de la música en la forma que sea más conveniente para cada caso. Se trata de una disciplina cuyo recorrido, rigor científico y fundamentos teóricos se han ido cimentando desde hace más de 70 años mediante trabajos de investigación desarrollados a nivel internacional. 
Los contenidos y conceptos que aparecen en esta introducción y que son más relevantes serán desarrollados más adelante. Así, y teniendo en cuenta todo lo expuesto anteriormente, la presente tesis doctoral responde a un objetivo principal, en torno al cual gira todo el proceso de investigación y de intervención musicoterapéutica desarrollado:

- Valorar el grado de contribución de una intervención de Musicoterapia basada en técnicas de música e imagen (MI) en el desarrollo de la competencia emocional y en la disminución de la muestra de conductas propias del Trastorno por Déficit de Atención (TDAH) en un grupo de niños con y sin este diagnóstico.

Los objetivos específicos, hipótesis y sub-hipótesis establecidos para el proceso de investigación (dado que está basado en un enfoque mixto) son desarrollados con más detenimiento y detalle en el Capítulo V: Metodología de la Investigación.

\section{JUSTIFICACIÓN}

\section{Académica}

La presente tesis doctoral se encuadra dentro de la legislación del Real Decreto 99/2011, de 28 de enero, por el que se regulan las enseñanzas oficiales de doctorado en España (BOE n³5, de 10 de febrero de 2011). Más en concreto, hace referencia al artículo 13 de dicho documento, en el que se establece el requisito de que el doctorando elabore y redacte un trabajo original de investigación en cualquier campo de conocimiento.

Este trabajo de investigación fue desarrollado bajo el marco del Programa de Ayudas para la Formación del Profesorado Universitario (FPU) del Ministerio de Educación, Cultura y Deporte del Gobierno de España. Por ello sigue las especificaciones recogidas en la Resolución de 26 de diciembre de 2014, de la Secretaría de Estado de Educación, Formación Profesional y Universidades, por la que se convocan ayudas para la formación de profesorado universitario, de los subprogramas de Formación y de Movilidad incluidos en el Programa Estatal de Promoción del Talento y su Empleabilidad, en el marco del Plan Estatal de Investigación Científica y Técnica y de Innovación 20132016 (BOE $\mathrm{n}^{\circ} 313$, de 27 de diciembre de 2014) y corresponde a la referencia FPU14/03106. Como tal, se llevó a cabo por medio de un contrato predoctoral a tiempo completo en la Facultad de Educación de Segovia (Universidad de Valladolid), en el Departamento de Didáctica de la Expresión Musical, Plástica y Corporal, entre octubre de 2015 y junio de 2019. 
Esta tesis doctoral ha sido desarrollada en el marco del Programa de Doctorado Investigación Transdisciplinar en Educación, ofertado por la Escuela de Doctorado de la Universidad de Valladolid. Por ello se presenta conforme a los requerimientos establecidos en el artículo 3 de la Resolución 8 de junio de 2016, del Rectorado de la Universidad de Valladolid, por la que se hace pública la normativa para la presentación y defensa de la tesis doctoral en la Universidad de Valladolid (BOCYL no 114 de 15 de junio de 2016) en cuanto a su modalidad y contenidos. Este artículo se refiere a la presentación de una tesis doctoral por medio de la modalidad ordinaria, por lo que se sigue la estructura indicada y se aporta una publicación relacionada con la tesis doctoral que cumple con los criterios de la Agencia Nacional de Evaluación de la Calidad y la Acreditación (ANECA).

Por otra parte, esta tesis doctoral opta a la mención de "Doctorado Internacional", y para ello se han provisto de los medios necesarios y recogidos igualmente en el Real Decreto 99/2011, de 28 de enero, mencionado previamente. El doctorando realizó una estancia de investigación de tres meses en el Programa de Musicoterapia de la Universidad Estatal de Nueva York en New Paltz (SUNY New Paltz). Esta estancia fue avalada por el Programa de Ayudas a la Movilidad para Estancias Breves y Traslados Temporales, del Ministerio de Educación, Cultura y Deporte, en base a la Resolución de 22 de diciembre de 2016, de la Secretaría de Estado de Educación, Formación Profesional y Universidades, por la que se convocan ayudas complementarias destinadas a beneficiarios del subprograma de formación del profesorado universitario. Es por ello que el resumen y los capítulos de discusión y conclusiones (Capítulo VII. Discusión de los Resultados de Investigación y Capítulo VIII. Conclusiones) se incluyen tanto en español como en inglés, y que los informantes de la tesis y una de las personas que forman parte del tribunal pertenecen a universidades no españolas.

\section{Personal}

El interés por el estudio del Trastorno por Déficit de Atención/Hiperactividad (TDAH) surge desde el momento en que relacioné mi Trabajo Fin de Grado con esta temática, en el año 2014, para finalizar mi Grado en Educación Primaria. Más adelante, este mismo tema, pero abordado desde un punto de vista y un enfoque muy diferentes, dio forma a mi Trabajo Fin de Máster. Ahora este camino de exploración e investigación respecto a este tema culmina con un formato que tenía realmente ganas desarrollar: el diseño y aplicación de una intervención de Musicoterapia sistematizada, y el seguimiento de un proceso terapéutico real con niños, para valorar el grado de contribución respecto a su estado emocional, físico y social. 
Más allá de esto, debo admitir que existe cierta implicación personal que me lleva a empatizar con los niños que presentan este diagnóstico, ya que, habitualmente, no son comprendidos por el entorno, son vistos como niños revoltosos que no muestran interés por nada, agresivos, con problemas de comportamiento, etc. En el tiempo que llevo estudiando temas relacionados con la Educación y la Musicoterapia me he encontrado con pocas personas que de verdad se paren a entender los problemas y dificultades que se ven en este tipo de casos, los cuales, en algunas ocasiones tienen una relación directa con no haber vivido durante los primeros años de vida en un entorno familiar seguro y estable.

Dicen que nuestras elecciones y las decisiones que tomamos están íntimamente relacionadas con nuestra propia vivencia y experiencia personal. A lo largo de mi trabajo con este tema hay muchas personas que me han dicho que me conecta tanto porque soy un poco así, hiperactivo. Siempre me ha hecho gracia cuando me lo han dicho. Realmente no sé si me siento identificado directamente con casos concretos de niños diagnosticados de Trastorno por Déficit de Atención/Hiperactividad, pero sí sé que siento una enorme empatía y amor por todos los niños que vienen a este mundo y quedan huérfanos, viven en situación de pobreza o, simplemente, no se encuentran con un núcleo familiar estable y equilibrado, que les provea amor, cuidado, protección y seguridad. También sé que, por medio de mi trabajo y la continuación de procesos de investigación, nunca voy a dejar de hacer todo lo que esté a mi alcance por ayudar a este y otros colectivos vulnerables.

\section{ESTRUCTURA DEL TRABAJO}

Tras esta introducción, el capítulo I, Hacia una Educación Inclusiva, contextualiza el trabajo en torno a la realidad educativa actual en relación con la igualdad de oportunidades que todo el alumnado ha de tener independientemente de su diversidad cultural, social y/o de aprendizaje. Se hace un recorrido histórico hasta llegar al concepto de Educación Inclusiva como un movimiento y estilo de enseñanza al que se debe aspirar para lograr el desarrollo integral del alumnado y para garantizar mejores procesos de concienciación social y de colaboración entre iguales.

El capítulo II, El Trastorno por Déficit de Atención/Hiperactividad (TDAH), presenta y desarrolla el concepto de uno de los trastornos del neurodesarrollo más extendidos entre la población infantil y juvenil en la actualidad. En primer lugar, se revisa su definición teórica, así como sus características principales, su etiología, el proceso de diagnóstico, su prevalencia y principales vías 
de intervención (farmacológicas y no farmacológicas). Por otra parte, recoge una serie de reflexiones y diferentes puntos de vista que han ido dando forma a lo largo de los últimos años a determinadas controversias que giran principalmente en torno al concepto de TDAH, su origen, su diagnóstico, su alta prevalencia y su tratamiento farmacológico.

En el capítulo III, La Musicoterapia como Intervención no Farmacológica, se presenta el concepto de esta disciplina, que es la que da sentido y forma al presente documento de tesis doctoral y al proceso de investigación llevado a cabo. En este capítulo se desarrolla detenidamente el concepto de Musicoterapia y se exploran sus características y elementos básicos, así como los fundamentos históricos, biológicos y psicológicos que cimientan esta disciplina. Además, se hace un recorrido por las principales técnicas, métodos y modelos de intervención musicoterapéutica que se emplean actualmente y que establecen las bases de la profesión y el trabajo como musicoterapeuta. Para cerrar este capítulo, se dedica un apartado final a la Musicoterapia en el ámbito educativo, se compara las similitudes y diferencias entre Educación Musical y Musicoterapia y se reflexiona sobre la aportación de la Musicoterapia en el trabajo con las necesidades educativas especiales y, más en concreto, con el Trastorno por Déficit de Atención/Hiperactividad.

Por medio del capítulo IV, Características de la Intervención Musicoterapéutica: Técnicas de Música e Imagen (MI), se describe de forma detallada el proceso de diseño de la intervención llevada a cabo, haciendo un repaso de los trabajos previos existentes, desde la creación del Modelo Bonny de Imagen Guiada con Música (BMGIM) hasta las técnicas de música e imagen (MI), pasando por los métodos y distintas adaptaciones que se han hecho del modelo original: Imagen Guiada con Música (GIM). De esta forma, actúa como capítulo de estado de la cuestión al tiempo que proporciona la información necesaria para comprender el método diseñado para ser aplicado específicamente con TDAH, ya que se explica cómo fue empleado a lo largo de la intervención llevada a cabo (duración de las sesiones, distribución en individuales y grupales, etc.).

En el capítulo V, Metodología de la Investigación, se describe con detalle el paradigma de investigación que se ha adoptado, así como el diseño o enfoque en base al cual se ha estructurado todo el proceso de investigación y los objetivos e hipótesis del estudio. Asimismo, se recoge información significativa sobre cómo fue desarrollado el trabajo de campo, desde el comienzo hasta el final de la intervención, cómo fue la forma de contactar con los colegios o la descripción personal de los niños participantes. Igualmente se explica cómo fueron utilizadas y se detallan tanto las técnicas cualitativas de obtención de 
información como los instrumentos cuantitativos de recogida de datos. A continuación, se describe minuciosamente cómo fue llevado a cabo el proceso de análisis de los datos desde ambas perspectivas (cuantitativa y cualitativa). El capítulo finaliza con algunas consideraciones ético-metodológicas y valorando los criterios de validez, fiabilidad y triangulación de la investigación.

A través del capítulo VI, Análisis de los Datos, se muestra todo el proceso de análisis de los datos obtenidos por medio de las escalas empleadas y las entrevistas y diario de investigación elaborados. Esta información se estructura en base a las categorías de investigación utilizadas para el análisis: conciencia emocional; regulación emocional; autonomía emocional; competencia social; competencia de vida y bienestar; hiperactividad e impulsividad; déficit de atención; trastorno de conducta. De esta forma, en este capítulo se presentan los resultados de la investigación y la contribución que las sesiones de Musicoterapia han tenido para los niños y sus familias.

En el capítulo VII, Discusión de los Resultados de Investigación, y, por ende, en su correspondiente traducción al inglés, Chapter VII. Discussion of Research Results, se valora el alcance de esta contribución al contrastar los resultados obtenidos con las investigaciones previas existentes. En esta ocasión, el capítulo se estructura en tres apartados. En primer lugar, se contrasta cómo ha repercutido la intervención a nivel emocional. A continuación, se valora de qué forma ha contribuido al campo de estudio y trabajo respecto al Trastorno por Déficit de Atención/Hiperactividad (TDAH). Este capítulo de discusión finaliza con un apartado en el que se valora el grado de contribución del trabajo de investigación en cuanto a la aplicación de técnicas de música e imagen (MI) en el trabajo musicoterapéutico con niños con y sin diagnóstico de TDAH.

Por último, el capítulo VIII, Conclusiones, así como su correspondiente traducción al inglés, Chapter VIII. Conclusions, cierra el trabajo contrastando el grado de cumplimiento de las hipótesis y objetivos establecidos previamente, reflexionando sobre posibles limitaciones y futuras líneas de continuación del trabajo de investigación, y con una serie de consideraciones finales que pretenden actuar como recomendaciones para los diferentes agentes que intervienen en los procesos de enseñanza-aprendizaje desde diferentes perspectivas y ámbitos de intervención: docentes, padres, madres, pedagogos, psicólogos, etc. 


\section{CONSIDERACIONES PREVIAS A LA LECTURA DE ESTA TESIS DOCTORAL}

Esta tesis doctoral se basa en un trabajo realizado con personas de forma cercana y delicada, y es por ello que en todo momento se escribe con máximo respeto y cuidado hacia los procesos vividos y compartidos durante el desarrollo de la investigación. Por lo tanto, está cargada de emociones y experiencias personales de los niños, niñas, padres y madres participantes en el estudio, y por ello es que la implicación emocional, la capacidad de empatía y el respeto por los procesos humanos por parte del lector mejorará sin lugar a dudas su experiencia al navegar a través del contenido del documento.

En el capítulo IV, Características de la Intervención Musicoterapéutica: Técnicas de Música e Imagen (MI), en la versión PDF del documento, se pueden escuchar ejemplos de temas musicales clicando sobre el nombre del tipo de música (en azul y subrayado). Se recomienda ir escuchándolos conforme se va leyendo su descripción, ya que de esta forma se puede ir conectando con las sensaciones y emociones que la música produce. Esto quiere decir que, no solo en este capítulo, sino en todo el documento, este trabajo proporciona información y recursos que esperan servir como ayuda para el trabajo en otros contextos y, por ello, se espera un uso responsable por parte de quien los utilice, y respeto hacia la figura del musicoterapeuta. El trabajo de investigación que da forma a este documento consiste en una intervención musicoterapéutica que fue llevada a cabo en un espacio provisto para tal fin por parte de un musicoterapeuta titulado.

Por otra parte, consideramos necesario aclarar que, por una cuestión de economía del lenguaje, se emplea el género masculino en algunos momentos del documento para referirse a un grupo de personas de forma general. El lenguaje utilizado es inclusivo en todo momento, y por ello se refiere a personas tanto del género masculino como del femenino cuando se emplea como genérico. El objetivo de ello es que la lectura y seguimiento del texto se hagan de forma lo más clara y fluida posible, lo cual se agradece a la hora de leer este tipo de trabajos.

Sin más dilación, bienvenido o bienvenida a esta tesis doctoral. Espero sinceramente que disfrutes de la lectura de este trabajo en el que las personas, la música y las emociones se interrelacionan a través de la sensibilidad, el respeto, la escucha y la comprensión. 




\section{CAPÍTULO I. HACIA UNA EDUCACIÓN INCLUSIVA}



Existe una profunda falta de respeto por los seres humanos en la vida moderna. Los negocios nos hacen pensar en nosotros mismos como capital humano. (...) Demasiados psicólogos ven su trabajo como un método para ayudar a las personas a adaptarse a lo que son, no a que emprendan sus travesías y descubran lo que podrían ser. Demasiadas instituciones educativas entrenan a las personas para ser engranajes en la maquinaria económica en lugar de educarlos en el arte de ser humanos completos. (Pearson, 1992, p. 18).

Esta reflexión, fundamentada en algunos de los principios de la psicología arquetípica, nos ayuda a ilustrar un pensamiento que guarda cierta relación con el enfoque de la Educación Inclusiva. Refleja el cambio de perspectiva en torno al cual se pasó de considerar que las personas con necesidades debían adaptarse a los ritmos de aprendizaje y a las demandas de una sociedad homogeneizadora, a asumir la posibilidad de que cada cual partiese de sus propias circunstancias para alcanzar el máximo desarrollo de sus potencialidades. El respeto hacia todos los seres humanos, el aprovechamiento de las características y particularidades individuales para lograr un crecimiento personal completo e integral y el hecho de ofrecer la oportunidad de que cada persona descubra lo que puede llegar a ser. Estas son algunas premisas que nos sitúan en la tendencia pedagógica que transformó el modo de valorar la atención a las personas con necesidades en la sociedad y en el ámbito educativo, y que cimentó las bases de lo que hoy en día conocemos como Educación Inclusiva y atención a la diversidad.

\section{DE LA EXCLUSIÓN A LA INCLUSIÓN. DEL ALUMNADO CON DISCAPACIDAD A LA DIVERSIDAD EDUCATIVA}

El camino hacia la inclusión no ha sido fácil. El asentamiento de este concepto dentro del ámbito de las Ciencias de la Educación es una realidad que se ha ido conformando a lo largo de años de historia y de pequeños avances, desde las primeras consideraciones del concepto de "retraso mental" hasta los movimientos de integración y, posteriormente, inclusión, pasando por el surgimiento de la Educación Especial como disciplina independiente, aunque siempre interconectada con el contexto educativo ordinario (Arnaiz, 2003).

Al igual que el concepto de Educación Inclusiva, la atención al alumnado con necesidades educativas especiales ha ido variando a lo largo de la historia en función de los cambios de pensamiento y, con ello, en relación con las refor- 
mas legislativas. De hecho, el surgimiento de la Educación Especial se produjo como consecuencia de la asunción de la obligatoriedad de la Educación a finales del siglo XIX (Lobato, 2001) y a raíz de la preocupación por atender a las personas con discapacidad a comienzos del siglo XX (Arnaiz, 2003). Antes de este momento las personas con necesidades quedaban excluidas y apartadas, de modo que se les negaba la oportunidad de recibir una educación integrada y de calidad.

A partir de aquel momento se consideró la necesidad de ofrecer una respuesta educativa a este colectivo, creando centros especiales destinados a acogerlos y enseñarlos. De esta forma los alumnos con necesidades eran atendidos, pero de manera aislada y segregada, es decir, fuera de las escuelas ordinarias. Esto supuso un punto de inflexión en cuanto al modo de proceder con este tipo de alumnado, que a través de una serie de modificaciones, replanteamientos y cambios de perspectivas dio lugar a lo que hoy en día conocemos como atención a la diversidad en su sentido más amplio. Esta evolución histórica queda recogida, a grandes rasgos y a modo de resumen, en la Tabla 1.

Tabla 1

Fases de evolución de leyes educativas en España

\begin{tabular}{|c|c|}
\hline "Período & Se trata del espacio temporal comprendido entre los años 1885 y \\
\hline Primigenio" & $\begin{array}{l}1965 \text { y se refiere a la fase inicial en la que se produjeron los primeros } \\
\text { intentos normativos relativos a la Educación Especial y que sentarían } \\
\text { las bases de la evolución histórica y las consecuentes repercusiones } \\
\text { del surgimiento de este concepto. }\end{array}$ \\
\hline $\begin{array}{l}\text { "Período } \\
\text { Intermedio o } \\
\text { Estructural" }\end{array}$ & $\begin{array}{l}\text { Esta fase, que se caracteriza por el cambio de paradigma en relación } \\
\text { con la idea de Educación Especial, comprende el periodo entre } 1965 \\
\text { y } 1978 \text {. Se produjeron cambios de mentalidad y de contexto que per- } \\
\text { mitieron el consiguiente avance y renovación de las normativas. }\end{array}$ \\
\hline $\begin{array}{l}\text { "Período de } \\
\text { Apogeo" }\end{array}$ & $\begin{array}{l}\text { Este periodo se corresponde con la franja temporal comprendida en- } \\
\text { tre } 1978 \text { y } 1985 \text {. En esta fase se toman medidas específicas de aten- } \\
\text { ción educativa orientadas a la no discriminación que quedaron expre- } \\
\text { samente recogidas en el marco constitucional. Se incluyen ideas que } \\
\text { suponen una referencia e influyeron positivamente en los procesos } \\
\text { de reconocimiento y la búsqueda de la integración del alumnado con } \\
\text { necesidades educativas especiales. }\end{array}$ \\
\hline $\begin{array}{l}\text { "Período } \\
\text { Actual" }\end{array}$ & $\begin{array}{l}\text { Esta fase acoge lo acontecido desde } 1985 \text { hasta } 2012 \text {. En este pe- } \\
\text { riodo se refleja de qué forma se ha considerado la atención al alum- } \\
\text { nado con necesidades educativas especiales en cada una de las leyes } \\
\text { educativas que se han ido promulgado, tales como la Ley Orgánica } \\
\text { General del Sistema Educativo (LOGSE), la Ley Orgánica de Cali- } \\
\text { dad de la Educación (LOCE, 12/2003) o la Ley Orgánica de Educa- } \\
\text { ción (LOE, 2/2006). }\end{array}$ \\
\hline
\end{tabular}

Fuente: Adaptado de Guirado y Sepúlveda (2012). 
A finales del siglo XIX y principios del siglo XX se tomaron algunas medidas como la creación del Patronato Nacional de Sordomudos, Ciegos y Anormales en 1910, su reestructuración en diversas secciones, la creación de la Escuela Nacional de Anormales en 1930 o la promulgación de la Ley de Instrucción Primaria del 17 de julio de 1945, mediante la cual se procedió a la creación de escuelas destinadas a la Educación Especial (Guirado y Sepúlveda, 2012). Teniendo en cuenta esta sucesión de procesos legislativos y el modo en que se denominaba a las personas con necesidades educativas especiales durante esta época, se puede apreciar el proceso de transición desde la exclusión de este colectivo hacia su segregación y atención específica en centros especializados que desempeñan su labor fuera de las escuelas ordinarias.

En el año 1978, a raíz de la elaboración del Plan Nacional de Educación Especial (PNEE), se extendió la idea de integración y surgió la preocupación por atender al alumnado con necesidades educativas especiales en centros ordinarios con el objetivo de lograr su integración y una educación de calidad para ellos, aludiendo a la responsabilidad del gobierno y los servicios públicos para garantizar este proceso:

1. Todo ser humano, con independencia de sus circunstancias personales de deficiencia o inadaptación, en virtud a consideraciones vinculadas a su propia dignidad, tiene el derecho inalienable a la Educación, sin que puedan considerarse aquéllas impedimento al ejercicio de este derecho o razón para la exclusión de los servicios educativos que requieran su realización personal. (...)

3. Cada deficiente tiene derecho precisamente a la educación que requiera el máximo desarrollo de sus capacidades, conforma al tipo y grado de su deficiencia y a su nivel personal de necesidades.

4. La obligación correspondiente al derecho de los deficientes a su educación constituye una responsabilidad pública, debiendo localizarse la competencia administrativa del Estado en el Ministerio, Educación en los organismos dependientes de él y en otras autoridades locales y regionales. (Instituto Nacional de Educación Especial, 1978, pp. 2-3).

No obstante, a pesar de que esta medida supuso el diseño y aplicación de recursos y programas de apoyo educativo y, con ello, un avance en el proceso de integración de este tipo de alumnado en las aulas ordinarias, en este documento se entiende que son los alumnos con necesidades quienes deben adaptarse a las condiciones del centro, así como al ritmo normalizado del resto de compañeros y a los contenidos y objetivos generalistas del currículo, a través 
de ayudas o medidas de atención individualizada que les faciliten esa tarea. Igualmente, en la Ley Orgánica de Ordenación General del Sistema Educativo (LOGSE), promulgada en 1990, se recoge de forma específica que los centros educativos deben proveer los recursos y medios adecuados para garantizar la adaptación del alumnado con necesidades educativas especiales, de modo que se sigue hablando en términos de normalización e integración escolar.

La atención a las necesidades de todo tipo de niños en relación con su desarrollo educativo y personal es un tema que lleva suscitando el interés de muchos profesionales relacionados con la investigación educativa desde hace más de veinte años (Fernández-Batanero, 2008). Sin embargo, fue a partir de la Conferencia Mundial de Educación para Todos, celebrada en Tailandia en 1990, cuando se produjo un cambio de perspectiva y arraigó el concepto de Educación Inclusiva. En este evento se consideraron y dispusieron algunas medidas para garantizar una educación equitativa de calidad para niños, jóvenes y adultos, independientemente de su condición social y cultural, partiendo del aprovechamiento de las características y potencialidades individuales (UNESCO, 1990).

A pesar de este avance a nivel mundial, se puede apreciar una ideología similar a la recogida en la LOGSE en la Ley Orgánica de Calidad de la Educación (LOCE, 12/2003), de modo que hubo que esperar hasta el año 2006 para encontrar palabras como equidad o principio de inclusión educativa en la Ley Orgánica de Educación (LOE, 2/2006): “[1]a escolarización del alumnado que presenta necesidades educativas especiales se regirá por los principios de normalización e inclusión y asegurará su no discriminación y la igualdad efectiva en el acceso y la permanencia en el sistema educativo" (p. 52).

Por otra parte, en lo que se refiere a la Ley Orgánica para la Mejora de la Calidad Educativa (LOMCE, 8/2013), que recoge algunas modificaciones sobre la LOE, nos encontramos con que apenas se incluyen nuevas consideraciones relativas al alumnado que presenta necesidades educativas especiales. Sin embargo, sí se modifica ligeramente uno de los párrafos relativos a los principios educativos. Por consiguiente, la idea que queda reflejada hoy en día desde el punto de vista de la legislación de nuestro país en relación con el principio de inclusión y equidad es la siguiente:

La equidad, que garantice la igualdad de oportunidades para el pleno desarrollo de la personalidad a través de la educación, la inclusión educativa, la igualdad de derechos y oportunidades que ayuden a superar cualquier discriminación y la accesibilidad universal a la educación, y que actúe como elemento 
compensador de las desigualdades personales, culturales, económicas y sociales, con especial atención a las que se deriven de cualquier tipo de discapacidad. (LOMCE, 8/2013, p. 9).

Dicho lo cual, a pesar de que la ley reconoce los principios de inclusión y equidad y de que el término de Educación Inclusiva ha pasado a formar parte del argot educativo y está presente de forma teórica en la realidad de los centros escolares, su comprensión sigue estando rodeada de cierta confusión entre los distintos profesionales envueltos en la labor educacional (Giné, 2009). En este sentido, Echeita y Ainscow (2011) apelan a la necesidad de transmitir y hacer llegar una idea global de inclusión, entendida como una respuesta orientada a la valoración de la diversidad de todo el alumnado y alejada, por lo tanto, de la concepción del tratamiento de personas con discapacidad dentro de las aulas ordinarias. Por ello, se convierte en algo innegable la necesidad de reflexionar sobre el concepto de diversidad.

\subsection{Asumir la diversidad como oportunidad de cambio}

Al consultar el diccionario de la Real Academia Española, nos encontramos con una definición que entiende la diversidad como variedad, desemejanza, diferencia o una gran cantidad de cosas distintas. Aplicado a los seres humanos, este término denota que dentro de un mismo grupo social existen diferencias sustanciales entre unos individuos y otros. En palabras de GimenoSacristán (2002), las personas son diferentes entre sí en cuanto a rasgos, facciones, capacidades, valores, etc., y no por ello son menos iguales en lo que se refiere a igualdad de tratamiento y de derechos en función de su propia naturaleza humana. Sin embargo, desde hace algunos años se vislumbra en nuestra sociedad un discurso que emite un principio de igualdad para enmascarar algunas diferencias que desvelan connotaciones denigrantes.

Por lo tanto, el hecho de afirmar que todos debemos gozar de igualdad de derechos y de oportunidades no es lo mismo que afirmar que todos somos iguales. De hecho, Pérez-Gómez (2002) habla de equivalencia de oportunidades, entendiendo como tal aquellas oportunidades de mismo nivel intelectual pero no mismo ritmo ni con igual contenido, para afirmar que la riqueza de la población reside, precisamente, en la variedad de capacidades, habilidades, intereses y motivaciones que tenga cada uno.

En este sentido, la diversidad referida a un grupo social se entiende como un espacio en el que confluyen tanto las diferencias individuales que conforman la identidad personal de cada individuo, como aquellas que, por convenciones sociales de distinta índole, pueden desembocar en formas de discriminación 
y marginación. En relación con ello, Gimeno-Sacristán (2002) acuña el término "diversidad que margina" para referirse a aquellas desigualdades que impiden ejercer los derechos básicos, participar en sociedad o disfrutar de bienes culturales, o que generan situaciones de confrontación. Es necesario, por tanto, valorar las individualidades que contribuyan al crecimiento personal y a la autonomía de cada individuo, y rechazar, por otra parte, aquellas interpretaciones o percepciones sociales que puedan resultar denigrantes, ofensivas o ignominiosas.

Guardando cierta similitud con este argumento, Arnaiz (2003) señala que el concepto de diversidad pretende abarcar una idea más amplia de lo que se refiere al alumnado con necesidades, pasando de considerar solo a los niños con discapacidad a incluir a todo tipo de alumnos cuyas características personales o culturales le pongan en una situación tal que dificulte su aprendizaje y su desarrollo personal. En este sentido, la Educación Inclusiva tiene el objetivo de considerar y dar valor a las particularidades de todos los niños de manera individualizada en aras de construir los procesos de enseñanza y aprendizaje desde las propias necesidades del alumnado. La idea de diversidad que hemos de asumir para lograr procesos y prácticas educativas inclusivas queda recogida de manera acertada por la UNESCO (2005):

Inclusion is concerned with providing appropriate responses to the broad spectrum of learning needs in formal and nonformal educational settings. Rather than being a marginal issue on how some learners can be integrated in mainstream education, inclusive education is an approach that looks into how to transform education systems and other learning environments in order to respond to the diversity of learners. It aims towards enabling teachers and learners both to feel comfortable with diversity and to see it as a challenge and enrichment of the learning environment, rather than a problem. (p. 15).

Dicho lo cual, se puede apreciar cómo se ha avanzado desde la preocupación por la atención educativa orientada a personas con discapacidad severa, hasta la consideración de que todo el alumnado es, per se, diverso y susceptible de merecer una atención individualizada y adaptada a sus necesidades. Así, la diversidad se entiende como una cualidad inherente a cualquier contexto educativo que está repleto, por lo tanto, de oportunidades de progreso y enriquecimiento personal para todos y cada uno de los alumnos. De hecho, según Giné (2009) la inclusión educativa trabaja desde y a través de todo tipo de diversidad, considerando como tal el alumnado con discapacidad, NEE o problemas graves de conducta y los grupos con mayor riesgo de exclusión social, 
con el objetivo de alcanzar una educación de calidad que les permita comprender la sociedad en la que viven y desenvolverse adecuadamente en ella. En líneas subsecuentes se exponen los principios básicos de la Educación Inclusiva, que tratan de dar forma al enfoque primordial en base al cual se puede llegar a comprender y practicar esta disciplina.

\subsection{Principios de la Educación Inclusiva}

Debido, precisamente, a la confusión que gira en torno al concepto de Educación Inclusiva, es preciso continuar arrojando luz al respecto, ampliar los horizontes y comunicar de forma transnacional los fundamentos de la inclusión como práctica educativa necesaria, para lograr que esta idea se extienda y sea considerada y asumida por parte de dirigentes políticos, instituciones públicas y privadas y diferentes profesionales envueltos en procesos de enseñanza y aprendizaje. Con ánimo de aunar perspectivas y proponer un enfoque común, Echeita y Ainscow (2011) destacan cuatro elementos básicos e inherentes a la Educación Inclusiva:

- "La inclusión es un proceso". Esta idea ayuda a entender los procesos de enseñanza y aprendizaje como un edificio que se construye entre todos, tanto niños como adultos. La diversidad se entiende como un contexto lleno de oportunidades que ayudan a crecer, y no como un conjunto de dificultades o problemas que es necesario amoldar a un ritmo de avance generalizado y estandarizado. Se trata de sacar partido a la diferencia y con ello hacer que el aprendizaje sea más enriquecedor y significativo. Así, las prácticas inclusivas buscan explorar en el día a día para descubrir nuevas maneras de dar respuesta a una diversidad cambiante y única en cada centro educativo. Igualmente, al asumir esta dinámica como un proceso debemos comprender que requiere de tiempo, y que puede haber momentos de incomprensión, estancamiento o incertidumbre que no deben conllevar una sensación de desánimo o frustración, sino que hay que tomarlos como retos y cambios positivos de los que igualmente se puede aprender. A pesar de que hay que tener en cuenta los resultados del alumnado, es tanto o más importante valorar los avances, los pequeños logros, la resolución de problemas, etc. que se va observando cada día, es decir, el camino que se recorre.

- "La inclusión busca la presencia, la participación y el éxito de todos los estudiantes". El sentido de la palabra "presencia" se refiere a la respuesta educativa a nivel institucional, es decir, que tiene que ver con el hecho de valorar si todos los niños asisten de forma 
regular a un centro determinado, independientemente de cuáles sean sus características personales. La "participación" se entiende como el papel que tienen los alumnos en las clases y está relacionado con la calidad de las experiencias educativas, así como con la percepción que tienen de su proceso de desarrollo personal en relación con su estado de bienestar físico, mental, social y emocional. Por último, el término "éxito" engloba todos aquellos aspectos relacionados con el nivel de aprendizaje del alumnado y con el grado en que se han alcanzado los objetivos contemplados en el currículo de la etapa que corresponda.

- "La inclusión precisa la identificación y la eliminación de barreras". Las "barreras" se presentan aquí para hacer referencia a todas aquellas creencias, actitudes y convicciones sociales, que pueden estar inmersas en el pensamiento cotidiano de las personas y que frecuentemente dan lugar a situaciones de marginación o exclusión en contextos educativos. De hecho, estas barreras condicionan la orientación y los principios del currículo y, por ende, las medidas de atención a la diversidad que ofrece el sistema. Es necesario, por lo tanto, cambiar el pensamiento sobre cómo debe la escuela responder a las necesidades de todos y cada uno de los alumnos para identificar quiénes se ven envueltos en tales situaciones producidas por la presencia de barreras. Recabar información y evaluar cada realidad en función de la cultura, la política y la práctica educativa es lo que brindará la oportunidad de tomar conciencia sobre los bloqueos y poder trabajar contra ello a través de planes de mejora que ayuden a transformar los contextos problemáticos en espacios de oportunidad, libertad, aprendizaje y crecimiento personal.

- "La inclusión pone particular énfasis en aquellos grupos de alumnos que podrían estar en riesgo de marginalización, exclusión, o fracaso escolar". El punto de mira de la Educación Inclusiva son todos aquellos estudiantes que estén en una situación personal y social tal que aumente el riesgo de exclusión, marginación o fracaso escolar. Es en este punto donde debemos prestar mayor atención para garantizar una atención adecuada a este tipo de alumnado, que razonablemente se puede enfrentar a sensaciones de vulnerabilidad e indefensión en contextos educativos. Dicho lo cual, es crucial valorar y evaluar la situación de estos alumnos para asegurar su presencia, su participación y su éxito en relación con su bienestar personal, físico, social y emocional. 


\section{RESPUESTA EDUCATIVA ANTE LA DIVERSIDAD}

La escuela es uno de los espacios en los que mejor se pueden apreciar las diferencias dentro de un grupo de niños, ya sea por su condición social (cultura, nivel socio-económico) o por determinadas características personales (discapacidades, u otro tipo de necesidades específicas). Teniendo en cuenta este contexto, claramente variado y diverso, resulta un tanto paradójico que la sociedad exija, implícita o explícitamente, igualdad de resultados de cara a responder a una competencia laboral prototípica y generalizada (Gimeno-Sacristán, 2002).

Parece obvio reconocer que es necesario un cambio de pensamiento en cuanto a la comprensión de la diversidad en las escuelas y en relación con lo que se considera que la Educación debe producir para la sociedad. De hecho, SantosGuerra (2002) se refiere a la función homogeneizadora de la escuela en forma de currículo, espacios, metodología y evaluaciones similares para todos los alumnos. "[U]na escuela academicista, históricamente diseñada con el fin de conseguir la transmisión homogénea de contenidos y el tratamiento uniforme de los estudiantes, no es el marco adecuado para responder a la disparidad de situaciones y a la heterogeneidad de individuos" (Pérez-Gómez, 2002, p. 67).

Parece que existe, por tanto, un conflicto de intereses entre la necesidad de atender a la diversidad en las escuelas y la de responder a las demandas de la sociedad en la que vivimos. En este sentido, la Educación debería avanzar desde la homogeneización de contenidos hacia el respeto e impulso de la heterogeneidad del alumnado y flexibilizar y diversificar el proyecto educativo y el currículo, ya que todo el cambio de pensamiento que lleva implícita la asunción del concepto de Educación Inclusiva se enfrenta a menudo con las estructuras e instituciones que conforman el sistema educativo.

En definitiva, la labor de la escuela a través de la Educación Inclusiva implica responder a la diversidad generando sentimientos de igualdad de derechos, respeto a la diferencia, valoración de la misma y solidaridad que faciliten la convivencia en una sociedad democrática que ha de considerar como valiosas las decisiones de toda la población (Casanova, 2011) y ofrecer igualdad de oportunidades para que cada niño pueda desarrollar sus potencialidades y generar su propia identidad, huyendo de la homogeneidad de contenidos y métodos. Sin embargo, nada de esto es posible si no se cambia la organización y planificación de los centros escolares y se plantean nuevas formas de entender la Educación, para lo cual se requiere flexibilidad en las instituciones, innovación y creatividad en la práctica docente y un trabajo cooperativo que implique a toda la comunidad educativa (Santos-Guerra, 2002). 
Dicho lo cual, es necesario un movimiento de transformación educativa tal que lleve las teorías sobre Educación Inclusiva a la realidad y a la práctica de los centros escolares (Rodríguez, Torrego y Flecha, 2013). Solo de esta forma será posible que las medidas de atención a la diversidad cambien de tal forma que no solo se responda a las necesidades de todo el alumnado, sino que además se asuma la individualidad y la diferencia como un derecho asumible y una oportunidad de continuo cambio, descubrimiento y crecimiento. En palabras de Echeita (2011), a pesar de que se pueden apreciar cambios y avances positivos en lo referido a la inclusión educativa en nuestro país, se trata de un panorama marcado por estancamientos, brechas y barreras que dificultan el avance hacia la superación de las situaciones de discriminación que se siguen produciendo cada día en las escuelas.

Dicho lo cual, en este contexto, en el que surge la necesidad de producir un cambio y una transformación educativa tal que dé respuesta a las constantes necesidades y características del alumnado, cobran forma nuevas prácticas educativas inclusivas. A continuación, se muestran algunas de estas perspectivas que cambian el modo de concebir y practicar la Educación.

\subsection{Algunas prácticas inclusivas}

En la actualidad aún son muchos los retos a los que ha de enfrentarse la Educación: fracaso escolar, marginación, discriminación, etc. Existen alumnos que no encuentran en las instituciones educativas un entorno adaptado a sus necesidades, que abandonan las enseñanzas porque no se les ofrece un aprendizaje individualizado y de utilidad para sus vidas, o que ni siquiera pueden optar a recibir una educación formal y adecuada. Ante los desafíos que han de afrontar los distintos profesionales envueltos en la labor educacional, cada vez es más creciente el interés por la Educación Inclusiva y el deseo por llevar a la práctica esta disciplina y hacerla realidad (Ainscow y Miles, 2009). Seguidamente se muestran algunas de las prácticas inclusivas que se están desarrollando actualmente en nuestro país.

\section{Aprendizaje basado en proyectos}

Esta propuesta educativa se basa en la premisa de que el alumnado aprende por descubrimiento a través de la interacción con el medio y en relación con las personas que lo constituyen (compañeros, familiares, profesorado) de tal modo que sus competencias se vean desarrolladas de forma dinámica y significativa (Rekalde y García, 2015). Cobra gran importancia, por tanto, el contexto dentro del cual se desenvuelven los alumnos, en todas sus vertientes: educativo, familiar, social, etc. Vergara (2016), que indica que el aprendizaje basado en proyectos - de ahora en adelante $\mathrm{ABP}$ - es una estrategia que trata de dar respuesta a las nuevas demandas de la Educación y la sociedad, recoge algunas consignas que orientan su enfoque: 
- "Aprender es un acto intencional: aprendo porque quiero". El ABP se fundamente en el hecho de que el aprendizaje surge desde el deseo y el interés de los estudiantes por la materia o asunto que están tratando. Partir de su propia intención, sus dudas, sus preguntas, sus aspiraciones, etc. hace que el proceso de aprendizaje sea más significativo y que el interés de los alumnos se mantenga a lo largo del mismo. De esta forma, un proyecto se inicia si la propuesta cuadra y conecta de manera acertada con las necesidades del alumnado.

- “Aprender es una acción práctica y útil: aprendo para algo". El hecho de aprender debe dar lugar a una utilidad que los alumnos puedan apreciar tácita y directamente en sus vidas. Tener la sensación de que un proyecto en el que están poniendo esmero y esfuerzo les lleva a producir cambios positivos en su entorno supone una motivación intrínseca y fomenta el deseo de continuar trabajando en la tarea. En este sentido, el proyecto propuesto debe ser llevado a la práctica y debe trabajar sobre situaciones reales, y no desde supuestos, modelos o marcos teóricos.

- "Los proyectos construyen experiencias educativas". Los proyectos se deben llevar a cabo de tal forma que contribuyan al desarrolo del alumnado en el aspecto emocional, físico, social e intelectual, así como en lo referente al fomento de las relaciones personales y las habilidades sociales, ya que se construyen en torno a experiencias comunicativas y de interrelación entre los alumnos y el contexto. Igualmente, deben promulgar la adquisición de herramientas y recursos útiles para su vida y están orientados al cambio personal o comunitario que se obtiene de la experiencia educativa desarrollada.

\section{Aprendizaje cooperativo}

El aprendizaje cooperativo parte de la importancia de aprovechar y emplear las habilidades personales de cada alumno para lograr objetivos comunes y alcanzar resultados con efectividad y calidad, al tiempo que se desarrollan habilidades de trabajo en equipo, colaboración, autonomía y solidaridad entre compañeros (Llopis, 2011). Según Pujolàs (2012), se trata de un concepto que está íntimamente relacionado con la Educación Inclusiva:

Por una parte, la única manera de atender juntos en una misma aula a alumnos diferentes - tal como exige la opción por una escuela inclusiva- es introducir en ella una estructura de 
aprendizaje cooperativa, en detrimento de una estructura individualista o competitiva, aún dominante en las escuelas actualmente. (...) Y, por otra parte, no puede haber propiamente cooperación -con el desarrollo de la solidaridad y el respeto a las diferencias que la cooperación supone- si previamente se han excluido de un aula a los que son "diferentes", si el aula no es inclusiva. (p. 91).

Igualmente, el aprendizaje cooperativo se caracteriza porque dentro de un grupo los alumnos asumen la responsabilidad de ayudar a sus compañeros en todo lo que sea posible además de contribuir a desarrollar las tareas grupales (López y Acuña, 2011). Por ello, es necesario considerar que los objetivos grupales estén relacionados con los objetivos individuales, de modo que tanto los intereses de grupo como los personales confluyan en una misma dirección.

\section{Comunidades de aprendizaje}

Las comunidades de aprendizaje son un proyecto de transformación educativa cuyo éxito en relación con la superación del fracaso escolar y la mejora de la convivencia ha sido desarrollado ya por gran parte de la comunidad científica a nivel internacional, y al que ya se suman más de cien centros de España y Latinoamérica (García-Carrión, Racionero, Torrego-González y GarcíaMonge, 2013). El objetivo de esta forma de entender y practicar la Educación es que todos los miembros de la comunidad educativa (alumnos, familiares y profesorado) formen parte activa de los procesos de enseñanza y aprendizaje. Asimismo, en esta ideología reside el deseo de que la escuela sea concebida como un gran proyecto en el que todos los participantes tienen algo que aportar de tal modo que contribuyan al descubrimiento y la adaptación. En palabras de Elboj, Puigdellívol, Soler y Valls (2005), las actividades en torno a las cuales se cimentan los procesos de enseñanza y aprendizaje son flexibles y han de adaptarse en todo momento a las necesidades de los miembros de la comunidad en relación con la sociedad de la información en la que han de desenvolverse.

El funcionamiento de una comunidad de aprendizaje se basa en el aprendizaje dialógico, de modo que toda la actividad educativa se desarrolla a través de procesos de diálogo entre profesorado, alumnado, familias y voluntariado en aras de lograr que todo el entorno de los niños contribuya a su aprendizaje (Flecha y Puigvert, 2015). La idea de lograr que un centro educativo se convierta en una comunidad de aprendizaje supone asumir la necesidad y la responsabilidad de reestructurar toda forma de organización, desde el desarrollo de las clases hasta la gestión del centro. Por ello, Jaussi (2006) da a conocer 
algunas "propuestas organizativas, metodológicas y formativas" que ayudan a comprender cómo puede funcionar esta práctica educativa:

- "El sueño conjunto: metas compartidas". Esta afirmación apela al sentimiento de implicación de todos los miembros de la comunidad como punto de partida clave y básico para desarrollar cualquier tipo de proyecto educativo con un objetivo común. Se trata de buscar y desarrollar estrategias que posibiliten la participación consciente y significativa de todas las personas implicadas, independientemente de su situación social o cultural.

- "Comisiones mixtas". Se trata de grupos de organización integrados por diferentes agentes de la comunidad con el objetivo de planificar las acciones a realizar en función de las prioridades y las necesidades comunes. De forma dialogada se realiza un reparto de tareas pertinente y se coordina la acción de cada uno de los miembros. Uno de los objetivos principales de esta dinámica es hacer a las familias (y a otro tipo de agentes que no formen parte del profesorado) partícipes de la toma de decisiones.

- "Formación de familiares". Uno de los aspectos que más enriquecen el desarrollo del proyecto educativo y, con ello, los procesos de enseñanza y aprendizaje, es la formación de las familias. Esto hace que aumente su interés por los contenidos, comprendan mejor la labor del profesorado y, por ende, se mejoren las relaciones de convivencia. Igualmente, la implicación de las familias repercute positivamente en el rendimiento de los alumnos y en sus resultados académicos. Este proceso de formación favorece una mejor coordinación y comunicación entre los diferentes participantes de la comunidad.

- “Más espacios y más tiempos de aprendizaje”. Implicar a todos los miembros de la comunidad en la que se encuadra el centro facilita el surgimiento e inclusión de otro tipo de contextos educativos, así como el enriquecimiento de la realidad del espacio escolar. En una comunidad de aprendizaje cada miembro aporta lo mejor de sí mismo en relación con sus conocimientos, capacidades o situación social o laboral. Es necesario, por tanto, que se mantenga una comunicación constante entre las personas implicadas. 
- "Grupos interactivos". A través de esta dinámica se pretende que todo tipo de participantes, ya sean familiares, voluntariado, educadores sociales, etc. entren en el aula como agentes educadores que se coordinan con el profesorado y le ayudan a atender a la diversidad del alumnado. De esta forma no solo se posibilita que todos los niños sean partícipes de la clase al mismo tiempo y de forma individualizada, sino que además se enriquecen los procesos de enseñanza y aprendizaje porque cada persona aporta su punto de vista con el objetivo de enseñar a ayudar. Así, el ambiente de la clase y la convivencia también mejoran.

- "Trabajo sobre normas y prevención de conflictos". Trabajar en base a una serie de normas establecidas y consensuadas ayuda a cimentar el sentimiento de prevención y resolución de conflictos. Para que estas normas trasciendan la realidad del centro educativo es necesario hacer partícipes a las familias a la hora de acordar las normas y asumir la importancia que merecen tanto dentro como fuera de la escuela. Por ello es conveniente organizar con cierta asiduidad asambleas, reuniones, comisiones mixtas, etc. 




\section{CAPÍTULO II. EL TRASTORNO POR DÉFICIT DE ATENCIÓN/HIPERACTIVIDAD (TDAH)}



En este capítulo se va a abordar, de manera global y desde diferentes puntos de vista y perspectivas, el concepto de Trastorno por Déficit de Atención/Hiperactividad. Así, en primer lugar se presenta la aproximación conceptual del trastorno, seguido de sus características básicas, su etiología, su prevalencia, el proceso de intervención mediante el cual se efectúa el diagnóstico y los distintos tipos de tratamiento existentes. Además, se presentan una serie de argumentos respecto a diferentes temas en torno a los cuales se ha generado y actualmente se sigue generando controversia y cierta polémica, como la propia formulación del trastorno, el elevado número de diagnósticos, que ha aumentado sustancialmente durante los últimos años, o el cuestionamiento de si la medicación farmacológica, aun siendo escogida en muchos casos como primera opción y recomendada para el tratamiento, es lo mejor para el desarrollo evolutivo del colectivo al que va dirigida.

\section{APROXIMACIÓN CONCEPTUAL Y CARACTERÍSTICAS BÁSICAS}

Tomando como referencia el Manual Diagnóstico y Estadístico de los Trastornos Mentales en su 5 ${ }^{\mathrm{a}}$ Edición (DSM-5), el Trastorno por Déficit de Atención/Hiperactividad - de ahora en adelante TDAH - es incluido en el grupo de trastornos del neurodesarrollo, es decir, aquellos que se manifiestan en algún momento del desarrollo evolutivo de las personas, normalmente de forma precoz antes de la etapa de Educación Primaria, y que afectan limitando la capacidad para el aprendizaje, el control de las funciones ejecutivas, el desarrollo de habilidades sociales y/o la gestión emocional, dando lugar a dificultades en el ámbito personal, social, académico, ocupacional (American Psychiatric Association, 2014).

Uno de los primeros psicólogos en hablar del TDAH y tal vez quien más tiempo y trabajo ha dedicado en profundizar en el estudio y comprensión del mismo, Barkley (1999), lo definió como un verdadero trastorno neurológico, de origen genético y cuya principal limitación es la producida por la incapacidad de autorregulación a distintos niveles (social, cognitivo, emocional, etc.). Esta dificultad para la autorregulación es lo que hace que los niños no puedan gestionar determinados problemas relacionados con la desinhibición, produciéndose así falta de control de algunas conductas inadecuadas y ciertas habilidades neuropsicológicas, como la memoria a corto plazo o la interiorización del lenguaje (Barkley, 1997). En un intento de poner a la comunidad educativa en conocimiento de las características básicas del TDAH y de las necesidades que presentan los niños diagnosticados, y en aras de lograr una mejor comprensión e intervención en las escuelas, Barkley (2008) afirmó: 
La única forma de justificarlo es asegurándonos [de] que los profesores entienden que esto es una incapacidad, así como las bases biológicas de la misma. El TDAH no es una elección, no es un fracaso en el desarrollo moral, ni el resultado de ser unos malos padres, sino que es una condición neurogenética. Una vez entendamos esto, aceptaremos que el TDAH es una incapacidad, y cuando conozcamos a un niño con este trastorno, nos volveremos más compasivos, con más ganas para llevar a cabo cambios en su comportamiento. (pp. 39-40)

Siguiendo el hilo de este discurso, otros expertos reconocen al TDAH como una perturbación o psicopatología de carácter neurológico que tiene que ver con una desordenación de los neurotransmisores que intervienen en la regulación de la actividad emocional y el movimiento, produciendo así los problemas conductuales mencionados, relacionados con la impulsividad, la falta de autocontrol y la gestión de las emociones (Aguilar-Cárceles, 2014; Aguilar-Millastre, 2014).

La mayor parte de la comunidad científica coincide en que algunas de las características definitorias o señas de identidad propias del trastorno se dan en torno a tres pilares clínicos: la inatención (o déficit de atención), la hiperactividad (unida a conductas impulsivas) y los problemas comportamentales y de relación social que pueden derivarse en determinadas situaciones y contextos, como la escuela o la familia (Aguilar-Cárceles, 2014; Aguilar-Millastre, 2014; Amador, Forns y Gonzàlez, 2010; American Psychiatric Association, 2014; Barkley, 1997, 1999, 2008; Castells y Castells, 2012; Fernández, 2018; Gálvez, 2010; Harvey, Lugo-Candelas \& Breaux, 2015; Pelayo-Terán et al., 2012; Rubiales, Bakker y Delgado, 2011; Ubieto, 2014; Vega, 2012).

Además, a nivel cognitivo el TDAH limita el control y manejo de determinadas funciones ejecutivas, es decir, todas aquellas actividades de procesamiento cerebral necesarias para realizar determinadas tareas (organizar, planificar, revisar), como la memoria de trabajo, la capacidad para regular emociones, motivación y persecución de un objetivo, la destreza para el diseño de estrategias y para la búsqueda de soluciones a los problemas y el desarrollo de la autoconciencia que permita, a su vez, la autorregulación conductual (Lecumberri, 2016).

Las características del trastorno llevan, igualmente, a problemas de relación social. Por lo general, un niño diagnosticado de TDAH se destaca y señala como un niño inquieto, molesto, conflictivo e incluso maleducado, insolente o irreverente, lo que puede dar lugar a cierto rechazo, no solo por parte de los 
alumnos sino también por parte de algunos profesores. La aparición de conductas impulsivas determina, en mayor o menor medida, el tipo de interacción que se establece entre el niño con TDAH y su entorno cercano. Es necesario, por ende, lograr que las personas que viven el día a día con él comprendan las dificultades y limitaciones que presenta a nivel emocional, conductual y relacional, de tal modo que les resulte más fácil empatizar con él, acogerlo y cuidarlo de forma natural (Barkley, 2008).

Desde un punto de vista emocional, los niños diagnosticados de TDAH son más vulnerables y sensibles a lo que ocurre en el entorno debido a las características propias del trastorno, viéndose afectado así el plano afectivo y relacional (Gallego, 2015). Esta carencia a nivel afectivo puede dar lugar a inseguridad, baja autoestima, frustración y, en ocasiones, puede llevar a desconfiar del ambiente, ya sea por la relación con los padres, por problemas vinculares durante los primeros años de vida, o por la actitud por parte de compañeros y profesores desde el momento en el que se hace explícito el diagnóstico y este pasa a formar parte de la realidad del aula y del centro escolar. Un niño diagnosticado de TDAH es consciente de cuándo es "etiquetado", y más aún de lo que afecta su "patología" al contexto en el que vive. Estas circunstancias pueden dar lugar al desarrollo de otros trastornos, es decir, a cierta comorbilidad, más o menos común en cada caso (Soutullo y Díez, 2007):

- Muy frecuentes (más el 50\% de los casos): trastorno negativista desafiante (desobediencia, hostilidad hacia figuras de autoridad), trastornos de conducta de diversa índole (problemas de adaptación, no respeto de las normas o mayor riesgo de rechazo o exclusión social).

- Frecuentes (hasta el 50\% de los casos): trastorno de ansiedad (por eventos traumáticos, fobias, problemas vinculares), trastorno del desarrollo de la coordinación (dificultad con la psicomotricidad fina), trastornos específicos del aprendizaje (dislexia, disgrafía, discalculia, dificultad de procesamiento y con el aprendizaje del lenguaje).

- Menos frecuentes (en torno al $20 \%$ de los casos): trastorno de tics, trastorno del humor, mayor riesgo de depresión y de desarrollo de enfermedad bipolar o trastorno de personalidad antisocial.

- Infrecuentes: trastorno generalizado del desarrollo, retraso mental, trastorno del espectro autista. 


\subsection{Etiología}

El TDAH está clasificado y considerado por la comunidad científica como un trastorno del neurodesarrollo. Sin embargo, las causas que originan el TDAH pueden ser varias y pueden estar asociadas a distintas situaciones o circunstancias que se den en la vida de un niño a lo largo de su crecimiento e incluso durante los meses de embarazo. En la actualidad, su definición, origen y características básicas siguen generando diferentes puntos de vista entre los profesionales implicados en el proceso de detección, diagnóstico y tratamiento del trastorno, tales como profesores, psicólogos, psicopedagogos, psiquiatras, orientadores, etc. (Pelayo-Terán, Trabajo y Zapico-Merayo, 2012).

A modo de ejemplo, y aun teniendo en cuenta que el DSM-5 es la principal guía y referencia empleada por los profesionales mencionados, cabe indicar que la Clasificación Integrada de Enfermedades (CIE) en su 10ª Edición incluye el TDAH en el grupo de trastornos de conducta y trastornos emocionales cuyo inicio se presenta habitualmente en infancia y adolescencia, y no como un trastorno del neurodesarrollo. Esta consideración, que aparentemente no dista mucho de la definición aportada en el DSM-5, aporta una perspectiva diferente respecto al origen del trastorno, que parece acercarse a un punto de vista que sitúa las causas en factores psicológicos o sociales, más que neurológicos o biológicos.

Resulta difícil determinar las causas del TDAH (Amador et al., 2010). En la mayor parte de los casos se pueden identificar detonantes no solo internos, hereditarios o biológicos, sino también externos o ambientales. Por ello, surgen dos perspectivas que se podrían considerar relativamente opuestas, aunque íntimamente relacionadas e interconectadas: el punto de vista del origen biológico, neurológico y/o genético, por un lado, y el de las causas culturales, ambientales y/o psicosociales, por otro (Bianchi, 2012; León-Guerrero, 2018):

- Los factores biológicos están fundamentados en evidencias provenientes del campo de la neurología y la biogenética. Esta perspectiva es la que justifica la deficiencia o alteración de algunos neurotransmisores encargados de la regulación conductual a nivel cerebral.

- Los factores psicosociales, que, aunque no son considerados la causa principal del origen del trastorno, pueden influir en tanto que un ambiente familiar desfavorable puede dar lugar no solo a detonantes de índole biológica, sino a carencias afectivas o a otro tipo de desatención que produzca problemas psicológicos determinados o traumas infantiles en la edad temprana. 
Desde un punto de vista biológico, diversos estudios han demostrado que el TDAH tiene un origen neurobiológico al aceptar la idea de que se produce un problema de base en el funcionamiento de la red neuronal, lo que afecta en mayor o menor medida al procesamiento cerebral relacionado con la regulación del movimiento (Ubieto, 2014). Igualmente, existe un componente genético significativo, probado y que se da hasta en un $75 \%$ de los casos diagnosticados, lo cual nos lleva a asumir este hecho como un factor determinante en el origen del trastorno (León-Guerrero, 2018). Si uno de los progenitores está diagnosticado de TDAH, existe entre un 55 y $57 \%$ de probabilidad de que se presente el trastorno en al menos uno de sus hijos (Amador et al., 2010). De hecho, teniendo en cuenta diversas investigaciones que han estudiado los factores genéticos en distintos tipos de familias, en casos de adopción, gemelos, etc. es posible afirmar que es uno de los trastornos más heredables de entre los más comunes que se dan en la población infantil y juvenil (Cavas, 2006).

Por otra parte, parece innegable aceptar que existen factores ambientales o culturales que pueden influir en el desarrollo o aparición del trastorno. Que un niño se críe en una familia desestructurada en la que el padre o la madre padece, por ejemplo, una drogodependencia, puede dar lugar a dificultades biológicas durante el propio embarazo o desencadenar otro tipo de problemas psicológicos o trastornos, comorbilidades relacionadas con carencias afectivas o traumas infantiles durante los primeros años de vida (Lecumberri, 2016).

De hecho, bastantes casos de TDAH se dan en niños adoptados o de acogida cuyos núcleos familiares han sido en origen inestables o desequilibrados. "Significativamente, dentro de los niños que son adoptados existen más probabilidades de desarrollar un cuadro de hiperactividad (...). [H]emos observado niños de procedencia china, eslavos e hispanos. Todos (...) manifestaban (...) un cuadro bien marcado de trastornos de la atención con hiperactividad" (Garrido-Landívar, 2017, p. 63). Como cabe esperar, estos niños tienen limitaciones a nivel emocional y sienten inseguridad debido a una falta de cimentación del vínculo afectivo y el apego con la figura materna y paterna en el momento del nacimiento o en los primeros años de vida:

Se ha dicho siempre que uno o varios abandonos en cadena de los vínculos afectivos en edades tempranas, generan en estos niños un estrés tanto físico, social, como mental-afectivo tan fuerte que tienden a tener menor tiempo de concentración y superan de peor manera la frustración de lo que algunos autores llaman adversidad social. (...) De hecho, romper el vínculo emocional tantas veces como suele ser habitual en estos niños 
adoptados a posteriori (abandonados por sus madres verdaderas, por las familias de sus padres, en los orfanatos), desarrollan emocionalmente menor resistencia al estrés y se traduce en niveles menores de concentración. (Garrido-Landívar, 2017, p. 63)

De hecho, es posible que determinadas experiencias traumáticas tengan lugar incluso en algún momento de la vida intrauterina del feto de tal forma que lo que ocurre en el ambiente familiar se quede impregnado a nivel inconsciente en la mente de los niños (Grof, 1999). En este sentido se puede originar un trauma infantil, por ejemplo, cuando se producen constantes discusiones en la pareja, debido a episodios o casos de violencia de género o incluso por medio de conversaciones en las que se habla de que es un bebé no deseado o cuyo mantenimiento va a suponer una gran dificultad para la familia. Los niños vienen al mundo preparados para recibir protección y cariño, por lo que cualquier tipo de carencia afectiva o maltrato por parte de referentes paternos y maternos que pueden no estar preparados para ofrecer ese amor incondicional puede dar lugar a distintos tipos de dificultades emocionales. Ubieto (2014) se refiere a este problema desde un punto de vista comprensivo:

El sufrimiento de estos padres, como el de muchos otros con niños diagnosticados con TDAH, es evidente, y qué duda cabe de que la existencia de un hijo o hija con TDAH suele generar importantes distorsiones en el seno de la familia. En este marco se hace difícil delimitar si el problema es una consecuencia del trastorno o previamente ya existían disfunciones familiares. Hay que señalar que la hiperactividad es más frecuente en niños que pertenecen a familias que tienen problemas conyugales, o bien cuando se dan relaciones hostiles entre padres e hijos. (p. 72)

En definitiva, aunque el TDAH tiene un origen biológico, es común que la disfuncionalidad se dé en el momento en que el entorno no ofrece una respuesta adecuada, es decir, cuando no se reflejan adecuadamente las conductas de modo que se produzca una mejor compresión de los hechos por parte del niño y el desarrollo de habilidades sociales que den lugar a la formación de relaciones saludables y vínculos emocionales estables (Gallego, 2015). En ocasiones las situaciones familiares de estrés o tensión llevan a padres y madres a expresar sus emociones hacia sus hijos de forma inadecuada, lo que dificulta la mejora de las relaciones y hace que sea complicado que se desarrolle su capacidad de regulación emocional o que no lleguen a entender cuál es la mejor forma de expresar sus emociones de forma asertiva. 


\subsection{No solo niños inquietos o inatentos: aspectos positivos del TDAH}

A menudo se habla y se escribe sobre las dificultades de los niños diagnosticados de TDAH, de sus problemas de adaptación o de lo conflictivos que pueden llegar a ser en determinadas situaciones. Sin embargo, existen una serie de características propias de este tipo de niños que deberían ser potenciadas como cualidades o capacidades positivas y que, por lo general, quedan ocultas tras una percepción aislada y condicionada por la etiqueta y por su clasificación como trastorno del neurodesarrollo. Teniendo en cuenta las características de la sociedad actual, la existencia de un alto nivel de hiperactividad e impulsividad es mal aceptada y comúnmente considerada como algo que es necesario corregir o erradicar (Fernández, 2018). Debido a este discurso social, cargado de tintes negativistas, se generan sentimientos de frustración e impotencia en los niños y de forma inevitable pasan a ser estigmatizados, en mayor o menor medida, y señalados como niños inquietos, molestos, inatentos, ensimismados, etc., quedando su propia personalidad y esencia relegadas a segundo plano.

De hecho, esta dinámica o modo de comprensión del problema da lugar a que una de las principales medidas de actuación sea el castigo unido a ciertas restricciones e imposición de límites en el colegio y en otros contextos, como la familia o el tiempo de ocio, lo que puede dar lugar a sentimientos de incomprensión y de falta de afecto por parte del niño, sobre todo si tenemos en cuenta que en muchas ocasiones no es consciente de lo que ocurre o no puede controlar sus conductas impulsivas (León-Guerrero, 2018). Así es como se genera la percepción a la que aludimos previamente, la de "el niño que da problemas" y que será señalado y tratado como tal, no solo por parte de sus compañeros sino, inevitablemente, por parte de algunos profesores. En cambio, si se aludiese más a sus características positivas se podría reducir esta percepción negativa que, por lo general, se tiene de los niños diagnosticados de TDAH.

En primer lugar, una de las características que puede estar presente en algunos casos es que sean niños nobles y sensibles, con un gran deseo de amar y de ser amados por el entorno. Habitualmente demuestran tener emociones auténticas, honestas y profundas, así como conciencia moral, sentimiento de arrepentimiento y capacidad real para reconocer los errores y pedir perdón. Además, son capaces de expresarse sin ningún problema, al igual que cualquier otro tipo de niño o adolescente, si empleamos tiempo para sentarnos a escuchar, acompañar y tratar de comprender cómo se sienten ante todo lo que ocurre a su alrededor y que, normalmente, no llegan a comprender del todo o no saben cómo gestionarlo: malas notas, castigos, estados depresivos, despistes, rechazo social, etc. (Ubieto, 2014). 
Por otra parte, lo que a veces es considerado como falta de atención o dispersión presente en el trastorno, es decir, la muestra conductual común de "estar ensimismado" en situaciones en las que cabría esperar estar atento, puede entenderse también como la capacidad de atender a varios aspectos de forma simultánea, a modo de multitarea, como si se tratase de una conservación reptiliana de primitivos reflejos propios de los primeros habitantes de este planeta (Castells y Castells, 2012). Es cierto que, en ocasiones, al observar cómo se comportan algunos niños diagnosticados de TDAH se puede apreciar, más que una falta de atención, la sensación de que están pensando en tantas cosas al mismo tiempo que no pueden poner freno a sus pensamientos, a su propio cerebro. En este sentido, y especialmente cuando surge el interés por la tarea, se producen momentos de hiperconcentración (Guerrero, 2006), entendiendo como tal la capacidad no solo de centrar la atención focalizada en lo que se está haciendo, sino de mantener una atención sostenida constante y que no cesará hasta que el problema, proyecto o idea haya sido resuelto.

Es necesario señalar, igualmente, que en muchos casos en los que existe TDAH existen también altas capacidades. No es difícil aceptar que pueda ocurrir si tenemos en cuenta que son niños muy ingeniosos e intuitivos, creativos, con sentido del humor, valoran especialmente el afecto y presentan cualidades destacables para el deporte, la expresión artística, la literatura, la inventiva y la música (Guerrero y Pérez, 2011). Precisamente, y de forma contraria a lo que cabría esperar por las características del trastorno, son niños con un innato sentido del ritmo inigualable y una gran capacidad para la coordinación a nivel corporal (Rickson, 2006).

A modo de conclusión, a continuación se enumeran algunas características que pueden estar presentes en los niños con diagnóstico de TDAH, siempre en función de cada caso, y que son recogidas por la Fundación Cantabria Ayuda al Déficit de Atención e Hiperactividad (Fundación CADAH, 2012, citado en León-Guerrero, 2018):

- Son ambiciosos, quieren ser "todo" cuando sean mayores.

- Son buenos para hablar en público.

- Son capaces de ver un orden en el caos.

- Se adaptan bien a los cambios.

- Son grandes generadores de ideas, son realmente creativos.

- Son compasivos consigo mismos, y especialmente con los demás.

- Son hábiles para solucionar problemas rutinarios.

- Siempre están dispuestos a probar y aprender cosas nuevas.

- Siempre están dispuestos a hacer nuevos amigos.

- Siempre están dispuestos a ayudar. 
- Siempre tienen una gran decisión, carisma e iniciativa.

- Siempre buscan caminos alternativos hacia un fin.

- Tienen buena reacción en situaciones de emergencia.

- Tienen buena capacidad para enfrentarse a situaciones difíciles.

- Tienen la habilidad de encontrar caminos para superar obstáculos.

- Tienen soluciones ocurrentes para resolver problemas.

- Tienen un gran sentido del humor.

- Tienen una gran memoria visual.

- Tienen un buen procesamiento en información por imágenes.

- Tienen una personalidad atractiva.

- Pueden llevar a cabo muchos proyectos al mismo tiempo.

- Miran una misma situación desde diferentes perspectivas o ángulos.

- Necesitan dormir menos que los demás.

- Son nobles, piden perdón y perdonan fácilmente.

\section{PROCESO DE DIAGNÓSTICO}

Un diagnóstico, independientemente del caso o situación en la que se dé, es un momento decisivo en la vida de un niño, así como para el ambiente que le rodea, especialmente en el entorno familiar. De alguna forma constituye un punto de inflexión a partir del cual los padres tendrán que tomar una serie de decisiones y atenciones específicas para tratar de dar a su hijo o hija una respuesta a sus necesidades. Incluso puede ser un momento en que se tengan que plantear si necesita algún tipo de tratamiento en concreto. Por lo tanto, es necesario que el diagnóstico tenga lugar siempre de forma contrastada, rigurosa y, por ende, acertada y oportuna. Por ello, lo más recomendable para que se den estas características durante el proceso de detección y diagnóstico de TDAH es que exista un protocolo de intervención en torno al cual los distintos profesionales implicados en dicha tarea se organicen y actúen de forma coordinada.

Dicho lo cual, el seguimiento de dicho protocolo debe ocurrir con el objetivo de abordar los casos de TDAH, no solo para prever y/o identificar el problema, sino también para tratar de no incurrir en errores de diagnóstico en casos en los que no sea necesario. Una atención adecuada y adaptada a las características y necesidades del niño requiere de la intervención multidisciplinar y coordinada por parte de profesionales de distintas áreas (Vega, 2012). De hecho, la complejidad del trastorno, así como su variabilidad en función de cada caso en concreto, incrementa la dificultad de emitir una solución acertada, por lo que es necesario que la información y las pruebas sean contrastadas y verificadas (Rubiales et al., 2011). 
Este protocolo puede variar en función de la región o Comunidad Autónoma donde se lleve a cabo el proceso de intervención. En el caso de la Junta de Castilla y León, por ejemplo, se considera un documento de organización y coordinación entre los distintos órganos implicados en la detección, diagnóstico y tratamiento del trastorno (familias, profesorado, pediatras, equipos de orientación educativa, psiquiatras infantiles, etc.), donde se señala concretamente el papel o función de cada grupo en el proceso (Láez, Requejo, Silvano y Velasco, 2011). Dicho proceso de intervención está diseñado en base a tres fases de intervención, tal y como se puede observar en la Tabla 2.

Tabla 2

Fases del protocolo de coordinación para TDAH (JCyL)

\section{$\begin{array}{lll}\text { FASES IMPLICADOS FUNCIONES } & \text { FIOS }\end{array}$}

\begin{tabular}{|c|c|c|c|}
\hline \multirow[b]{2}{*}{$\begin{array}{l}\text { 1. Detección } \\
\text { Temprana de } \\
\text { TDAH }\end{array}$} & \multicolumn{2}{|c|}{$\begin{array}{l}\text { Familia } \\
\text { Pediatra } \\
\text { Profesorado } \\
\text { Equipo directivo }\end{array}$} & Detección y notificación \\
\hline & \multicolumn{2}{|c|}{$\begin{array}{l}\text { Equipo de Orientación } \\
\text { Educativa o Departa- } \\
\text { mento de Orientación }\end{array}$} & $\begin{array}{l}\text { - Pre-evaluación } \\
\text { - Evaluación del Orientador } \\
\text { Educativo } \\
\text { - Informe de derivación } \\
\text { - Coordinación y seguimiento }\end{array}$ \\
\hline \multirow{2}{*}{$\begin{array}{l}\text { 2. Diagnóstico y } \\
\text { Tratamiento en } \\
\text { Atención Prima- } \\
\text { ria }\end{array}$} & \multicolumn{2}{|c|}{ Servicios sanitarios } & Consulta médica \\
\hline & \multicolumn{2}{|c|}{ Pediatra/MAP } & $\begin{array}{l}\text { - Evaluación del paciente } \\
\text { - Seguimiento y coordinación } \\
\text { - Derivación a servicios especia- } \\
\text { lizados }\end{array}$ \\
\hline \multirow{3}{*}{$\begin{array}{l}\text { 3. Diagnóstico y } \\
\text { Tratamiento en } \\
\text { Atención Espe- } \\
\text { cializada }\end{array}$} & \multicolumn{2}{|c|}{$\begin{array}{l}\text { Equipo de Salud Mental } \\
\text { Infanto-Juvenil }\end{array}$} & $\begin{array}{l}\text { - Derivación } \\
\text { - Valoración del paciente }\end{array}$ \\
\hline & \multirow{2}{*}{$\begin{array}{l}\text { Programa } \\
\text { de Aten- } \\
\text { ción al } \\
\text { TDAH }\end{array}$} & $\begin{array}{l}\text { Servicios } \\
\text { Sanitarios }\end{array}$ & $\begin{array}{l}\text { - Consultorías telefónicas } \\
\text { - Sesiones clínicas }\end{array}$ \\
\hline & & $\begin{array}{l}\text { Servicios } \\
\text { educativos }\end{array}$ & $\begin{array}{l}\text { - Adaptaciones metodológicas } \\
\text { - Programas específicos de in- } \\
\text { tervención } \\
\text { - Intervención, coordinación y } \\
\text { seguimiento del alumno, la fa- } \\
\text { milia, el profesorado y el centro. }\end{array}$ \\
\hline
\end{tabular}

Fuente: Adaptado de Láez et al. (2011).

A la hora de emitir dicho diagnóstico es imprescindible tener en cuenta y muy claras las muestras de conducta observables en los niños que permitirán reconocer e identificar el trastorno en distintos contextos (en el aula, en la familia, en los momentos de ocio, etc.). Independientemente del protocolo que se siga en el proceso de diagnóstico, lo cual dependerá en mayor o menor medida, 
como hemos dicho, de la región donde se produzca, la mayor parte de los profesionales implicados comparten la idea de seguir los criterios de diagnóstico recomendados en el manual DSM-5 (Bianchi, 2012). Así, este documento se convierte en la principal referencia y guía básica a la que dichos profesionales, provenientes de campos educacionales y de la salud, recurren frecuentemente para tratar asuntos relacionados con trastornos mentales de diversos tipos. Dichos criterios quedan recogidos en la Tabla 3.

Tabla 3

Criterios diagnósticos para el TDAH

Inatención:

a. No presta atención suficiente a los detalles o incurre en errores por descuido en las tareas escolares, en el trabajo o en otras actividades.

b. Tiene dificultades para mantener la atención en tareas o en actividades recreativas.

c. Parece no escuchar cuando se le habla directamente, parece tener la mente ocupada en otras cosas.

d. No sigue las instrucciones, no finaliza tareas escolares, encargos u obligaciones, se distrae o evade con facilidad.

e. Tiene dificultades para organizar tareas y actividades.

f. Evita, le disgusta o se muestra reacio a dedicarse a tareas que requieran un esfuerzo mental sostenido.

g. Extravía objetos necesarios para realizar tareas u otras actividades (ejercicios escolares, libros o herramientas).

h. Se distrae con facilidad por estímulos externos.

$i$. Con frecuencia se olvida de realizar las actividades u obligaciones cotidianas.

Hiperactividad e impulsividad:

a. Mantiene constante movimiento en las manos o los pies, o se mueve en su asiento.

b. Abandona su asiento en las clases o en otras situaciones en que se espera que permanezca sentado.

c. Corre excesivamente o trepa en situaciones en las que es inapropiado hacerlo.

d. Tiene dificultades para dedicarse tranquilamente a actividades recreativas.

e. Actúa como si estuviese ocupado en todo momento, "como si fuese movido por un motor".

f. Habla en exceso habitualmente.

g. Da respuestas precipitadas antes de que se hayan terminado de formular las preguntas.

h. Tiene dificultades para guardar turno.

$i$. Interrumpe o se inmiscuye en las actividades de otros (por ejemplo, se entromete en conversaciones ajenas).

Fuente: American Psychiatric Association (2014, pp. 59-60). 
Teniendo en cuenta estos criterios diagnósticos y en función de la presencia o no de unas conductas u otras, se pueden considerar distintos casos: presentación combinada de ambas áreas (inatención e hiperactividad/impulsividad), presentación predominante con falta de atención (si se cumplen solo los criterios diagnósticos del área de inatención) o presentación predominante hiperactiva/impulsiva (si se cumplen solo los criterios de hiperactividad e impulsividad), y, en cualquier caso, en aras de evitar incurrir en errores de diagnóstico, considerando en todo momento los siguientes criterios complementarios (American Psychiatric Association, 2014, pp. 59-60):

a. Al menos seis de los síntomas de inatención y al menos seis de los síntomas de hiperactividad/impulsividad se han mantenido durante, al menos, seis meses en un grado que no concuerda con el nivel de desarrollo y afecta a las actividades sociales y académicas.

b. Algunos síntomas estaban presentes antes de los 12 años.

c. Varios síntomas están presentes en dos o más contextos (la casa, la escuela, el grupo de amigos en momentos de ocio, etc.).

d. Los síntomas interfieren en el correcto funcionamiento social o académico de la vida del niño.

e. Los síntomas no están mejor justificados teniendo en cuenta otro trastorno mental.

En este sentido, y para evitar que se den casos de errores diagnósticos por partir de una información sesgada y descontextualizada, Lecumberri (2016) señala que la evaluación del TDAH se debe realizar a partir de datos obtenidos de distintas fuentes, como el historial médico y familiar, entrevistas con el niño, los padres y los profesores, el análisis y observación del comportamiento del niño en situaciones particulares como el entorno familiar o los lugares de recreo, un examen físico y neurológico, escalas de medición de conducta cumplimentadas por padres y profesores, etc. El diseño de escalas de valoración de conductas pretende favorecer la coordinación y el intercambio de información entre los distintos profesionales, como por ejemplo entre los psicólogos y los maestros (Farré y Narbona, 2013). En definitiva, la evaluación del TDAH debe ir orientada a (Lecumberri, 2016):

- Confirmar que se trata de un caso de TDAH, descartando así otro tipo de trastorno. 
- Determinar el subgrupo al que pertenece: presentación combinada de ambas áreas, presentación predominante de falta de atención, etc.

- Conocer qué áreas están afectadas, lo cual facilitará la individualización del tratamiento.

- Valorar cómo afecta al ámbito familiar y concretar qué medidas pueden ser recomendadas a los padres.

- Valorar cómo afecta al ámbito escolar y concretar qué medidas de actuación pueden ser recomendadas a los profesores.

- Diseñar un proceso de tratamiento y seguimiento, así como evaluaciones peródicas.

\subsection{Prevalencia}

Actualmente, el TDAH es uno de los trastornos más generalizados, llegando a representar hasta el 5\% de la población infantil y juvenil a nivel internacional en la mayoría de las culturas (American Psychiatric Association, 2014). Por lo tanto, se ha de considerar como uno de los temas de mayor interés en la sociedad actual, más en concreto en relación con el ámbito educacional (Skutle et al., 2015). De hecho, es común que este tema salga a debate en distintas situaciones o conversaciones con maestros, psicólogos, pediatras o familias comprometidas con la educación de sus hijos y sensibilizadas con el tema, especialmente si conviven o están acostumbrados a trabajar con casos de TDAH diagnosticados. Con ánimo de tratar de concretar el porcentaje de prevalencia a nivel internacional, en la Tabla 4 se refleja una recopilación en función de los diagnósticos emitidos en distintos países.

A pesar de que el porcentaje de diagnósticos es similar en estos países (entre el 3\% y el 7\% aproximadamente) y de que el manual DSM-5 recoge una media acordada de en torno al 5\% del total de la población infantil y juvenil, es necesario considerar las diferencias de prevalencia que se dan no solo entre países, sino también entre distintos tipos de poblaciones dentro de una misma cultura (American Psychiatric Association, 2014):

Las diferencias entre las prevalencias del TDAH de diferentes regiones parecen ser atribuibles principalmente a las diferentes prácticas diagnósticas y metodológicas. No obstante, también puede haber una variación cultural en las actitudes hacia 
los comportamientos de los niños o su interpretación. Los porcentajes de identificación clínica en Estados Unidos para las poblaciones afroamericanas y latinas tienden a ser más bajos que para las poblaciones caucásicas. Las evaluaciones de síntomas de los informantes podrían verse influidas por el grupo cultural del niño y del informante, lo que indica que en la evaluación del TDAH es importante que la práctica clínica sea culturalmente apropiada. (p. 62)

Tabla 4

Diagnóstico y prevalencia media de TDAH a nivel internacional

País

Prevalencia (\%)

\begin{tabular}{cc}
\hline Alemania & $4.2 \%$ \\
Australia & $7.15 \%$ \\
Brasil & $5.8 \%$ \\
Canadá & $3.65 \%$ \\
Estados Unidos & $3.8 \%$ \\
Holanda & $2.8 \%$ \\
Nueva Zelanda & $3.9 \%$ \\
\hline
\end{tabular}

Fuente: Adaptado de Aguilar-Cárceles (2014).

Además, si analizásemos la prevalencia del TDAH en alguno de los países más empobrecidos del mundo, como Liberia, Sierra Leona o la República del Níger, donde las necesidades que deben ser cubiertas guardan relación con el mantenimiento de unas condiciones saludables básicas, es lógico que este trastorno no sea diagnosticado, ya sea por falta de medios o, simplemente, porque no se presenta como un problema al haber otros asuntos más importantes de los que preocuparse. En cambio, en países como EEUU, España o Australia, más desarrollados, la exigencia de la sociedad y del sistema educativo puede producir que unos síntomas aparentemente leves den lugar a una desregulación en el desarrollo evolutivo de los niños, pudiendo afectar peyorativamente a su capacidad de adaptación social durante toda la vida si no se toman las medidas adecuadas (Fernández, 2018).

En el caso de España no se han recogido estadísticas a nivel nacional o autonómico mediante las cuales se pueda estimar el porcentaje de prevalencia. No obstante, a partir de un trabajo de investigación basado en una revisión sistematizada de estudios epidemiológicos en niños y adolescentes diagnosticados de TDAH menores de 18 años, se puede estimar que en el año 2012 la preva- 
lencia ascendía al 6,8\% (Catalá-López et al., 2012). Además, según un estudio realizado en 2009, el número de niños diagnosticados en la Comunidad de Castilla y León era del 6\% del total de la población infantil, así como en torno al 4\% en las Islas Baleares y Canarias, según estudios del 2009 y el año 2012 respectivamente. Se puede observar, por lo tanto, que estos porcentajes oscilan dentro del rango de prevalencia estimado y aceptado por la comunidad científica a nivel internacional. En cualquier caso, tener en cuenta estas estadísticas de forma literal supone aceptar que el TDAH se da, aproximadamente, en uno o dos niños de cada clase de veinte alumnos.

Por otra parte, cabe señalar que el trastorno se da en distinta medida en función de la variable sexo, produciéndose el doble de casos en niños, e incluso en una proporción de tres a uno, por lo que se encuentran pocos casos de TDAH en niñas y, por lo general, presentan más predominancia de síntomas de inatención que de hiperactividad e impulsividad (León-Guerrero, 2018). Además, los diagnósticos son elevados en casos de adopción y programas de acogida (Castells y Castells, 2012), aunque no se pueda clarificar con una certeza absoluta si las causas son de origen biológico, debido a problemas o circunstancias específicas de los padres biológicos o ambiental, por cómo pueda repercutir a nivel psicológico y emocional una falta de atención en los primeros años de vida, un proceso de adopción, el cambio constante de una familia de acogida a otra, etc.

\section{FORMAS DE INTERVENCIÓN}

Una vez el TDAH ha sido diagnosticado, las medidas o intervenciones a través de las cuales se procede en el proceso de tratamiento, que irá orientado a la mejora de la situación del niño, se clasifican, a grandes rasgos, en dos grandes grupos: la medicación farmacológica y las intervenciones no farmacológicas (Aguilar-Millastre, 2014; Amador et al., 2010; Castells y Castells, 2012; Gálvez, 2010; Harvey et al., 2015; Garrido-Landívar, 2017; Martín-Navarro, 2012; Vega, 2012).

A pesar de que se pueda creer que son vías de actuación que funcionan la una en contraposición de la otra, lo cierto es que se producirá una mejor atención a las necesidades y características del niño cuanto más combinada, interdisciplinar y contrastada sea la intervención, dando lugar así a un tratamiento multimodal, basado en el abordaje familiar, psicológico, pedagógico y farmacológico, y en el que los distintos profesionales (maestros, psicólogos, pediatras) actúen de forma coordinada (Lecumberri, 2016). En otras palabras, el proceso de tratamiento será diseñado a largo plazo, se irá adaptando a las 
necesidades que se vayan presentando en función de las circunstancias y ha de ser desarrollado en torno a cuatro pilares: el farmacológico, el psicoterapéutico, el de asesoramiento a los padres y el de trabajo en red entre docentes, trabajadores sociales y clínicos (Ubieto, 2014). En palabras de Garrido-Landívar (2017):

Hemos de saber que existen otros [tratamientos] y "distintas intervenciones psicoterapéuticas”, que en las revisiones clínicas actuales lo llaman intervención Psicosocial, muy eficaces para reducir las manifestaciones sintomáticas de los aspectos afectivos, sociales, personales y de implicación en el grupo, además de una gran variedad de orientaciones psicoeducativas y de orientación a las familias. Este paquete terapéutico se hace hoy tan indispensable que no es posible asumir un tratamiento completo si no es mixto, fundamentalmente hablando. Farmacológico más intervención psicosocial. (p. 110)

\subsection{Tratamiento farmacológico}

La medicación farmacológica es la principal medida empleada para el tratamiento del TDAH, por delante de las intervenciones no farmacológicas, debido a los resultados que se han ido obteniendo y a la consideración, predominantemente desde un punto de vista biológico, de que se trata de un trastorno del neurodesarrollo cuya principal carencia se encuentra, básicamente, en la falta de capacidad en la regulación de transmisores a nivel cerebral (Barkley, 2008; Aguilar-Cárceles, 2014). Como es lógico, esta percepción puede llevar a pensar que la forma más eficaz de intervenir de cara al control y regulación de las conductas impulsivas y la falta de atención es ayudar al cerebro químicamente para que funcione como se cabría esperar a la hora de tener lugar determinados procesamientos cognitivos y emocionales. Ubieto (2014) alude a esta tendencia a optar por la medicación como principal vía de intervención:

El abordaje farmacológico, si nos fijamos en los datos de Estados Unidos, en la actualidad está considerado como la opción básica del tratamiento a pesar de que siempre se insista en que el tratamiento del TDAH es multimodal. Aproximadamente uno de cada 5 adolescentes en secundaria y uno de cada 10 en primaria está siendo medicado en este momento. (p. 59) 
Mediante el tratamiento basado en fármacos, especialmente de tipo estimulante, que son los más recomendados para casos de TDAH, se ha demostrado una mejora en el comportamiento, los resultados académicos y las relaciones sociales de entre un 50\% y 95\% de casos de niños diagnosticados (Barkley, 1999). Los psicoestimulantes, cuya eficacia se ha constatado desde hace más de 70 años (Vega, 2012), actúan positivamente incrementando los niveles de atención y disminuyendo la hiperactividad y la impulsividad (Aguilar-Millastre, 2014).

De entre este tipo de estimulantes, que actúan en el sistema nervioso central activando o modificando el estado de alerta, el metilfenidato es el más empleado, seguido de la dextroanfetamina, la mezcla de sales de anfetaminas y la pemolina (Amador et al., 2010). El uso de metilfenidato es ampliamente recomendado porque mejora de forma sustancial los síntomas del trastorno a nivel comportamental, cognitivo, académico y social, lo cual es avalado por muchos estudios (Cavas, 2006). Estos medicamentos actúan directamente a nivel físico y neurológico, por lo que sus efectos se hacen muy visibles al poco tiempo de haber sido suministrados. Algunos de los efectos positivos que producen estas sustancias son (Lecumberri, 2016):

- Mejora los procesos de atención, reduce los distractores y favorece la respuesta ante estímulos durante la realización de tareas.

- Mejora la memoria, el procesamiento matemático, la comprensión lectora y los fallos de ortografía.

- Mejora la concentración y la organización.

- Mejora la psicomotricidad fina, especialmente en actividades relacionadas con el dibujo y la escritura.

- Disminuye la actividad física, favorece la capacidad de relajación.

- Mejora el control de los impulsos, la regulación conductual y el autocontrol. Aumenta el tiempo de búsqueda de opciones o alternativas, disminuyen la agresividad y las situaciones de riesgo.

- Mejora el comportamiento y el cumplimiento de normas. 
- Mejora la relación social con compañeros, profesores y familiares, de modo que se favorece la afectividad y se refuerza el sentimiento de pertenencia a un grupo.

No obstante, varios expertos reconocen que los efectos secundarios que estos fármacos pueden tener a largo plazo no han sido estudiados ni constatados rigurosamente por el momento, y que pueden afectar negativamente en el proceso de formación de conexiones neuronales y, en definitiva, en el desarrollo evolutivo de los niños (Aguilar-Millastre, 2014; Amador et al., 2010; Cavas, 2006). El suministro de fármacos en edades tempranas puede conllevar ciertos riesgos, por lo que es recomendable e incluso necesario que este tipo de tratamiento parta de una buena evaluación individual, sea aplicado con certeza y seguridad y que sea revisado a menudo para recalcular la dosis adecuada y retirarlo en caso de que ya no sea necesario (Lecumberri, 2016). "[L]a creciente toma de estimulantes (...) en preescolares hace que la determinación de la validez del diagnóstico a esta edad tan temprana tenga una importancia capital como para sopesar con mucha prudencia los riesgos y beneficios del tratamiento temprano" (Garrido-Landívar, 2017, p. 85).

\subsection{Medidas no farmacológicas}

Otra de las vías de intervención que tiene lugar en procesos de tratamiento de niños diagnosticados de TDAH son las medidas no farmacológicas, en las que, como su propio nombre indica, la intervención no está basada en medicamentos. Es recomendable que las actuaciones no farmacológicas sean aplicadas siempre durante el proceso de tratamiento, no solo de forma complementaria, en aquellos casos en los que se estén suministrando medicamentos (Barkley, 2008), sino también como principal medida en casos en los que la severidad del trastorno no es muy elevada y se puede prescindir de la prescripción farmacológica (Gálvez, 2010; Vega, 2012). En cualquier caso, el tratamiento adecuado para niños diagnosticados de TDAH debe estar formado por distintas técnicas y procedimientos para lograr los mejores resultados (Amador et al., 2010).

Estas medidas se pueden clasificar en intervenciones psicopedagógicas, orientadas a dar una buena respuesta educativa y mejorar aspectos relacionados con el progreso académico, la inclusión del niño en la escuela y la disminución del fracaso escolar, e intervenciones psicológicas, encaminadas a atender aspectos sociales, conductuales y emocionales del niño diagnosticado y a dar un soporte a las familias, así como indicaciones y recomendaciones a otros profesionales, como los maestros (Aguilar-Millastre, 2014). 
Desde un punto de vista psicopedagógico, se debe trabajar para que el niño reciba una atención adecuada y adaptada a sus necesidades, de tal forma que pueda avanzar a lo largo de su escolarización tanto como sea posible. En esta intervención, por lo tanto, se ven implicados los profesores, el orientador y el psicólogo del centro, así como otros profesionales que estén trabajando con el niño si es necesario debido a sus características: especialista en audición y lenguaje, logopeda, etc. En este contexto, una de las medidas que funcionan para contribuir a la mejora del progreso académico y combatir las dificultades de aprendizaje del niño son las técnicas de modificación de conducta y el tratamiento cognitivo (Castells y Castells, 2012).

Uno de los papeles más importantes en este proceso de atención es el de los docentes y, especialmente, el del tutor del niño, ya que son quienes más tiempo pasarán con él en el contexto escolar y los responsables directos de su educación. La figura del maestro debe representar una autoridad positiva que ayude a poner límites cuando sea necesario, a orientar en la organización y dosificación de las tareas académicas y a repercutir positivamente en el ambiente de aula y su inclusión dentro del grupo (Barkley, 2008). En determinadas ocasiones es necesario, incluso, que el espacio en el que se desarrollan los procesos de enseñanza-aprendizaje (el aula), así como el modo de comprender dichos procesos (lo que va directamente unido a la perspectiva pedagógica) sean reorganizados y adaptados para obtener una buena respuesta educativa para los niños diagnosticados de TDAH (León-Guerrero, 2018).

El tratamiento psicológico busca ayudar al niño a nivel cognitivo a desarrollar estrategias de organización, así como habilidades de gestión emocional y social. Trabajar en este nivel de forma consciente puede contribuir a la mejora de la autoestima, del nivel de autocontrol y de la capacidad para mantener la motivación y la concentración, dando lugar así a un mayor nivel de autoconcepto (Nizar, 2017). Esta intervención es proporcionada por psicólogos y psicopedagogos tanto del ámbito público, es decir, quienes forman parte de la realidad escolar en torno a la cual se desarrollan los procesos de enseñanzaaprendizaje que envuelven al niño, como del ámbito privado, en aquellos casos en los que las familias optan también por recurrir a ayuda externa y especializada. Sin embargo, el tratamiento a nivel psicológico no debe quedarse en el contexto de las sesiones individuales o la consulta, sino que debe ser apoyado e impulsado también por las familias y los docentes, propiciando así el trabajo en red para una mejor respuesta y, con ello, mejores resultados a nivel académico, familiar y social (Vega, 2012). La siguiente cita textual ayuda a comprender la función de esta intervención psicológica: 
La Psicoterapia. Les va a ayudar a quererse y a aceptarse como son. Suele utilizar ayuda psicológica individual y de grupo. Hablan de sus sensaciones y sentimientos, estudian los comportamientos inadecuados, sus consecuencias y las distintas opciones para manejar sus emociones. Interviene a dos niveles, en el manejo de la atención y de la conducta. Se enseñan técnicas para modificar los comportamientos, el objetivo es aumentar las conductas adecuadas y disminuir las conductas inadecuadas, tanto en el ámbito familiar como escolar. (Lecumberri, 2016, p. 92)

En cualquier caso, es altamente recomendable que las medidas no farmacológicas acompañen siempre el proceso de desarrollo del alumnado diagnosticado de TDAH, ya que se incrementarán positivamente sus habilidades cognitivas, emocionales y sociales, independientemente de si es necesaria también la toma de medicamentos específicos. Además, esta intervención debe ser adaptada al momento del proceso, a las circunstancias y las necesidades que se vayan presentando de forma concreta, por lo que es necesario que sea prolongada y revisada a lo largo del tiempo.

Dentro de este tipo de medidas se incluyen las llamadas terapias alternativas, que, en mayor o menor medida, pueden contribuir en el proceso de tratamiento del alumnado con TDAH de forma complementaria, sobre todo teniendo en cuenta las características de cada niño y, con ello, con qué tipo de intervención se lograrán mejores resultados. Dentro de este grupo se incluyen algunas acciones, disciplinas o actividades como la homeopatía, el reiki, el diseño y adaptación de una dieta equilibrada, la fitoterapia, la meditación, la osteopatía, el yoga, la naturopatía o la musicoterapia, entre otros, sobre las cuales nos detendremos a hablar más adelante.

\section{CONTROVERSIAS EN TORNO AL TDAH}

A la hora de hablar sobre TDAH hay determinadas causas que han producido, durante los últimos años, que se genere cierta controversia en relación con ello. En primer lugar, por el hecho de que sea uno de los trastornos con mayor incidencia entre la población infantil y juvenil, unido al incremento exponencial del número de diagnósticos, especialmente durante los últimos años. Por otra parte, que la principal medida de intervención sea, en la mayoría de los casos, la medicación farmacológica, aun cuando puede conllevar cierto riesgo para el correcto desarrollo evolutivo del alumnado diagnosticado de TDAH. Por último, que gran parte de estos alumnos sean etiquetados por el hecho de ser movidos o inatentos, mientras algunos expertos reconocen en ellos la ca- 
pacidad de emprendimiento, una gran creatividad y facilidad para la multitarea, lo cual puede estar provocado, de hecho, por la sociedad moderna, dinámica y digitalizada en la que vivimos hoy en día.

Estos hechos hacen que surja la polémica y la controversia y, con ello, opiniones contrapuestas frente a la prescripción farmacológica, al elevado número de diagnósticos e, incluso, ante la consideración de que el TDAH sea realmente un trastorno neurológico de origen genético y/o biológico, cuya naturaleza impida un desarrollo normal de la persona a lo largo de su vida. Esto es lo que vamos a explorar, a través de distintos argumentos que surgen al respecto, en este apartado. El debate que surge al respecto queda reflejado por medio de las siguientes palabras de Zapico Merayo y Pelayo-Terán (2012):

A pesar de la importante labor de unificación de criterios diagnósticos (...), algunas diferencias han persistido (...). Algunas de estas discrepancias, junto con una prevalencia creciente del diagnóstico y al mismo tiempo de la prescripción de estimulantes y otros psicofármacos destinados al tratamiento del TDAH has auspiciado al mismo tiempo críticas y distintos puntos de vista tanto desde la opinión pública como de distintos profesionales sanitarios, educativos y sociales en relación con una creciente preocupación por la protección al menor y la medicalización de problemas no tanto psiquiátricos como variaciones de la normalidad. (pp. 97-98)

\subsection{TDAH, ¿construcción social?}

El primer punto de polémica surge de la propia definición del TDAH, es decir, de su consideración como trastorno de origen neurológico, cuyo origen se sitúa en mayor medida en causas biológicas y cuya naturaleza es básicamente genética e innata, lo que implica que es una condición que acompañará a la persona diagnosticada a lo largo de su vida, generando dificultades y limitaciones en su proceso de desarrollo evolutivo. Esta idea, enunciada y respaldada por gran parte de la comunidad científica (Aguilar-Cárceles, 2014; Aguilar-Millastre, 2014; Amador et al., 2010; American Psychiatric Association, 2014; Barkley, 1997; Castells y Castells, 2012; Harvey et al., 2015; Pelayo-Terán et al., 2012; Rubiales et al., 2011), es directamente cuestionada, sin embargo, por algunos profesionales y expertos, también familiarizados con el alumnado de estas características, como veremos a continuación de forma argumentada. 
Ya en el año 1975 se publicaron dos artículos relacionados con "el mito del niño hiperactivo", en los que Scharg y Dikovy se referían al TDAH como una forma de etiquetar a los niños movidos e inatentos, medicarlos y erradicar así su naturaleza inquieta (Zapico Merayo y Pelayo-Terán, 2012). Este ha sido durante muchos años, y hoy en día sigue siendo, un punto de debate al que los distintos profesionales tanto de la práctica clínica (pediatras, psiquiatras, etc.) como del ámbito educativo (docentes, psicopedagogos, etc.) atienden a menudo para tratar de seguir avanzando y obteniendo nuevas y mejores formas de intervención (Franco, 2012).

Leon Benasayag, doctor en Medicina especializado en neurología infantil, por ejemplo, defiende abiertamente que el TDAH no es un trastorno de origen neurológico, un síndrome o una enfermedad, sino un constructo teórico influenciado sustancialmente por un gran impacto social que lo convirtió en una tendencia y dio lugar a su extensión y, por tanto, al aumento del número de diagnósticos. De hecho, apunta que este hecho puede estar relacionado con el surgimiento y el desarrollo de la sociedad globalizada, lo que, unido a la masificación de las aulas y al estilo de vida acelerado, productivista y materialista que define nuestra rutina, pudo dar lugar a la definición de este nuevo "trastorno", originando así un gran impacto en la salud de los niños, padres y maestros (Benasayag, 2009a). En ciertas ocasiones, el mundo en el que nos desenvolvemos y a través del cual interactuamos, cada vez más orientado a la producción, no solo de objetos sino también del propio ser humano como producto orientado a obtener un rendimiento, hace que dejemos de lado aspectos importantes relacionados con las necesidades humanas básicas físicas, emocionales y sociales. Esto, como parte esencial de nuestra sociedad, puede verse reflejado en el sistema educativo.

Igualmente, y sobre todo en función del grado de severidad, el TDAH puede ser considerado un rasgo humano como cualquier otro, que se manifiesta a través de una gran activación, aunque en algunos casos sea de forma extrema y preocupante, llegando a estar relacionado con síntomas de ansiedad, pero no con una condición genética irrevocable (Guerrero, 2006). En este sentido, la respuesta que emite el cerebro en algunos casos puede estar relacionada con un estado de alerta que hace que el alumnado diagnosticado de TDAH necesite de forma instintiva estar atento a distintos estímulos al mismo tiempo, y no a una sola actividad o tarea (Castells y Castells, 2012). En otras palabras, más que "padecer" un trastorno se trata de vivir activo ante el medio, tener ideas, demostrar creatividad y buena predisposición a la multitarea y el aprendizaje (Pérez-Galán, 2009). A colación de esto, Guinot (2013) señala la importancia de identificar la diferencia entre lo patológico y lo que no lo es: 
[H]ay que definir la línea entre lo patológico y no patológico, porque no es lo mismo estar triste que estar deprimido o estar nervioso que estar sufriendo ansiedad, por desgracia, en la sociedad actual nos hemos empeñado en poner a todo una etiqueta y esto es algo muy negativo. (...) Cuando estamos poniendo, pues, la etiqueta a un menor de que es "hiperactivo" o de que tiene "TDAH" o peor aún le decimos que él "es un TDAH" (...), lo que conseguimos es que la persona acepte ese rol como propio y, en lo que nosotros denominamos un efecto Pigmalión negativo, no sea capaz de hacer cosas que podría, porque "es normal" que no pueda. (pp. 30-31)

De hecho, en cierto sentido muchas de las necesidades educativas que han ido surgiendo a lo largo de los años y, con ello, la necesidad de atender a los niños con necesidades especiales en contextos educativos, de alguna forma han sido construidos o enunciados para responder a las necesidades que la sociedad ha ido imponiendo, más que como necesidades propias del alumnado con ciertas características (Barton, 2011). De esta forma cobra sentido la perspectiva de que los niños inatentos y/o hiperactivos no pueden atender adecuadamente a las clases y llegar así a alcanzar los mismos objetivos que el resto de sus compañeros en el mismo tiempo, es decir, que no llegan a conseguir "lo que se cabría esperar" de un alumno o alumna "sin necesidades" especiales o específicas de apoyo educativo. En cierto sentido, el propio concepto de Educación, y el modo en que está organizada, determina y condiciona algunas de las necesidades que, en realidad, se han presentado y son abordadas o tratadas como problemas de la naturaleza del alumnado.

Si tenemos en cuenta la relación existente entre la sociedad en la que vivimos y la Educación, es decir, el modo en que esta se refleja en cómo están configurados y organizados los procesos de enseñanza-aprendizaje, aún es posible encontrarnos con una función homogeneizadora de la escuela (Santos-Guerra, 2002). En este contexto, donde el objetivo es que todo el alumnado alcance los mismos resultados al mismo tiempo y, con ello, contribuir a una competencia laboral prototípica y generalizada (Gimeno-Sacristán, 2002), no es de extrañar que los niños que presentan características propias del TDAH no encajen en aulas en las que simplemente hay que escuchar y recibir contenidos y que se pretenda "amoldarles" hacia la "normalización" o "igualdad" respecto al resto de compañeros. Una escuela en la que los contenidos sean transmitidos de forma homogénea y generalizada, ignorando las características y necesidades individuales del alumnado, nunca logrará, a no ser que cambie desde su base, ofrecer una respuesta educativa adaptada a la disparidad de situaciones que pueden surgir en el aula. 
Como vemos, este debate entre la perspectiva neurobiológica y la de origen social se lleva desarrollando desde hace más de setenta años, y todo apunta a que va a seguir siendo así. De hecho, hay pocos trastornos o problemas, ya sean físicos o mentales, en torno a los cuales se haya generado tanta controversia como en el caso del TDAH (Fernández, 2018). En cualquier caso, esta necesidad de estipular los límites entre lo patológico y las convicciones sociales, directamente relacionada con dos puntos de vista enfrentados, nunca debería desorientar el objetivo primordial, que es la atención a las características y necesidades del alumnado, independientemente de si las dificultades que puedan surgir son de origen biológico, genético, social o ambiental (Zapico Merayo y Pelayo-Terán, 2012).

\subsection{En relación con el número de diagnósticos}

Como se ha explicado previamente, el TDAH es uno de los trastornos mentales con más incidencia entre la población infantil y juvenil, no solo en nuestro país sino también a nivel internacional (más en unos países que en otros) y cuya prevalencia, además, más se ha incrementado a lo largo de los últimos años, llegando a alcanzar, aproximadamente y de forma general, entre un $3 \%$ y $7 \%$ de los casos (Aguilar-Millastre, 2014; American Psychiatric Association, 2014; Gálvez, 2010; Rubiales et al., 2011). Este hecho puede dar lugar a cierta controversia, ya que se puede llegar a pensar que se están cometiendo errores diagnósticos relativos a la consideración del trastorno, a su extensión o incluso a la falta de información o rigurosidad en los procesos de intervención.

Refiriéndose a este aumento exponencial del número de diagnósticos a lo largo de los últimos años, hay quien ha llegado a hablar, incluso, de una verdadera "epidemia" de TDAH, carente de bases fundamentadas y que dista mucho de representar las necesidades auténticas de los niños, especialmente en algunos casos en que se produce un diagnóstico desacertado (Benasayag, 2009a). En determinadas ocasiones, el diagnóstico viene dado a través de una prueba de evaluación aislada, dejando de lado o sin considerar de manera significativa otra serie de factores como el grado de afectación de otras áreas de la vida del niño, como el ámbito social o educativo (Zapico Merayo y PelayoTerán, 2012). En este sentido, se pueden producir carencias a nivel metodológico que den lugar a errores o confusiones y se consideren casos en los que se den algunas características de TDAH, pero en los que no se reúnan todos los elementos y criterios diagnósticos necesarios para tomar una decisión certera e identificar el trastorno con seguridad. De hecho, en un estudio exploratorio cualitativo realizado en el año 2015 , en el que se realizaron entrevistas 
en profundidad a once profesionales relacionados con el trabajo con el TDAH, todos ellos coincidieron en la idea de que el problema no está en debatir sobre el origen o las causas del trastorno, sino en que se diagnostiquen casos que realmente no lo son debido a problemas metodológicos o de coordinación (Acebes-de Pablo y Giráldez-Hayes, 2019).

Este problema, que puede ser denominado como tendencia a "sobrediagnosticar", fue reconocido y tuvo lugar en un caso concreto, un estudio realizado en un Centro de Salud Mental de Murcia, mediante el cual se pudo contrastar que, tras una primera valoración de posibles casos de TDAH, cierto porcentaje de los mismos presentaba en realidad un trastorno mental específico, un Trastorno Generalizado del Desarrollo o una disfunción a nivel familiar (Gálvez, 2010). Una razón que puede justificar que se produzcan estos errores es que, a menudo, los síntomas identificados con el TDAH, como la hiperactividad y la impulsividad, pueden estar originados en realidad en causas muy distintas, como la ansiedad, el miedo al abandono o necesidades emocionales no resueltas, como algunas carencias afectivas significativas, y no por ello tienen que ser una muestra directa y clara de que existe el trastorno. Aunque se pueden dar casos de comorbilidad (de hecho, suele ser bastante común, de ahí la dificultad para realizar el diagnóstico), pueden darse igualmente síntomas aislados y no asociados a ningún trastorno específico.

Otro hecho que puede repercutir peyorativamente en estos errores diagnósticos es que la propia subjetividad que, de forma involuntaria e inevitable, envuelve la opinión de los profesionales del ámbito sanitario y educativo, así como de las familias, cuando tienen que considerar o no posibles casos de TDAH durante el proceso de intervención (Guinot, 2013). Ya hemos visto previamente la connotación que tiene el trastorno a nivel social, y cómo a veces influye esto negativamente en la vida del alumnado, dando lugar a la generación de etiquetas y a situaciones de estigmatización. En nuestra sociedad disponemos de mucha información y es común que, por no seguir un protocolo de forma pertinente, se saquen conclusiones o se emitan juicios aislados u orientados únicamente por una percepción individualista de la realidad. Esto puede ocurrir, por ejemplo, cuando de forma no intencionada se produce un "diagnóstico" previo a la consulta, en el momento en que una familia va al médico indicando que su hijo es hiperactivo, porque no puede estarse quieto y además su profesor tutor también lo cree así. Ubieto (2014) resume esta tendencia de la siguiente forma: 
¿Son todos los niños hiperactivos, cuando así lo parecen? Rotundamente, no. Por eso es muy importante tener unos "protocolos objetivos", que nos indiquen y cercioren con un nivel de significación clínica y estadística alta, si es o no es hiperactivo. Porque hay muchos niños, sobre todo en los primeros años, que pueden dar síntomas de nerviosos, que no paran, no se entretienen con nada, molestan, incordian y, sin embargo, en las pruebas no son significativas esas demostraciones conductuales. Hemos dicho con mucha gratuidad, "¡mi niño es hiperactivo!" y nos quedamos tan tranquilos diciéndolo en todos los ambientes en los que se desenvuelve. Puede ser nervioso, pero no ser hiperactivo. Puede tener algunos problemas de conducta, pero no ser hiperactivo. (p. 59)

Un error diagnóstico puede, de hecho, producirse en dos direcciones: tanto si se diagnostican como TDAH casos en los que se están produciendo simplemente problemas conductuales, como si se considera un caso real de TDAH como un problema conductual aislado o puntual (Bianchi, 2012). Es necesario, por lo tanto, el seguimiento meticuloso y riguroso de protocolos específicamente diseñados para que se pueda llevar a cabo un diagnóstico acertado, evitando así incurrir en negligencias cuyos perjuicios serán sufridos por el niño diagnosticado.

\subsection{Respecto a la medicación farmacológica}

A pesar de que el tratamiento basado en la ingesta de algunos medicamentos como los psicoestimulantes (metilfenidato y dextroanfetamina) ha sido testado y probado de tal forma que ha demostrado ser eficaz para la regulación de los síntomas propios del TDAH, tales como la hiperactividad, la inatención y la impulsividad (Barkley, 2008; Castells y Castells, 2012), los efectos secundarios de estos fármacos existen (Lecumberri, 2016; Ubieto, 2014). Por lo tanto, su prescripción debe ser considerada y sopesada rigurosamente, especialmente en edades tempranas (Garrido-Landívar, 2017), ya que aún no se ha tenido la oportunidad de constatar dichos efectos perjudiciales a largo plazo, ni de determinar cómo pueden afectar en el desarrollo evolutivo natural del alumnado diagnosticado de TDAH (Aguilar-Millastre, 2014; Amador et al., 2012; Cavas, 2006). 
Algunos de los efectos secundarios a los que puede dar lugar el metilfenidato $^{1}$, que es la primera opción recomendada para el tratamiento farmacológico, son el insomnio, la cefalea, el nerviosismo, la irritabilidad, el temblor, los mareos, posibles convulsiones, taquicardia, hipertensión arterial, dolor abdominal y, en casos extremos y concretos, episodios psicóticos (Ubieto, 2014). A partir de diversos estudios realizados desde el punto de vista de la fármacovigilancia se ha comprobado que algunas de las sustancias empleadas en el tratamiento del TDAH, especialmente el metilfenidato, genera adicción y farmacodependencia, y que sus efectos adversos, relacionados con el riesgo cardiovascular y la supresión del apetito, pueden afectar o perjudicar en el proceso natural de crecimiento de los niños (Bignone, Serrate y Diez, 2009).

${ }^{1}$ Reacciones adversas del metilfenidato (extraídas de un prospecto de Metilfenidato Sandoz EFG 36 mg comprimidos de liberación prolongada).

- Digestivas: frecuentes (náuseas y vómitos, dolor abdominal, diarrea, sequedad de boca, dispepsia); poco frecuentes (estreñimiento).

- Hepáticas: poco frecuentes (aumento de transaminasas); muy raras (aumento de fosfatasa alcalina, hiperbilirrubinemia, insuficiencia hepática, encefalopatía hepática); frecuencia desconocida (hepatitis autoinmune).

- Cardiovasculares: frecuentes (hipertensión arterial, taquicardia, palpitaciones, arritmia cardiaca); poco frecuentes (dolor precordial); raras (angina de pecho); muy raras (infarto agudo de miocardio, parada cardiaca, isquemia cerebral, enfermedad de raynaud); frecuencia desconocida (vasculitis y arteritis cerebral, ictus, hemorragia cerebral, taquicardia supraventricular, bradicardia, extasistole).

- Neurológicas/psicológicas: muy frecuentes (insomnio, nerviosismo, cefalea); frecuentes (mareo, somnolencia, discinesia, hiperactividad, agresividad, agitación, ansiedad, depresión, irritabilidad, alteraciones de la conducta); poco frecuentes (sedación, temblor, psicosis, alucinaciones visuales, acústicas o táctiles, tendencias suicidas, alternaciones del humor, tics, síndrome de gilles tourette); raras (manía, desorientación, reducción del líbido); muy raras (convulsiones, síndrome neuroléptico maligno, suicidio consumado o en grado de tentativa, apatía, comportamientos repetitivos, exceso de atención); frecuencia desconocida (delirio, confusión, dependencia psicológica, crisis epilépticas tónico-clónicas, migraña, acatisia, corea).

- Respiratorias: frecuentes (rinofaringitis, tos, dolor faríngeo o laríngeo); poco frecuentes (disnea).

- Genitourinarias: poco frecuentes (hematuria); raras (ginecomastia); frecuencia desconocida (priapismo).

- Dermatológicas: frecuentes (prurito, erupciones exantemáticas, urticaria, alopecia); raras (eritema, exceso de sudoración, erupciones con maculas); muy raras (dematitis exfoliativa, eritema multiforme).

- Alérgicas: poco frecuentes (reacciones de hipersensibilidad, con angioedema, artritis e incluso anafilaxia).

- Osteomusculares: frecuentes (dolor osteomuscular); poco frecuentes (mialgia); muy raras (calambres musculares).

- Oftalmológicas: poco frecuentes (visión borrosa, diplopía); raras (midriasis, trastornos de la acomodación ocular).

- Hematológicas: muy raras (anemia, leucopenia, trombopenia, purpura trombocitopénica idiopática); frecuencia desconocida (pancitopenia).

- Metabólicas: frecuentes (anorexia, pérdida o aumento de peso, retraso en el crecimiento).

- Generales: frecuentes (fiebre); poco frecuentes (astenia); muy raras (escalofríos); frecuencia desconocida (hiperpirexia). 
Lecumberri (2016) resume algunos de los principales efectos secundarios del metilfenidato:

- La pérdida de apetito es uno de los efectos más comunes, dándose hasta en un $80 \%$ de los casos, por lo que se recomienda que la medicación se tome después de las comidas.

- El insomnio se puede producir en un $85 \%$ de los casos, especialmente al comienzo del tratamiento.

- Aumento de la intensidad, frecuencia o duración de los tics en determinados casos, sobre todo cuando este síntoma ya está asociado al TDAH o cuando se presenta comorbilidad con síndrome de Gilles o de Tourette.

- Dolores de cabeza, irritabilidad, temblor, ansiedad.

- El dolor abdominal y las náuseas es menos frecuente. Pueden tener lugar sobre todo al comienzo del tratamiento.

- Aumento de la tensión arterial diastólica y de la frecuencia cardíaca, en cuyo caso se precisa de mantener controles periódicos.

- Se produce un efecto rebote mediante el cual, después de tres o cuatro horas tras haber ingerido el medicamento, los síntomas hiperactividad e irritabilidad se intensifican durante un tiempo.

Igualmente, algunos de los fármacos que no son estimulantes, sino inhibidores de la recaptación de la noradrenalina, como la atomoxetina, que por lo general es la segunda opción más recomendada, presentan efectos secundarios similares a los del metilfenidato, como el cansancio y la sensación de sedación, la disminución del hambre, aumento de la tensión arterial y de la frecuencia cardiaca, insomnio, mareos, náuseas, irritabilidad, dolor abdominal (Ubieto, 2014).

La existencia de dichos efectos adversos, unida al hecho de que no se pueda conocer con certeza la repercusión de la ingesta de estos medicamentos a largo plazo, es decir, si afecta de forma negativa en el proceso de desarrollo evolutivo de los niños, hace que se torne una situación, cuanto menos, preocupante, para los distintos profesionales involucrados en el proceso de intervención y tratamiento del TDAH. En un estudio publicado en la revista The 
American Journal of Psiquiatry se reflejó que una gran parte de niños y adolescentes que habían tomado este tipo de sustancias, metilfenidato en concreto de forma continuada presentaban conductas orientadas hacia tendencias suicidas (Gálvez, 2010).

Otro punto de debate y polémica que surge con fuerza en este sentido es la reacción ante la posición que la industria farmacéutica adopta en este proceso, más en concreto por el hecho de que las ventas de medicamentos orientados al tratamiento del TDAH se hayan disparado durante los últimos años:

Las ventas de los fármacos más usados (Adderall, Ritalin, Concerta) se han multiplicado en los últimos cinco años y mientras que en el 2007 este mercado obtuvo unos beneficios de 4.000 millones de dólares (3.122 millones de euros); en el 2012 las ventas fueron de 9.000 millones de dólares (7.025 millones). Debido a su eficacia en los casos más graves, el uso de los fármacos se ha extrapolado a los que simplemente padecen rasgos del trastorno, convirtiendo el tratamiento con estimulantes en una especie de atajo popular para mejorar las calificaciones de los estudiantes sin tener en cuenta el riesgo para la salud. (Ubieto, 2014, p. 59)

En este sentido, no es difícil asumir que muchos profesionales cuestionen si se trata más de un problema en sí, o de si los intereses de las empresas farmacéuticas se anteponen a las necesidades reales de la población infantil y juvenil. Algunos autores, de hecho, reivindican clara y fervientemente que la medicación es dañina, sobre todo en casos en los que no es necesaria e, incluso, afirman que el TDAH es una invención, una construcción social que responde a intereses económicos y empresariales y que ignoran las necesidades reales de la población infantil (Benasayag y Ferreyra, 2009).

Teniendo en cuenta estos argumentos, la reacción más común ante la medicación es la recomendación de incidir más en las intervenciones educativas, psicoterapéuticas y psicosociales, basadas en técnicas de modificación de conducta, terapia cognitiva, trabajo en red con padres y profesores etc. (Zapico Merayo y Pelayo-Terán, 2012). En algunos casos extremos puede ocurrir, incluso, que esta reacción lleve a que algunos profesionales aboguen únicamente por el uso de determinadas terapias alternativas, como veremos a continuación. 


\subsubsection{Terapias complementarias como intervención para el TDAH}

Incluimos este concepto aquí porque en la mayor parte de los casos surge como reacción directa en contraposición ante la intervención farmacológica y porque en los protocolos de intervención para el tratamiento del TDAH a menudo no son incluidas o consideradas. Sin embargo, varios son los expertos que recomiendan que de algunas de estas intervenciones se dé un uso asiduo de forma complementaria, mientras se están desarrollando otras formas de intervención, como el tratamiento farmacológico y/o no farmacológico, y no como una medida aislada que actúe de forma única:

Las medicinas alternativas están caracterizadas por emplear medios naturales, como por ejemplo el agua, el sol, los vegetales o los minerales, para mantener y equilibrar la salud. Las diversas terapias empleadas por las medicinas alternativas se pueden clasificar en (...) estructurales, [que] se basan en la manipulación manual de las diferentes partes del cuerpo (...), activadoras de fuerza vital, [que] pretenden estimular los procesos curativos del organismo (...) [y] reguladoras del estado emocional, [que] enfocan la curación a través de procesos cerebrales. (Tarrida, 2000, p. 105)

Este tipo de intervenciones, aplicadas de forma alternativa o complementaria, abogan por una intervención holística cuyo objetivo es atender a los seres humanos de forma integral en sus tres dimensiones: cuerpo, mente y espíritu (Verdú, 2018). Algunas de ellas, de hecho, tratan de atender algunas necesidades humanas específicas, como la conexión a nivel espiritual o el equilibrio entre las distintas partes que componen un organismo, las cuales a menudo no se ven cubiertas mediante otro tipo de intervenciones, como la farmacología o la psicoterapia.

En relación con el tratamiento para el TDAH, una de las primeras medidas que se recomiendan a la hora de intervenir y hacer un seguimiento de un caso, es el diseño y adaptación de una dieta equilibrada, así como abundante ejercicio físico, lo cual lleva, de forma inevitable, a hacer determinados cambios positivos en el estilo de vida (Castells y Castells, 2012). Estas acciones, aunque puede haber quien no las considere terapias en sí mismas o en el sentido estricto de la palabra, son medidas que, una vez hayan sido consideradas y aplicadas a la rutina de tal forma que acompañen el tratamiento habitual (farmacológico o no farmacológico), contribuirán, en mayor o menor medida, a lograr un equilibrio entre las necesidades emocionales y físicas y la regulación hacia un estado de bienestar más significativo. 
Los cambios en la dieta, unidos a un seguimiento activo del mantenimiento de una alimentación saludable (equilibrada, variada, suficiente y bien distribuida) y consumir los cinco grupos de alimentos al día, partiendo de un buen desayuno (cereales integrales, frutas frescas y secas, lácteos, semillas), puede contribuir en cierta medida a la mejora de las muestras conductuales propias del TDAH (Pazo, 2009). Es posible, por lo tanto, que la falta de una alimentación adecuada agrave los síntomas del trastorno o que genere otro tipo de sensaciones en los niños, como ansiedad o estrés.

Por otra parte, y como cabría esperar por convencimiento lógico, el ejercicio físico repercute en gran medida en la disminución de la hiperactividad y, como consecuencia directa, en la regulación de las conductas impulsivas, hablando en términos generales (Castells y Castells, 2012), pero sobre todo si se realiza en contacto con la naturaleza (Gálvez, 2010). De hecho, la falta de contacto con la naturaleza puede originar, en sí misma, problemas relacionados con la salud física y mental de la población infantil y juvenil, dando lugar a mayores niveles de estrés, cefaleas, dificultad de concentración, etc. (Corraliza y Collado, 2011). Esto, teniendo en cuenta que vivimos en una sociedad cada vez más urbanizada, en la que la mayor parte de las situaciones se viven en torno a la rutina acelerada y la contaminación (no solo ambiental sino también acústica) es, por tanto, un tema a considerar, ya que puede tener repercusiones negativas directas en el desarrollo evolutivo del alumnado. En este sentido, se ha comenzado a hablar, incluso, del denominado "síndrome de déficit de naturaleza" (Louv, 2008). De hecho, esto puede dar lugar a muchos de los problemas, trastornos o dificultades de aprendizaje a los que hoy en día nos enfrentamos, como, por lo que nos concierne, el TDAH, entendiéndolo así más como un problema de origen ambiental que biológico o genético:

Some are hyperactive. Some are distracted. Some are obese. Schools can improve both health and learning by reintroducing students to the natural world. (...) [A] child had a problem -he was hyperactive- and could not pay attention. Because he disrupted the other students, he had been expelled from school. At first, his parents did not know what to do. But they were observant. They had already seen hoy nature calmed their son and helped him focus. Over the next decade, they seized every opportunity to introduce him to the natural world -to beaches, forests, and dunes as well as to rivers and mountains of the American West. The little boy turned out fine. (Louv, 2009, p. 24) 
Como contraposición, el mantenimiento del contacto con la naturaleza en la vida del alumnado diagnosticado de TDAH puede mejorar su capacidad atencional, así como desarrollar su creatividad y la autonomía para enfrentarse a situaciones adversas, lo cual puede incidir directamente en una mejor regulación de situaciones de frustración (Corraliza y Collado, 2011). Igualmente, el contacto con la naturaleza puede estar ligado a la terapia con animales, tanto en relación con mascotas (perros, gatos o pájaros), lo que dará lugar a una disminución del estrés, el desarrollo de empatía y de la capacidad de asunción de responsabilidades y, en muchos casos, la mejora del ambiente familiar, como en concreto orientada hacia la hipoterapia, equinoterapia o terapia asistida ecuestre, en cuyo caso se puede obtener beneficios terapéuticos directos, así como la mejora sustancial de la coordinación espacio-temporal y el equilibrio (Gasalberti, 2006).

Otras de las terapias alternativas cuyo beneficio se ha visto reflejado en el proceso de tratamiento en casos de TDAH son el reiki, la naturopatía (Guinot, 2013), el yoga, la estimulación cognitiva, la meditación, la osteopatía, el masaje infantil y la optometría (García-González, 2014). Algunas de ellas, como la naturopatía, la meditación, el reiki y el yoga guardan relación directa con la búsqueda del equilibrio entre las tres dimensiones del ser humano (cuerpo, mente y espíritu), por lo que estarían clasificadas dentro del grupo de activadoras de fuerza vital (Tarrida, 2000). Su objetivo es, en definitiva, que el trabajo a nivel consciente y holístico, es decir, a nivel físico, cognitivo y emocional, contribuya a la regulación de emociones, conductas y sentimientos, lo cual puede dar lugar a un mayor equilibrio interior y, con ello, una mayor autoestima, mejor capacidad de relajación y de gestión de situaciones estresantes, etc.

Por otra parte, la fitoterapia y la homeopatía pueden actuar también para gestionar las conductas impulsivas e hiperactivas. De hecho, la combinación de $50 \mathrm{mg}$ de Ginkgo biloba y $200 \mathrm{mg}$ de Panax quinquefolius (un extracto del gingeng americano), ambas sustancias provenientes de la naturaleza, demostró una gran mejoría en los síntomas del TDAH a través de un ensayo clínico efectuado con un grupo de 36 niños que tomó dos cápsulas diarias (Benasayag, 2009b). Asimismo, un tratamiento con homeopatía puede dar lugar a mejoras sustanciales a nivel cognitivo y comportamental, reducir las conductas impulsivas y la hiperactividad y mejorar los procesos de atención, pudiendo incluso llegar a igualar los efectos del metilfenidato, lo cual da la posibilidad de optar por su sustitución (Gálvez, 2010). 
La estimulación cognitiva actúa directamente a nivel cerebral, tratando de activar o estimular funciones cerebrales específicas para desarrollar habilidades cognitivas que se ven limitadas en algunos casos (Rubiales et al., 2011). La terapia de juego, por su parte, ayuda a estimular la capacidad de evocación, relacionada con procesos de simbolización, y el factor atencional (GarcíaGonzález, 2014). Enseñar de forma lúdica hace que aumente la motivación de forma intrínseca en los procesos de enseñanza-aprendizaje y que los contenidos sean transmitidos y adquiridos de forma natural y agradable. Como ejemplo, la magia, entendida no solo como un juego, sino también como un proyecto orientado con determinación hacia unos objetivos claros, puede obtener distintos beneficios en casos de TDAH (Arrufat, 2017):

- La magia exige, en sí misma, de mucha disciplina, es necesario ser constante, perfeccionar las técnicas para conseguir los efectos deseados ante el público.

- Para ello hay que tener paciencia y perseverancia, lo que puede repercutir a nivel positivo en una mejor regulación de la frustración, así como la gestión de emociones y sentimientos negativos que puedan ir surgiendo a lo largo del proceso, como la ira, la desilusión, la asunción de errores, etc. y, con ello, estimular otras actitudes positivas, como la resiliencia, la seguridad en uno mismo o la superación.

- Para realizar trucos de magia, tanto en el espectáculo como durante el proceso de aprendizaje, es necesario que se dé una atención sostenida acompañada de un mantenimiento meticuloso de la concentración.

- Se trabaja una de las funciones ejecutivas que se ven limitadas en el TDAH: la memoria de trabajo, que tiene que estar en funcionamiento para memorizar las técnicas, el orden de los trucos y de los movimientos, el monólogo ante el público, etc.

- En relación con ese último punto, se promueven las habilidades sociales y de comunicación al hablar en público e interactuar con los asistentes.

- A la hora de realizar los trucos se favorece la coordinación óculomanual, ya que se tiene que tener control respecto a lo que se hace, lo que se piensa y lo que se dice. 
- Repercute en el reconocimiento social por parte del entorno, lo supone una gran aportación, ya que, por ende y de forma directa, aumenta la autoestima, el autoconcepto, la confianza en sí mismo y el sentimiento de pertenencia a un grupo.

En cualquier caso, es necesario tener en cuenta que no todos estos métodos complementarios están basados en evidencias científicas y, por lo tanto, es necesario hacer una distinción entre todos ellos. De acuerdo con las referencias consultadas, se puede hacer una diferenciación entre aquellos métodos cuyo respaldo está basado en teorías o experiencias educativas, como la magia (Arrufat, 2017) o el contacto con la naturaleza (Louv, 2008), y los que están fundamentados en evidencias científicas, como la naturopatía (Benasayag, 2009b) o la Musicoterapia, como veremos en el capítulo siguiente.

La Musicoterapia se puede incluir dentro del grupo de terapias alternativas reguladoras del estado emocional (Tarrida, 2000). Aunque hablaremos de ella más detenidamente en el siguiente capítulo, a grandes rasgos cabe señalar que a través de esta disciplina se puede mejorar la coordinación y la capacidad de autocontrol, que es la principal limitación del alumnado diagnosticado de TDAH (Barkley, 2008). Además, ayuda sustancialmente a desarrollar la capacidad de regulación emocional, lo cual influye directamente en relación con la disminución de conductas impulsivas (Rickson, 2006).

Dicho lo cual, todas estas medidas alternativas pueden contribuir en el proceso de tratamiento del TDAH en relación con los síntomas de déficit de atención, hiperactividad y las conductas impulsivas. Sin embargo, a pesar de que en algunos discursos sean planteadas como alternativa a la medicación farmacológica, o incluso como reacción ante esa forma de intervención, lo más recomendable es que actúen de forma complementaria en el proceso de tratamiento de cada caso, de modo que cada tipo de terapia, actividad o disciplina pueda hacer su mejor aportación para el beneficio del niño, a partir de un tratamiento específico, adaptado, sistematizado e individualizado, farmacológico y/o no farmacológico según se requiera (García-González, 2014). Aunque siempre depende del grado de severidad y especificaciones del trastorno, si tenemos en cuenta que la medicación y las medidas psicoterapéuticas y psicosociales son los dos tipos de intervenciones más testadas y comprobadas, puede resultar un tanto arriesgado aplicar un tratamiento basado únicamente en terapias alternativas. De hecho, estas pueden ser consideradas medidas no farmacológicas que, junto con la intervención farmacológica, deberían formar parte de un tratamiento interdisciplinar, coordinado y adaptado (Garrido-Landívar, 2017; Ubieto, 2014). 




\section{CAPÍTULO III. LA MUSICOTERAPIA COMO INTERVENCIÓN NO FARMACOLÓGICA}



En este capítulo se abordará de forma global el concepto de Musicoterapia, de modo que se parte de una breve introducción histórica y de los fundamentos teóricos de la disciplina para continuar profundizando en sus características y elementos básicos y sus principales formas de intervención. En la última parte del capítulo se hace especial hincapié en el ámbito de la aplicación de la Musicoterapia en contextos educativos, así como su función en el campo de las necesidades educativas especiales y, de forma más concreta, en relación con la intervención y tratamiento en casos de TDAH, que es el tema que más nos concierne.

\section{FUNDAMENTOS TEÓRICOS DE LA MUSICOTERAPIA}

\subsection{Perspectiva histórica}

El empleo de la música con fines terapéuticos ha sido reconocido a través de diferentes manifestaciones a lo largo de la historia de la humanidad en diferentes culturas, localizaciones geográficas y épocas. En las culturas primitivas, los chamanes concebían la música como un medio a través del cual se ahuyentaban los malos espíritus y se atraía la salud y la prosperidad, mientras que en la antigua Grecia y Roma grandes filósofos como Platón o Aristóteles concedieron a la música un gran valor terapéutico como un elemento que da serenidad al alma o como facilitador de catarsis emocionales (Betés, 2000). En la Edad Media se recuperó la teoría grecolatina de los cuatro humores (colérico, melancólico, sanguíneo y flemático) considerando que la música podía despertar estas sensaciones en los seres humanos, hasta tal punto que se registró la primera obra de recopilación de una veintena de diferentes efectos producidos por la música.

Durante el Renacimiento y el Barroco se siguió nutriendo esta tendencia, especialmente en el Barroco con el surgimiento de la "doctrina de los afectos", que consideraba que el objetivo de la música era despertar las pasiones y emociones de los seres humanos. Así lo consideraron los compositores de este periodo, como Bach, Haendel o Vivaldi, con la intención de producir sensaciones muy específicas en el oyente, lo que produjo un mayor impacto social en cuanto al valor terapéutico de la música como material potenciador de sentimientos.

Desde este momento y en adelante, sobre todo a lo largo de los siglos XVII y XVIII, se comienzan a producir textos relacionados con la función terapéutica de la música de forma más sistemática. Sin embargo, la definición del concepto de Musicoterapia, unido a la crecimiento y posterior sistematización de la disciplina y a su concepción como profesión emergente comenzó a forjarse 
como tal después de la Segunda Guerra Mundial. Uno de los primeros referentes a nivel mundial fue Juliette Alvin, violonchelista que en el año 1958 fundó la British Society for Music Therapy and Remedial Music, lo que actualmente es la British Society for Music Therapy, y desarrolló una de las primeras formaciones universitarias en Musicoterapia en el año 1969. En Latinoamérica, en concreto en Argentina, destacó la labor de Rolando Benenzon, psiquiatra que, junto a Julio Bernaldo de Quirós, médico y foniatra, constituyó la Asociación Argentina de Musicoterapia en el año 1966 e iniciaron una formación universitaria en Musicoterapia en la Universidad del Salvador (Betés, 2000). Además, su creciente inquietud por esta disciplina le llevó a desarrollar uno de los cinco modelos de intervención reconocidos a nivel mundial.

En Estados Unidos el proceso de sistematización de la profesión comenzó, de manera similar, en la segunda mitad del siglo XX. En el año 1950 se creó la National Association for Music Therapy (NAMT) y en el año 1971 la American Association for Music Therapy (AAMT). En 1998 estas dos asociaciones, dispares en un origen en relación con estilo de enseñanza y contenidos de las formaciones en Musicoterapia, fueron unificadas bajo el nombre de American Music Therapy Association (AMTA), que sigue funcionando en la actualidad con más de 4000 miembros. En este país destacan figuras como Tayer Gaston, que fue uno de los fundadores de la NAMT y el creador del primer máster en Musicoterapia en la Universidad de Kansas (Davis, Gfeller y Thaut, 2012) y Helen Bonny, violinista y musicoterapeuta que, al igual que Benenzon, desarrolló uno de los cinco modelos de intervención reconocidos a nivel mundial en el ámbito de la Musicoterapia: el Modelo Bonny de Imagen Guiada con Música (BMGIM), que además será uno de los ejes vertebradores de esta tesis doctoral.

De igual forma que en otros países, en España el camino de regularización de la Musicoterapia como profesión comenzó a partir de la segunda mitad del siglo XX. Sin embargo, en el año 1920 se registra el libro "La música como medio curativo de las enfermedades nerviosas. Algunas consideraciones sobre la Musicoterapia", de manos del médico Dr. Candela Ardid. Esta es tal vez, por lo tanto, la primera aparición de la palabra "Musicoterapia" en nuestro país. Es posible que se emplease la música como medio terapéutico en distintas instituciones sanitarias y en el ámbito clínico, pero no se consideraba la Musicoterapia como una disciplina en sí misma.

En el año 1974 se fundó la Asociación Española de Musicoterapia y la Asociación Catalana de Musicoterapia fue cimentada en el año 1984 (Betés, 2000). Actualmente existen más de veinte asociaciones de Musicoterapia dis- 
tribuidas por la geografía española, así como la Federación Española de Asociaciones de Musicoterapia (FEAMT) que fue constituida con el objetivo de aunar esfuerzos y promover la regulación de la profesión en España. Por otra parte, existe un grupo de diez asociaciones acreditadas en la Confederación Europea de Musicoterapia (EMTC) que, de igual modo, trabajan coordinadamente con el fin de preservar los criterios de reconocimiento de la disciplina a nivel europeo y de mantener con rigurosidad una continuidad en la organización de congresos nacionales de Musicoterapia de calidad científica.

\subsection{Fundamentos biológicos}

La música, al igual que otros estímulos externos a nuestro cuerpo, ha de ser percibida por nuestro sentido del oído, procesada y transformada para que produzca un mensaje inteligible en nuestro cerebro. En otras palabras, sabemos que la música actúa en nuestro organismo a nivel bioquímico. Resulta relevante, por lo tanto, entender de qué manera esta disciplina actúa en nuestro cuerpo y justificar la necesidad de comprenderlo al desarrollar determinados tipos de procesos terapéuticos.

En primer lugar, se ha demostrado que los efectos fisiológicos que la música produce en nuestro organismo son muy perceptibles y medibles. Puede producir alteraciones en la presión sanguínea, el ritmo cardíaco y el pulso, así como estimular o relajar la respiración en función de las características que tenga y el tipo de respuesta que produzca en las personas. Además, la música puede producir respuestas musculares y motóricas, como el fenómeno de restitución, que disminuye la fatiga ocular, movimientos peristálticos del estómago, modular el nivel de resistencia al dolor y tener algunos efectos relajantes a nivel físico, así como repercutir en diferentes sentidos en la respuesta cerebral (Poch, 2011).

La Musicoterapia repercute a nivel cerebral en procesos neuronales relacionados con determinadas funciones físicas (Hernández-Ruiz, 2019), como el desarrollo de la motricidad fina, la ejercitación de la musculatura facial y fonadora, la correspondencia rítmico-corporal, la ejecución bilateral o el desarrollo o rehabilitación de la marcha. El empleo de la Musicoterapia a nivel neurológico puede, por lo tanto, producir beneficios en el tratamiento de trastornos físicos y enfermedades neurodegenerativas, como el Parkinson o el Alzheimer (Leivinson, 2005).

Por otra parte, la relación que se establece entre la música y el trabajo del cuerpo en Musicoterapia resulta, cuanto menos, significativa. Conociendo que en determinados casos existe una correlación tácita entre problemas psicológicos y problemas físicos, como por ejemplo en casos de experiencias 
traumáticas como el abuso infantil, los desastres naturales o la vivencia de una guerra (van der Kolk, 2015), se puede trabajar la relación de las personas con su cuerpo a través de dinámicas como música y movimiento, la danza o la biodanza, así como por medio de técnicas psicoterapéuticas de exploración introspectiva que pueden dar lugar a experiencias kinestésicas e incluso transpersonales, necesarias en algunos procesos terapéuticos. De hecho, la escucha corporal es un método experiencial cuyo potencial terapéutico a nivel físico reside en el hecho de que el oyente recibe la música en un estado alterado de conciencia y refleja sobre ella su propia experiencia personal (Viega, 2009).

En la Tabla 5 quedan reflejados, a modo de recopilación, algunos de los efectos biológicos que hemos ido mencionando, y otros que no han sido expuestos, por parte de diferentes autores.

Tabla 5

Efectos biológicos de la Musicoterapia

- Desarrollo del oído.

- Acelerar/retardar las funciones orgánicas.

- Actuación sobre el sistema nervioso central y periférico.

(Rodrigo, 2000)

- Producción de respuestas musculares y movimientos peristálticos del estómago.

A nivel - Modulación del nivel de resistencia al dolor.

fisiológico - Relajación a nivel físico.

(Poch, 2011)

- Mejora de la respiración.

- Realineación global del cuerpo.

(Bosco, 2000)

- Estimulación de la producción de endorfina.

- Reforzamiento del sistema inmunitario.

- Mejora de la autopercepción y el control corporal a través del ritmo.

(Vaillancourt, 2009)

- Desarrollo psicomotor.

- Desarrollo sensorio-perceptivo.

- Integración y desarrollo del esquema corporal.

- Desarrollo de la organización espacio-temporal.

A nivel (Rodrigo, 2000)

neuroló-

gico - Tratamiento y rehabilitación de la marcha en trastornos o enferme-

dades que repercuten en el movimiento corporal.

- Estimulación de respuestas físicas ante estímulos sonoros y musica-

les en casos de traumatismos cerebrales severos.

(Davis et al., 2012)

Fuente: Elaboración propia a partir de los autores citados. 


\subsection{Fundamentos psicológicos}

Por todos es conocido que la música produce efectos a nivel psicológico, sobre todo en el plano emocional. Además, tal y como se puede apreciar en el capítulo de antecedentes históricos, la música ha formado parte de la vida de la cultura de los seres humanos desde tiempos inmemoriales como eje vertebrador de rutinas, rituales, festejos, etc. debido a su repercusión a nivel afectivo, social y relacional. La Musicoterapia parte del potencial de la música para producir cambios en diferentes ámbitos de la vida de las personas.

De hecho, desde el punto de vista de la psicología de la música esta es estudiada desde diferentes perspectivas como la relación entre la música y las emociones, la música como lenguaje, el enfoque evolutivo, el enfoque educativo (orientado al campo de la enseñanza de la música) y el enfoque psicométrico, entre otras (Vera, 2000). En este sentido, para el campo de la Musicoterapia tiene especial relevancia estudiar los efectos que la música tiene a nivel emocional, así como el valor que tiene y las posibilidades que ofrece como lenguaje no verbal. Igualmente, tanto el enfoque evolutivo, que analiza los comportamientos y las conductas musicales de los seres humanos conforme van creciendo, como el enfoque psicométrico, que determina perfiles musicales mediante la validación y utilización de test psicológicos, son de utilidad a la hora de realizar evaluaciones previas sonoro-musicales en Musicoterapia.

La música, en función de su carácter, su forma, su condición anímica, etc. puede producir distintas sensaciones, emociones y sentimientos. En este sentido y siguiendo como base la concepción de las cuatro emociones básicas (alegría, tristeza, miedo y enfado) son varias las investigaciones que se han desarrollado con el objetivo de analizar y categorizar los tipos de respuesta emocional que se pueden dar al escuchar música. En uno de estos estudios se llegó a afirmar que reacciones como la alegría, la tristeza, el miedo y la tranquilidad son universales e innatas en todos los seres humanos, e incluso se analizó qué tipo de música genera una u otra sensación (Vieillard et al., 2008).

Sin embargo, muchos estudios han demostrado que los efectos que produzca la música son mayores cuanto mayor sea la relación que guarde con una persona y el significado o valor que tenga para ella (Wigram, Pedersen y Bonde, 2011), y este es uno de los pilares del proceso musicoterapéutico. De esta forma, una obra que produce alegría a una persona puede irritar o entristecer enormemente a otra si lo asocia con un recuerdo duro, o una pieza concebida 
para generar calma puede producir ansiedad a alguien si, por ejemplo, no soporta el hecho de cerrar los ojos y sentarse a escuchar música. Por ello la historia personal unida a las preferencias musicales de los clientes será relevante de cara al desarrollo del proceso terapéutico. La reacción que tenga una persona ante la música depende, por lo tanto, de sus antecedentes ambientales y culturales, así como de su propia personalidad.

A nivel cognitivo, la música puede tener repercusión en procesos relacionados con el mantenimiento de la concentración o el trabajo de la atención focalizada y sostenida, contribuir al desarrollo de la comunicación oral, aumentar la capacidad de espera, ejercitar la capacidad de evocación, desarrollar la imaginación y estimular la creatividad. Igualmente, a través del trabajo con música, ya sea mediante la Educación Musical o experiencias musicales de otro tipo, se ven involucrados los dos hemisferios cerebrales, tanto el derecho como el izquierdo, de modo que al tiempo que se está aprendiendo una obra musical con letra, por ejemplo, se está ejercitando el procesamiento del lenguaje.

En lo referente al ámbito social y relacional, sabemos que la música ha sido empleada a lo largo de la historia en rituales, festejos y otro tipo de eventos orientados a desarrollar la unión de los individuos en una sociedad, es decir, a fortalecer el sentimiento de pertenencia al grupo, a la comunidad en la que se vive (Borling \& Miller, 2007). En este sentido, la música en sí funciona como elemento de unión y, de hecho, uno de los ámbitos de aplicación de la Musicoterapia es el comunitario. A través de sesiones de improvisación grupales, por ejemplo, se trabaja la interacción y se favorece el desarrollo de habilidades comunicativas y sociales que harán que las personas implicadas puedan participar mejor de la sociedad en la que se van a desenvolver. De alguna manera la música nos conecta con arquetipos sonoros y con el inconsciente colectivo, de modo que se refuerza nuestra sensación de pertenencia a la humanidad en su sentido de gran comunidad.

En la Tabla 6 quedan reflejados, a modo de recopilación, algunos de los efectos psicológicos que hemos ido mencionando, y otros que no han sido expuestos, por parte de diferentes autores. 


\section{Tabla 6}

\section{Efectos psicológicos de la Musicoterapia}

\begin{tabular}{|c|c|}
\hline \multirow{3}{*}{ A nivel emocional } & $\begin{array}{l}\text { - La música repercute en nuestro cuerpo, nuestra mente } \\
\text { y nuestra alma, seamos conscientes de ello o no. } \\
\text { - La música puede ser entendida y utilizada como una } \\
\text { pantalla proyectiva de las necesidades de nuestra psique. } \\
\text { (Bush, 1995) }\end{array}$ \\
\hline & $\begin{array}{l}\text { - La música ayuda a desarrollar habilidades relacionadas } \\
\text { con una mayor capacidad de regulación emocional. } \\
\text { - Esta regulación emocional lleva a una mejor gestión de } \\
\text { los conflictos relacionales. } \\
\text { (Colegrove, Havighurst, \& Kehoe, 2019) }\end{array}$ \\
\hline & $\begin{array}{l}\text { - Sensibilización afectivo-emocional. } \\
\text { - Reforzamiento de la autoestima y la personalidad. } \\
\text { - Favorece la liberación o catarsis emocional. } \\
\text { (Rodrigo, 2000) }\end{array}$ \\
\hline $\begin{array}{c}\text { A nivel } \\
\text { socio-afectivo }\end{array}$ & $\begin{array}{l}\text { - Fortalecimiento de pautas de conducta facilitadoras de } \\
\text { interacción y adaptabilidad. } \\
\text { - Autorrealización, integración del yo y afianzamiento } \\
\text { de identidad personal. } \\
\text { - Fomento de relaciones interpersonales. } \\
\text { - Integración social y grupal. } \\
\text { (Rodrigo, 2000) } \\
\text { - Lo sonoro forma parte de la vida de los seres humanos } \\
\text { y nos conecta automáticamente con personas, rutinas, } \\
\text { experiencias previas, etc. } \\
\text { (Lucas, 2013) }\end{array}$ \\
\hline \multirow{3}{*}{ A nivel cognitivo } & $\begin{array}{l}\text { - Desarrollo intelectual (imaginación, creatividad, aten- } \\
\text { ción, memoria, conceptualización, comprensión, obser- } \\
\text { vación, agilidad mental). } \\
\text { - Desarrollo de expresión oral y comunicación. } \\
\text { (Rodrigo, 2000) }\end{array}$ \\
\hline & $\begin{array}{l}\text { - Desarrollo del lenguaje. } \\
\text { - Mejora de procesamiento cognitivo. } \\
\text { (Wigram et al., 2011) }\end{array}$ \\
\hline & $\begin{array}{l}\text { - Mejora del rendimiento académico en casos en los que } \\
\text { se tiene relación recurrente con experiencias musicales. } \\
\text { - Estimulación del desarrollo global de la inteligencia. } \\
\text { (Vaillancourt, 2009) }\end{array}$ \\
\hline
\end{tabular}

Fuente: Elaboración propia a partir de los autores citados. 


\section{LA MUSICOTERAPIA COMO DISCIPLINA}

\subsection{Aproximación conceptual y características básicas}

La consideración de la Musicoterapia como disciplina ha sido, y sigue siendo, especialmente en determinados contextos, un proceso lento y complicado que requiere de una continua reflexión sobre la práctica orientada a lograr una conceptualización más sólida, así como una sistematización de la profesión más cimentada y rigurosa. La búsqueda de una definición adecuada, acertada y aceptada vive y perdura en la mente de cada musicoterapeuta a la hora de debatir con colegas de profesiones relacionadas, al desarrollar programas académicos, al presentarse a una oferta de trabajo o en el momento de luchar por la normalización y regularización de la disciplina en distintos tipos de instituciones y a nivel nacional e internacional (Bruscia, 1996). El camino que se ha de recorrer hacia el reconocimiento de la profesión hace necesario considerar y demostrar los orígenes, las características y los fundamentos de la Musicoterapia de forma precisa y pormenorizada.

Teniendo en cuenta una de las primeras aportaciones que se hizo en relación con la definición de Musicoterapia como disciplina en sí misma, podría ser entendida como el uso dosificado y controlado de la música en diferentes contextos relacionados con trastornos físicos, mentales o emocionales, ya sea en la edad adulta o en la etapa infantil, y con objetivos orientados al tratamiento, la rehabilitación y la educación de las personas que asisten a las sesiones (Alvin, 1967). Por lo tanto, en la segunda mitad del siglo XX ya se consideraba en algunas instituciones como una forma de intervención cuyo objetivo era el de favorecer el desarrollo personal, físico y emocional de distintas poblaciones.

Desde un comienzo los musicoterapeutas se han preocupado por distinguir la función terapéutica de la música en contraposición con la idea de creación musical, que es el objetivo que generalmente prima en determinados contextos de Educación Musical. Esto quiere decir que lo que prevalece es la idea de que la música, de la cual forman parte igualmente el sonido y el silencio, es un medio a través del cual se pueden generar interacción y procesos de comunicación con objetivos terapéuticos. De esta forma la música no se entiende como un fin en sí misma, sino como un recurso cuyo valor terapéutico no depende de la perfección ni de la calidad de las ejecuciones. En Musicoterapia la relación terapéutica entre terapeuta y paciente parte de lo sonoro y se desarrolla por medio de ello, es decir, a través de distintos elementos e instrumentos vibratorios, sonoros y musicales con el fin de favorecer la calidad de vida de las personas y la mejora de la dimensión social (Benenzon, 2011). 
La Musicoterapia ha sido también definida como una disciplina paramédica en la que la creación de un vínculo de comunicación bidireccional entre musicoterapeuta y paciente a través de la música, el movimiento y el sonido actúa como beneficio para el desarrollo personal individual de cara a lograr una mejor participación en la sociedad (Rodrigo, 2000). La intervención siempre va orientada y adaptada a las necesidades de cada persona, planteando objetivos a corto y largo plazo y teniendo en cuenta sus características y necesidades específicas.

La Musicoterapia utiliza la capacidad de la música para evocar imágenes, emociones y sensaciones, aplicada de forma sistemática y rigurosa por un profesional cualificado, para producir cambios en la vida de las personas, no solo a nivel mental sino también físico (Bonny, 1986). Al tiempo que se fortalece y se desarrolla con cierta continuidad la relación terapéutica, se fortalece el proceso de crecimiento y evolución personal de tal modo que se vea reflejado en el modo en que los pacientes se presentan, expresan y desenvuelven en sociedad en los diferentes momentos del proceso.

Debido a las diferentes perspectivas, vertientes o autores que han aportado definiciones de esta disciplina, y a la variabilidad a la que está sometida su consideración por estar en constante evolución y desarrollo, la Confederación Mundial de Musicoterapia redactó una definición genérica con el objetivo de aunar puntos de vista, ámbitos de aplicación, consideraciones, etc.:

La Musicoterapia es el uso de la música y/o de los elementos musicales (sonido, ritmo, melodía y armonía) por un terapeuta cualificado con un cliente o grupo, en un proceso dirigido a facilitar y promover la comunicación, las relaciones, el aprendizaje, la movilización, la expresión, la organización y otros objetivos terapéuticos relevantes, con el fin de suplir necesidades de tipo físico, emocional, mental, social y cognitivo. La musicoterapia tiene como finalidad desarrollar potenciales y/o restaurar funciones del individuo de forma que él o ella puedan conseguir una integración tanto intra como interpersonal y, como consecuencia, una mejor calidad de vida a través de la prevención, la rehabilitación o el tratamiento. (WFMT, 1996, citado en Wigram et al., 2011)

En definitiva, la Musicoterapia se da en el momento en que se genera un proceso terapéutico entre musicoterapeuta, paciente y la música como elemento intermediario primordial, el cual se va desarrollando a lo largo del tiempo y a través de distintas formas de interacción y comunicación. 


\subsubsection{El papel del musicoterapeuta}

El musicoterapeuta es un terapeuta cualificado que tiene la responsabilidad de adaptar las intervenciones a las características y necesidades de cada persona, así como de realizar un seguimiento profesional y minucioso de la evolución del proceso terapéutico en los diferentes casos con los que trabaje. Es el facilitador de momentos de expresión, comunicación e interacción. Es un acompañante, un guía que orienta el tratamiento a través de objetivos terapéuticos claros, la valoración y la evaluación. Ayuda a promover, mantener o mejorar un estado de bienestar y de seguridad en la vida de sus pacientes.

A pesar de que existen, de manera estipulada, diferentes modelos, métodos y técnicas como formas de intervención en Musicoterapia, cómo trabaje el musicoterapeuta dependerá, en mayor o menor medida, de su formación profesional, su compromiso con la actualización e innovación en su práctica diaria, las supervisiones que reciba y su propio proceso y trabajo a nivel personal (Ferrari, 2013). Estos elementos, de vital importancia en la formación y el trabajo de los musicoterapeutas, definirán su identidad profesional y la orientación del rol que desempeñen en las sesiones.

La formación profesional básica debe aportar suficientes contenidos, incluyendo fundamentos básicos históricos, psicológicos y fisiológicos, perspectivas de los diferentes modelos de intervención, técnicas y métodos de práctica clínica, herramientas de pre-evaluación, seguimiento y valoración, enfoques de investigación, ética profesional, etc., para formar y cimentar la base del futuro trabajo de los musicoterapeutas. La educación y preparación de este perfil ha de ser multidisciplinar, de modo que los programas de formación deben cubrir aspectos relacionados con la psicología, la antropología, la biología, la fisiología, el movimiento, la danza, la psicoterapia, la sociología, etc. además de contenidos musicales y horas de práctica clínica supervisada (Davis et al., 2012). Actualmente, en España es requerido completar un Máster específico en Musicoterapia de 60 créditos para poder ejercer la profesión. En otros países, como Estados Unidos o Alemania, los programas universitarios pueden ser de hasta cuatro años de duración, es decir, lo que equivaldría a una carrera de Grado de 240 créditos.

La supervisión es necesaria en la carrera del musicoterapeuta, así como en otras profesiones relacionadas con el campo de la salud mental, porque es primordial reflexionar sobre la práctica diaria, recibir opinión y retroalimentación sobre la forma en la que se está trabajando con los clientes. De la existencia o no de situaciones de supervisión depende, en mayor o menor medida, que el proceso terapéutico sea saludable y seguro o, por el contrario, contraproducente o incluso peligroso. De hecho, ya durante la etapa de formación 
básica debe haber procesos de seguimiento y supervisión (lo que se denominan supervisiones pre-profesionales) que orienten a los estudiantes para mejorar sus habilidades y comportamientos a través de la observación, la reflexión, la enseñanza, la evaluación y el asesoramiento por parte de los supervisores (McClain, 2000). La supervisión profesional, es decir, la que se realiza una vez se ha completado la formación básica, resulta trascendental para conservar la perspectiva respecto al propio trabajo terapéutico que se está realizando, o lo que es lo mismo, para ser consciente de que la dirección en la que se está actuando es la correcta cuando surgen dudas. Además, la supervisión contribuye a la constante actualización e innovación en la práctica, aportando mayor conocimiento sobre teorías y técnicas, formas de intervención, ética profesional, roles y responsabilidades, etc.

De igual manera, el trabajo a nivel personal es fundamental para garantizar que el proceso terapéutico no se vea mermado o condicionado por las necesidades personales que el musicoterapeuta pueda proyectar en sus sesiones de manera inconsciente. El papel y la responsabilidad de un terapeuta es ayudar, por lo que no puede ver en las personas con quien trabaja una figura de apoyo, ni puede ver su práctica clínica como una respuesta a sus propias necesidades. Cuando los roles de la relación terapéutica se revierten o se confunden, es decir, cuando el musicoterapeuta busca la posibilidad de cubrir sus carencias a través de su trabajo, aunque sea de forma inconsciente, se está produciendo una contratransferencia (Bruscia, 2007). Por ello es necesario el autocuidado, la atención continua al estado emocional y la autopercepción por parte del musicoterapeuta.

El perfil del musicoterapeuta será configurado, por lo tanto, en función de la formación básica que haya recibido, la especialización escogida y/o formación continua que realice, las situaciones de supervisión y la influencia de su propio proceso personal, así como las vivencias que le hayan acompañado a lo largo de su vida. En la Figura 1 quedan recogidos, a modo de esquema y resumen, estos aspectos. 


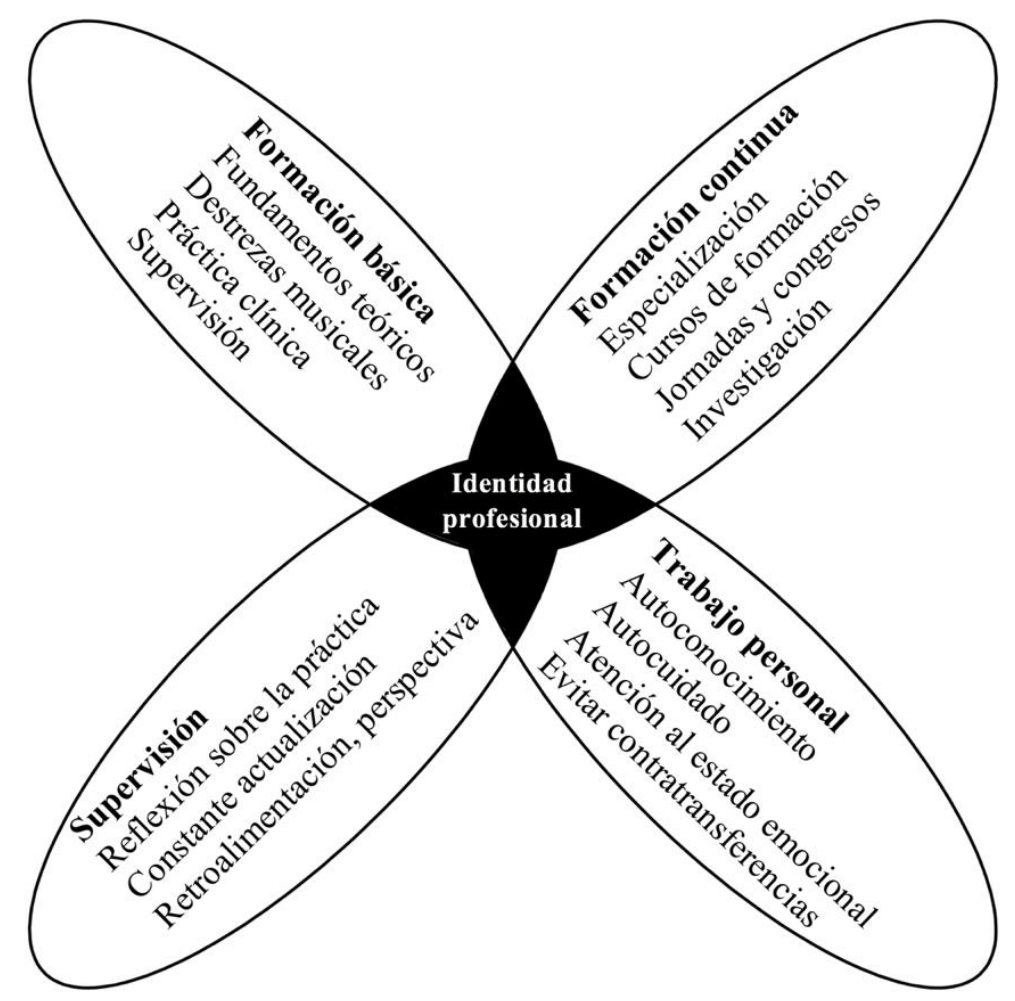

Figura 1. Formación de la identidad profesional del musicoterapeuta. Elaboración propia.

\subsubsection{El papel de la música}

La música es el espacio en torno al cual se ordenan situaciones terapéuticas y se conforman procesos. Es el medio a través del cual se produce comunicación e interacción, y la herramienta principal con la que cuenta el musicoterapeuta para orientar su trabajo y alcanzar objetivos. En definitiva, es la base, el colchón, el contenedor, los cimientos sobre los que se apoya y desarrolla el proceso musicoterapéutico.

En primer lugar, la música es considerada, y ha sido considerada a lo largo de los años, como un lenguaje en sí mismo que forma parte de la vida diaria de las personas, y que nos conecta de forma inconsciente y automática con nuestro mundo interior, nuestra percepción del mundo y nuestra forma de relacionarnos con nuestros semejantes. Aplicado a la situación de Musicoterapia, la música, incluyendo por lo tanto todo tipo de elementos sonoros, se presenta como un medio de comunicación no verbal, es decir, un canal que permite a las personas comunicarse de forma instintiva, natural e innata sin la necesidad de usar la palabra (Benenzon, 2011). 
Es necesario tener en cuenta, como se ha indicado previamente, que la música en situación de terapia no se concibe de igual manera que en los contextos de educación musical, es decir, como producción, creación o exhibición, sino que está al servicio de los pacientes y de las necesidades que se vayan presentando en el desarrollo del proceso terapéutico. Por ello es posible que sean incorporados elementos no musicales y que los objetivos de las sesiones vayan más allá de cánones estéticos, buscando otro tipo de experiencias sensoriales y relevantes para el proceso. Dicho lo cual, se debe considerar que hay factores en situación de terapia que no se encuentran en contextos estrictamente musicales y que determinarán, en mayor o menor medida, el uso que el musicoterapeuta haga de la música en un encuadre clínico (Bruscia, 1996). Dichos factores quedan reflejados en la Tabla 7.

Tabla 7

Factores que determinan en terapia el modo de empleo de la música

\begin{tabular}{|c|c|}
\hline $\begin{array}{l}\text { Prioridades } \\
\text { de la terapia }\end{array}$ & $\begin{array}{l}\text { La prioridad en terapia es adaptar y orientar el proceso a las necesi- } \\
\text { dades del cliente a través de la música. Esto quiere decir que la mú- } \\
\text { sica es primordialmente escogida, improvisada o creada en función } \\
\text { de su relevancia y valor a nivel clínico. Igualmente se trata de pre- } \\
\text { servar la calidad de los instrumentos y los sonidos, pero hay que te- } \\
\text { ner en cuenta que en muchas ocasiones los clientes tendrán la nece- } \\
\text { sidad de explorar elementos básicos de la música o traerán a las se- } \\
\text { siones sus propias preferencias musicales. }\end{array}$ \\
\hline $\begin{array}{c}\text { La } \\
\text { perspectiva } \\
\text { de no juzgar }\end{array}$ & $\begin{array}{l}\text { Es necesario aceptar y valorar el esfuerzo de los clientes a la hora de } \\
\text { crear música o interaccionar a través de ella. Muchas de las personas } \\
\text { que acuden a Musicoterapia carecen de formación musical extensa, } \\
\text { por lo que se trata de tener capacidad de adaptación y de ayudar a } \\
\text { que identifiquen, conecten y desarrollen sus potenciales musicales, } \\
\text { siempre al servicio de su propio proceso terapéutico. }\end{array}$ \\
\hline $\begin{array}{c}\text { Las } \\
\text { aplicaciones } \\
\text { multisenso- } \\
\text { riales de la } \\
\text { música }\end{array}$ & $\begin{array}{l}\text { La música conecta a los seres humanos a través de todos nuestros } \\
\text { sentidos, no solo por medio del oído. Es por ello que en situación de } \\
\text { Musicoterapia es necesario comprender y aceptar la libertad de em- } \\
\text { pleo de los instrumentos y de los elementos sonoros. Un objeto se } \\
\text { puede tocar, oler, ver, escuchar e incluso saborear en función de cuá- } \\
\text { les sean las necesidades del cliente y los objetivos del proceso. De } \\
\text { hecho, las posibilidades multisensoriales de la música la hacen ideal } \\
\text { para un proceso terapéutico, sobre todo en aquellos casos en los que } \\
\text { las incapacidades están producidas por daños sensoriales o motóri- } \\
\text { cos. Igualmente, el musicoterapeuta tiene la posibilidad de orientar } \\
\text { la experiencia musical hacia los canales sensoriales que se quieran } \\
\text { trabajar. }\end{array}$ \\
\hline $\begin{array}{c}\text { Las } \\
\text { relaciones } \\
\text { entre música } \\
\text { y otras artes }\end{array}$ & $\begin{array}{l}\text { Definir los límites de la Musicoterapia es complicado porque habi- } \\
\text { tualmente se relaciona la música con otras disciplinas artísticas } \\
\text { como la poesía, el teatro, la danza o la pintura. De hecho, en las se- } \\
\text { siones se trabajará en determinados casos a través del dibujo, la es- } \\
\text { critura de canciones, el movimiento corporal, la dramatización, la } \\
\text { historia musical, etc., por lo que el espacio y los límites de lo musical } \\
\text { son, también desde esta perspectiva, relativos y adaptables al con- } \\
\text { texto y las necesidades. }\end{array}$ \\
\hline
\end{tabular}

Fuente: Adaptado de Bruscia (1996). 
Por otra parte, la música puede ser reflejo directo de necesidades emocionales, afectivas y físicas y acompañar, como hilo conductor, el proceso terapéutico de los clientes. En algunas vertientes, como el Modelo Bonny de Imagen Guiada con Música (BMGIM) o la Musicoterapia Analítica, se trabaja con la música como una portadora y contenedora de la psique, una pantalla proyectiva que permite conectar con el mundo interior y el inconsciente de los clientes. Debido a la importancia de su presencia en las sesiones, a su papel de guía y soporte y a su gran potencial como intervención no verbal, ya que produce momentos de exploración, intensificación emocional, estabilización, integración, etc., puede ser considerada incluso como figura de co-terapeuta (Bush, 1995).

\subsubsection{Clasificación de métodos de trabajo en Musicoterapia}

En función del modo de proceder que tenga el musicoterapeuta en relación con la situación de terapia y sus clientes y a cómo sea empleada la música, las técnicas de intervención en Musicoterapia se pueden clasificar, a grandes rasgos, en dos vertientes: la Musicoterapia activa y la Musicoterapia receptiva. En el primer caso los clientes exploran los elementos sonoros, la música se experimenta de forma activa, se crea o se interpreta. En cambio, en las técnicas receptivas los pacientes reciben la música en su cuerpo a través de la escucha, sin participar de forma activa en ningún tipo de actividad musical, pero sí de tal modo que se impliquen procesos terapéuticos a nivel psicológico, emocional y fisiológico.

Algunas de las técnicas de intervención incluidas dentro de la Musicoterapia activa son la improvisación, la composición y la re-creación (Bruscia, 2007). Dicha clasificación queda expuesta y sintetizada en la Tabla 8. 
Tabla 8

Métodos activos empleados en Musicoterapia

El cliente crea música a través de su propia voz o mediante la utilización de instrumentos. El musicoterapeuta recibe y escucha la experiencia de improvisación e interactúa con el cliente en base a ella, favoreciendo la comunicación y persiguiendo trabajar los objetivos terapéuticos.

Experiencias
de
improvisación

Hay varios tipos de improvisación: no referencial (se parte del silencio, sin ningún estímulo externo, a través de un instrumento musical), referencial (se improvisa en base a algo que se quiera trabajar, como un sentimiento, una situación, una imagen, una persona, etc.), con canciones (se improvisa la melodía, la letra o el acompañamiento en base a una canción o pieza musical conocida), vocal no referencial (se emplea únicamente la voz, sin ningún estímulo asociado), corporal (empleando únicamente sonidos del cuerpo), con medios mixtos (se puede utilizar cualquier tipo de emisor de sonido como la voz, el cuerpo o instrumentos musicales) y dirigida (en la que el cliente orienta al musicoterapeuta y a los compañeros, en caso de haberlos, sobre cómo se desarrolla la improvisación).

En este tipo de intervención el cliente aprende o ejecuta vocal o instrumentalmente algún tipo de música compuesta previamente o que se presente en la situación de sesión. No se emplea la palabra "interpretación" debido a que se puede asociar a la situación en la que un músico ofrece una audición o concierto ante

Experiencias re-creativas un público. Recordemos que en Musicoterapia la música se concibe como un medio al servicio de unos objetivos terapéuticos.

Se puede tratar de una re-creación instrumental (mediante el empleo de instrumentos), o vocal (a través de la voz), así como de producciones musicales (en las que el cliente participa en la creación de una obra musical), juegos y actividades musicales (el cliente participa en actividades musicales como el juego de las sillas o canciones cómicas, entre otras) o actividades de dirección (en las que el cliente dirige la ejecución de una música en vivo).

El musicoterapeuta ayuda y guía en el proceso de escritura de canciones cuyo contenido esté relacionado con el mundo interior y el proceso terapéutico del cliente.

Las experiencias de composición se pueden dar en diferente

Experiencias de composición forma: parodias de canciones (se trata de cambiar la letra de una canción ya creada, conservando la melodía y el acompañamiento), escribir canciones (el cliente compone una canción original, o algunas partes de ella, como la letra o la melodía, con la ayuda del musicoterapeuta), composición instrumental (crear una pieza instrumental o alguna parte como la melodía o el ritmo), actividades de notación (crear un sistema de notación) y collages musicales (selección y combinación de algunas secuencias de sonidos o melodías para crear una grabación que explore cuestiones autobiográficas y terapéuticas).

Fuente: Adaptado de Bruscia (2007). 
Los métodos receptivos, por su parte, están generalmente relacionados con dinámicas de relajación, la exploración introspectiva, el desarrollo de la creatividad, la expresión emocional, etc. El cliente o paciente recibe la música, que puede ser una improvisación o ejecución en directo por parte del musicoterapeuta, o una grabación seleccionada, la experimenta en su propio cuerpo y responde a ella de forma interna o verbal y/o gestualmente (Bruscia, 1996). Hay diversos estudios que han demostrado que la escucha de música en contextos terapéuticos reduce el estrés y la ansiedad (Kim \& Stegemann, 2016). Existen diferentes formas de emplear las técnicas receptivas en Musicoterapia de tal forma que se interrelacione el contenido de las sesiones con el proceso terapéutico y la historia personal de los clientes (Grocke y Wigram, 2011):

- Dinámicas de relajación musical para niños, adolescentes y adultos en diferentes contextos clínicos.

- Audición para la evocación de imágenes, incluyendo la imaginación musical dirigida y no dirigida y las dinámicas grupales, tanto para trabajar a través de elementos del inconsciente como para desarrollar la creatividad.

- Debate sobre canciones (con letra) que estén directamente relacionadas con el proceso terapéutico de los clientes.

- Reminiscencia a través de canciones, es decir, empleo de técnicas de introspección, retrospección y reflexión por medio de piezas musicales significativas relacionadas con recuerdos, memorias y experiencias del pasado de los clientes.

- Experiencias auditivas basadas en la música preferida del cliente.

- Actividades relacionadas con la apreciación de la música, cuyo objetivo primordial es que el musicoterapeuta ayude al cliente a entender y valorar esta disciplina.

- Collage musical y otras manifestaciones relacionadas con el arte, como el dibujo libre o el mandala, que surjan como forma de expresión a través de la escucha activa y la experimentación.

- Audición somática, relacionada con la terapia de sonido o vibroacústica, en la que el cliente recibe a nivel físico y corporal la música y las vibraciones sonoras. 
- Audición eurítmica, aplicada a ejercicios corporales, trabajo a nivel motriz y otros comportamientos motores.

Tanto los métodos activos como los receptivos forman parte de las técnicas que se pueden emplear a la hora de trabajar en el ámbito de la Musicoterapia. De hecho, en función de cómo sea la persona con la que se está interviniendo y en qué forma esté orientado su proceso terapéutico, así como el momento en el que se encuentre en cada paso que dé, será más conveniente un modo de proceder u otro. El musicoterapeuta ha de valorar estos factores a la hora de proponer, diseñar y desarrollar una intervención o un proyecto.

\subsection{Principales modelos de intervención}

Dentro de las diferentes vertientes de intervención, es decir, los distintos métodos y técnicas aplicadas y desarrolladas en el ámbito musicoterapéutico, destacan cinco modelos cuya filosofía y perspectiva ha sido definida, estructurada, contrastada y desarrollada de tal modo que fueron configurados y reconocidos a nivel mundial, durante el desarrollo del IX Congreso Mundial de Musicoterapia en Washington, como formas de intervención validadas y de calidad. Esto quiere decir que estos modelos tienen unas características y procedimientos específicos que son aceptados por la comunidad musicoterapéutica internacional por el valor y la eficacia que a través de la investigación se ha demostrado en diferentes culturas. Hablamos del Modelo Bonny de Imagen Guiada con Música (BMGIM), el Modelo Nordoff-Robbins, la Musicoterapia Analítica, el Modelo Benenzon y el Modelo Conductista.

\subsubsection{El Modelo Bonny de Imagen Guiada con Música (BMGIM)}

The emphasis and even the identity of the field of music therapy is changing due, in large part, to the introduction of holistic medicine and its acknowledgement that the total person mind, body and spirit - must be brought to the "healing table". Music is the ideal instrument for this change, since it is so intimately involved in both our inner and outer lives. (Bonny, 1986, pp. 3-4)

La atención terapéutica para el bienestar de las personas desde el punto de vista mental, corporal y espiritual, es decir, la percepción holística de la salud en los seres humanos, fue una teoría que cobró reconocimiento en el seno de la comunidad científica y conformó nuevas perspectivas en diferentes enfoques de intervención psicoterapéutica a partir de los años setenta. Esta idea 
en relación con la aplicación de la música en procesos terapéuticos, considerando su beneficio para la salud y bienestar de las personas, fue lo que sentó las bases del modelo del que pasamos a hablar a continuación.

El surgimiento del Modelo Bonny de Imagen Guiada con Música - de ahora en adelante BMGIM, por sus siglas en inglés, Bonny Method of Guided Imagery and Music - se remonta a los años setenta, época en la que su creadora, la violinista y musicoterapeuta Dra. Helen Lindquist Bonny, comenzó a trabajar en el Centro de Investigación del Psiquiátrico de Maryland en EE.UU., donde previamente se trataba a determinados pacientes de forma experimental a través de sesiones psicoterapéuticas con drogas alucinógenas como el LSD. En el año 1972 se prohibió el uso de esta sustancia en investigación y fue entonces cuando Helen Bonny emprendió un tratamiento experimental psicoterapéutico basado en la escucha activa de música. A partir de una profunda relajación que conducía a estados no ordinarios de conciencia y con la ayuda de la función intensificadora de la música, trabajaba a través de procesos mentales subconscientes e inconscientes con el objetivo de resolver algunas de las dificultades psicológicas de pacientes alcohólicos y enfermos terminales de cáncer (Wigram et al., 2011). Así fue como el modelo dio sus primeros pasos.

A partir de 1973, Bonny comenzó a orientar su trabajo de investigación a la sistematización y establecimiento de este tratamiento como un nuevo método de intervención en Musicoterapia. Para ello estudió los efectos que la música podía tener en la mente de las personas a través de procesos de exploración de la consciencia, lo que le llevó a escribir junto a Louis Savary, autor de algunos libros de crecimiento personal y espiritual (Clark, 2002). De esta forma, ambos dieron a conocer las posibilidades que ofrece la música para descubrir estados de conciencia inusuales para los seres humanos y recogieron algunas orientaciones sobre cómo estimular la imaginación y trabajar con varios estilos musicales, tanto de forma individual como en grupo (Bonny y Savary, 1994).

En base a estas observaciones, y tomando conciencia de los efectos psicológicos que producía la música en las sesiones, decidió agrupar algunas obras y ordenarlas con un determinado fin en función de los objetivos que se planteasen en cada sesión, creando así cinco programas musicales. Estos, que tenían una duración aproximada de nueve minutos, iban encaminados a estimular la capacidad imaginativa de los pacientes, establecer relaciones de soporte en grupo, producir situaciones terapéuticas de afecto y relajación, inducir procesos introspectivos para retornar a momentos importantes de la infancia, y generar experiencias significativas y positivas en situaciones de intervención con determinados tipos de crisis (Clark, 2002). 
De esta forma se establecieron estos programas como recursos, y eran utilizados para ayudar a pacientes que estaban teniendo malas experiencias en su vida oflashback problemáticos, a trabajar a través de sus emociones y miedos para obtener sensaciones de relajación, resolución e integración. Esta fue la primera forma de organización de música con objetivos claros, y lo que sentó las bases y la esencia del modelo: la selección y ordenación de obras musicales cuyos efectos tenían repercusión en relación con fines terapéuticos definidos.

Cuando Helen Bonny completó su tesis doctoral en el año 1976, ya había desarrollado y sistematizado el método en su forma esencial, es decir, en situación de psicoterapia individual, y este modo de proceder es lo que hoy en día conocemos como el Modelo Bonny de Imagen Guiada con Música. Cada sesión, de unos noventa minutos de duración, consta de una conversación inicial o pre-sesión (preludio), una inducción, un periodo central de trabajo introspectivo y escucha activa del programa musical escogido, denominado viaje o experiencia musical, y una situación de integración y toma de conciencia sobre lo acontecido, a la que llamamos post-sesión o epílogo (Ventre, 2002).

Durante el preludio, cuya duración estimada es de 20 o 25 minutos, el terapeuta escucha atentamente la percepción consciente que el paciente tiene sobre su estado de ánimo y sus problemas, tratando de focalizar un objetivo para la sesión. La intención en este momento es que el paciente tome conciencia de su situación personal en relación con su cuerpo y sus emociones, sentimientos y sensaciones, conectando el mundo exterior con su mundo interior. La función del terapeuta en esta fase de la sesión es conocer la experiencia del paciente en relación con su estado anímico y valorar su nivel de energía para escoger el programa musical adecuado (Gimeno, 2005). Juntos elaborarán un objetivo o foco que será trabajado en la sesión.

La inducción, que dura entre dos y siete minutos, consiste en ayudar al paciente a entrar en un estado de relajación tal que le permita conectar con estados no ordinarios de conciencia y explorar niveles profundos de la mente, para trabajar así desde su mundo interior. La función del terapeuta es dar instrucciones para facilitar la relajación, a través de distintas técnicas: imaginar un color, producir tensión-relajación, conectar con el momento presente, etc. El objetivo de esta fase es que el paciente pase de un nivel de pensamiento lógico, consciente y controlado, a un estado de la mente en el que las experiencias ocurren de manera más flexible en cuanto a tiempo y espacio (Wigram et al., 2011), donde los sentimientos, imágenes y sensaciones surgen de manera inconsciente y arbitraria. 
Una vez se ha realizado la inducción, el terapeuta formula la intención o foco planteado en el preludio para recordar el objetivo de la sesión y reproduce el programa musical que ha seleccionado previamente. Así es como comienza el viaje, cuya duración se estima entre treinta y cuarenta minutos. Durante este periodo el paciente entrará en contacto con aspectos relevantes de su mundo interior, puntos de conflicto y experiencias significativas. El terapeuta es el guía, y como tal su cometido es acompañarle en su viaje, acogiendo y explorando cualquier imagen que surja. Esta información ha de obtenerla tanto del propio paciente, que irá verbalizando la experiencia, como de la observación de su cuerpo, las expresiones faciales, etc. En este método la palabra "imaginación" se refiere a todo tipo de imágenes, ya sean visuales, auditivas, corporales, táctiles, olfativas y gustativas, así como recuerdos, emociones y sensaciones (Wigram et al., 2011). La música está muy presente y actúa como co-terapeuta, ya que acompaña y arropa al paciente intensificando los sentimientos y las sensaciones de importancia (Lin et al., 2010).

Después del viaje es necesario que el paciente regrese a un nivel de pensamiento ordinario, por lo que la última pieza musical del programa tiene la función de llevarle a un estado de calma y tranquilidad que le permita enraizar su cuerpo y conectar con la situación real de sesión y el lugar en el que se encuentra físicamente. Esta es una de las funciones del terapeuta en la última fase de la sesión, el epílogo. Además, debe ayudar al paciente a reflexionar sobre su experiencia, a integrar y regular lo que ha ocurrido y a tomar conciencia sobre sus avances personales (Gimeno, 2005). Para facilitar este proceso se ofrece al paciente que dibuje un mandala, lo que puede ayudarle a plasmar los sentimientos que han surgido sin necesidad de recurrir a la palabra (Bush, 1995). Para finalizar la sesión, el terapeuta guía la reflexión sobre el mandala verbalmente y ayuda al paciente a tomar conciencia, integrar y estabilizarse para poder proceder al cierre de forma segura.

Este formato de sesión fue captando el interés en distintos ámbitos, se fue conformando como modelo de intervención musicoterapéutica y movilizando hacia la profesionalización. En el año 1987 se creó la Association for Music and Imagery - de ahora en adelante AMI -, cuyo objetivo principal reside en el interés de dar a conocer y promover el método y sus adaptaciones, ofrecer una formación reglada, prácticas y la posibilidad de sumarse a proyectos de investigación, así como generar desarrollo personal a través de redes profesionales y difusión entre sus miembros. 
Algunas de las importantes funciones que desempeñó esta asociación fue la de definir el método y, en base a ello, programar una formación para generar terapeutas cualificados, a los que se denomina Fellow. Así, se determinó que se debía designar como el Método Bonny de Imagen Guiada y Música (BMGIM, por sus siglas en inglés) el modelo en su forma original, es decir, en situación de psicoterapia individual. Así, la AMI aportó la siguiente definición para este formato:

The Bonny Method of GIM is a music-centered, transformational therapy, which uses specifically programmed classical music to stimulate and support a dynamic unfolding of inner experience in service of physical, psychological and spiritual wholeness. The GIM therapist/guide maintains an active dialogue with the listener throughout the session, providing encouragement and focus for the emotions, images, physical sensations, memories and thoughts which occur. (Association for Music and Imagery, 1990, p. 4, citado en Clark, 2002, p. 22)

Por otra parte, se aunó bajo la idea de Imagen Guiada con Música - de ahora en adelante GIM, por sus siglas en inglés - tanto el formato original como todo tipo de adaptaciones del mismo. Siguiendo esta línea, en el año 1988 dos de las primeras facilitadoras del método y compañeras de Helen Bonny, Sierra Stokes Stearns y Carol Bush, crearon el Instituto Atlantis de Conciencia y Música con el objetivo de ofrecer la formación en el método GIM y extenderla por todo el mundo.

En la actualidad la AMI registra en su página web a un total de 280 Fellows en todo el mundo, distribuidos por países como se muestra en la Tabla 9. Teniendo en cuenta estos datos, se puede apreciar la gran diferencia entre unas regiones y otras, como por ejemplo Estados Unidos, donde destaca la tradición relativa a la formación del método GIM, en comparación con Hungría, que cuenta únicamente con un terapeuta cualificado. En España el número es bastante más elevado que en otros países, ya que se han organizado distintas promociones de formación de posgrado a través del Instituto Atlantis de Conciencia y Música. Además, en el Instituto Música, Arte y Proceso, situado en Vitoria-Gasteiz, se ofrece la misma formación de forma reglada. Ambas vías están acreditadas por la Asociación de Música e Imagen. 
Tabla 9

Distribución de Fellows por países según la AMI

\begin{tabular}{cccc} 
País & $\begin{array}{c}\text { Número de } \\
\text { Fellows }\end{array}$ & País & $\begin{array}{c}\text { Número de } \\
\text { Fellows }\end{array}$ \\
\hline Argentina & 1 & India & 1 \\
Australia & 6 & Italia & 8 \\
Austria & 2 & Japón & 3 \\
Brasil & 1 & Holanda & 1 \\
Bulgaria & 2 & México & 9 \\
Canadá & 44 & Noruega & 1 \\
China & 3 & Escocia & 2 \\
Colombia & 4 & Sudáfrica & 5 \\
Dinamarca & 4 & Corea del Sur & 25 \\
Finlandia & 2 & España & 30 \\
Alemania & 26 & Suecia & 3 \\
Grecia & 5 & Suiza & 5 \\
Hong Kong & 6 & Taiwán & 2 \\
Hungría & 1 & Reino Unido & 10 \\
Irlanda & 5 & Estados Unidos & 100 \\
Singapur & 1 & & \\
\hline
\end{tabular}

Fuente: extraído de la web de la Association for Music and Imagery el 26/10/2020.

En definitiva, el Modelo Bonny de Imagen Guiada con Música podría ser definido como un método humanista de crecimiento y transformación personal, cuyo fundamento parte del empleo de programas musicales orientados hacia diferentes objetivos a nivel psicológico y el trabajo a través de estados no ordinarios de conciencia. Su empleo y eficacia han sido contrastados en ámbitos relacionados con la psicoterapia clínica, trastornos psiquiátricos, adicciones, trauma, terapia de pareja y familiar, crecimiento personal y creatividad, etc.

\subsubsection{EI Modelo Nordoff-Robbins}

Fue creado por Paul Nordoff, compositor y pianista americano, y Clive Robbins, profesor inglés de educación especial, quienes colaboraron juntos para desarrollar el modelo y trabajaron como musicoterapeuta y co-terapeuta en el desarrollo de las sesiones. Además, debido a que grababan habitualmente las sesiones de Musicoterapia, tanto a individuales como grupales, hoy en día se conservan gran cantidad de vídeos que sirven como repositorio de utilidad docente en los programas de formación de musicoterapeutas a nivel internacional. 
También conocido como Modelo de Musicoterapia Creativa, está basado en la improvisación y lleva implícito un trabajo de actualización e implicación constante por parte del terapeuta en tres niveles (Bruscia, 2010):

- En primer lugar, el musicoterapeuta utiliza, crea y/o improvisa la música a través de la improvisación para tener una base sobre la cual se comenzará a establecer interacción y comunicación.

- En segundo lugar, el musicoterapeuta tiene la responsabilidad de tomar y/o mantener el contacto con el paciente a través del cual se produzca una experiencia terapéutica en el espacio musical y personal que previamente se ha generado.

- Por último, el musicoterapeuta valora, orienta y soporta el proceso terapéutico, planificando qué y con qué objetivos se va a trabajar en la siguiente sesión, siempre teniendo en cuenta las fases del desarrollo creativo del paciente.

En lo referido a este tercer nivel, es decir, a la continuidad del proceso terapéutico, el musicoterapeuta organiza a través de tres fases: el "contacto exploratorio" (por medio del cual se va conociendo al paciente, cómo se manifiesta en el encuadre terapéutico y sus capacidades potenciales), el "desarrollo integrativo" (fortalecer el vínculo, focalizar objetivos terapéuticos concretos) y la "comunicación y actualización personal" (buscar y conseguir mayores niveles de interacción y relación y aumentar confianza, autonomía y competencia) (Lorenzo e Ibarrola, 2000).

Dicho lo cual, se trata de un modelo que se centra en el ámbito de trabajo activo, es decir, en el cual el paciente participa de manera activa en la situación terapéutica a través de la creación musical y la improvisación. La interacción entre musicoterapeuta y paciente se desarrolla a través de la música, especialmente por medio de técnicas de improvisación. El Musicoterapeuta ejerce el papel de guía en el proceso de interacción, de tal modo que genere una base armónica y/o melódica tal que permita que tenga lugar la comunicación (predominantemente no verbal) entre los participantes en un espacio musical seguro y de confianza. Igualmente, es el facilitador que promueve la continuidad de las interacciones entre terapeuta y paciente o entre los miembros del grupo. 
Debido al diseño del modelo, se recomienda que haya dos personas que trabajen de forma simultánea, mediante los roles de musicoterapeuta y co-terapeuta. Esto facilita que, mientras una persona está proporcionando una base armónica (según el modelo se usa el piano, pero hoy en día existen adaptaciones y se emplea igualmente la guitarra) sobre la cual se desarrolla la situación terapéutica, la otra puede interactuar con el/los participante/s y favorecer así la interacción, las respuestas y el desarrollo de experiencias significativas. Esta dinámica, unida al empleo de la voz cantada y a la necesidad de crear, de forma original y espontánea, estructuras rítmicas y melódicas concretas y adaptadas al contexto y a las personas implicadas, hace que la música actúe como eje central de este modelo y en la experiencia, lo que implica una formación musical sólida por parte de los musicoterapeutas (Wigram et al., 2011).

El Modelo ha sido desarrollado especialmente en el ámbito de las necesidades educativas especiales y orientado al trabajo con niños con discapacidad u otros trastornos de diversos tipos (Nordoff \& Robbins, 1971). Sin embargo, en varios países se han llevado a cabo a través de procesos de investigación adaptaciones para facilitar su aplicación en el trabajo con adultos en los ámbitos neurológico, psiquiátrico y de enfermedad terminal (Wigram et al., 2011).

\subsubsection{La Musicoterapia Analítica}

Ideada en los años 70 por Mary Priestley, violinista y musicoterapeuta británica, la Musicoterapia Analítica es el resultado de la incorporación de la teoría psicoanalítica al ámbito del empleo de la música con fines terapéuticos. La propia creadora la entendía como el uso de la improvisación como un medio de expresión versátil que existe entre el musicoterapeuta y cliente, basado en una orientación simbólica y psicoanalítica que ayuda a comprender el modelo como una herramienta creativa para explorar la vida interior de las personas, fomentando así mayor autoconocimiento y ayudándoles a progresar en su camino hacia el crecimiento personal (Priestley, 1994).

De esta manera, partiendo de autores como Sigmund Freud o Carl Jung, en este modelo se trata de analizar y comprender la manifestación de procesos inconscientes a través de dinámicas de improvisación musical. Por lo tanto, lo que diferencia este modelo de otras intervenciones basadas en la improvisación como técnica principal, como el modelo Nordoff-Robbins, es el modo en que se comporta el paciente y la forma en que el musicoterapeuta recibe, interpreta y responde a su mensaje. 
A menudo la improvisación surge a partir de emociones, sensaciones o situaciones que los clientes quieran traer a sesión para trabajar sobre ello. De esta manera se conecta la situación de terapia con su vida y con su proceso personal a nivel profundo e interior. Al igual que en el Modelo BMGIM, el objetivo primordial de la Musicoterapia Analítica es trabajar sobre los obstáculos o bloqueos que impiden a las personas alcanzar y desarrollar su máximo potencial a nivel personal. En este sentido se podría asumir que ambos modelos siguen una corriente eminentemente humanista.

Las sesiones pueden ser individuales, de dúo o grupales, aunque las más comunes debido al enfoque del modelo son las sesiones individuales. Una única sesión está formada por diferentes fases o momentos: identificación del contenido de terapia, definición de roles, improvisación y debate (Bruscia, 2010):

- En primer lugar, el musicoterapeuta analítico identifica el contenido de la terapia en base a un tema, situación o inquietud que el paciente ponga de manifiesto al comienzo de la sesión. Igualmente, el musicoterapeuta toma en consideración la información previa de sesiones anteriores para orientar la continuidad del proceso terapéutico.

- El objetivo de la designación de roles es facilitar que en la sesión se den los elementos necesarios para evocar acertadamente el contenido que se ha focalizado previamente. Así, si el objetivo de la sesión es "explorar el vacío", el paciente puede emprender ese camino de exploración mientras el terapeuta le va acompañando o guiando, como soporte, o si, en cambio, se trata de trabajar "el odio hacia mi madre", el terapeuta puede interpretar este papel asumiendo características propias de la madre en relación con el proceso del paciente.

- En el momento de la improvisación, la idea es que el paciente dé forma musical a un título que esté relacionado con el contenido terapéutico y el rol que ha asumido. Este es el modo de que se exprese el mundo interior a través de la música y el sonido y, por tanto, constituye el momento de exploración e investigación a nivel terapéutico y personal.

- Por último, una vez ha finalizado la improvisación se debate sobre lo ocurrido. En un primer momento el musicoterapeuta trata de captar las primeras reacciones verbales del paciente, ayudándole a tomar conciencia sobre cómo ha reaccionado de forma interna y 
externa, de modo que ambos debatan sobre estas impresiones inmediatas. Además, pueden escuchar algún fragmento grabado de la improvisación para profundizar en su significado y, con ello, en el trasfondo terapéutico y su relevancia para el proceso.

- Es muy importante, igualmente, la preparación del entorno, es decir, de la sala donde se desarrolla la terapia. Es recomendable que haya dos espacios diferenciados: la zona de instrumentos, destinada a la improvisación, y la zona de debate, con dos asientos, para que terapeuta y paciente hablen sobre lo que ha ocurrido.

El modelo de Musicoterapia Analítica fue diseñado especialmente para el trabajo con adultos en el campo de la psiquiatría y en situación de consulta privada para ayudar a personas con experiencias traumáticas o dificultades para avanzar en la vida, terapia de pareja, problemas neuróticos, fobias, depresión, etc. (Priestley, 1994). Igualmente, se han desarrollado adaptaciones para tratar casos de niños y adolescentes con trastornos de personalidad, con problemas de adaptación social o de conformación de la identidad (Wigram et al., 2011).

\subsubsection{El Modelo Benenzon}

Se trata de una corriente que parte del principio de individuación sonora y lo trabaja desde un punto de vista psicoanalítico. Fue creado por Rolando Omar Benenzon, psiquiatra, músico y compositor nacido en Buenos Aires que lleva investigando en el campo de la Musicoterapia más de treinta años y continúa actualizando su propio modelo en la actualidad.

El Modelo Benenzon concibe que el ser humano es en sí mismo sonido y que, por lo tanto, la personalidad se conforma en función de las experiencias sonoras que hayamos tenido a lo largo de nuestra vida e, incluso, antes del nacimiento, es decir, durante los meses de gestación. De esta forma nuestra identidad personal se configura en base a una serie de elementos sonoros propios de nuestra vida rutinaria tanto exógenos (naturaleza, voces, instrumentos, aparatos electrónicos, etc.) como endógenos (latido, respiración, etc.). Esto hace que a lo largo del crecimiento del ser humano se vaya definiendo lo que el autor denomina identidad sonora o ISO, que engloba el conjunto de elementos sonoros y movimientos que pertenecen a un individuo y lo caracterizan como persona, incluyendo como tales las energías sonoras heredadas genéticamente y a través de los movimientos vibracionales durante la vida uterina, así como todas las experiencias analógicas desde el nacimiento hasta la vida adulta (Benenzon, 2011). 
Así, el principio de identidad sonora parte del hecho de que una persona se autodefina y reconozca en un perfil sonoro determinado, que será único e irrepetible, para orientar un proceso terapéutico adaptado e individualizado en función de esta base de preferencias sonoras. Aun así, el trabajo musicoterapéutico no está solo fundamentado en el ISO del paciente, sino que está íntimamente relacionado también con el ISO del terapeuta hasta el punto que el proceso comenzará una vez se hayan identificado ambos perfiles y se haya producido una primera interacción en la relación terapéutica. Recordemos que la orientación del perfil del musicoterapeuta repercute siempre, en mayor o menor medida, en la forma que tome la intervención y el proceso terapéutico que se desarrolle.

En función de la naturaleza o el origen de los elementos que conforman las preferencias sonoras se pueden distinguir cuatro tipos de ISO: "el ISO universal, el ISO gestáltico, el ISO cultural y el ISO grupal” (Benenzon, 2011, pp. 67-90). El primero engloba todas aquellas energías sonoras heredadas de nuestros ancestros y que nos conectan con la historia de la humanidad y con lo que Jung denominó el inconsciente colectivo, tales como el latido cardíaco, el sonido de la respiración y determinados arquetipos sonoros, como el sonido del agua o del viento. El ISO gestáltico está situado también en el inconsciente, pero está formado por elementos sonoros que se van incorporando a lo largo del crecimiento personal del individuo, es decir, conforme se va desarrollando su historia personal. El ISO cultural incluye todos aquellos estímulos externos pertenecientes al ambiente y entorno cercano al individuo, como los sonidos familiares, el folklore, las costumbres, etc. Por último, el ISO grupal se origina y desarrolla desde el momento en que la persona comienza a interactuar con otras personas, es decir, en función de cómo se relacione en sociedad.

Se concibe que el inconsciente está en constante movimiento y que manda de forma latente continuas señales a nuestra vida diaria, con el deseo de manifestarse, como si de un volcán a punto de erupción se tratase. En la Figura 2 queda representada la visualización del funcionamiento de la mente humana en los diferentes espacios que intervienen: el inconsciente (Inc), el preconsciente $(\mathrm{Pc})$ y el consciente $(\mathrm{Cs})$, con los cuatro tipos de ISO localizados en la parte de la mente en que actúan. 


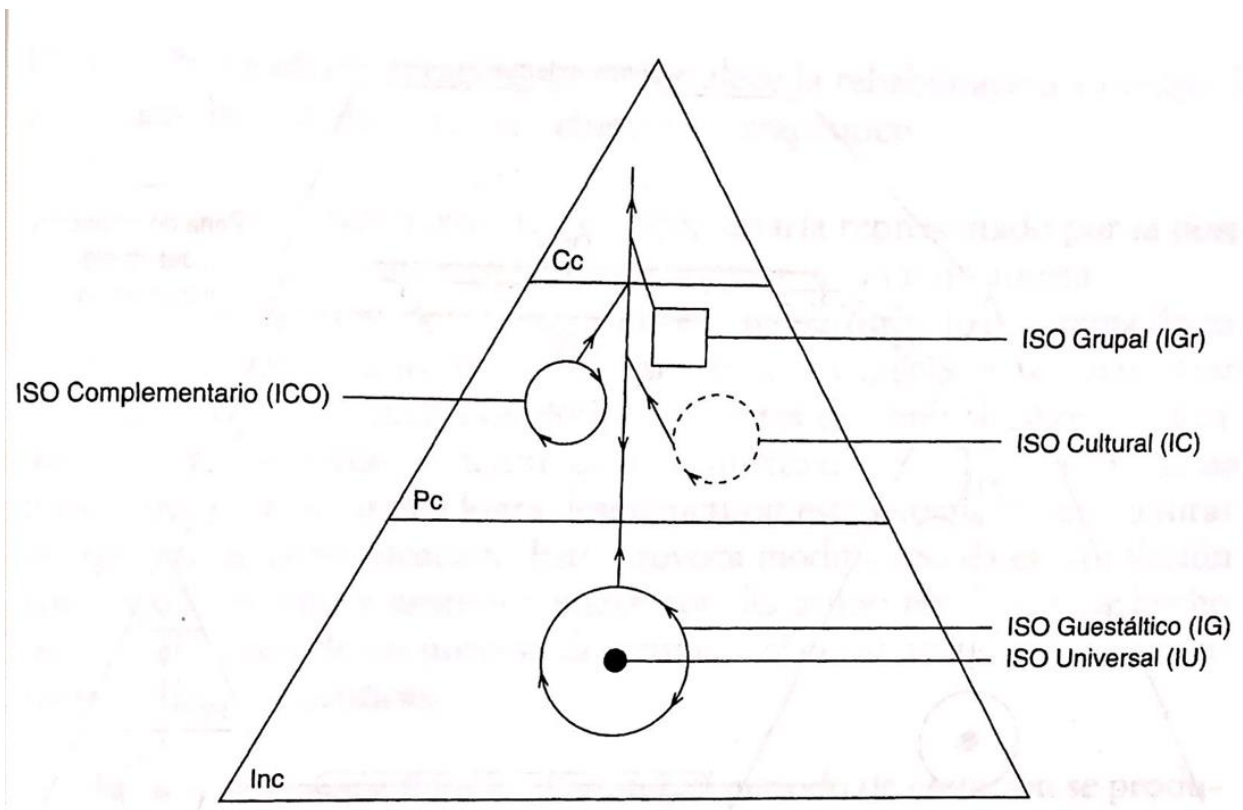

Figura 2. Representación de identidades sonoras y estados de la mente. Fuente: Benenzon (2011).

\subsubsection{EI Modelo Conductista}

Tal y como su propio nombre indica, la Musicoterapia Conductista parte de una perspectiva psicológica orientada hacia lo cognitivo-conductual y su vía de acción es, primordialmente, el trabajo sobre las conductas humanas con el objetivo de modificar aquellas que se consideren disruptivas o disfuncionales y lograr otras que sean más adaptativas y significativas, de modo que repercutan de forma positiva en la vida de los pacientes. Dicho lo cual, este modelo está íntimamente relacionado con los principios de condicionamiento clásico y operante, planteados por Pávlov y por Skinner respectivamente, de tal manera que la música, empleada como estímulo o como refuerzo positivo o negativo, tiene el fin de contribuir a nivel terapéutico a través de un proceso de modificación de conductas.

El gran exponente dentro de este modelo es Clifford Madsen, profesor de Educación Musical, Musicoterapia, Investigación y Psicología de la Música en la Universidad Estatal de Florida. Él mismo, junto con Vance Cutter, publicó un artículo en 1966 en el que definía la Musicoterapia Conductista como la combinación entre el conductismo, comprendido como la corriente o fundamento teórico y filosófico de base, el proceso de análisis pormenorizado de la conducta, y la música, empleada como estímulo, impulso, centro de atención o recompensa, es decir, como medio propicio a través del cual se puede desarrollar un proceso terapéutico (Wigram et al., 2011). 
Se distinguen diferentes fases en el proceso dentro de esta corriente conductista (Mercadal-Brotons, 2000):

- En primer lugar, el musicoterapeuta encuadra el diagnóstico o características del cliente con quien va a trabajar, ya sea adulto o niño, en un determinado contexto, como puede ser un hospital o una escuela de educación especial. De esta forma se focaliza el proceso terapéutico en las conductas que se pretenden modificar.

- A continuación, se procede a realizar la evaluación de la conducta mediante la obtención y valoración de distintos tipos de información, como la historia clínica y evolutiva de los pacientes, que ayuda a conocer mejor el ambiente en el que se han desarrollado y, con ello, orientar e individualizar el tratamiento. La información sobre la relación entre el paciente y la música permite identificar las preferencias musicales para diseñar actividades que resulten de interés para el paciente.

- Una vez se ha recogido esta información se planifica y diseña un programa de tratamiento, o una adecuación curricular individualizada si es en el ámbito educativo, en el que se recojan objetivos, técnicas que se llevarán a cabo, cómo se realizará el seguimiento, cómo se evaluarán resultados, etc.

- Al cabo de un tiempo, transcurridas ya algunas semanas desde el comienzo de la intervención, se realiza una evaluación del proceso y de los resultados obtenidos hasta el momento, para valorar si la Musicoterapia está resultando ser eficaz para el proceso de la persona.

Algunos de los ámbitos en los que se puede trabajar la modulación o el refuerzo de conductas son el emocional, el fisiológico, el motriz, el psicológico, el perceptivo y el cognitivo. Los objetivos que se suelen plantear con tal fin guardan relación con el fomento de procesos de comunicación, el contacto social y la interacción, el trabajo de la atención y la concentración, el desarrollo de la autonomía, etc. El Modelo Conductista ha sido aplicado en el campo de la geriatría, en casos de niños y adultos con necesidades educativas especiales y en el ámbito hospitalario y clínico (Wigram et al., 2011). 


\section{MUSICOTERAPIA EN EL ÁMBITO EDUCATIVO}

La base de que se defienda la presencia de Musicoterapia en contextos educativos se fundamenta en la concepción de que la música es beneficiosa en sí misma en el desarrollo evolutivo, especialmente en la etapa de la infancia. La música permite que el niño conecte con su intuición y con su capacidad de creación y exploración, al tiempo que repercute en su estado emocional y físico (Vaillancourt, 2009). Los elementos sonoros y las vibraciones están presentes incluso desde antes del nacimiento, durante los meses de gestación, de tal modo que el vínculo entre los padres y el bebé se va fortaleciendo a través de la voz, las nanas, el tacto, etc. La música y el sonido, que debemos concebir más como algo innato, necesario e inherente a todos los seres humanos que como una opción, comienza en el interior de la madre y acompaña a las personas a lo largo de toda la vida (Fridman, 1997).

La música juega un importante papel a lo largo del crecimiento del niño, teniendo en cuenta la teoría de las inteligencias múltiples, propuesta por Gardner, y especialmente en la etapa evolutiva preoperacional, enunciada por Piaget, en relación con el desarrollo de la comunicación, la percepción y el pensamiento simbólico (Hargreaves, 1998). En este sentido, el trabajo en el ámbito de la estimulación temprana nos demuestra la importancia de favorecer el desarrollo de habilidades básicas socioemocionales y cognitivas en el periodo comprendido entre el nacimiento y el comienzo del colegio, a los seis/siete años de edad. Por lo tanto, la Musicoterapia aplicada en el campo de la estimulación temprana va orientada al desarrollo de las dimensiones cognitiva, socio-emocional y sensorio-motriz de los niños mediante el empleo de recursos musicales y sonoros. En la Figura 3 se pueden apreciar algunos de los beneficios que tiene la música no solo en la Educación General, sino también dentro del ámbito de la Educación Especial.

Dicho lo cual, la Musicoterapia parte de los fundamentos teóricos biológicos y psicológicos presentados anteriormente para desarrollar su función dentro del ámbito educativo. Así, la Musicoterapia educativa (o Musicoterapia en Educación) se da en contextos educativos y actúa en correlación con los objetivos curriculares, de tal forma que se promueva el crecimiento personal de cada alumno y el desarrollo de sus potencialidades (Wigram et al., 2011). En este caso, la figura del musicoterapeuta desarrolla su labor como una actividad complementaria al proceso de enseñanza-aprendizaje y el proceso terapéutico va orientado a la mejora de la dimensión cognitiva y emocional de los alumnos. Dicha actividad puede estar incluida en el horario lectivo, igual que otro tipo de intervenciones, como logopedia o fisioterapia, en los centros en los que es necesario, o funcionar como actividad extraescolar. 


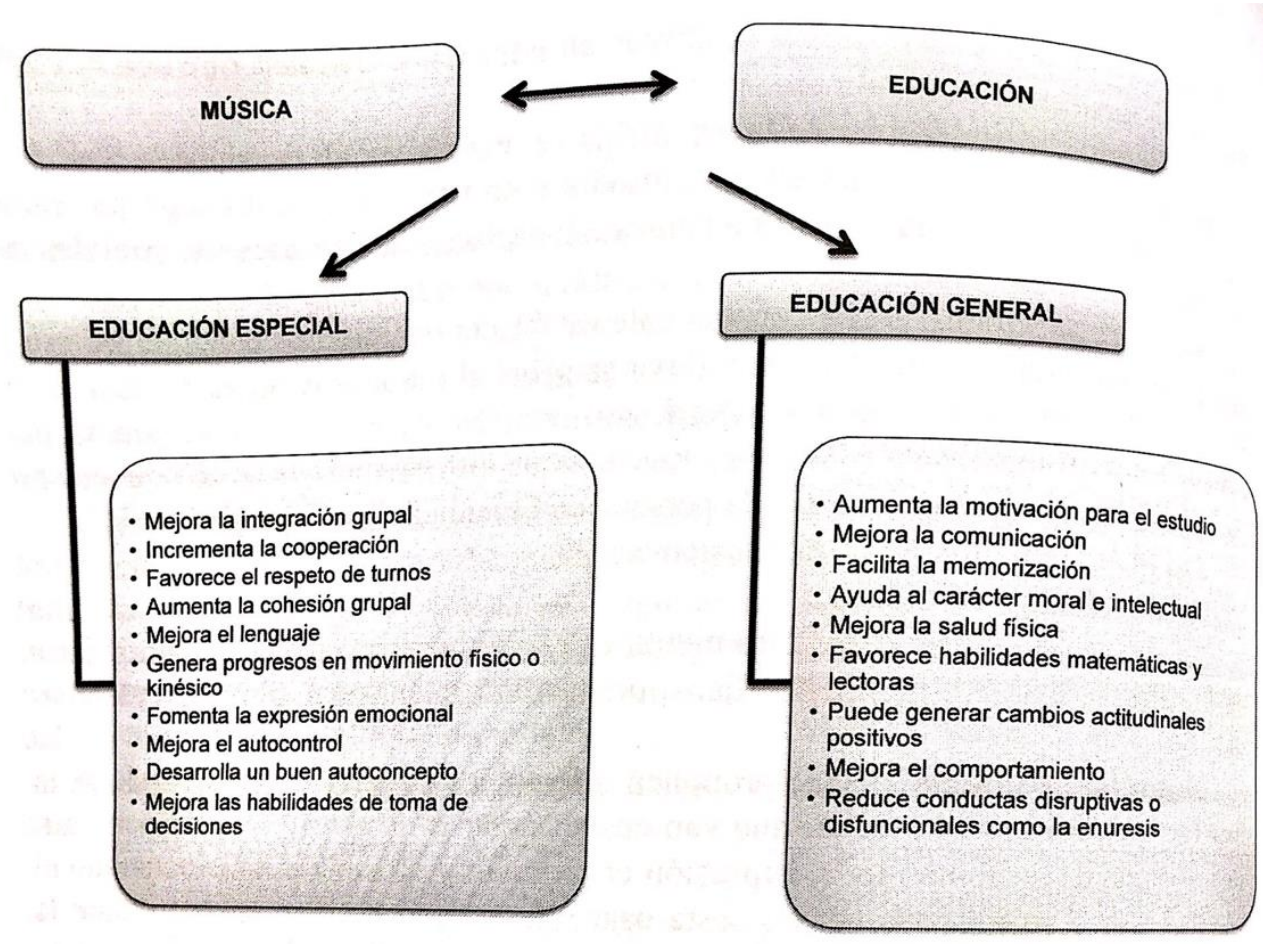

Figura 3. Beneficios de la música en educación. Fuente: Lucas (2013)

A la hora de hablar sobre los beneficios de la música en el desarrollo evolutivo es común pensar que estos están implícitos en la asignatura de música. Sin embargo, es necesario considerar que la labor del musicoterapeuta y, con ello, la función de la Musicoterapia, es muy distinta al trabajo de los maestros de música, es decir, al campo de la Educación Musical. La primera diferencia entre ambas disciplinas es que tanto la forma de trabajar como las técnicas empleadas van orientadas hacia objetivos muy distintos, en un caso educativos y en otro caso terapéuticos. Esto quiere decir que, aunque haya contenidos interdisciplinares, el musicoterapeuta no planteará, como objetivo primordial, enseñar conocimientos y destrezas musicales básicas, ni el maestro de música orientará el proceso de enseñanza-aprendizaje hacia fines terapéuticos, relacionados con la mejora de algún aspecto relacionado con la vida, la salud o la integración de los alumnos, en primera instancia. Otro aspecto que diferencia la Musicoterapia de la Educación Musical es que un maestro de música no actuará como musicoterapeuta, a no ser que tenga la formación necesaria y el contexto sea propicio para desarrollar ambas actividades de forma simultánea o paralela (Benenzon, 1971). Debido a que, como se ha explicado previamente, la Musicoterapia es una disciplina relativamente nueva, este sigue siendo un punto importante de reflexión y debate aún hoy en día y, por ello, es relevante remarcar esta diferenciación. 
No obstante, a menudo la finalidad de ambas disciplinas confluirá en un mismo punto en el que los objetivos sean muy similares, de tal forma que se estén trabajando aspectos comunes. De hecho, Bruscia (1996) clasifica cuatro prácticas educativas relacionadas con ambas perspectivas: "Educación Musical Especial", como una situación en la que un maestro de música emplea técnicas de adaptación para facilitar que los alumnos con necesidades sean partícipes del aprendizaje musical de una forma más significativa (p. 88), "música evolutiva", como el empleo de la música para promover el desarrollo de preescolares y niños sin necesidades especiales (p. 89), "Musicoterapia en Educación Especial”, en la que se persigue enseñar a niños con necesidades conocimiento y habilidades necesarias para la vida (p. 89) y "Musicoterapia evolutiva", orientada concretamente hacia objetivos clínicos que faciliten el crecimiento de niños cuyo desarrollo evolutivo se haya visto afectado en algún área (p. 91).

Así, se entiende que existen dos vías principales de intervención: la Musicoterapia aplicada al contexto de Educación general, de tal forma que actúe con todos los niños que asisten a un centro educativo, y la Musicoterapia aplicada al ámbito de la atención de las necesidades educativas especiales, es decir, que haga especial hincapié en aquellos alumnos cuyo desarrollo evolutivo y situación personal responda a una serie de características determinadas. Cuando se trata de la aplicación de actividades a través de la música y con fines terapéuticos dentro del contexto del aula, algunos de los beneficios que se pueden observar son el alivio del estrés y la tensión, la disminución de la actividad física, la relajación, el desarrollo de la imaginación y la creatividad y la obtención de sensaciones agradables en momentos de descanso (Grocke y Wigram, 2011). Igualmente, la presencia de Musicoterapia en la Educación repercute de forma positiva en el desarrollo emocional de los niños, así como a nivel físico y cognitivo. En cambio, cuando se trata del trabajo con necesidades educativas especiales se plantean otro tipo de objetivos, más concretos, individualizados y adaptados a las características de cada caso y a las necesidades que se presenten en el proceso.

\subsection{Musicoterapia y necesidades educativas especiales}

Recordemos que el alumnado con necesidades educativas especiales incluye a todos aquellos niños cuyo desarrollo evolutivo se haya visto limitado en alguna dimensión (física, cognitiva, emocional, etc.) dando lugar a algún tipo de trastorno o discapacidad, de tal modo que su situación educativa se vea afectada y se requiera de adaptaciones curriculares o algún tipo de apoyo educativo. En este contexto, la Musicoterapia puede ofrecer una respuesta de mejora ante las necesidades que se presentan en distintos casos relacionados con discapacidades, disfunciones, trastornos o deficiencias (Alvin, 1971). Se trata 
de uno de los ámbitos de intervención más explorados dentro del campo de la Musicoterapia desde el surgimiento de esta disciplina (Benenzon, 2011; Bruscia, 1996; Goodman, 2007; Martí, 2000; Nordoff \& Robbins, 1971; Lacárcel, 1990; Rodrigo, 2000; Wigram et al., 2011), y que se sigue desarrollando en la actualidad.

Hablando en términos generales, en las sesiones musicoterapéuticas en grupos de trabajo con niños con necesidades educativas especiales se establecen conexiones emocionales y personales a través de la música y distintos elementos que actúan como arquetipos sonoros, resultado de nuestra herencia ontogénica y filogénica, que todos los seres humanos percibimos de forma innata y que repercuten directamente en las reacciones psicofisiológicas, el movimiento corporal y las relaciones que establecemos con el entorno, nuestros semejantes y el ambiente en el que crecemos y nos presentamos como personas (Lacárcel, 2006). De esta forma, se producen momentos de interacción y comunicación que repercuten en el desarrollo de habilidades sociales y cognitivas, como la memoria y la atención (LaGasse, Manning, Crasta, Gavin, \& Davies, 2019), e igualmente en el trabajo de las capacidades sensoriomotrices como el hecho de caminar, la psicomotricidad fina, etc.

Algunos de los beneficios que aporta la presencia de Musicoterapia en el trabajo con necesidades educativas especiales (Poch, 2011):

- Ayuda en el diagnóstico clínico y psicopedagógico. El modo en que los niños responden y actúan frente a la música, cómo cantan, cómo bailan, de qué modo desarrollan su conducta en relación con los elementos sonoros y en situación grupal, etc. constituye información de gran valor para obtener un mejor conocimiento de sus capacidades y, por lo tanto, a la hora de realizar una evaluación psicopedagógica. Este tipo de información no se contempla en otros tipos de test, como por ejemplo los psicológicos.

- En torno a la música se genera una atmósfera afectiva que da pie al surgimiento de conexiones emocionales tales que permitan la libre expresión de emociones y el soporte socio-emocional que se necesita para hacer frente a la soledad, la incomprensión y la frustración que experimentan algunos niños. Este ambiente aporta una percepción del espacio como algo emotivo, acogedor y reconfortante.

- La danza, cuando sea posible su utilización en función de las características del grupo, igualmente crea un espacio de libre expresión a través del cual se permite y facilita la liberación de sentimientos, la comunicación e interacción a través del lenguaje no 
verbal, la reducción de la ansiedad, la relajación y la conexión personal entre los participantes de la sesión.

- Se promueve la ejercitación de habilidades cognitivas y la adquisición de conocimientos por medio de las sesiones musicoterapéuticas y el trabajo interdisciplinar de manera conjunta con otros profesionales del centro educativo donde se desarrolle el programa.

La estimulación de habilidades sociales, la generación de mayor conciencia de la identidad personal, la expresión y comprensión de emociones y el desarrollo del lenguaje, la coordinación, el esquema corporal y la bilateralidad son algunos de los objetivos musicoterapéuticos que se persiguen de forma general al trabajar con niños con NEE (Wigram et al., 2011). Recordemos que uno de los fundamentos de la intervención musicoterapéutica es el empleo del lenguaje no verbal como base sobre la cual se facilita la interacción entre las personas. De esta manera, en determinados casos, como en deficiencias que impiden o dificultan el empleo de la palabra, la Musicoterapia ofrece un espacio seguro y de confianza en el que prácticamente cualquier tipo de persona tiene la oportunidad de expresarse, ya sea por medio del movimiento físico, un instrumento musical o la voz. En la Tabla 10 quedan reflejados algunos de los casos en los que se ha demostrado la eficacia de la aplicación y el desarrollo de intervenciones basadas en Musicoterapia.

Tabla 10

\section{Musicoterapia para discapacidades o trastornos}

- Niños con afecciones de cromosomas o metabólicas innatas: Síndrome de Down, Síndrome de Williams, Síndrome de Asperger, Síndrome del X frágil, etc.

- Niños con autismo.

- Niños con retraso del desarrollo global y retraso mental.

- Niños con daños emocionales tempranos.

- Niños nacidos con dependencia a drogas y alcohol.

- Niños con trastornos de aprendizaje específicos.

- Niños con Déficits de Atención, Control Motor y de Per-

Musicoterapia cepción.

para... - - Niños con Trastorno por Déficit de Atención con Hiperactividad.

- Niños con función débil del cerebro izquierdo.

- Niños con daño cerebral: parálisis cerebral, espasticidad e incapacidad atetoide.

- Niños con deterioro auditivo.

- Niños con esclerosis tuberosa.

- Niños con problemas de comportamiento, comunicación, sociales o de atención (ningún diagnóstico en concreto).

- Niños hospitalizados por procedimientos quirúrgicos o enfermedades graves.

Fuente: Adaptado de Wigram et al. (2011, p. 185). 


\subsection{Musicoterapia y TDAH}

La Musicoterapia aplicada al TDAH no constituye un campo en el que la investigación se haya desarrollado tanto como para que la literatura científica al respecto sea abundante en la actualidad (Briseño, 2019). Algunos de los motivos de este hecho pueden ser que probablemente el perfil del musicoterapeuta e investigador no se da de tal manera que se aúne un conocimiento que permita desarrollar estudios rigurosos en este ámbito, o que en diversos contextos o instituciones se opte en primera instancia por invertir en otro tipo de intervenciones, principalmente las medidas farmacológicas, entre otros aspectos (Mateos y San Romualdo, 2012).

Uno de los primeros beneficios que puede ofrecer la música en caso de los niños diagnosticados de TDAH es que se trata de una motivación en sí misma, es decir, de un elemento que les ayuda a focalizar y mantener la atención en la tarea que se está desarrollando (Álvarez, 2004). Los estímulos sonoros que surjan en una improvisación, por ejemplo, pueden ser tan cambiantes y variables y sucederse de tal forma que se alcancen momentos extensos de atención sostenida por parte de un niño o grupo de niños con estas características. El hecho de que se vean envueltos en una actividad musical hace que se produzcan procesos de escucha activa y, con ello, que se mantenga la atención (Dewi, Rusmawati, \& Ratnaningsih, 2015) y se regularice el concepto de temporalidad, así como distintos procesamientos cognitivos (Benzon, 2009; Slater \& Tate, 2018).

Igualmente, el trabajo a nivel corporal, ya sea por medio de la dramatización, la danza o incluso la escucha receptiva o una instrumentación, facilita la canalización de la energía que este tipo de niños suelen presentar. Por ejemplo, el trabajo a través de técnicas receptivas de Musicoterapia aplicadas en el contexto educativo puede hacer que se disminuyan los niveles de ansiedad, tensión y estrés, que se mejore la concentración en el estudio y las tareas y que los niños diagnosticados de TDAH adquieran un mayor autoconocimiento que les ayude a alcanzar momentos de relajación (Grocke y Wigram, 2011; Llamas, 2014). A menudo el trabajo con música activa y de ritmo marcado, así como a través de experiencias vivenciales como los círculos de percusión o las improvisaciones, repercute de forma positiva en este colectivo porque responde a su necesidad de constante movimiento y ayuda a canalizarlo y regularlo. De hecho, a menudo se ven identificados en las actividades musicales porque ven reflejado su propio ritmo interno (Alonso y Bermell, 2008). 
En relación con ello, las conductas impulsivas son una respuesta o un reflejo del mundo interior en algunos casos diagnosticados de TDAH, por lo que pueden estar relacionadas con determinados tipos de sensaciones como la ansiedad, el miedo o la intranquilidad. Así, la capacidad de autorregulación suele estar relacionada con el estado emocional de los niños, y en este punto la Musicoterapia también contribuye de forma positiva (Rickson, 2006). Además, esta capacidad de autorregulación mejora de forma sustancial cuando se trabaja con actividades de un fuerte sentido rítmico (García-Huidobro, 2015). Mediante el trabajo con la música y, especialmente, el ritmo, se puede ejercitar la conciencia temporal, la coordinación y, con ello, la autorregulación a nivel conductual (Wiebe, 2007). De igual modo, el control de la impulsividad se puede trabajar por medio de actividades que requieran una demora entre un estímulo externo y la respuesta por parte de los niños, como por ejemplo en el caso de los ecos rítmicos (Acebes-de Pablo y Carabias-Galindo, 2016).

Por otra parte, tal y como se ha explicado previamente en diversos puntos, las sesiones grupales de Musicoterapia constituyen un espacio de libre expresión en el que cada persona se siente escuchada, puede presentarse y comportarse con naturalidad, sinceridad y honestidad, por lo que se trata de una vía idónea por medio de la cual se pueden trabajar objetivos como la cohesión grupal, las relaciones, la aceptación y la confianza. Igualmente, el tratamiento musicoterapéutico en sesiones individuales ayuda a corregir conductas disruptivas y agresivas, así como a desarrollar habilidades sociales y fortalecer la gestión emocional, lo que repercutirá positivamente en la forma en que los niños diagnosticados de TDAH se relacionan en su entorno, tanto con sus compañeros como con sus padres y profesores (Peñalba, 2010).

Como se puede apreciar, las técnicas de intervención que se pueden aplicar en casos de TDAH es muy variada: improvisaciones, trabajo a nivel corporal, música y movimiento, danza, instrumentaciones, escucha activa, métodos receptivos, etc. En la Tabla 11 se recogen algunos de los métodos empleados en el ámbito del trabajo con Musicoterapia y TDAH a partir de una investigación en la que se recogió un cuestionario entre un total de 268 musicoterapeutas estadounidenses. 
Tabla 11

Métodos de Musicoterapia empleados en el tratamiento del TDAH

\begin{tabular}{lcc}
\multicolumn{1}{c}{ Método } & $\begin{array}{c}\text { Número de } \\
\text { respuestas }\end{array}$ & Porcentaje \\
\hline Música y movimiento & 73 & $74 \%$ \\
Improvisación instrumental & 66 & $67 \%$ \\
Tocar música & 62 & $63 \%$ \\
Canto en grupo & 54 & $55 \%$ \\
Aprendizaje musical & 46 & $47 \%$ \\
Otras artes creativas & 35 & $36 \%$ \\
Relajación asistida por música & 31 & $32 \%$ \\
Improvisación vocal & 22 & $22 \%$ \\
Enfoque en Educación Musical & 17 & $17 \%$ \\
Método Orff & 16 & $16 \%$ \\
Nordoff-Robbins & 5 & $5 \%$ \\
Aprendizaje vocal & 5 & $5 \%$ \\
Otros & 22 & $22 \%$
\end{tabular}

Fuente: Adaptado de Jackson (2003, p. 307).

Dicho lo cual, algunos de los contenidos que se pueden desarrollar y trabajar a través de las sesiones de Musicoterapia en casos diagnosticados de TDAH desde un punto de vista sensorio-motriz son la regulación del cuerpo a través de la música, el aumento de la conciencia corporal, el control del movimiento corporal, la coordinación entre cuerpo y ritmo y el empleo del cuerpo como forma de expresión. Dentro del área cognitiva, la atención focalizada ante un estímulo externo, el mantenimiento de la atención sostenida durante periodos de tiempo adaptables, el desarrollo de la capacidad de evocación, el aumento del tiempo de espera (lo que conlleva control de conductas impulsivas), el desarrollo de la comunicación oral, la identificación, localización y selección de distintos estímulos sonoros, la asociación de estímulos sonoros con su referente visual, el desarrollo del lenguaje y el establecimiento de turnos comunicativos. Por último, en la dimensión socio-emocional se puede trabajar la identificación y expresión de emociones básicas, la regulación y gestión emocional, la generación de demanda espontánea, la aceptación de límites, la participación en círculos comunicacionales, el reconocimiento de las emociones en los demás y el establecimiento y/o mantenimiento de contacto visual y corporal. 

CAPÍTULO IV. CARACTERÍSTICAS DE LA INTERVENCIÓN MUSICOTERAPÉUTICA: TÉCNICAS DE MÚSICA E IMAGEN (MI) 

El método empleado para la intervención realizada durante el trabajo de campo de este estudio parte de los principios del BMGIM y se fundamenta, asimismo, en el empleo de algunas de sus técnicas psicoterapéuticas, la utilización del mandala como medio de expresión y de algunas de las piezas musicales seleccionadas por su creadora, la Dra. Helen L. Bonny, en el surgimiento del modelo en su forma original. Sin embargo, dadas las características específicas del colectivo con el que se trabajó (niños de entre 7 y 11 años con y sin diagnóstico de TDAH) habría sido poco fructuoso aplicar el modelo en su formato original debido a la larga duración y la complejidad de las sesiones, como a continuación explicaremos. Por tanto, ya que se consideró necesario realizar adaptaciones del BMGIM, este capítulo trata de servir como justificación y aclaración de las diferentes perspectivas, adaptaciones y formas de intervención que han sido desarrolladas a raíz de la investigación y exploración del modelo en su forma original para, a raíz de ello como forma de justificación, finalmente dar lugar a la explicación y descripción del método resultante y que fue empleado para la intervención durante el desarrollo del trabajo de campo.

\section{FUNDAMENTACIÓN DEL MÉTODO DE MUSICOTERAPIA EMPLEADO PARA LA INTERVENCIÓN}

\subsection{Adaptaciones del BMGIM}

Como hemos visto previamente, en su forma original el BMGIM constituye uno de los cinco modelos de intervención musicoterapéutica reconocidos a nivel mundial, el cual se desarrolla en un entorno privado y en situación de terapia individual. Recordemos que la sesión tiene de media noventa minutos de duración, los cuales se distribuyen en cuatro momentos: la pre-sesión (conversación inicial entre el terapeuta y el paciente, orientada al establecimiento de un foco para la sesión), la inducción (relajación e inicio del trabajo a nivel interno), el viaje o experiencia musical (trabajo psicoterapéutico a nivel profundo mientras se reproduce la sucesión de piezas musicales escogida) y la post-sesión (en la que se dibuja un mandala y se produce una conversación entre terapeuta y paciente orientada a la integración y cierre de lo acontecido durante la sesión).

Sin embargo, a pesar de que esta es la estructura original del modelo y, con ello, la principal forma en que es aplicado, el constante surgimiento de necesidades específicas por parte de distintas poblaciones con las que se trabaja a través de la Musicoterapia ha ido dando lugar al diseño de adaptaciones del 
BMGIM para posibilitar su aplicación en contextos y situaciones muy dispares, como el tratamiento de adultos con trastornos mentales de distinta índole, situaciones traumáticas, ansiedad, depresión, adicciones, contextos hospitalarios, etc., así como el trabajo con niños y adolescentes con necesidades emocionales concretas u otros problemas (de adaptación, riesgo de exclusión social, etc.) (Muller, 2014). De hecho, cualquier tipo de adaptación del modelo original, en la que se conserve el trabajo a través de la imaginación y estados no ordinarios de la conciencia, ha pasado a ser designada como técnicas de Imagen Guiada con Música - de ahora en adelante GIM, por sus siglas en inglés, Guided Imagery and Music - siendo la expresión BMGIM empleada solo para referirse al modelo en su forma de aplicación original (Bruscia, 2002).

Por otra parte, la definición de música e imagen (music and imagery) surge para referirse al empleo de la música como soporte receptivo en un trabajo a través de estados ordinarios de conciencia (Summer, 2010). A través de esta técnica se emplea una única pieza de música, o una sucesión breve de piezas musicales, con el objetivo de proporcionar un soporte emocional en el proceso terapéutico de la persona. Debido a que se trabaja en estados ordinarios de conciencia, el proceso psicológico es menos profundo y, a veces, menos invasivo, por lo que se recomienda para casos en los que la persona no está preparada para profundizar de forma intensa en su proceso terapéutico.

De hecho, dentro de las adaptaciones del BMGIM se distinguen distintos niveles de intervención en función de la implicación emocional para el cliente, de las técnicas empleadas y la música seleccionada: nivel de apoyo (en el que se comienza a trabajar de forma introductoria y no invasiva, dando soporte e identificando recursos internos que faciliten el inicio del proceso terapéutico), nivel intenso o reeducativo (cuando la persona está preparada para crear cambios a través de su mundo interior) y nivel reconstructivo (cuando se llega a un punto de estabilidad emocional que permite enfocar los problemas y tomar decisiones con serenidad) (Muller, 2014). En este sentido, las técnicas de música e imagen se incluyen en el nivel de apoyo y, por cómo son desarrolladas, se puede considerar que establecen el límite entre el GIM y otro tipo de técnicas empleadas en el ámbito de la Musicoterapia receptiva (Muller, 2014; Summer, 2010).

El desarrollo de adaptaciones del BMGIM ha dado lugar a la consolidación de algunas técnicas de intervención específicas y aplicables en distintos contextos y situaciones, como la Relajación de Música e Imagen - MIR, por sus siglas en inglés, Music Imagery Relaxation - cuyo objetivo es lograr que el paciente se sienta en un espacio de confort y seguridad que le permita afrontar una situación delicada (como puede ser, por ejemplo, una operación) con 
cierta serenidad y tranquilidad, y el Viaje de Música e Imagen - MIJ, por sus siglas en inglés, Music Imagery Journey - que consiste en la estimulación de la imaginación a través del empleo de técnicas de GIM con el objetivo de encontrar recursos internos que ayuden a sobrellevar situaciones de estrés (Gimeno, 2015). En la Tabla 12 pueden apreciarse las diferencias entre estas dos técnicas y la forma del modelo original (BMGIM).

\section{Tabla 12}

Distinciones entre el Modelo Bonny de Imagen Guiada con Música (BMGIM) y las técnicas Relajación de Música e Imagen (MIR) y Viaje de Música e Imagen (MIJ)

\begin{tabular}{|c|c|c|c|}
\hline Elements & Bonny Method of GIM & MIJ & MIR \\
\hline Purpose & Self-exploration & Self-exploration & To quiet the mind \\
\hline $\begin{array}{l}\text { Type of } \\
\text { therapy }\end{array}$ & Re-constructive & $\begin{array}{l}\text { Supportive and re-edu- } \\
\text { cative }\end{array}$ & Supportive \\
\hline Positioning & $\begin{array}{l}\text { Lying down with eyes } \\
\text { closed }\end{array}$ & $\begin{array}{l}\text { Lying down or sitting } \\
\text { on a couch with eyes } \\
\text { closed or open }\end{array}$ & $\begin{array}{l}\text { Lying down with } \\
\text { eyes closed or } \\
\text { open }\end{array}$ \\
\hline Prelude & Preliminary conversation & $\begin{array}{l}\text { Preliminary conversa- } \\
\text { tion finding focus for } \\
\text { the session }\end{array}$ & $\begin{array}{l}\text { Creating rapport to } \\
\text { find keywords of } \\
\text { the patient's expe- } \\
\text { rience of well-be- } \\
\text { ing/relaxation }\end{array}$ \\
\hline Induction & $\begin{array}{l}\text { Brief relaxation; finding } \\
\text { an image as the focus }\end{array}$ & $\begin{array}{l}\text { Brief relaxation; find- } \\
\text { ing an image as the fo- } \\
\text { cus with a positive out- } \\
\text { come }\end{array}$ & $\begin{array}{l}\text { Spoken with music } \\
\text { that contains the } \\
\text { patient's experi- } \\
\text { ence of well-be- } \\
\text { ing/relaxation }\end{array}$ \\
\hline $\begin{array}{l}\text { Music } \\
\text { listening }\end{array}$ & $\begin{array}{l}\text { Dialogue between pa- } \\
\text { tient and Bonny Method } \\
\text { practitioner }\end{array}$ & $\begin{array}{l}\text { Dialogue between pa- } \\
\text { tient and Bonny } \\
\text { Method practitioner }\end{array}$ & $\begin{array}{l}\text { Music is played at } \\
\text { the same time as } \\
\text { the induction is } \\
\text { given }\end{array}$ \\
\hline $\begin{array}{l}\text { Music } \\
\text { genre }\end{array}$ & $\begin{array}{l}\text { Mostly classical, includ- } \\
\text { ing Helen Bonny pro- } \\
\text { grams }\end{array}$ & $\begin{array}{l}\text { Patient preferences: } \\
\text { New Age, soundtrack, } \\
\text { light jazz, classical }\end{array}$ & $\begin{array}{l}\text { Patient prefer- } \\
\text { ences: New Age, } \\
\text { light jazz, classical }\end{array}$ \\
\hline $\begin{array}{l}\text { Music } \\
\text { length }\end{array}$ & $30-45$ minutes & $10-15$ minutes & $5-10$ minutes \\
\hline Postlude & $\begin{array}{l}\text { Review of imagery expe- } \\
\text { riences; exploration of } \\
\text { how the imagery relates } \\
\text { to client-stated focus of } \\
\text { the session; client draws } \\
\text { parallels and meaning } \\
\text { from imagery }\end{array}$ & $\begin{array}{l}\text { Session is processed } \\
\text { though supportive ther- } \\
\text { apy, validating feelings } \\
\text { and reinforcing positive } \\
\text { experience; "anchor" } \\
\text { must be clear and con- } \\
\text { nected for the client to } \\
\text { relax }\end{array}$ & $\begin{array}{l}\text { No process of re- } \\
\text { flection if the pa- } \\
\text { tient falls asleep; } \\
\text { when awake, check } \\
\text { how the experience } \\
\text { was }\end{array}$ \\
\hline Mandala & Yes & No & No \\
\hline $\begin{array}{l}\text { Practitioner } \\
\text { training }\end{array}$ & $\begin{array}{l}\text { Bonny Method GIM } \\
\text { trained }\end{array}$ & $\begin{array}{l}\text { Bonny Method GIM } \\
\text { trained }\end{array}$ & Music Therapist \\
\hline
\end{tabular}

Fuente: Gimeno (2015, pp. 179-180). 
Además de las adaptaciones diseñadas con el objetivo de adecuar la experiencia musical y terapéutica a las necesidades individuales de los pacientes, otro tipo de cambios efectuados por el musicoterapeuta pueden ir orientados a adaptar las sesiones al número de personas que participan en la situación de terapia. Es el caso de la técnica de Música e Imagen Grupal - GrpMI por sus siglas en inglés, Group Music and Imagery - en la que las imágenes son autogeneradas en el interior de los participantes de una sesión al tiempo que escuchan la música (Grocke y Wigram, 2011). Este tipo de sesiones suelen ser llevadas a cabo en grupos de pacientes con ciertos objetivos terapéuticos en común, o cuyos temas a trabajar guarden relación anímica o emocional, y siguen un esquema organizacional similar al de la estructura original de BMGIM, aunque adaptado al tiempo del que se dispone y a la situación grupal (March-Luján, 2017). En este caso, el musicoterapeuta mantiene un diálogo inicial con los participantes con el objetivo de identificar un foco u objetivo común. Una vez ha hecho eso, facilita una relajación o inducción para todo el grupo y, a continuación, reproduce un programa musical no muy extenso (entre 10 y 20 minutos) durante el cual los pacientes desarrollan su proceso a través del viaje musical y su propia imaginación. Después pueden dibujar un mandala y compartir su experiencia con el resto del grupo y el musicoterapeuta. En este tipo de sesión se puede actuar en los tres niveles de intervención planteados previamente (de apoyo, reeducativo o reconstructivo) en función de las necesidades del grupo de pacientes (Hertrampf, 2015).

Algunas adaptaciones se fueron diseñando con el objetivo de adecuar la forma y características del modelo a las circunstancias y necesidades de la población objeto de terapia, de modo que pueden ir orientadas a la modificación de la duración de alguna de las partes de la sesión (inducción, experiencia musical, conversación) y en función del número de personas a las que van dirigidas (formato individual o grupal). Así, han sido desarrolladas adaptaciones de diversos tipos en determinados trastornos físicos (Wigle-Justice \& Kasayka, 1999), para contextos hospitalarios, en concreto para enfermos oncológicos (Gerge, Pedersen, Gattino \& Wärja, 2020; Gimeno, 2010), personas con fibromialgia (Torres, 2015) e incluso para grupos de pacientes con enfermedad inflamatoria intestinal (March-Luján, 2017). Igualmente, en geriatría (Short, 2007) y para contextos psiquiátricos, en casos de depresión severa (Summer, 2010) y autismo (Clarkson, 1995). También se han desarrollado adaptaciones específicas en el tratamiento psicoterapéutico de veteranos de guerra (Blake, 1994) y adultos refugiados (Beck et al., 2018), en ambos casos diagnosticados con trastorno de estrés postraumático, para músicos con daño cerebral (Cohen, 2015) y para casos de refuerzo de la cohesión grupal y crecimiento personal (Pehk, 2015), entre otras. 


\subsubsection{Aplicación de GIM en niños}

Al igual que en otro tipo de poblaciones, el BMGIM ha sido adaptado de forma específica al trabajo con niños y adolescentes, en función de distintas necesidades y características propias del colectivo, y principalmente en dos direcciones: en relación con la duración de la sesión y de la música, y en lo referido a la selección y el modo de empleo de las piezas musicales (Muller 2014).

En casos de niños de entre seis y diez años de edad pertenecientes a un contexto psiquiátrico, la duración de las sesiones puede ser considerada entre veinte y treinta minutos, con una experiencia musical de entre cinco y diez minutos de duración (Wesley, 2002). Como se ha indicado previamente, la disminución de la duración de la sesión hace que se disminuya igualmente la expansión y exploración de la conciencia y, con ello, la profundidad del trabajo psicológico, pero en algunos casos, por las características de los niños, es necesario que este trabajo sea más superficial y menos invasivo o menos intenso. Roy (1996), por su parte, desarrolló sesiones grupales de GIM de aproximadamente una duración de cuarenta minutos, con una experiencia musical de entre cinco y veinte minutos, en una clase de educación secundaria femenina.

La disminución de la duración de la experiencia musical facilita el mantenimiento de la atención y relativiza la intensidad del trabajo a nivel psicológico. Además, el uso de determinadas piezas de música clásica o académica de forma individual puede servir para dar soporte y seguridad, y contener así momentos delicados de un proceso terapéutico (Skaggs, 1997). Este tipo de música puede ayudar a reforzar la autoestima, estimular la creatividad, disminuir el estrés, despertar e intensificar sentimientos internos cuando sea necesario (Roy, 1996) o producir momentos de relajación y mayor autoconciencia en casos de niños escolarizados en la etapa de Educación Primaria (Powell, 2007). Bonny y Savary (1994) también desarrollaron adaptaciones de BMGIM para niños y adolescentes de acogida y señalaron que el empleo de música académica puede ayudar a solidificar la conciencia y la percepción de la realidad y, con ello, el autoconcepto y el sentimiento de pertenencia a un grupo.

A través de una combinación entre improvisación musical y GIM, Vilá (2015) describe cómo se desarrolló el mundo interior a nivel emocional y cognitivo de una niña de once años con problemas académicos y motivacionales, al tiempo que mejoraba la relación social con su entorno, especialmente con su familia, al cabo de catorce sesiones. Esta adaptación, cuyas sesiones tenían una duración de 45 minutos, consistía en establecer un diálogo inicial a través 
del cual se establecía un foco sobre el que trabajar, un momento de improvisación libre relacionada con el foco de la sesión y el estado emocional de la niña, una inducción breve, una experiencia musical receptiva (de unos 10-15 minutos de duración) y una post-sesión con realización de mandala para integrar lo ocurrido. Como vemos, la sesión sigue la estructura y orientación teórica del BMGIM en su forma original, pero varía en cuanto a la duración y por el hecho de que se incluye una parte de improvisación, y esto es por lo que esta intervención es considerada una adaptación, es decir, una técnica de GIM.

Por su parte, Fugle (2015) relata cómo una adaptación de BMGIM puede ayudar a niños que han vivido experiencias traumáticas, favoreciendo la expresión emocional y la capacidad de relajación y de autorregulación a través de experiencias musicales alegres y constructivas. En este caso se propone el empleo no solo de música académica, sino también de música étnica, jazz y música pop, a través de una sesión que consta de tres partes: una inducción, un viaje o experiencia musical breve y el dibujo de un mandala. Además, se especifica que durante la realización del mandala es posible que se siga reproduciendo una pieza musical que ayude a los niños a integrar la experiencia o a relacionarla con el dibujo que están haciendo. En todo momento se tiene en cuenta que la música dé un soporte que permita que el trabajo terapéutico se realice en un nivel de seguridad y confianza adecuado.

En relación con ello, Kang (2017) demuestra cómo las técnicas de música e imagen, como intervención de soporte en un caso de niños testigos de violencia doméstica, repercuten de forma positiva en el desarrollo de la capacidad de expresión y gestión emocional. Una vez más vemos cómo la influencia teórica del modelo original se adapta a las características y necesidades del contexto.

\subsection{Delimitación entre GIM y otras técnicas de Musicoterapia receptiva}

Como se ha explicado previamente, la Musicoterapia receptiva abarca todo tipo de técnicas de intervención en las que los usuarios de las sesiones no participan de forma activa en la experiencia musical (improvisación, composición de canciones, etc.) sino que reciben la música en su cuerpo con distintos objetivos terapéuticos: búsqueda de calma y relajación, gestión emocional, exploración del inconsciente, desarrollo de la imaginación y la creatividad, etc. Debido a ello, y dada la similitud entre el GIM y algunas técnicas de intervención receptivas, en las que los participantes se limitan a escuchar música, resulta relevante, e incluso necesario, explicar las diferencias entre ambas perspectivas, es decir, señalar dónde están los límites entre las adaptacio- 
nes del BMGIM (GIM), el concepto de música e imagen y otras técnicas propias del ámbito de la Musicoterapia receptiva. Bruscia (1996) define esta última de la siguiente manera:

En las experiencias receptivas, el cliente escucha música y responde a la experiencia silenciosamente, verbalmente o de otro modo. La música usada puede ser una improvisación en vivo o grabada, o interpretaciones o composiciones del cliente o el terapeuta, o bien grabaciones comerciales de música, comprendiendo varios estilos (clásica, rock, jazz, country, espiritual, new age). La experiencia auditiva puede enfocarse a los aspectos físicos, emocionales, intelectuales, estéticos o espirituales de la música; y las respuestas del cliente se diseñan según el objetivo terapéutico de la experiencia. (Bruscia, 1996, pp. 120-121)

Dicho lo cual, la principal diferencia que se ha de considerar entre estas dos aproximaciones es la forma en la que trabaja la persona que realiza la sesión. Una de las consignas que define el trabajo de GIM es que la persona esté desarrollando el proceso terapéutico a través de un estado no ordinario de conciencia, es decir, desde un estado de relajación, con los ojos cerrados y centrando la atención en su mundo interior (Muller, 2014; Summer, 2010), mientras que en algunas técnicas de Musicoterapia receptiva, como la audición activa de improvisaciones grabadas, o la reminiscencia a través de la audición, la reflexión y el debate, es más probable que la persona esté trabajando por medio de un estado ordinario de conciencia (Grocke y Wigram, 2011).

En lo que se refiere a la selección de la música, debido a la orientación filosófica y teórica del BMGIM, lo más común es que en GIM se emplee música académica, e incluso adaptaciones de los programas musicales originales del modelo, mientras que en casos en los que se empleen técnicas de Musicoterapia receptiva es más probable que se dé un uso más amplio de estilos musicales. Igualmente, muchas adaptaciones de BMGIM han ido incorporando distintos tipos de música en función de las necesidades que van presentando los participantes. Por ejemplo, en la adaptación de Fugle (2015), orientada a niños que han vivido experiencias traumáticas, introduce el empleo de música jazz, étnica y new age.

Dentro de este contexto, las técnicas de música e imagen establecen el límite entre las adaptaciones de BMGIM y otro tipo de intervenciones propias del ámbito de la Musicoterapia receptiva (Muller, 2014; Summer, 2010). Esto se debe a que, hablando en términos generales, en las experiencias de música e 
imagen el trabajo psicológico suele producirse a través de estados ordinarios de conciencia, pero se trata de una técnica de intervención que se encuentra directamente influenciada por los principios y la filosofía del modelo original $\mathrm{y}$, por tanto, puede conservar las selecciones musicales originales, algunas técnicas psicoterapéuticas propias del modelo, el momento de realización del mandala, etc.

\subsection{Música, emociones y estados de ánimo}

Una de las premisas básicas tanto del BMGIM, como de sus adaptaciones (GIM), y de las técnicas de música e imagen, es la repercusión e impacto que tiene la música a nivel emocional en las personas y, más aún, en relación con la función que pueden desempeñar determinados tipos de música como apoyo en momentos concretos de un proceso terapéutico. De hecho, esta función que encontramos en la música, unida al trabajo por medio de estados no ordinarios de conciencia, fue una de las primeras consideraciones que inspiraron a la Dra. Helen L. Bonny al comienzo del planteamiento del modelo. En otras palabras, ella se preguntó cómo la música podía ser empleada para facilitar el trabajo profundo a nivel emocional a través de estados no ordinarios de conciencia y por medio de procesos psicoterapéuticos de reflexión, autoconocimiento e introspección orientados al desarrollo del mundo interior de las personas.

La relación entre la música y las emociones en el ser humano es un tema que lleva suscitando el interés de gran parte de la comunidad científica durante décadas, hasta el punto de que a lo largo del siglo XX han sido varios los estudios que se han dedicado a tratar de clasificar diversos tipos o estilos de música en función de las distintas emociones o sentimientos que pueden producir, desde sus comienzos (Myers, 1922) hasta su final (Leblanc, 1987), obteniendo resultados muy variables y de los cuales resultaba difícil extraer generalizaciones (Blasco y Sanjosé, 2000). Esto se debe a que las reacciones emocionales que pueda tener un ser humano ante una pieza o experiencia musical dependen en cierta o gran medida de su historia personal y de las circunstancias que esté viviendo en ese momento, entre otros aspectos.

En su origen, los primeros programas que fueron diseñados estaban orientados al trabajo de situaciones o procesos emocionales concretos, y esta concepción se ha mantenido a lo largo de los últimos años durante el proceso de desarrollo y evolución que el BMGIM ha experimentado, tanto en forma como en contenido. Así, los programas musicales principales del modelo están elaborados con el objetivo de trabajar aspectos emocionales y terapéuticos concretos, como por ejemplo procesos de duelo, experiencias traumáticas (a 
veces relacionadas con la infancia y con el cuidado del niño interior), determinados puntos de inflexión trascendentales en la vida de la persona, momentos de pérdida de la identidad personal, indecisión o frustración, etc.

Por su parte, Bruscia (1998), en su trayectoria como musicoterapeuta, formador y terapeuta especializado en BMGIM, publicó una recopilación de obras musicales cuidadosamente seleccionadas y organizadas en diferentes discos en función de las emociones, sensaciones, sentimientos o estados de ánimo que generaban en las personas. En esta clasificación se pueden apreciar los distintos tipos de selecciones musicales individuales organizadas en discos (Bruscia, 1998):

- Música imaginativa (Imaginative $C D$ ), que incluye aquellas piezas sugerentes, que favorecen los procesos de surgimiento de imágenes, especialmente visuales, aunque también olfativas, corporales, etc. e, incluso, la aparición de recuerdos emergentes.

- Música de apoyo (Supportive CD), que engloba obras de forma y carácter gentil, agradables al oído, que ofrecen un soporte al oyente, y que son empleadas, como su propia definición indica, cuando una persona necesita recuperar soporte, apoyo o cierta seguridad, en un momento delicado de su proceso terapéutico.

- Música creativa (Creative $C D$ ) que, de forma similar a cómo actúa la música imaginativa, favorece los procesos mentales relacionados con la imaginación, con el surgimiento y desarrollo de ideas, es decir, con la capacidad creativa del ser humano.

- Música emotiva (Emotive CD), seleccionada con la intención de evocar en los oyentes distintos tipos de emociones y sentimientos, es decir, de favorecer una respuesta emocional, más específica o más arbitraria, en función de las circunstancias personales de quien se encuentra en medio de un proceso terapéutico.

- Música de exploración (Explorative CD), que es aquella que invita a la persona a ir más allá de la superficie del pensamiento cognitivo, es decir, a profundizar en el conocimiento de uno mismo a través del camino que lleva hacia el acercamiento, descubrimiento, confrontación y resolución de conflictos internos inconscientes. 
- Música positiva (Positive CD) que, en ocasiones de forma similar a la música de soporte, se emplea para generar sensaciones positivas en la persona, especialmente cuando se considera que esto es algo necesario para continuar con el proceso terapéutico. En ocasiones puede ser también música agradable, con gran carga emocional, pero orientada hacia sentimientos relacionados con la alegría, la belleza, el agradecimiento, etc.

- Música lastimera (Plaintive $C D$ ), cuya traducción literal se puede tornar o considerar un tanto enrevesada, pero que, al mismo tiempo, representa con bastante acierto la función e intención que tiene de cara a un proceso terapéutico. Se trata de aquella música que despierta en los seres humanos sensaciones devastadoras y emociones como el dolor, la tristeza o el desasosiego, tan presentes en el trabajo a nivel psicoterapéutico con procesos de duelo, trauma infantil o el resultado de otro tipo de eventos traumáticos como desastres naturales, guerras, etc.

- Música "de transporte" (Transportive CD). En esta ocasión, la traducción de este grupo de selecciones musicales también puede resultar extraña. Sin embargo, si consideramos lo que esta música produce en el oyente, su definición cobra sentido. Aquí se incluyen piezas evocadoras que nos llevan, en el plano imaginativo, a otros lugares, a escenarios peculiares, lugares fantásticos, escenas mitológicas o incluso a recuerdos de nuestra infancia o de cualquier otro momento vital de nuestro pasado. En este nivel de trabajo se pueden establecer, igualmente, conexiones arquetípicas. De ahí el nombre, se podría traducir incluso como "música que nos transporta", o música evocadora, que aporta más sentido en relación con su función.

- Música regenerativa (Regenerative $C D$ ) cobra protagonismo en aquellos momentos de un proceso terapéutico donde la persona está trabajando a nivel profundo, empleando un gran esfuerzo mental y emocional y, con ello, surge la necesidad de reconstruirse, recomponerse o resurgir, a nivel metafórico. En este sentido, se podría considerar también como una música grande e intensa, que, al tiempo que ayuda a explorar y confrontar sentimientos complicados, nutre a nivel emocional y corporal. 
- Música activa (Active $C D$ ), que hace que la persona conecte con emociones más activas, que demandan mayor implicación, seguridad, fuerza y energía a nivel corporal, cuando así lo requiera el proceso terapéutico. Corresponde con momentos en los que surge la necesidad de confrontar situaciones que despiertan enfado, odio, rencor o aprensión, en función del caso y de las circunstancias.

Igualmente, y como se ha indicado previamente, la vertiente del BMGIM se ha ido desarrollando a lo largo de los años, lo que ha dado lugar al diseño de nuevos programas cuyos objetivos siguen siendo trabajar situaciones emocionales concretas. La creación de nuevos programas musicales se ha ido sucediendo para dar respuesta a las necesidades emocionales que han ido emergiendo junto con el desarrollo de la sociedad en la que vivimos. Por ejemplo, un aspecto que se consideró en el año 2002, y que no había sido atendido hasta este momento, es el trabajo a nivel profundo con la paradoja, como concepto abstracto y recurso psicoterapéutico, relacionado con el reconocimiento y gestión de las sombras interiores, la dualidad entre el sufrimiento y el bienestar y, en definitiva, con el proceso de individuación del ser humano (Stokes-Stearns, 2014). Por su parte, Bruscia (2014) ha desarrollado, por medio de la investigación y la evaluación, otra serie de programas relacionados con conceptos arquetípicos específicos, como la relación con la masculinidad y la feminidad, entre otros aspectos.

Teniendo en cuenta los programas musicales originales del BMGIM, creados por la Dra. Helen L. Bonny, así como las aportaciones de Bruscia (1998, 2014), Stokes-Stearns (2014) y la propia experiencia y aprendizaje del investigador principal, las selecciones musicales empleadas en el método empleado durante el desarrollo de la intervención fueron organizadas en torno a seis estados anímicos o sensaciones concretas de cara a la situación y los objetivos de cada sesión:

- Música de introducción y exploración a nivel interno. La música introductoria abre posibilidades ante la mente e imaginación de quienes la escuchan. Puede ayudar a realizar preguntas a nivel interno, a plantear imágenes determinadas e incluso, en algunos casos, a evocar imágenes retrospectivas o recuerdos. Se suele emplear en las primeras sesiones, sobre todo en casos en los que el participante no tiene claro qué objetivo quiere trabajar o con qué tipo de emociones necesita conectar. En este sentido, la música de 
introducción y exploración favorece el planteamiento de interrogantes a nivel interno, así como distintos tipos de conexiones a nivel emocional. Es una forma de tener un primer acercamiento hacia las experiencias de música e imagen y, por tanto, se suele tratar de selecciones musicales que carecen de tensión y que no tienen mucha carga emocional.

- Música positiva o de soporte. Como su propio nombre indica, se trata de un tipo de música que produce sensaciones de bienestar, tranquilidad o estabilidad, no solo a nivel emocional sino también a nivel físico y psicodinámico. Es necesario emplear música de este carácter en determinados momentos de un proceso terapéutico, especialmente cuando la persona está atravesando un momento complicado o durante el cual su nivel anímico o de energía le impide encontrar fuerzas para continuar con el proceso. También se trata de la música más empleada en la técnica de música e imagen, ya que actúa principalmente en el nivel de apoyo al trabajar con personas cuyo proceso no puede ser desarrollado a nivel intenso o profundo, como es el caso de determinadas enfermedades mentales (esquizofrenia, psicosis), personas con salud delicada (cáncer, fibromialgia), niños expuestos a experiencias traumáticas o episodios de abuso, etc.

- Música para trabajar con la tristeza. Se trata de piezas musicales que favorecen la conexión a nivel interno con emociones profundas y delicadas, como pueden ser la tristeza, el dolor, la pena o la desazón. Se emplean en momentos en los que la persona necesita afrontar circunstancias dolorosas del pasado o de la situación presente, con el objetivo de facilitar la expresión emocional y la liberación de este tipo de sentimientos que, en determinadas ocasiones y en función de cómo se den las circunstancias, pueden ser reprimidos, lo cual suele derivar en situaciones de dificultad para la gestión emocional. Dicho lo cual, estas selecciones musicales son intencionadamente de carácter profundo, melancólico e incluso desalentador, en algunos casos. 
- Música para trabajar con el miedo y/o la indefensión. La música que ayuda a establecer conexiones con estas emociones es aquella que produce incertidumbre y cuyo carácter es oscuro e incierto, de tal forma que pueda evocar temor, intranquilidad o aprensión hacia la posibilidad de adentrarnos más en ella, conocerla mejor, o simplemente escucharla. Esta música también se relaciona, igualmente, con la sensación de inocencia e indefensión propiamente dicha que tiene un niño o una niña en cualquier tipo de situación de vulnerabilidad. Por ejemplo, es el tipo de música adecuada para trabajar con personas que estén tratando de superar situaciones de abuso o cualquier tipo de experiencia delicada en la que otra figura (habitualmente de autoridad) se ha aprovechado de ella, y se encuentre exactamente en el momento de confrontación de los recuerdos dolorosos.

- Música para trabajar con el enfado. Las selecciones musicales escogidas dentro de este espectro del estado anímico tienen un ritmo marcado, mucha energía y, en algunas ocasiones, auténtica agresividad en su carácter y forma de expresión musical. Uno de los objetivos principales de este tipo de música es actuar a nivel psicodinámico y corporal, estableciendo conexiones entre mente y cuerpo para permitir o facilitar la descarga emocional de sentimientos en situación de conflicto interno. Es necesario resaltar y aclarar que el objetivo de este tipo de música no es el de cabrear a la persona que recibe la sesión, o alterar su estado emocional de forma disfuncional, sino favorecer el proceso de conexión, gestión y expresión del enfado de forma saludable y segura, es decir, en una situación de terapia en la que el paciente o usuario es consciente de que puede expresar sus emociones libremente y de que el musicoterapeuta está ahí para acompañar, ayudar y contener el proceso terapéutico. Esta música también puede ser reconocida como "activa" (Bruscia, 1998) por la relación que guarda con la agitación emocional y física que existe en algunos casos.

- Música de integración, cierre y/o vuelta a la calma. Este tipo de música está orientada al final de una sesión, es decir, al momento al que corresponde cerrar el proceso que se haya vivido, integrarlo $\mathrm{y}$ regresar a un estado de quietud y/o estabilidad emocional tal que permita a la persona comprender lo que ha experimentado y relacionarlo con su proceso terapéutico y con su mundo interior. Por lo tanto, ha de tratarse de música de velocidad no muy rápida, con ritmo sencillo e intuitivo (no demasiado marcado) y, lo que es más 
importante, sin una gran implicación o exigencia a nivel emocional, especialmente que no se relacione con alguno de los grupos descritos previamente como el enfado, el miedo o la tristeza. Esta música debe ayudar al participante de la sesión a volver a un estado de calma que le ayude a integrar lo ocurrido. Puede tener relación con el grupo de música positiva, pero es importante resaltar que su objetivo no es el de despertar nuevas conexiones emocionales intensas o profundas. Las selecciones musicales de este tipo son las que cierran la mayor parte de los programas originales del BMGIM. De hecho, son las piezas a las que se recurre cuando se da el caso de que la persona que está recibiendo la sesión necesita más acompañamiento musical, ya sea al final del viaje o mientras dibuja el mandala.

De esta forma, la elección musical tenía lugar en función del estado anímico y el nivel de energía que los participantes del estudio traían a la situación de terapia, y siempre en consonancia con su situación personal en el presente, ya fuese en relación con lo acontecido en el colegio, en su núcleo familiar o con su grupo de amigos, información que era obtenida siempre en la situación de diálogo o conversación inicial. De esta forma se trataba de relacionar directamente la realidad personal del niño con su estado anímico y el carácter de la música.

En relación con ello, y teniendo en cuenta la información aquí expuesta, es necesario destacar y aclarar que las selecciones musicales, así como su categorización u organización en torno a distintas atmósferas anímicas, por su carácter y forma, no deben entenderse ni emplearse como una guía aplicable a cualquier tipo de persona en cualquier tipo de circunstancia. De hecho, uno de los aspectos más importantes de un proceso terapéutico es que la respuesta que se dé y, con ello, el tipo de música escogida, esté directamente relacionada con la situación personal del participante, es decir, con las necesidades emocionales que presente en función de las circunstancias que estén aconteciendo su vida en ese momento.

\subsection{El papel del cuerpo en GIM}

En determinados casos, la conexión entre la mente y el cuerpo de una persona resulta trascendental y especialmente relevante para el desarrollo de un proceso terapéutico. Es en estos casos, en los que la vida de la persona se ha configurado (o reconfigurado) en base a distintos tipos de experiencias traumáticas, donde se puede percibir la importancia que tiene el cuerpo para el reconocimiento y la identificación del dolor ocasionado y, posteriormente, su contribución en el proceso de superación del trauma. Los episodios de abuso, 
maltrato o abandono infantil, u otro tipo de eventos o situaciones traumáticas concretas, como la vivencia de guerras, desastres naturales, violaciones, etc. reconfiguran la percepción a nivel cerebral y emocional y se quedan plasmados, en forma de sensaciones físicas, en el cuerpo; en ocasiones, de hecho, en partes concretas que se han visto directamente involucradas o afectadas (van der Kolk, 2015):

Mientras registremos las emociones básicamente en nuestra cabeza, podemos más o menos controlar, pero sensaciones como que se nos hunde el pecho o que nos golpean la barriga son insoportables. Haremos lo posible para que estas sensaciones viscerales terribles desaparezcan, ya sea aferrándonos desesperadamente a otro ser humano, volviéndonos insensibles con drogas o alcohol o llevándonos un cuchillo a la piel para sustituir unas emociones abrumadoras por unas sensaciones definibles. ¿Cuántos problemas de salud mental, desde la adicción a las drogas al comportamiento autolesivo, empiezan como un intento de sobrellevar el dolor físico insoportable de nuestras emociones? (p. 1467)

De hecho, lo que ocurre en el cerebro de las personas que se ven envueltas en situaciones traumáticas, especialmente si se producen durante la primera infancia, es que se quedan estancados en un estado cerebral de supervivencia, de modo que perciben su entorno de forma distinta llegando incluso a permanecer en estado de alerta constante ante los estímulos que el ambiente les ofrece (van der Kolk, 2015).

Dentro de este contexto, en el trabajo a través del método GIM el cuerpo se ve involucrado a menudo, en función de las necesidades emocionales y físicas que la persona transmita y perciba en sí misma. La música nunca actúa solo a nivel mental o emocional, sino también a nivel físico y psicodinámico, de modo que el cuerpo se ve involucrado de forma directa en la experiencia terapéutica (Bonny, 1986):

Music evokes physiological responses. Rhythm, the energizer of music, is related to heart rate, blood pressure, breathing and the whole multitude of vibrational periodicities that make up the body structures. The tension/release dynamic inherent in Western musical composition further enhance the rhythmic balances desired in good health. (p. 5) 
En relación con lo expuesto anteriormente, en el GIM la música ofrece una respuesta psicodinámica ante las necesidades físicas de cada persona, estableciendo una relación directa con el cuerpo y la mente, y una conexión entre los tres elementos. Partiendo de algunas de las premisas de la terapia psicodinámica, en el GIM se pueden trabajar aspectos relacionados con la pérdida y el establecimiento de las relaciones paternofiliales, la represión de experiencias traumáticas y la reestructuración de procesos cognitivos relacionados con los mecanismos de defensa, los niveles de conciencia y las funciones cerebrales encargadas de la regulación corporal (Bruscia, 2002a). Es por ello que, a menudo, la elección de la música se realiza, entre otros aspectos, en función del grado de energía anímica y física que presenta la persona en el momento de comenzar la sesión, ya que es necesario que el carácter y la fuerza de la música sean acordes a la disposición que la persona tenga hacia el trabajo psicológico durante la sesión, que varía en función de las circunstancias y del propio desarrollo gradual del proceso terapéutico.

\subsection{Utilidad del mandala como objeto proyectivo}

Uno de los primeros profesionales en descubrir el concepto de mandala en su propia vida y, a raíz de ello, en relacionarlo con el mundo interior y emplearlo en experiencias terapéuticas, fue el propio Carl Jung. Ya en torno al año 1916 se documentan los primeros mandalas que el psicólogo y psiquiatra suizo dibujó, así como el comienzo de su interés por este instrumento como recurso para el trabajo en psicoterapia, que se desarrolló a partir de 1920, logrando un mayor grado de conocimiento y comprensión de su empleo (Shamdasani, 2012). Para él, el mandala, concebido dentro de este contexto de trabajo a nivel psicoterapéutico, es una representación de la persona, que tiene lugar de forma inconsciente al haber tenido algún tipo de experiencia terapéutica previa. Explica que el mandala está relacionado con la expresión del alma desde la psique, sin que la propia persona sea consciente de que se está produciendo este proceso, y que representa el camino que esa persona ha vivido, su trayectoria vital y los pasos que ha ido tomando, si se sucede a lo largo del tiempo de forma secuencial en relación con un proceso terapéutico (Shamdasani, 2012).

Considerando que, en este contexto, el mandala no se refiere a los dibujos geométricos propios de algunas culturas orientales, sino a una representación de la psique de las personas a nivel inconsciente, Moore y Gillette (1993) reflejan con bastante acierto la concepción que tenía Jung en relación con los mandalas: 
Jung (...) denominó "mandalas" a estos cuadros de la organización central, adoptando el nombre que posee el budismo tibetano para estas representaciones. Notó que cuando aparecían los mandalas en los sueños y en las visiones de los que se psicoanalizaban, siempre eran curativos y proporcionaban vida. Siempre significaban renovación y (...) mostraban que la personalidad estaba reorganizándose de una manera más centrada, que se estaban estructurando y tranquilizando. (p. 72)

Teniendo esto en cuenta, y trasladando este concepto al trabajo con BMGIM, el mandala actúa como proyección de las emociones, sensaciones físicas e imágenes que se hayan producido a nivel inconsciente durante la sesión, de tal forma que tienen lugar tomas de conciencia tales que permiten que se establezcan conexiones entre el mundo interior de las personas y su comprensión a nivel consciente. Lo que hace del mandala un recurso de utilidad para el trabajo a nivel psicoterapéutico es que permite expresar emociones y sentimientos de forma inconsciente, sin la necesidad de utilizar la palabra, lo cual implica que resulte más sencillo transmitir y gestionar sensaciones que a menudo generan conflictos internos (Bush, 1995). Por ello, se favorece que la persona que realiza la sesión pueda descubrir este material psicológico, compartirlo con el terapeuta y tomar conciencia sobre cómo influye eso en su vida y qué puede hacer para gestionarlo de forma funcional.

\subsubsection{Relación con el dibujo infantil}

$\mathrm{Al}$ igual que el mandala supone una representación inconsciente e instintiva del mundo interior de un adulto que se encuentre inmerso en un proceso terapéutico, el dibujo infantil actúa como pantalla proyectiva de las necesidades emocionales de los niños, de tal forma que en sus creaciones se pueden apreciar, en muchos casos, el reflejo de situaciones personales o familiares delicadas, emociones o necesidades afectivas específicas, o determinados tipos de sentimientos relacionados con la realidad cercana al niño. Así lo expresan Lowenfeld y Brittain (1980):

La figura que un niño dibuja o pinta es mucho más que unos cuantos trazos en un papel. Es una expresión del niño íntegro correspondiente al momento en que pinta o dibuja. Algunas veces, los niños pueden estar totalmente absorbidos por el arte, y entonces su obra puede alcanzar una real profundidad de sentimientos y perfección. (...) Cada dibujo refleja los sentimientos, la capacidad intelectual, el desarrollo físico, la aptitud perceptiva, el factor creador implícito, el gusto estético, e incluso el desarrollo social del individuo. (p. 39) 
La importancia de la expresión a través de determinados medios artísticos, como la pintura, el dibujo o el modelado, reside precisamente en el hecho de que constituye una necesidad natural y espontánea para todos los niños, quienes a diario exploran intuitivamente diferentes formas de comunicación a través de estos medios, para transmitir información relativa a su propia experiencia en relación con su entorno más cercano (Fosati y Segurado, 2014; Quinlan, Schweitzer, Khawaja, \& Griffin, 2015). De esta forma, el dibujo comprende un recurso que facilita, por su propia naturaleza, procesos cognitivos relacionados con la expresión emocional y el desarrollo de la creatividad y la imaginación.

Por otra parte, cabe destacar que una de las formas de expresión distinguidas dentro de los distintos tipos de dibujo infantil es, precisamente, el mandala. Kellogg (1979) se refiere a ello como una forma específica que se puede apreciar en los dibujos infantiles, a la que se refiere como composiciones basadas en la existentica de un círculo o cuadrado, a menudo dividido en cuatro partes bien diferenciadas. De hecho, tal y como afirma la propia autora, ella misma contrastó esta idea con Carl Jung en 1954, lo cual llevó a este a considerar y reafirmar la presencia del mandala como una condición de expresión arquetípica e innata, común a todos los seres humanos, que va tomando forma a nivel consciente conforme los niños van creciendo (Kellogg, 1979). Por lo tanto, existe una conexión entre el dibujo infantil y el concepto de mandala del modo en que fue concebido por Jung, aunque solo se aprecie en algunos ejemplos, y no en la gran mayoría de los casos a la hora de analizar los dibujos infantiles (Machón, 2009).

\section{IMPLICACIONES PARA EL TDAH Y DESCRIPCIÓN DEL MÉTODO DE MUSICOTERAPIA EMPLEADO: TÉCNICAS DE MÚSICA E IMAGEN (MI)}

Tal y como se ha indicado al inicio de este capítulo, el método empleado para la intervención llevada a cabo durante el trabajo de campo de la presente tesis doctoral, parte de los fundamentos del BMGIM, pero, debido a las características del colectivo con el que se trabaja, fue necesario que fuese adaptado a las circunstancias y el contexto en torno al cual fue desarrollada dicha intervención.

Del modelo original este método conserva los principios filosóficos y teóricos, la mayor parte de las selecciones musicales empleadas, la presencia de un diálogo inicial y final, a modo de reflexión e integración, y la realización de un mandala al finalizar la sesión. La realización de un mandala se incluye debido a la relevancia de este recurso como objeto proyectivo emocional en 
situación de terapia (Bush, 1995; Shamdasani, 2012) y a su naturaleza y utilidad como medio de expresión en forma de dibujo infantil dentro del contexto en el que estamos trabajando (Fosati y Segurado, 2014; Kellogg, 1979; Lowenfeld y Brittain, 1980; Machón, 2009), justificación que ha sido recientemente expuesta en el apartado anterior.

De hecho, en algunos estudios previos realizados, en los que se trabajó con las artes como forma de intervención para casos de TDAH, se demostró que la expresión a través de las artes sirve como una forma de canalizar el comportamiento impulsivo y agresivo, relacionado con la hiperactividad y el estrés social, y transformarlo en formas creativas de auto-regulación emocional que conducen a una mayor capacidad de relación social (Henley, 1998, 1999). Más en concreto, y en relación con el formato de nuestro estudio, varios estudios demuestran que el trabajo con mandalas repercute de forma positiva en el autocontrol y la regulación de las características propias del TDAH, así como en el desarrollo de la creatividad y la capacidad de expresión emocional a la hora de relacionarse con el entorno (Castaño y Ortiz, 2019).

Sin embargo, del modelo original este método no puede conservar ni la duración establecida (tanto de la sesión como del viaje musical) ni el nivel de procesamiento cognitivo en relación con el estado de la conciencia a través del cual se está trabajando. En el trabajo con niños, una sesión de una hora y media puede ser contraproducente, ya que la duración de los momentos de atención, en relación con la capacidad de concentración que se da en edades tempranas, disminuye en comparación con estas características en la edad adulta (Roy, 1996; Wesley, 2002), más cuando se trata con la presencia de casos de TDAH, como ocurre en nuestro estudio. Por ello, al disminuir el tiempo de la sesión y de la experiencia musical, la intensidad del trabajo a nivel psicológico se relativiza y disminuye en cierta medida.

De hecho, por las características propias que suelen presentar los niños diagnosticados de TDAH, la posibilidad de trabajar a través de un estado no ordinario de conciencia disminuye, especialmente en algunos casos en los que estos niños, debido a su hiperactividad, no son capaces de cerrar los ojos y/o relajarse para escuchar una música de forma pausada y centrando la atención en sus sensaciones y emociones. Resulta relevante considerar esto, sobre todo si tenemos en cuenta que una de las partes esenciales para llegar a un estado no ordinario de conciencia es la inducción a un estado de relajación profunda (Bonny, 1986).

Dicho lo cual, debido a las características de los niños en general, y de los niños diagnosticados de TDAH en particular, durante las sesiones no se con- 
dicionaba a ninguno de los participantes a escuchar la música en una determinada postura corporal (sentados, tumbados, de pie, etc.), con los ojos abiertos o cerrados o a través de estados de relajación específicos o inducidos. Se permitía a los niños que tomasen la decisión de cómo iban a escuchar la música, incluso escuchándola mientras dibujaban o mientras exploraban el espacio de la sala, en función de las necesidades y preferencias que presentasen cada día. Por lo tanto, teniendo en cuenta que se considera técnicas de GIM a aquellas adaptaciones del modelo original que conservan el trabajo a través de estados no ordinarios de conciencia (Bruscia, 2002), no se puede decir que el método empleado en nuestro estudio sea GIM, ya que este nivel de procesamiento cognitivo no se alcanzaba en todos los casos, aunque sí pudiese darse en algunos momentos de forma puntual.

En este sentido, la adaptación GIM que más se asemeja a este método es la técnica de Música, Imagen y Relajación o MIR (Gimeno, 2015), en cuanto a duración de la música se refiere (entre cinco y diez minutos, como se explicará más adelante) y debido al carácter de soporte que tiene esta técnica. Sin embargo, el método empleado para nuestro estudio dista de esta adaptación en que no necesariamente tiene que existir una inducción a un estado de relajación y en que se realiza un mandala al finalizar la sesión (lo cual no se hace en la técnica de MIR).

Cabe por tanto considerar que este método está basado en técnicas de música e imagen, al comprender como este concepto el trabajo a través de estados ordinarios de conciencia y piezas musicales seleccionadas tanto por su carácter de soporte emocional como por sus posibilidades estimuladoras de la imaginación y la creatividad (Summer, 2010).

En lo que se refiere a la duración de las sesiones, fueron organizadas en torno a dos formatos bien diferenciados: individual y grupal. Siguiendo a Wesley (2002), la sesión individual tenía una duración de entre veinte y treinta minutos, de los cuales en torno a cinco o diez eran dedicados a la escucha receptiva-activa de la música. Nótese que, llegados a este punto, se emplea la expresión "escucha receptiva-activa" porque, al tiempo que la música es escuchada o recibida, de tal forma que no es creada directamente por los participantes, los niños están trabajando de forma activa, ya sea a nivel emocional y/o cognitivo, a la hora de explorar y expresar sus emociones y/o al dibujar el mandala, por lo que se considera relevante esta consideración y la pertinente aclaración. Las sesiones individuales fueron llevadas a cabo durante las seis primeras semanas. 
Por otra parte, las sesiones grupales tenían una duración recomendada de entre treinta y cuarenta minutos, de los cuales entre cinco y veinte se dedicaban al momento de escucha receptiva-activa. Se trata este de un tiempo adecuado para que el grupo pueda explorar a nivel emocional, de forma no invasiva y de tal modo que dé tiempo a procesar lo ocurrido sin que el grupo llegue a dispersarse (Roy, 1996). Las sesiones grupales se llevaron a cabo durante las seis últimas semanas del trabajo de campo.

Tanto en las sesiones grupales como en las individuales existía un momento de diálogo inicial y otro de reflexión final, que servía como procesamiento de la sesión para tomar conciencia sobre lo acontecido. La música empleada se basó, mayoritariamente, en selecciones originales del modelo (adaptando la duración), predominantemente obras propias de la música académica, ya que este tipo de música puede contribuir positivamente en el desarrollo de la autoestima, la estimulación de la creatividad y la disminución del estrés (Roy, 1996), producir momentos de relajación y mayor autoconciencia (Powell, 2007) y desarrollar la conciencia y la capacidad de percepción de la realidad (Bonny y Savary, 1994). También fueron empleadas algunas de las piezas musicales propuestas por Powell (2007) para el trabajo con niños en la etapa de primaria, e incluso algunos temas contemporáneos o actuales (Fugle, 2015) en caso de que fuese necesario.

A la hora de establecer el diálogo inicial el musicoterapeuta preguntaba a los niños cómo se sentían en el momento de llegar a la sesión. Para ello, a menudo era de utilidad preguntar por cómo había ido en el colegio ese día, ya que habitualmente surgían emociones derivadas de la relación con los compañeros, con las que podíamos trabajar en la sesión. Cabe señalar en este punto que el musicoterapeuta seleccionaba la música en la mayor parte de los casos, excepto en algunos momentos en los que consideraba conveniente permitir que los niños escogiesen la música, con el objetivo de fortalecer el vínculo terapéutico.

Para llevar a cabo la reflexión final después de realizar el ejercicio de escucha, se preguntaba a los niños por el contenido del mandala y se les preguntaba qué les había parecido la música, cómo les había hecho sentir, o qué se habían imaginado. Todo este proceso se realizaba teniendo muy presentes la capacidad de escucha y de empatía hacia lo que los niños necesitasen compartir en cada momento, sin emitir juicios y permitiendo que se expresasen en un entorno seguro y de confianza, lo cual fue importante para el proceso de construcción y fortalecimiento del vínculo terapéutico. 
Así, siguiendo las recomendaciones de Robb et al. (2018) referidas al reporte de elementos de diferentes intervenciones de Musicoterapia, en este estudio se incluye información sobre el tipo de música empleada, la persona que escoge la música, el formato de la música (grabada), otros materiales empleados (como los mandalas), estrategias de intervención, la organización de las sesiones (número, duración y frecuencia) e información relativa a las credenciales y titulación del facilitador de la intervención e investigador principal.

En definitiva, y teniendo en cuenta todo lo expuesto en este capítulo, podemos considerar que el método empleado en la intervención de este estudio se basa en la aplicación de técnicas de música e imagen para el trabajo con niños sin y con diagnóstico de TDAH, en función de las necesidades físicas y emocionales que presentasen en cada sesión, y en el que la presencia de la música, como soporte emocional y estimuladora de la experiencia imaginativa y creativa, y el mandala, como medio que puede favorecer la expresión y que puede aportar mucha información y contenido a nivel emocional, son de vital importancia. 




\section{CAPÍTULO V. METODOLOGÍA DE LA INVESTIGACIÓN}





\section{INTRODUCCIÓN}

En el presente capítulo se describen todos los aspectos relacionados con el diseño de investigación, los objetivos e hipótesis, así como los detalles sobre la contextualización y la temporalización del desarrollo de la intervención musicoterapéutica y las distintas técnicas de obtención de información e instrumentos de recogida de datos. Se trata de una investigación con un diseño mixto paralelo de triangulación concurrente o DITRIAC. Los datos se obtuvieron de forma paralela mediante instrumentos cuantitativos de recogida de datos (escala EDAH, Evaluación del Trastorno por Déficit de Atención con Hiperactividad y escala de observación del desarrollo emocional para ciclo inicial) y técnicas cualitativas de obtención de la información (observación participante, diario de campo y entrevista semiestructurada). El proceso de análisis de datos se dio siguiendo el esquema del diseño DITRIAC, tal y como se explica a continuación.

\section{PRINCIPIOS DE LA INVESTIGACIÓN}

\subsection{Paradigma de la investigación}

La orientación teórica y filosófica que esté detrás de una investigación delimitará, en mayor o menor medida, los objetivos que se formulen, la forma de plantear y analizar el objeto de estudio, el modo en que se considere y sea abordado el contexto donde se realice la investigación, cómo sea obtenida y tratada la información, los resultados que se obtengan, la repercusión y alcance social del estudio, etc. El paradigma de investigación constituye una concepción general del objeto de estudio dentro de una disciplina, de los problemas que van a ser estudiados, del método que debe emplearse y del modo de explicar, interpretar o comprender, en función de los objetivos planteados, los resultados obtenidos a través de una investigación (Khun, 1970). Es, por lo tanto, necesario, que esta perspectiva sea planteada y justificada desde el inicio.

A pesar de que los enfoques de investigación han sido configurados habitualmente en base a dos perspectivas metodológicas principales (cuantitativa y cualitativa), los procesos de investigación pueden ser desarrollados desde tres perspectivas diferentes: el enfoque positivista, el enfoque interpretativo y el enfoque socio-crítico (Ricoy, 2006). De hecho, es común asociar el empleo de la metodología cuantitativa al enfoque positivista, y la metodología cualitativa a los enfoques interpretativo o socio-crítico. Sin embargo, lo que define los principios de una investigación no son los métodos y técnicas empleados, sino el posicionamiento teórico y filosófico que se asuma, que irá directamente relacionado con los objetivos que se planteen y con los resultados que se obtengan. 
El primero de ellos, el enfoque positivista, se preocupa por estudiar algún aspecto de la realidad, analizarlo y tratar de predecir los sucesos ocurridos para emitir leyes universales aplicables a todos los seres humanos. Por su parte, en el enfoque interpretativo el investigador se hace preguntas sobre la realidad, se plantea por qué y de qué forma se desarrollan las relaciones humanas, pero sin emitir acciones que puedan dar lugar a producir cambios en un contexto determinado. Por último, en el enfoque socio-crítico el investigador no solo reflexiona sobre el contexto que está estudiando, sino que todo el proceso de investigación va orientado hacia el emprendimiento de acciones que contribuyan a la transformación y mejora de ese contexto o realidad concreta.

Por otra parte, si consideramos la clasificación de López, Monjas y Pérez (2003) tenemos dos perspectivas principales: la racionalidad técnica y la racionalidad práctica. La racionalidad técnica es aquella cuyo objetivo principal es, al igual que el enfoque positivista, analizar un aspecto de la realidad para tratar de generar leyes universales que expliquen en términos generales el comportamiento de los seres humanos. Por su parte, la racionalidad práctica centra su atención en comprender el porqué, cómo se desarrollan los procesos humanos, es decir, que reflexiona sobre una realidad concreta para, llegado el caso y dada la oportunidad, poder transformarla para mejor.

Como vemos, esta racionalidad técnica corresponde a nivel teórico con el enfoque positivista, mientras que la racionalidad práctica engloba las perspectivas interpretativa y socio-crítica, y se situará en una orientación u otra en función de las necesidades que surjan en el contexto donde se esté desarrollando la investigación o en base a los objetivos que el equipo investigador quiera plantear.

En este sentido, si nos posicionásemos en una perspectiva positivista o técnica lo que estaríamos haciendo sería observar o analizar la realidad para tratar de generalizar algún tipo de conocimiento. Sin embargo, en esta investigación se ha trabajado directamente con una realidad o grupo social concreto (diez niños con y sin diagnóstico de TDAH y sus madres, padres y tutoras) y las preguntas de investigación van orientadas principalmente a comprender por qué y cómo ha influido el método aplicado en estos niños y en su entorno, por lo que no cabe duda de que nos situamos dentro de una racionalidad práctica. Además, todas las acciones del trabajo de campo, así como los procesos de reflexión y análisis de datos, van orientados a la mejora de la situación personal, académica y social de los niños, por lo que nos situamos dentro de una orientación eminentemente socio-crítica. 


\subsection{La utilidad del enfoque mixto: Diseño de Triangulación Concurrente (DITRIAC)}

Por definición, un enfoque mixto de investigación implica la recolección de datos tanto cualitativos como cuantitativos, que serán relacionados de modo que una perspectiva complemente e influya a la otra, con el objetivo de constituir una aproximación metodológica conjunta tal que permita responder a una o varias preguntas de investigación y/o hipótesis, ya sea comparando e interpretando los resultados de ambas vertientes para dar una respuesta contrastada a las preguntas de investigación (diseño mixto paralelo convergente) $\mathrm{u}$ organizando el estudio en diferentes fases, de modo que los resultados de una fase proporcionen información para el planteamiento de la siguiente (diseños mixtos secuenciales) (Burns \& Masko, 2016; Magee, 2016).

El empleo de métodos mixtos se ha extendido considerablemente a lo largo de los últimos años, ya que su planteamiento ayuda a abordar de forma natural distintos aspectos de la realidad, especialmente en determinados campos en los que la información se obtiene a través de diversas fuentes y técnicas variadas (Hernández-Sampieri, Fernández y Baptista, 2014). El empleo complementario de instrumentos cuantitativos de recogida de datos y de técnicas cualitativas de obtención de información hace que esta aproximación metodológica favorezca el estudio y comprensión de la realidad sobre la que se está investigando, ya que cada perspectiva puede aportar su mayor utilidad a un enfoque mixto integrado y orientado a las circunstancias de un contexto o a las características de los participantes de una investigación.

Por ejemplo, si en un hospital se quiere valorar el grado de dolor que un grupo de pacientes en concreto siente ante una nueva forma de intervención, el equipo de investigación podrá recopilar la percepción de estos pacientes a través de escalas de medición de la autopercepción del dolor. No obstante, si además realiza entrevistas individuales a cada uno de ellos, complementará los datos obtenidos y estará profundizando en la comprensión de la realidad, en las razones que se conectan con esa autopercepción, o incluso en la indagación de otro tipo de factores relacionados con su situación personal y que pueden repercutir en el grado de autopercepción del dolor físico, como pueden ser la inestabilidad o dolor emocional, la ansiedad, la depresión, el proceso de duelo por la pérdida de un ser querido o de un compañero de habitación en el propio hospital, el sentimiento de soledad, etc.

En nuestro caso, la información se fue obteniendo de forma complementaria y simultánea por ambas vías (cuantitativa y cualitativa) conforme se iba desarrollando el trabajo de campo, ya que el objetivo iba orientado a contrastar las hipótesis y responder a preguntas de investigación comunes, por lo que nos 
posicionamos en un diseño mixto paralelo (Burns \& Masko, 2016; Magee, 2016). Además, en concreto se trata de un diseño de triangulación concurrente - de ahora en adelante DITRIAC - (Hernández-Sampieri et al., 2014), y como tal responde al esquema organizativo representado en la Figura 4.

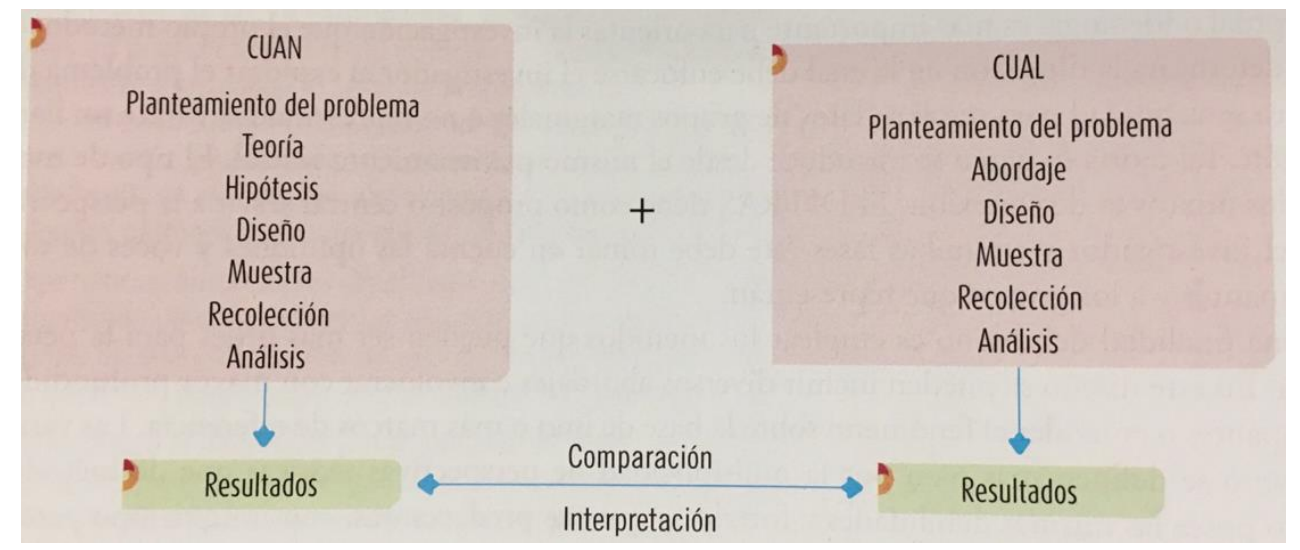

Figura 4. Diseño de triangulación concurrente (DITRIAC). Fuente: HernándezSampieri et al. (2014).

En nuestro estudio se siguió el esquema de este diseño de metodología mixta, y cabe señalar también que la forma en la que se integró la información cualitativa y cuantitativa en nuestro estudio vino dada, en primera instancia, por los instrumentos cuantitativos escogidos para la recolección de datos. Las categorías cualitativas se establecieron en base a los bloques temáticos que se incluyen en estas escalas, para favorecer así el posterior proceso de análisis de los datos, comparación de las dos vías (cuantitativa y cualitativa) y, con ello, la interpretación de los resultados. La forma en la que se integran la información cuantitativa y cualitativa se puede apreciar de forma más clara en el capítulo de análisis de los datos.

\subsubsection{Perspectiva cuantitativa: diseño longitudinal}

El principal objetivo de la investigación cuantitativa es el conocimiento del mundo a través de la experimentación empírica, es decir, la demostración de hechos por medio del planteamiento de hipótesis que serán aceptadas o refutadas al finalizar el proceso del trabajo de campo. De esta forma, los nuevos descubrimientos deben ser objetivos, medibles, cuantificables y generalizables o extrapolables a situaciones similares a las acontecidas durante el desarrollo de la experimentación (Usher y Bryant, 1992). En este sentido, la perspectiva cuantitativa permite sistematizar los resultados obtenidos para aceptar o rechazar las hipótesis planteadas a priori. Igualmente, pretende que la situación de experimentación pueda ser reproducida en otros contextos para corroborar la fiabilidad y validez de un estudio. 
Este tipo de trabajos de investigación basados en la experimentación pueden tener tres diseños diferentes: longitudinal, transversal (Manterola, Quiroz, Salazar y García, 2019), y la combinación de ambos en el diseño secuencial (Montero y León, 2002). En primer lugar, el diseño longitudinal se basa en el seguimiento de un grupo de sujetos durante un periodo de tiempo determinado, tomando medidas de algunas variables en dos o más momentos (al menos antes y después). Por otra parte, el diseño transversal consiste en comparar en un mismo momento temporal distintos grupos de sujetos, lo que supone un diseño en el que tienen lugar mediciones intersujeto. Por último, en el diseño secuencial surge de la combinación de los otros dos tipos de diseños, de forma que se utilizan ambos tipos de fórmulas de muestreo, así como las técnicas de recogida y análisis de datos.

En lo que se refiere a nuestro trabajo, se encuadra dentro de los fundamentos del diseño longitudinal. La principal ventaja que presenta esta forma de investigación frente al diseño transversal es que permite valorar los cambios que se han producido en un mismo grupo de sujetos durante un tiempo determinado, es decir, que se llevan a cabo mediciones intrasujeto, como ocurre en nuestro estudio. Dado que esta investigación se plantea valorar los efectos que tiene la intervención musicoterapéutica basada en técnicas de música e imagen, el diseño longitudinal se considera acertado.

Más en concreto, la metodología cuantitativa y, en concreto, este diseño longitudinal, nos permite comparar de forma sistemática, a través de herramientas cuantitativas específicas como son la escala Evaluación del Trastorno por Déficit de Atención con Hiperactividad, y la escala de observación del desarrollo emocional para ciclo inicial, que serán descritas con más detenimiento más adelante, los resultados que ha tenido nuestra intervención. Es decir, de qué forma el método musicoterapéutico aplicado ha repercutido en la vida de los participantes en lo referido a su capacidad de gestión emocional y la muestra de conductas hiperactivas, impulsivas y déficit de atención.

\subsubsection{Perspectiva cualitativa: estudio de casos múltiples}

La investigación cualitativa aporta narraciones que, limitadas en el espacio y en el tiempo, proporcionan información relevante que ayuda a comprender en profundidad contextos y hechos que ocurren en un determinado momento y lugar (Flick, 2004). En este sentido, la percepción cualitativa del objeto de estudio hace que la investigación se adapte constantemente a los participantes, a las situaciones que se dan y al modo en que se establecen y desarrollan las relaciones, ya que su objetivo es contribuir a una mejor comprensión o transformación de una realidad concreta (Barba, 2013). 
Uno de los objetivos principales de la investigación cualitativa es comprender un contexto desde dentro, observando, describiendo, explicando e interpretando los discursos, experiencias, comunicaciones y relaciones que se producen entre un determinado número de informantes pertenecientes a ese contexto (Flick, 2014). Por lo tanto, algunas de las características propias del enfoque cualitativo es que la forma en que la información es obtenida es flexible y adaptable a las necesidades del contexto, que una de las principales premisas es la reconstrucción del significado y que su concepción no es generalizadora, sino que pone su atención en lo particular y concreto (Ruiz, 2003).

Dentro de los diferentes diseños de investigación cualitativa que existen (investigación-acción, estudio de caso, etnografía, etc.) nuestro trabajo se encuadraría en el diseño de estudio de casos múltiples, ya que se profundiza en el conocimiento de más de dos sujetos, estudiando cómo cambia la realidad que gira en torno a los participantes de la investigación (Bogdan \& Biklen, 2003).

En relación con la temática de nuestro estudio cabe destacar que la perspectiva cualitativa ha sido empleada en gran cantidad de investigaciones relacionadas con el ámbito de la Educación Inclusiva, ya que algunas técnicas de obtención de información, como la observación participante, la entrevista o la observación etnográfica, resultan de especial utilidad para recoger las percepciones no solo de los profesionales implicados, sino también de los participantes de la investigación, en muchos casos niños con necesidades especiales (Rodríguez-Fuentes, 2005).

Más en concreto, muchos profesionales del ámbito de la Musicoterapia señalan que a través de la metodología cualitativa los datos y la información que son recogidos están directamente relacionados con las experiencias entre el musicoterapeuta, sus pacientes y otros participantes de la investigación (Wheeler, 2014). Por lo tanto, en nuestro estudio la observación participante, el desarrollo de entrevistas, el seguimiento activo a través de diarios e informes de sesión cualitativos son algunas de las técnicas que nos ayudan a comprender y analizar el proceso terapéutico de los participantes y, con ello, el alcance de la intervención musicoterapéutica.

\section{OBJETO DE ESTUDIO}

El objetivo general o foco de atención de nuestro trabajo de investigación es valorar la repercusión que tiene la intervención musicoterapéutica, es decir, si producirá cambios positivos en relación con la conducta y capacidades de los niños participantes. Para abordar este objetivo general se plantean los siguientes objetivos e hipótesis, dando respuesta así a las dos perspectivas presentes en el diseño mixto. 


\subsection{Objetivos}

A la hora de plantear los objetivos desde la perspectiva cualitativa la idea es que sean valorados desde un punto de vista transversal y global. De alguna forma, los objetivos reflejan en su formulación todo el proceso de investigación que se está llevando a cabo.

1. Valorar la Musicoterapia y, en concreto, las técnicas de música e imagen, como medio para favorecer la expresión emocional en niños sin diagnóstico de TDAH de entre 7 y 11 años de edad.

2. Considerar la Musicoterapia y, en concreto, las técnicas de música e imagen, como intervención no farmacológica en casos de niños con diagnóstico de TDAH de entre 7 y 11 años de edad.

3. Explorar las posibilidades del mandala como objeto de proyección y expresión emocional en casos de niños con y sin diagnóstico de TDAH.

4. Conocer la relación entre el tipo de música empleada y la respuesta emocional de niños con y sin diagnóstico de TDAH.

5. Valorar la repercusión que tiene la intervención musicoterapéutica en otros contextos de la vida de los niños, tales como la familia, la escuela o los momentos de ocio.

\subsection{Hipótesis}

Las hipótesis planteadas, por su parte, buscan una respuesta derivada de la valoración de si nuestra intervención ha emitido cambios al comparar los valores obtenidos antes y después del proceso musicoterapéutico.

H1.- La Musicoterapia, por medio de técnicas específicas de música e imagen, repercute de forma positiva en el nivel de competencia emocional de niños con y sin diagnóstico de TDAH de entre 7 y 11 años de edad.

H1.1.- Las técnicas de música e imagen aumentan el nivel de conciencia emocional de niños con y sin diagnóstico de TDAH.

H1.2.- Las técnicas de música e imagen aumentan la capacidad de regulación emocional de niños con y sin diagnóstico de TDAH. 
H1.3.- Las técnicas de música e imagen aumentan el nivel de autonomía emocional de niños con y sin diagnóstico de TDAH.

H1.4.- Las técnicas de música e imagen aumentan la competencia social de niños con y sin diagnóstico de TDAH.

H1.5.- Las técnicas de música e imagen aumentan la competencia de vida y bienestar de niños con y sin diagnóstico de TDAH.

H2.- La Musicoterapia, por medio de técnicas específicas de música e imagen, reduce las muestras de déficit de atención, hiperactividad, impulsividad y trastorno de conducta en casos de niños con diagnóstico de TDAH de entre 7 y 11 años de edad.

H2.1.- Las técnicas de música e imagen reducen el déficit de atención en casos de niños con diagnóstico de TDAH.

H2.2.- Las técnicas de música e imagen reducen la muestra de conductas hiperactivas e impulsivas en casos de niños con diagnóstico de TDAH.

H2.3.- Las técnicas de música e imagen reducen el nivel de trastorno de conducta en casos de niños con diagnóstico de TDAH.

\section{DISEÑO METODOLÓGICO}

\subsection{Contextualización}

La selección de los niños participantes se realizó mediante un muestreo no aleatorio por conveniencia. El motivo por el cual se escogieron niños con y sin diagnóstico de TDAH fue el hecho de que la intervención se desarrollase por medio de un ambiente más inclusivo, en el que estuviesen presentes ambos tipos de niños, y no de tal forma que se disgregase a unos u otros.

Para ello, se envió un correo electrónico a todos los colegios de Educación Primaria y Educación Infantil de la provincia de Segovia. La información de contacto de cada colegio fue obtenida a través de la base de datos empleada para las asignaturas Practicum I y II de la Facultad de Educación de Segovia. En dicho correo se transmitía información sobre el estudio y se invitaba a las familias a que formasen parte activa de la investigación. El documento que fue enviado con tal fin puede visualizarse en el Anexo I. 
De un total de 68 colegios que fueron contactados, se obtuvo respuesta efectiva del C.E.I.P. Marqués de Lozoya, situado en la localidad de Torrecaballeros, y del C.E.I.P. San José, el C.E.I.P. Fray Juan de la Cruz y el C.E.I.P. Nueva Segovia, localizados en la ciudad de Segovia. Entendemos por "respuesta efectiva" aquella mediante la cual se facilitó el encuentro y comunicación con las personas que pasaron a formar parte activa de la investigación y que son descritas en el apartado siguiente.

El trabajo de campo fue desarrollado a lo largo de tres meses, en concreto entre el 6 de marzo y el 8 de junio de 2017. La intervención fue organizada en doce sesiones, de las cuales seis fueron individuales, con una duración aproximada de 30-45 minutos, y otras seis fueron grupales, de 60 minutos de duración orientativa). La intervención fue llevada a cabo en el aula pequeña de música del edificio Santiago Hidalgo, antigua Escuela Universitaria de Magisterio de Segovia.

\subsection{Descripción de los participantes}

En total el grupo de niños participantes en el estudio está compuesto por cinco niños con diagnóstico de TDAH y cuatro niños sin diagnóstico de TDAH:

Con diagnóstico de TDAH:

- J1. Con 9 años durante el desarrollo de la intervención, es un niño lleno de alegría, actividad y deseo de compartir su mundo interno con las personas que forman (o no) parte de su vida. Es un niño con diagnóstico de TDAH con más incidencia en las conductas hiperactivas e impulsivas, pero sin muestra de trastorno de conducta. Sufrió un accidente tras el cual, debido a un golpe fuerte en la cabeza, estuvo en coma durante varios meses. Su madre compartió en la entrevista previa a la intervención que este hecho hizo que se acrecentasen las dificultades de desarrollo del lenguaje y la recuperación de esta y otras funciones de procesamiento cerebral. El principal objetivo que nos plantemos con él a través de las sesiones fue ayudarle a canalizar toda su energía y a mejorar la capacidad de relajación.

- J2. Con 11 años de edad, es un niño creativo, tiene un mundo interior rico y amplio que le gusta compartir. Es hermano de J1. Le encanta dibujar y esta es una de las muestras más claras de su creatividad. Se trata de un niño con diagnóstico de TDAH, aunque, en este caso, con especial presencia de déficit de atención y dificultad de concentración. Esto le lleva a tener ciertas dificultades a la hora de llevar a cabo las tareas del colegio, que fue uno de los principales objetivos que nos planteamos a la hora de trabajar con él. 
- $\quad$ N. De 9 años de edad, es un niño inteligente, con altas capacidades y realmente creativo, lo cual demostró una y otra vez durante las sesiones, especialmente a la hora de conectar emocionalmente con la música y expresarse a través del dibujo. Está diagnosticado de TDAH, y en su caso la principal muestra de conductas relacionadas con este trastorno guardaba relación con el déficit de atención y la dificultad de concentración durante los meses que duró la intervención. Esto se debe a que en aquel momento recibía medicación a diario. Sus padres compartieron que cuando los efectos de la medicación pasaban sí había muestras claras de hiperactividad, impulsividad y trastorno de conducta. De hecho, este fue el principal objetivo o foco de trabajo que nos planteamos durante la entrevista previa a la intervención.

- F. Con 7 años de edad, es un niño lleno de amor que tiene el deseo de compartir su mundo interior con sus compañeros, aunque sus circunstancias hayan sido algo más complicadas que las de otros niños. Con diagnóstico de TDAH, es un niño en el que las muestras de hiperactividad, impulsividad y trastorno de conducta se hacían evidentes en diferentes circunstancias, como por ejemplo a la hora de salir de las sesiones o al relacionarse con otros niños. El objetivo principal que nos planteamos trabajar al hablar con su madre fue aumentar la capacidad de regulación en relación con este tipo de conductas hiperactivas e impulsivas, así como determinadas muestras de agresividad y el desarrollo de vínculos afectivos significativos, ya que es un niño en situación de adopción.

- Y. Con 9 años de edad, es un niño cuyo mundo interno es inmenso e imaginativo, y está cargado de historias y vivencias que necesitan salir a la luz y ser compartidas con compañeros, profesores, padres, etc. Tiene muestras claras de hiperactividad, impulsividad y trastornos de conducta, especialmente cuando se relaciona con otros compañeros. Como veremos en el siguiente capítulo, de análisis de los datos, la conducta de Y parece tener origen en la situación de inestabilidad emocional que ha vivido desde los primeros años de vida, ya que se trata de un niño que, con solo 8 años de edad, está viviendo con su cuarta familia de acogida. 
Sin diagnóstico de TDAH:

- A. De 10 años de edad, es una niña alegre, tranquila y sociable. Su relación con su mundo emocional es directa, consciente y significativa. Esto es algo que se hacía evidente a lo largo del proceso musicoterapéutico, por la forma de responder a la música y, sobre todo, por la forma de expresarse a través de los dibujos, siempre llenos de carga emocional significativa. El interés de su madre por la Musicoterapia vino por el hecho de que consideraba que le costaba mucho centrar la atención en los estudios.

- I1. De 8 años de edad, es una niña realmente alegre, creativa y sociable. También está íntimamente relacionada con sus emociones de forma significativa y es capaz de compartirlas con los demás, expresándose de forma funcional en la mayor parte de las situaciones. El motivo de acudir a las sesiones fue, principalmente, que mejorase su capacidad de gestionar y expresar sus emociones cuando guardan relación con situaciones de conflicto.

- D2. Con 8 años de edad, es un niño encantador, muy alegre y motivado, siempre con ganas de acudir a las sesiones y dispuesto a participar y ayudar a sus compañeros en caso de ser necesario. Al iniciar la intervención, su madre dijo que los objetivos que le gustaría que trabajase guardaban relación directa con su capacidad de gestión emocional y con la capacidad de atención a la hora de centrarse en los estudios.

- M. Con 10 años de edad, a pesar de haber pasado por circunstancias complicadas al encontrarse en situación de acogida (es hermano de "Y") es alegre, optimista y, en determinadas situaciones, muy noble. Cuando comenzamos la intervención su padre de acogida pensó que la Musicoterapia le vendría bien, al igual que a su hermano "Y", para mejorar la capacidad de gestión emocional, así como para trata de regular algunas conductas no apropiadas.

Además, se contó con la participación, como informantes clave, de la madre de "J1" y "J2", los padres de "N", la madre de "F", los padres de acogida de "M" y "Y", la madre de "A" y las madres de "I1" y "D2". También se contó con la colaboración de las maestras tutoras de los niños con diagnóstico de TDAH. Por lo tanto, en la investigación participaron un total de 23 personas. 


\subsection{Técnicas e instrumentos de recogida de datos}

Debido al diseño de enfoque mixto, se utilizaron tanto instrumentos cuantitativos de recogida de datos como técnicas cualitativas de obtención de información. Así, en este apartado se describen la escala de evaluación de conductas EDAH y la escala de observación del desarrollo emocional para ciclo inicial, como escalas de recogida de datos cuantitativos, y la entrevista semiestructurada, la observación participante, el diario de campo y la recogida de material audiovisual y fotografías como técnicas cualitativas de obtención de información.

\subsubsection{Instrumentos cuantitativos de recogida de datos}

\subsubsection{Escala Evaluación del Trastorno por Déficit de Atención con Hiperactividad (EDAH)}

En el caso del TDAH, a lo largo de los últimos años se han desarrollado diferentes escalas para facilitar su detección y diagnóstico. Por ejemplo, el cuestionario de Gillberg, elaborado en Suecia por medio de una muestra de 3448 niños y niñas de la ciudad de Götenberg, o las distintas escalas de Conners, publicadas durante los años 1969 y 1970, que fueron diseñadas para ser cumplimentadas desde el punto de vista tanto de los profesores como de los padres, y unificadas más adelante (en el año 1973) en una única publicación en la que incluía una versión abreviada recogiendo los ítems de mayor puntuación (Farré y Narbona, 2013). Para nuestro trabajo de investigación se empleó la escala Evaluación del Trastorno por Déficit de Atención con Hiperactividad - de ahora en adelante EDAH - de tipo Likert de 0 a 3 (se puede observar en el Anexo II), cuyos ítems quedan reflejados en la Tabla 13.

Este instrumento fue completado por el investigador principal para cada uno de los niños con diagnóstico de TDAH participantes en la intervención musicoterapéutica. Asimismo, la misma escala fue completada por las maestras tutoras con el objetivo de comparar los puntos de vista tras el proceso de investigación (Anexo III). 
Tabla 13

Ítems de la escala EDAH distribuidos por factores

\begin{tabular}{|c|c|c|}
\hline $\begin{array}{c}\text { Área I: } \\
\text { Hiperactividad// }\end{array}$ & $\begin{array}{l}\text { 1. Tiene excesiva inquietud motora. } \\
\text { 5. Exige inmediata satisfacción a sus demandas. } \\
\text { 3. Molesta frecuentemente a otros niños. } \\
\text { 13. Se mueve constantemente, intranquilo. } \\
\text { 17. Es impulsivo e irritable. }\end{array}$ & $\begin{array}{l}\text { Hiperacti- } \\
\text { vidad/im- } \\
\text { pulsivi- } \\
\text { dad. }\end{array}$ \\
\hline Inatención & $\begin{array}{l}\text { 4. Se distrae fácilmente, muestra escasa atención. } \\
\text { 7. Está en las nubes, ensimismado. } \\
\text { 8. Deja por terminar las tareas que empieza. } \\
\text { 19. Sus esfuerzos se frustran fácilmente, es incons- } \\
\text { tante. } \\
\text { 2. Tiene dificultades de aprendizaje escolar. }\end{array}$ & $\begin{array}{l}\text { Déficit de } \\
\text { atención. }\end{array}$ \\
\hline $\begin{array}{c}\text { Área II: } \\
\text { Trastornos de } \\
\text { conducta }\end{array}$ & $\begin{array}{l}\text { 11. A menudo grita en situaciones inadecuadas. } \\
\text { 12. Contesta con facilidad. Es irrespetuoso y arro- } \\
\text { gante. } \\
\text { 15. Tiene explosiones impredecibles de mal genio. } \\
\text { 14. Discute y pelea por cualquier cosa. } \\
\text { 9. Es mal aceptado por el grupo. } \\
\text { 16. Le falta el sentido de la regla, del "juego lim- } \\
\text { pio". } \\
\text { 10. Niega sus errores o echa la culpa a los otros. } \\
\text { 18. Se lleva mal con la mayoría de sus compañeros. } \\
\text { 6. Tiene dificultad para las actividades cooperati- } \\
\text { vas. } \\
\text { 20. Acepta mal las indicaciones del profesor. }\end{array}$ & \\
\hline
\end{tabular}

Fuente: Farré y Narbona (2013, p. 29).

\subsubsection{Escala de observación del desarrollo emocional para ciclo inicial}

Con el objetivo de valorar la repercusión del estudio en relación con el desarrollo de las competencias emocionales de los niños participantes, se empleó una adaptación de la escala de observación del desarrollo emocional para ciclo inicial - de ahora en adelante EODE -, de tipo Likert de 0 a 3, que está basada en las aproximaciones teóricas e investigaciones previas del GROP (Grupo de Investigación en Orientación Psicopedagógica, por sus siglas en catalán) (Filella-Guiu, Pérez-Escoda, Agulló y Oriol, 2014) y en la escala de observación de la competencia emocional de López-Cassá (2007).

Tal y como se puede apreciar en la Tabla 14, esta escala se estructura en base a cinco bloques de competencias emocionales, respondiendo a lo que el GROP ha denominado el "modelo pentagonal de competencias emocionales" (Filella-Guiu et al., 2014). 
Tabla 14

Bloques de la escala de observación del desarrollo emocional

1. Conciencia emocional. 1.1. Siente emociones básicas.

1.2. Reconoce emociones básicas en los demás.

2. Regulación emocional. 2.1. Es capaz de relajarse.

2.2. Es capaz de pedir ayuda.

2.3. Es capaz de encontrar solución a los problemas.

3. Autonomía emocional. 3.1. Reconoce sus cualidades físicas.

3.2. Reconoce sus cualidades académicas.

3.3. Reconoce sus cualidades personales.

4. Competencia social. 4.1. Sabe pedir permiso.

4.2. Sabe dar las gracias.

4.3. Sabe pedir perdón.

5. Competencia de vida y 5.1. Muestra una actitud positiva. bienestar. 5.2. Es creativo.

Fuente: Adaptado de Filella-Guiu et al. (2014).

Esta escala fue completada por el investigador principal, al igual que la escala EDAH, al inicio y al final de la intervención musicoterapéutica, para valorar la repercusión de la investigación en relación con la competencia emocional de los niños participantes. Además, las familias también completaron esta escala con el fin de comparar su punto de vista con el del investigador principal (Anexo IV).

\subsubsection{Técnicas cualitativas de obtención de información}

\subsubsection{Entrevista semiestructurada}

En investigación cualitativa, las entrevistas nos sirven para escuchar y recopilar el discurso y la experiencia de los participantes de una investigación de forma directa y personal, hasta tal punto que el investigador recoge información sobre el mundo vivido por esas personas, su opinión, su forma de procesar una vivencia y, con ello, cómo sienten su situación personal, escolar, académica o laboral (Kvale, 2011). En otras palabras, a través de este tipo de conversaciones entre entrevistador y entrevistado se puede acceder al conocimiento, a las sensaciones, a la posición que adoptan los participantes ante el estudio del que están formando parte o a cómo está repercutiendo o afectando este en su situación personal, lo cual resulta relevante especialmente cuando los objetivos de la investigación van orientados a la transformación o mejora del contexto con el que se está trabajando. 
En nuestro caso esta técnica de obtención de información fue empleada con las familias de los niños con y sin diagnóstico de TDAH, antes y después de la intervención. Por ello, de entre los distintos tipos de entrevista cualitativa que existen en función del grado de estructuración (en profundidad, estructurada, semiestructurada, etc.) se optó por la entrevista semiestructurada, porque este tipo de entrevista ayuda a organizar las preguntas de investigación y a su posterior organización y categorización, pero igualmente deja espacio para que tengan lugar y se puedan desarrollar determinados temas de conversación emergentes (Verd y Lozares, 2016) que, en ocasiones, tienen igual o incluso mayor relevancia que las preguntas de investigación planteadas a priori.

Todas las entrevistas fueron grabadas en audio y transcritas literalmente. Esto favorece que la información obtenida por medio de entrevistas pueda ser organizada, estructurada y transformada en un texto susceptible de ser analizado y categorizado posteriormente (Kvale, 2011). Además, el hecho de que se esté grabando la conversación hace que el entrevistador esté más tranquilo sabiendo que no se le va a escapar información textual relevante, lo que hace que pueda estar más receptivo y atento a la conversación, favoreciendo así la interacción con la persona a la que está entrevistando (Rodríguez-Gómez, Gil y García, 1999). Los participantes fueron informados tanto en el momento de proporcionar información sobre la investigación, en la reunión inicial previa a la intervención, como en el preciso momento antes de comenzar la entrevista, de que la conversación iba a ser grabada y transcrita. El hecho de comunicar esto a los informantes ayuda a que no se sientan incómodos, alarmados o presionados por la presencia del objeto grabador (Taylor y Bogdan, 2010). En los Anexos V y VI se puede observar la transcripción de las entrevistas realizadas antes y después de la intervención.

\subsubsection{Observación participante y diario de campo}

Así como en la observación no participante el investigador se sitúa fuera de la realidad que está estudiando, de forma objetiva y con menos implicación a nivel emocional, en la observación participante el investigador forma parte de la realidad o contexto con el que está trabajando, así como de los procesos que se van desarrollando. En ocasiones, su presencia influye en cómo se configuran las relaciones interpersonales, por lo que ha de tener cuidado de no contaminar o condicionar el contexto, aunque, por otra parte, su presencia hace también que se genere más confianza entre él y las personas que participan en la investigación conforme esta se va desarrollando (Barba, 2013). Esto resulta relevante, especialmente, en aquellas investigaciones cuyos objetivos 
van encaminados a la transformación o mejora del contexto sobre el que se está trabajando. En estos casos, el investigador puede actuar, precisamente, como agente motor de los cambios positivos que se quieren introducir para que la realidad personal, laboral o social de los participantes mejore.

De hecho, es lo que ocurre en el caso de nuestro estudio, en el que el investigador principal asumió dos roles. Por una parte, actuó como musicoterapeuta al dirigir las sesiones, lo cual conlleva una implicación personal y emocional que lo sitúa, inevitablemente y, por otra parte, en posición de observador participante. Esto implica y justifica que su papel fuese orientado tanto al correcto desarrollo de la intervención musicoterapéutica que fue aplicada, como a la observación de lo que ocurría en las sesiones para poder recoger o reflejar todo lo que resultase relevante en relación con las categorías de investigación. Además, circunstancialmente ejerció el papel de entrevistador con las familias y los profesores tutores de los niños. La dificultad de la observación participante reside, por tanto, en la capacidad de adaptación que se demuestre a la hora de asumir los diferentes roles, y el mayor beneficio que aporta esta técnica es que la información que se obtiene de los procesos de los que el investigador forma parte es profunda, personal y auténtica. En palabras de Rodríguez-Gómez et al. (1999):

Los diferentes roles que puede asumir el investigador (...) nos dan una idea de las posibilidades que quedan abiertas al abordar la observación adoptando un papel determinado. (...) El observador participante puede acercarse en un sentido más profundo y fundamental a las personas y comunidades estudiadas y a los problemas que les preocupan. (...) [E]l investigador no necesita que nadie le cuente cómo han sucedido las cosas o cómo alguien dice que han sucedido, él estaba allí y formaba parte de aquello. (pp. 165-166)

Para facilitar las tareas de recopilación de información, reflejo del proceso terapéutico y reflexión sobre ello, a lo largo de la intervención se fue elaborando un diario de investigación. Este instrumento se redacta a partir de las notas que el investigador va tomando por medio de los procesos de observación, y permite reflejar no solo la información obtenida de forma directa del trabajo de campo, sino también su propia experiencia y posición, es decir, sus ideas, vivencias, sentimientos, impresiones, momentos de incertidumbre o duda, reflexiones, etc. (Verd y Lozares, 2016). Igualmente, este diario sirvió para el registro de los mandalas o dibujos infantiles que se iban creando en las sesiones de Musicoterapia (Anexo VII). 


\subsubsection{Material audiovisual y fotografías}

También con el objetivo de facilitar el proceso de recogida de información, así como el análisis de los datos, las sesiones fueron grabadas en vídeo y los mandalas y dibujos realizados por los niños fueron fotografiados. Todo este material fue archivado para hacer más significativo el proceso de análisis de las sesiones. La grabación en vídeo supone un gran soporte para ayudar a los investigadores a captar detalles o determinada información que pueda pasar inadvertida, ya que registra todo lo que ha ocurrido y permite recoger todos los acontecimientos de forma continuada (Taylor y Bogdan, 2010).

En nuestra investigación, los vídeos sirvieron para recoger detalles e información que pudiera haberse olvidado o pasado por alto en el momento de desarrollo de las sesiones, como por ejemplo determinados gestos de los niños, o expresiones verbales con gran carga y significado a nivel emocional. Las fotografías de los mandalas, por su parte, ayudan en gran medida a comprender de qué forma se manifestaban las diferentes emociones y formas de sentir la música a lo largo de la intervención musicoterapéutica, como veremos en el apartado de análisis de los datos.

\subsection{Proceso de análisis de datos}

Tal y como se ha indicado previamente, en el diseño DITRIAC, tanto los datos cuantitativos como la información cualitativa se obtienen de forma simultánea y complementaria conforme se va desarrollando el trabajo de campo (en nuestro caso, a lo largo del proceso de intervención musicoterapéutica). Por ello, el análisis de datos se lleva a cabo de forma paralela desde cada una de las perspectivas con el fin de llegar al último paso: la comparación e interpretación de los resultados. A continuación, se describe cómo se llevó a cabo el análisis de datos cuantitativos y cualitativos.

\subsubsection{Análisis de los datos cuantitativos}

Como se ha explicado previamente en el enfoque de la investigación, desde el punto de vista cuantitativo nuestro trabajo responde a un diseño longitudinal. En este tipo de estudio se valoran los cambios producidos por el proceso de intervención en un grupo de participantes determinado. Por lo tanto, se trata de un diseño de análisis intrasujeto.

Para llevar a cabo este proceso de análisis de datos, y dado que el número de niños participantes no es muy elevado, se realizaron pruebas no paramétricas, sustituyendo en nuestro caso la T de Student por la prueba de Wilcoxon. De esta forma conseguimos la misma medición que conseguiríamos con las pruebas paramétricas, pero en una muestra de sujetos más pequeña. 
Así, se llevó a cabo este proceso de análisis de datos cuantitativos para valorar si se habían producido cambios estadísticamente significativos en el grupo al comparar el inicio con el final de la intervención, aplicando la prueba de Wilcoxon para un nivel de confianza del 5\%. Para realizar la comparación entre el punto de vista del investigador principal con el de las familias y las tutoras al final de la intervención también se empleó la prueba de Wilcoxon. Cabe señalar también que, a la hora de mostrar esta información en el capítulo de análisis de datos, se muestran tanto los valores de las medias, ya que esto puede proporcionar una mayor comprensión de la interpretación de los resultados, como los valores de las medianas, ya que la prueba de Wilcoxon opera con dichos valores. Para llevar a cabo todo este proceso de análisis se utilizó el programa de análisis estadístico SPSS Statistics.

\subsubsection{Análisis de la información textual cualitativa}

El análisis de datos cualitativos es una de las tareas más complicadas y arduas, aunque igualmente interesantes y atractivas, de un proceso de investigación. Es el momento en el que el investigador tendrá que dar a toda la información textual obtenida un significado cuya relevancia sea adecuada y de utilidad para responder a las preguntas de investigación que se habían planteado en un primer momento, así como a las que puedan haber surgido durante el desarrollo del trabajo de campo (Rodríguez-Gómez et al., 1999). Para realizar el análisis de contenido textual se siguieron algunas de las fases propuestas por Kvale (2011) para el análisis de datos cualitativos, centradas en la búsqueda de significado de los textos: codificación de significado, condensación del significado e interpretación del significado. Para facilitar este proceso se empleó el programa informático de análisis cualitativo ATLAS.ti (Anexo VIII).

\subsubsection{Proceso de codificación o categorización del significado}

En el primer procedimiento, es decir, el proceso de codificación (o, en función del autor que se refiera al término, de categorización) del significado se delimitan una serie de palabras clave, denominados códigos o categorías, que ayuden a organizar y estructurar la información en base a unos temas que a menudo estarán relacionados con las preguntas de investigación. Una vez la información ha sido reorganizada en función de estas categorías, se facilita la tarea de comparación y análisis de los datos.

De esta manera, el proceso de categorización nos ayuda a reducir la gran cantidad de información textual obtenida a través del trabajo de campo y convertirla en fragmentos de texto cuya reestructuración favorece la comprensión de los contenidos, ofrece un panorama o visión global del estudio y facilita las comparaciones y el análisis de datos (Ruiz, 2012). De alguna forma se puede 
entender que el planteamiento y definición de categorías es una parte clave de cualquier investigación de corte o influencia cualitativa, ya que su correcto establecimiento garantiza, en mayor o menor medida, que los resultados obtenidos se ajusten a las preguntas de investigación planteadas (Tójar, 2006). De hecho, en algunas ocasiones el surgimiento de nuevas categorías que no estaban planteadas a priori hace que algunos puntos de vista, opiniones o impresiones de los participantes que pueden haberse pasado por alto por el investigador tomen importancia. Son las denominadas categorías emergentes, que surgen en algún momento del trabajo de campo y que pasan a formar parte inherente del propio proceso de investigación.

Para llevar a cabo este sistema de análisis de datos, al inicio del trabajo de campo fueron planteadas una serie de categorías a priori que se reflejan en la Tabla 15. Como se puede observar, se definieron en base a los ítems que estructuran las escalas cuantitativas empleadas para facilitar el proceso de comparación y análisis de datos posterior.

Tabla 15

Categorías elaboradas antes del comienzo del trabajo de campo

\begin{tabular}{cl}
$\begin{array}{c}\text { Nombre de } \\
\text { la categoría }\end{array}$ & \multicolumn{1}{c}{ Breve definición } \\
\hline EODE1_CE & $\begin{array}{l}\text { Muestras de conducta relacionadas con la conciencia emocional, como sen- } \\
\text { tir emociones básicas o la capacidad de reconocer emociones básicas en los } \\
\text { demás. }\end{array}$
\end{tabular}

EODE2_RE Muestras de conducta relacionadas con la regulación emocional, como la capacidad de relajación, de pedir ayuda o de encontrar solución a los problemas.

EODE3_AE Muestras de conducta relacionadas con la autonomía emocional, como el reconocimiento propio de las cualidades físicas, académicas o personales.

EODE4_CS Muestras conductuales relacionadas con la competencia y/o adaptación social, como capacidad de pedir permiso, perdón o dar las gracias.

EODE5_CVB Muestras conductuales relacionadas con la competencia de vida y bienestar, como la muestra de una actitud positiva o la creatividad.

EDAH1_HI Muestra de conductas relacionadas con la hiperactividad y la impulsividad, como la excesiva inquietud motora, la intranquilidad o la exigencia de satisfacción inmediata a las demandas.

EDAH2_A Muestra de conductas relacionadas con el déficit de atención, como la distracción, la escasa atención, las dificultades de aprendizaje escolar, la frustración o la dificultad para trabajar de forma constante.

EDAH3_TC Muestras conductuales relacionadas con mal comportamiento o trastornos de conducta, como la agresividad, el mal genio, las dificultades de relación social, la mala aceptación del grupo o los problemas en las actividades cooperativas.

Fuente: Elaboración propia. 


\subsubsection{Fases de condensación e interpretación del significado}

La fase de condensación del significado consiste en resumir fragmentos de texto que son muy largos en una o dos oraciones que conserven el significado de la cita, para facilitar así su posterior análisis y comparación con otras partes de los resultados (Kvale, 2011). En la Figura 5 se puede apreciar en qué consiste este procedimiento a través de un ejemplo sencillo extraído de un informe de ATLAS.ti. El contenido es la cita, el fragmento textual categorizado proveniente de una entrevista semiestructurada, y en el comentario se puede observar el proceso de condensación del significado. Esto, que no deja de ser un procedimiento sencillo, facilitó el análisis de la información textual, especialmente en los casos en los que la cita es muy extensa y, de este modo, se puede visualizar con mayor facilidad.

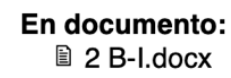

B: Por su fuerza de voluntad, que es impresionante. Él estaba con una mesita de esas de plástico de los niños pequeños y se subió encima, se puso de pie y se cayó para atrás. Cuando esto tenía tres añitos y medio, casi cuatro... Y en ese momento, entra en coma, menos mal que vivimos cerca de Segovia, porque el niño casi ni respiraba. Le hicieron una operación tremenda, de la cual pensamos que no sabían si iba a salir, le quitaron medio cráneo... Nos dijeron que el accidente había sido más grave que un accidente de tráfico, o sea, un traumatismo severo. $Y$ entonces, estuvo en coma mucho tiempo y cuando despertó del coma, tenía la mirada perdida, no hablaba, no se movía, no sujetaba nada... La mirada perdida, como estos niños que les ves, con un daño cerebral irreversible.

\section{Comentario:}

B explica el accidente que tuvo su hijo y cómo eso impactó en la familia. Se dio un golpe muy fuerte en la cabeza, estuvo en coma mucho tiempo y cuando despertó no hablaba, no se movía.

Figura 5. Extracto de un ejemplo de condensación del significado. Elaboración propia.

Por su parte, la fase de interpretación del significado corresponde con el momento en que el investigador revisa el contenido de la información textual de forma profunda y crítica, estableciendo relaciones de significado e identificando puntos en común entre los discursos para triangular las fuentes y llegar a conclusiones coherentes (Kvale, 2011). Se trata de un procedimiento delicado y riguroso del cual puede depender que los resultados de una investigación sean contrastados, fiables y trascendentales. Esta fase se puede apreciar en el proceso de análisis de los datos y en el apartado de resultados, no solo a la hora de comparar la información textual cualitativa, sino también a la hora de cruzar dicha información con los datos cuantitativos obtenidos. Recordemos que en el diseño DITRIAC (Hernández-Sampieri et al., 2014) la información cualitativa y los datos cuantitativos son comparados e interpretados de forma conjunta con el objetivo de dar lugar a resultados comunes $\mathrm{y}$, con ello, respuestas a las preguntas de investigación planteadas previamente. 


\section{CUESTIONES ÉTICO-METODOLÓGICAS}

Cuando en una investigación se ven envueltas personas que actúan como informantes o como participantes activos de tal forma que lo que ocurra a lo largo del estudio puede influir en su situación personal, académica, familiar, etc., es necesario tener en cuenta algunas cuestiones que garanticen el cuidado y respeto hacia su integridad física y emocional, así como otros principios relacionados directamente con la ética de la investigación.

En primer lugar, tanto a la hora de informar a los participantes en la investigación como una vez había comenzado el trabajo de campo y a lo largo de todo el proceso de desarrollo del estudio, hasta su final, se tuvieron en cuenta algunas de las consideraciones básicas relacionadas con la ética de la investigación y recogidas por la American Psychological Association (2010) en su manual de publicaciones:

- Consentimiento informado para la investigación. En todo momento se informó a los participantes de las características del estudio, su propósito y objetivos, la forma en que se iba a desarrollar la intervención musicoterapéutica, las implicaciones que podría tener a nivel emocional, los beneficios que pudiese haber en la vida de los niños y a los que pudiese dar lugar la investigación, la duración estimada, los procedimientos a seguir en relación con la obtención de la información, la libertad de abandonar el estudio en cualquier momento o de negar la utilización de los datos obtenidos una vez llegado a su término, etc. El modelo de consentimiento informado diseñado y proporcionado se recoge en el Anexo IX. Las copias cumplimentadas y firmadas por las familias no se recogen por una cuestión de protección de datos y con el objetivo de garantizar el proceso de anonimato.

- Consentimiento informado para grabar voz en la investigación. A la hora de realizar una entrevista semiestructurada se solicitó a los entrevistados tanto el permiso para grabar la conversación como el consentimiento para que esa grabación fuese guardada, archivada y posteriormente transcrita para que pudiese ser analizada pertinentemente.

- Engaño en la investigación. Bajo ningún concepto se ocultó información relevante relativa a la investigación, ni información relacionada con los resultados del estudio, ni información acerca de los riesgos que pudiese implicar la participación. 
- Retroalimentación. En todo momento se informó de la posibilidad de acceder a la información que se iba obteniendo y a la construcción de análisis de datos que de la investigación se iba derivando. Es decir, que los participantes tenían total libertad para conocer lo necesario en relación con la naturaleza del estudio, el desarrollo del trabajo de campo, el análisis de los datos, los resultados obtenidos o las conclusiones extraídas.

- Informe de los resultados de la investigación. La información obtenida del trabajo de campo ha sido extraída de las entrevistas semiestructuradas con las familias, de las sesiones de Musicoterapia con los niños y de las correspondientes reuniones con los profesores tutores, de modo que no se trata de información inventada o falsa, sino que es real, verídica y ajustada a lo acontecido durante el desarrollo de la investigación.

- Plagio. En esta investigación no se presentan datos ni cualquier otro tipo de información que haya sido registrada o publicada previamente por otros autores.

- Publicación duplicada de datos. En la presente investigación no se presentan ni emplean datos que hayan sido utilizados previamente para otra investigación o publicados en algún otro tipo de soporte.

Igualmente, se tuvieron en cuenta otras cuestiones éticas que, según Flick (2014), deben ser consideradas por el investigador antes, durante y después del proceso de investigación:

- Relevancia. En este sentido, el autor insta al investigador a preguntarse, antes del inicio de la investigación, si el estudio que está planteando aporta nuevo y relevante conocimiento al campo sobre el que se va a trabajar. En nuestro caso podemos justificar, teniendo en cuenta no solo la revisión de la literatura, sino el propio testimonio de las personas informantes, tanto en esta como en otras investigaciones previas, que la aplicación de la Musicoterapia y, más en concreto, de técnicas de música e imagen, en casos de TDAH apenas ha sido explorada y, por tanto, que el tema de investigación planteado es novedoso y relevante.

- Los participantes. Esta premisa, que se refiere a si la elección de los participantes en el estudio es adecuada y justificada, especialmente si se trata de personas vulnerables como niños, ancianos o 
enfermos, fue considerada en tanto que se partía de la idea de que la intervención musicoterapéutica podría tener repercusiones positivas en la situación personal y académica de los niños con y sin diagnóstico de TDAH, así como en su entorno familiar. Desde un principio se tuvo en cuenta, igualmente, la vulnerabilidad de este colectivo y, por ello, se tomaron las medidas y consideraciones necesarias en relación con su seguridad y estabilidad emocional.

- La selección. Se refiere a los conflictos que puedan surgir entre personas pertenecientes a un mismo contexto en relación con las decisiones que tome el investigador a la hora de escoger a quienes serán los participantes del estudio. En nuestro caso, el número de respuestas obtenidas fue relativamente escasa, y todos los participantes encajaban en el perfil de selección (niños y niñas de entre 7 y 11 años con y sin diagnóstico de TDAH), por lo que este dilema ético no tuvo lugar en ningún momento.

- Perturbación. En todo momento se trató de que la actuación del investigador principal no resultase invasiva, intimatoria o irreverente en los diferentes momentos de intervención: las entrevistas semiestructuradas, las conversaciones informales, las reuniones grupales o las reuniones con los tutores. Esta premisa se refiere tanto a los momentos en los que el investigador está hablando con los informantes y llega a un punto en el que surge información especialmente delicada, como a la no alteración de las rutinas y costumbres de las personas participantes. En este sentido, los horarios de la intervención, así como las situaciones de entrevista con las familias y las reuniones con los tutores, fueron adaptados a las circunstancias personales y laborales de los participantes en la medida de lo posible.

- Avasallamiento. Relacionada con la premisa anterior, esta se refiere a la capacidad del entrevistador para no sobrepasar los límites del consentimiento que los participantes han establecido en diferentes situaciones, tales como el acceso a espacios, personas o cierto tipo de información. En relación con ello, desde el comienzo del acceso al campo se siguieron los pasos establecidos por los protocolos de cada uno de los colegios contactados, y las necesidades y solicitudes de los participantes una vez habían sido seleccionados en la medida de lo posible. 
- Precisión. En lo referido al análisis de los datos, en todo momento se trató que fuese metódico, sistematizado, contrastado y riguroso. Asimismo, durante el proceso de investigación los datos fueron revisados varias veces con ayuda del material audiovisual, con el objetivo de asegurar que se ajustasen todo lo posible a la realidad de lo ocurrido a lo largo del trabajo de campo.

Por otra parte, en lo referido a las consideraciones éticas relacionadas con la realización de entrevistas en investigación cualitativa, y dado que en nuestro estudio se llevaron a cabo entrevistas semiestructuradas, se tomaron en consideración las siguientes premisas enunciadas por Kvale (2011), que deben ser tenidas en cuenta siempre a la hora de realizar entrevistas cualitativas de cualquier tipo:

- Situación de entrevista. En una conversación entre entrevistador y entrevistado, especialmente cuando estas personas no se conocen, pueden darse situaciones delicadas, momentos incómodos, nerviosismo, estrés, etc. De hecho, es posible que algunos de los temas que surgen durante la conversación estén relacionados directamente con la historia personal del informante y, por lo tanto, que se den momentos de implicación emocional, ya sean dolorosos o alegres, ante los cuales el investigador debe mostrar su apoyo y comprensión sin emitir juicios para que la entrevista se desarrolle de la forma más natural posible. Dicho lo cual, durante las situaciones de entrevista en todo momento se tuvieron en cuenta las consecuencias que puede tener la interacción entre entrevistador y entrevistado, manteniendo la compostura y mostrando amabilidad y comprensión ante las diferentes circunstancias personales.

- Transcripción. Las entrevistas fueron transcritas palabra por palabra, literalmente, de tal forma que se reflejase fielmente el discurso, la opinión y perspectiva de los informantes.

- Confidencialidad. La reserva del anonimato fue garantizada para todas las personas entrevistadas. Asimismo, se siguió este proceso para todos los participantes en la investigación, tal y como se explica a continuación. 
Por último, el proceso de anonimato se garantizó desde el inicio de la investigación hasta el final. Para ello, se emplearon las iniciales de los niños participantes (como se ha mostrado previamente en la descripción de los participantes) y se designó a sus padres y madres como tal, respectivamente y según correspondiese. En las imágenes recogidas (las fotografías de los mandalas) se han borrado los nombres de los niños cuando lo escribían al terminar los dibujos. Por último, los vídeos no se hicieron públicos en ningún momento y no han sido mostrados en ningún tipo de evento ni congreso científico.

\section{CRITERIOS DE VALIDEZ, FIABILIDAD Y TRIANGULACIÓN}

Para finalizar con este capítulo de metodología de la investigación, solo queda explicar de qué modo están presentes los criterios de validez y fiabilidad en nuestro estudio.

La validez se refiere, en términos generales, a la fuerza, la corrección y la verdad que se demuestra tener en cuenta a la hora de elaborar un trabajo de investigación (Kvale, 2011). La validación depende en gran medida de la calidad del conocimiento que se está recogiendo, en el caso de las investigaciones cualitativas, y de si las herramientas empleadas para la recogida y el análisis de los datos obtenidos han sido testadas y validadas $\mathrm{y}$, por lo tanto, son robustas, cuando se trata de investigaciones de corte cuantitativo.

La fiabilidad, por su parte, hace alusión a la confiabilidad y a la coherencia de los hallazgos obtenidos tras un proceso de investigación determinado. En otras palabras, este criterio trata de responder a la pregunta de si la investigación llevada a cabo es reproducible por otros investigadores, en otro momento y/o en otros lugares (Kvale, 2011). Desde una perspectiva cualitativa, suele surgir la pregunta de si una investigación podría ser reproducida de forma exactamente igual aun cuando los informantes cambiarían. Desde el punto de vista cuantitativo, este concepto responde al grado de fiabilidad de los instrumentos de medida, esto es, al grado de consistencia o de repetición de las medidas en un mismo sujeto, lo que se suele medir a través del grado de coherencia o correlación entre los ítems de una escala.

Tanto la escala EDAH como la escala de observación de desarrollo emocional para ciclo inicial cumplen los criterios de validez y fiabilidad: 
- Para el estudio de la validez de la escala EDAH, (Farré y Narbona, 2013) contaron con una muestra de 43 alumnos, cuyos profesores respondieron a este instrumento, dando como resultado global un coeficiente de alfa de Cronbach de 0,93. Para calcular la fiabilidad desarrollaron un estudio psicométrico, hallando las correlaciones de cada ítem con su factor, de cada ítem con su total y de cada factor con el total, dando como resultado un coeficiente de alfa de Cronbach de 0,9523 (Farré y Narbona, 2013).

- En el caso de la escala de observación de desarrollo emocional para ciclo inicial, Filella et al. (2014) la sometieron a un proceso de validación por jueces (en total 12) quienes, al preguntarles si cada ítem de la escala era unívoco, relevante y comprensible, las medias resultantes fueron $8^{\prime} 7,9^{\prime} 2$ y 9,7, respectivamente. Por otra parte, para analizar la fiabilidad de la escala utilizaron el cálculo de la consistencia interna mediante el coeficiente alfa de Cronbach, dando como resultado $0.83,0.77,0.76,0.84$ y 0.75 respectivamente para cada uno de los bloques de competencia emocional: conciencia emocional, regulación emocional, autonomía emocional, competencia social y competencia de vida y bienestar (Filella et al., 2014).

Por otra parte, además de considerar estos criterios, a lo largo del proceso de investigación se tuvieron en cuenta en todo momento dos de las estrategias de triangulación recogidas por Stake (1999), como son la triangulación de las fuentes y la triangulación metodológica:

- Se llevó a cabo una triangulación de las fuentes, ya que la información se obtuvo en todo momento desde diferentes vías: las sesiones de Musicoterapia (punto de vista del investigador), la vivencia de los niños, el testimonio de los padres y el punto de vista de las tutoras.

- La triangulación metodológica viene dada directamente por el enfoque mixto, ya que en el diseño DITRIAC la información se obtiene a través de técnicas cualitativas e instrumentos cuantitativos. En nuestro caso, tal y como se ha explicado previamente, se emplearon la escala EDAH, la escala de observación de desarrollo emocional para ciclo inicial, el diario de investigación, la observación participante y la entrevista semiestructurada. 




\section{CAPÍTULO VI. ANÁLISIS DE LOS DATOS}



En este capítulo se presentan los resultados extraídos del proceso de análisis de los datos desde un punto de vista tanto cuantitativo como cualitativo. Recordemos que, en la investigación por métodos mixtos y, más en concreto, en el Diseño de Triangulación Concurrente o DITRIAC, la información se va obteniendo de forma complementaria desde ambas perspectivas (cuantitativa y cualitativa) para ser finalmente comparada e interpretada (Hernández-Sampieri et al., 2014), que es el modo en que se hace en este capítulo.

Por una parte, se analizan las pruebas estadísticas descriptivas y no paramétricas pertinentes (prueba de Wilcoxon), comparando los valores cuantitativos antes y después de la intervención, para valorar si los cambios que hayan tenido lugar durante la intervención han sido significativos (para un nivel de confianza - de ahora en adelante n.d.c. - del 5\%). Estos datos se desprenden de la escala EODE, de observación de desarrollo emocional, empleada (para todos los niños, con y sin diagnóstico de TDAH) y de la escala EDAH para la evaluación de conductas propias del TDAH (solo en los casos de niños con este diagnóstico). Cabe recordar, igualmente, que estas escalas fueron cumplimentadas también por las familias y por las tutoras de los niños, respectivamente, después de la intervención, con el objetivo de contrastar la opinión del investigador principal con la del entorno más cercano a los niños participantes en el estudio.

Por otra parte, se contrasta y complementa esta información con los datos cualitativos (categorizados y analizados tal y como se ha explicado previamente) que se desprenden de las entrevistas a las familias, llevadas a cabo antes y después de la intervención, y del diario de investigación, en el que se han ido relatando los aspectos más destacables de las sesiones de Musicoterapia (individuales y grupales). Además de esta información cualitativa, el análisis cuantitativo también es complementado con la aportación de algunos mandalas, creados por los niños en las sesiones, que guardan una relación directa con las categorías de investigación que están siendo analizadas.

A la hora de analizar la información textual obtenida desde el punto de vista de la investigación de encuadre cualitativo se han desprendido un total de 1454 citas. En este capítulo se ven reflejadas aquellas que corresponden con las categorías de investigación que son contrastadas con los datos cuantitativos obtenidos de la escala de observación de desarrollo emocional y la escala EDAH para la evaluación de conductas propias del TDAH. Estas categorías se presentan en el siguiente orden: conciencia emocional, regulación emocional, autonomía emocional, competencia social y competencia de vida y bienestar (escala EODE); hiperactividad e impulsividad, inatención y trastorno de conducta (escala EDAH). 


\section{REPERCUSIÓN DE LA INTERVENCIÓN A NIVEL EMOCIONAL}

\subsection{Conciencia emocional}

Recordemos que, dentro de la escala EODE, el valor cuantitativo de conciencia emocional hace alusión a la competencia o capacidad, por parte de los niños participantes en el estudio (tanto los que están diagnosticados de TDAH como los que no), de sentir emociones básicas, por una parte, y de reconocer emociones básicas en los demás, por otra. Desde un punto de vista cualitativo, se han tomado en consideración estos ítems de la escala, de forma literal, designando las citas textuales correspondientes bajo la categoría EODE1_CE. En la Tabla 16 se presenta una breve definición de esta categoría.

Tabla 16

Categoría cualitativa para el análisis textual de conciencia emocional

\begin{tabular}{|c|c|c|c|c|}
\hline Nombre & Citas & Definición & Cuándo se usa (ejemplo) & $\begin{array}{l}\text { Cuándo no se usa } \\
\text { (ejemplo) }\end{array}$ \\
\hline EODE1_CE & 103 & $\begin{array}{l}\text { Citas textuales en las } \\
\text { que se alude a la ca- } \\
\text { pacidad de reconocer } \\
\text { emociones básicas en } \\
\text { uno mismo y en los } \\
\text { demás por parte de } \\
\text { los niños participan- } \\
\text { tes. }\end{array}$ & $\begin{array}{l}\text { "Ha conectado también mucho } \\
\text { con el miedo, hacía muchas cosas } \\
\text { de miedo... (...) pero también con } \\
\text { cosas muy alegres; sin embargo, } \\
\text { con la ira, nada, no ha hecho cosas } \\
\text { con ira... (...) Sí, la tristeza con el } \\
\text { miedo, algo ha hecho..." }\end{array}$ & $\begin{array}{l}\text { "Mira, yo he inten- } \\
\text { tado con él dibujar la } \\
\text { figura humana, aun- } \\
\text { que aún no la dibuja } \\
\text { bien, no tiene idea de } \\
\text { la proporción". }\end{array}$ \\
\hline
\end{tabular}

Como se puede observar, esta categoría ha recibido 103 citas textuales, por lo que se trata de una de las categorías con más citas extraídas. De antemano, esto nos indica que la conciencia emocional se trata, por lo tanto, de uno de los puntos de interés que más presente ha estado a lo largo de esta investigación, tanto en las entrevistas a las familias (antes y después de la intervención) como en el desarrollo de la intervención musicoterapéutica.

Desde el punto de vista cuantitativo, el primer paso es considerar si se han producido cambios estadísticamente significativos a raíz de la intervención de Musicoterapia llevada a cabo, así como durante su desarrollo. Para ello, se lleva a cabo la comparación entre los valores totales de conciencia emocional 
antes y después de la intervención aplicando la prueba de Wilcoxon. Teniendo en cuenta la información mostrada en la Tabla 17, se puede asumir que se han producido cambios estadísticamente significativos en la conciencia emocional de los niños participantes para un n.d.c. del $5 \%(Z=-2,72$; $\mathrm{p}<, 05)$.

Tabla 17

Conciencia emocional antes y después de la intervención

\begin{tabular}{lccccc} 
& Media & Mediana & D. T. & $\mathbf{Z}$ & Sig. \\
\hline Antes de la intervención & 2,00 & 2,00 & 1,00 & & \\
Después de la intervención & 5,00 & 5,00 &, 87 & & \\
\hline $\begin{array}{l}\text { Nota: Para todas las tablas siguientes: } \\
\text { D.T.= Desviación Típica. Sig.= Nivel de Significación. Z= Estadístico de Wilcoxon. }\end{array}$
\end{tabular}

Fuente: Elaboración propia.

Así, tomando en consideración los valores de las medias antes y después de la intervención, se puede asumir que la competencia de conciencia emocional ha aumentado de forma significativa. De hecho, ya en las primeras sesiones se podía apreciar cómo esta competencia emocional se estaba mostrando en algunos casos concretos de los niños participantes. Veamos, a modo de ejemplo, el mandala de "A" (de 10 años de edad y sin diagnóstico de TDAH), dibujado en su primera sesión, en el que se puede apreciar claramente esta capacidad en relación con el reconocimiento de sus propias emociones (Figura 6):

El dibujo está cargado de fuerza emocional y de sentimientos de relación social, concretamente familiares. En el centro se dibuja a sí misma bailando, que es una actividad que realiza y que le encanta, le hace sentir feliz, representa la pasión (color rojo) y la alegría (color naranja) en su vida. A la izquierda se representa a sí misma con su madre intentando hacer un baile que le había enseñado, con la palabra "amistad" (color verde). Por otra parte, vemos a su perro, que ha muerto hace unos días, por lo que lo representa asociado a la tristeza (color azul). Hay una asociación psicológica entre estas emociones y el color que emplea en cada una de ellas, ella misma da la explicación de por qué ha escogido cada color. El título aporta información del dibujo por sí solo: "Mis sentimientos bailando". (Diario de investigación, Sesión 1 de A) 


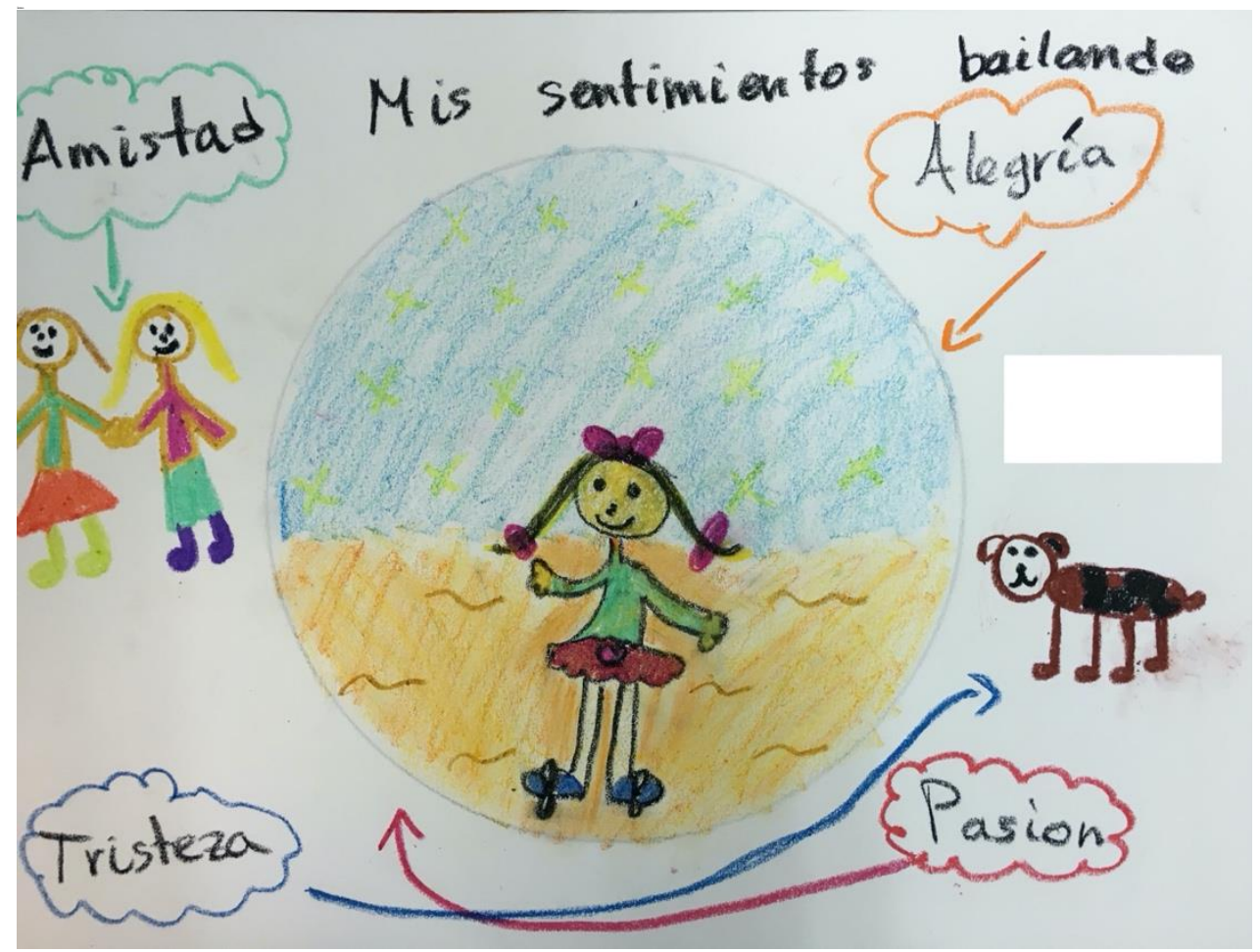

Figura 6. Mandala de A, Sesión 1. 09/03/2017.

La situación de terapia y el efecto de la música contribuyen a que se produzca una conexión y expresión a nivel emocional. Este ejemplo resulta de especial relevancia si tenemos en cuenta la actitud que "A" tenía al inicio de esta primera sesión, así como la información proporcionada por su madre antes y después de la intervención:

Es muy tímida, tiene la voz muy suave, y el lenguaje corporal indica algo similar, parece que al principio de la sesión siente vergüenza o que está poco receptiva. Ella misma admite que está nerviosa porque es la primera vez que viene y no sabe lo que vamos a hacer.

(Diario de investigación, Sesión 1 de A)

[C]uando llegué a casa le dije: "Mira, A, es que te voy a apuntar a una especie de estudio, una tesis de psicología... Mira, toma el papelito y nos lo leemos entre las dos". Y, claro, lo primero que vi es que, a lo mejor, ella ya sabía lo que era eso, porque lo habían hablado en clase, pero enseguida se puso a llorar, preguntándome si tenía algo malo.

(Entrevista a madre de A, antes de la intervención)

Mira, al principio, te lo dije, como que tenía un poco de miedo, cuando la expliqué que iba a venir aquí, pero luego, cuando se iba, se iba muy tranquila, eso sí que lo he notado al salir de la clase.

(Entrevista a madre de A, después de la intervención) 
Otro ejemplo que resulta de gran utilidad para complementar y contrastar esta información guarda relación con dos mandalas dibujados por "N" en su segunda y cuarta sesión, que corresponden con las Figuras 7 y 8 respectivamente. Recordemos que "N" es un niño de 9 años de edad, diagnosticado de TDAH, que estaba recibiendo medicación durante el desarrollo de la intervención, por lo que la necesidad de movimiento constante no se hacía tan visible como la dificultad para mantener la atención y la concentración en determinadas tareas.

En su segunda sesión individual, "N" mostró una actitud bastante distinta a la de la primera sesión. Así como en la primera sesión se mostraba tímido y realizó un mandala muy pequeño y aparentemente sencillo, con escaso significado o carga a nivel emocional, en la segunda sesión hizo un dibujo muy significativo, ya que dejó volar su imaginación para identificar sensaciones como la diversión y la fantasía, y conectar con emociones como la alegría o la felicidad (Figura 7):

$\mathrm{N}$, manteniendo en todo momento una atención concienzuda en la realización de su dibujo, pasa de utilizar un espacio muy reducido para dibujar trazos medidos, muy delicados y tímidos, a emplear todo el espacio de forma más libre para plasmar un paisaje enorme, expandido, lleno de color, fantasía, fuerza, alegría y diversión. Se trata de un dibujo de libre expresión. De hecho, él mismo afirma que es solo una pequeña parte de todo lo que ha imaginado. Se ha visto a sí mismo allí explorando todo, entrando en cada casa y descubriendo cada detalle. La expresión de su cara cuando cuenta su experiencia está llena de alegría y entusiasmo.

(Diario de investigación, Sesión 2 de N)

Por otra parte, en la quinta sesión "N" demostró una gran capacidad de conciencia emocional al expresar cómo quería escuchar una música relacionada con el otoño, y cómo se relacionaba esto con unas sensaciones emocionales concretas y determinadas (Figura 8):

Tiene muy claro que le apetece escuchar música de otoño. Le pregunto cómo es esta música y dice que tiene que tener violín y que es entre alegre y triste. Me llama mucho la atención que haga esta reflexión a nivel emocional, bastante avanzada y profunda teniendo en cuenta su edad. (...) El mandala habla por sí solo: "El otoño descomunal". Después de pintar se muestra más contento, la expresión de su cara cambia y refleja mucha más alegría. Le pregunto qué siente al ver el dibujo, dice que cuando lo mira se olvida de todo y se ríe al decirlo. Se va de la sesión tranquilo y alegre.

(Diario de investigación, Sesión 5 de N) 


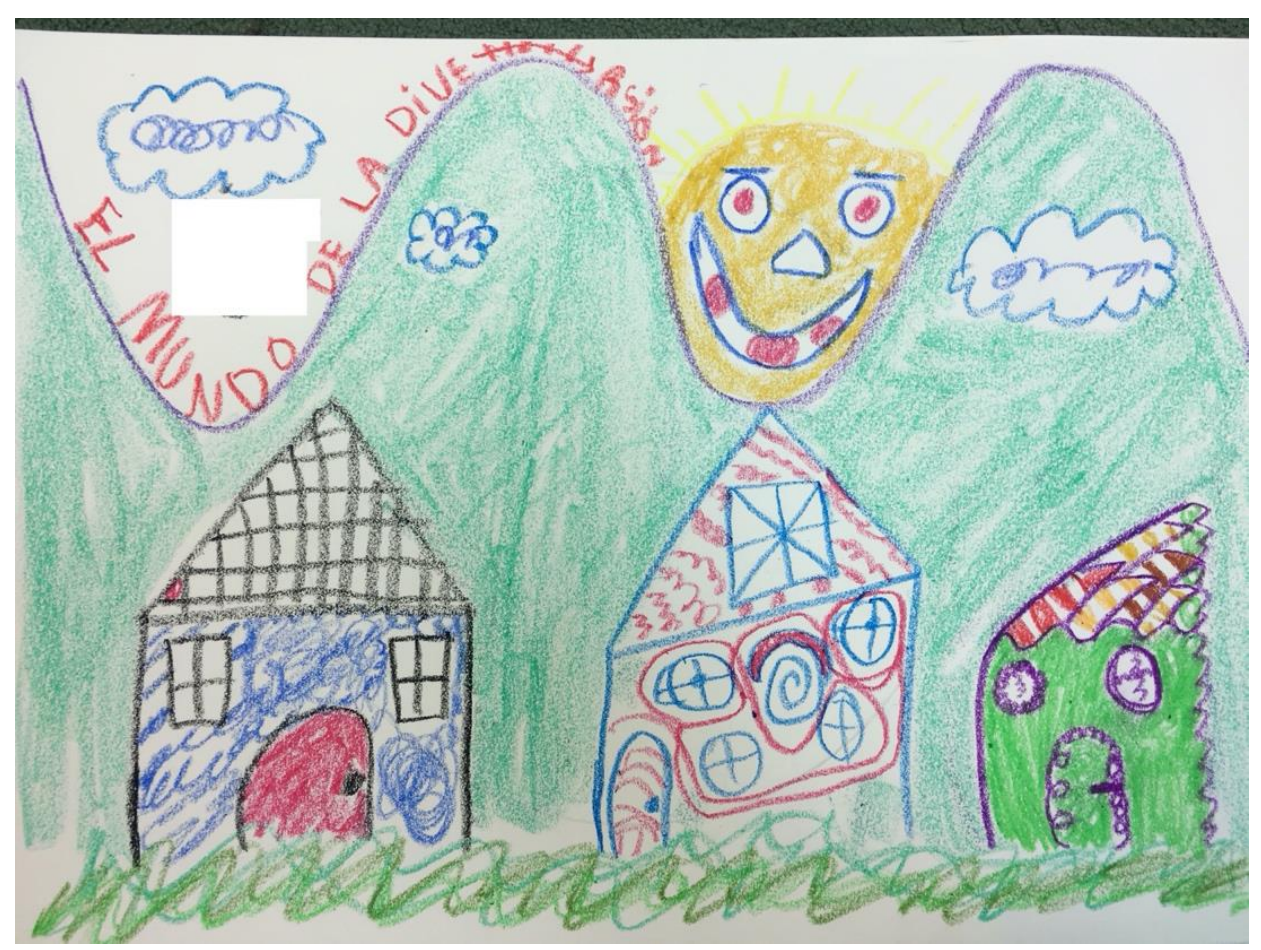

Figura 7. Mandala de N, Sesión 2. 15/03/2017.

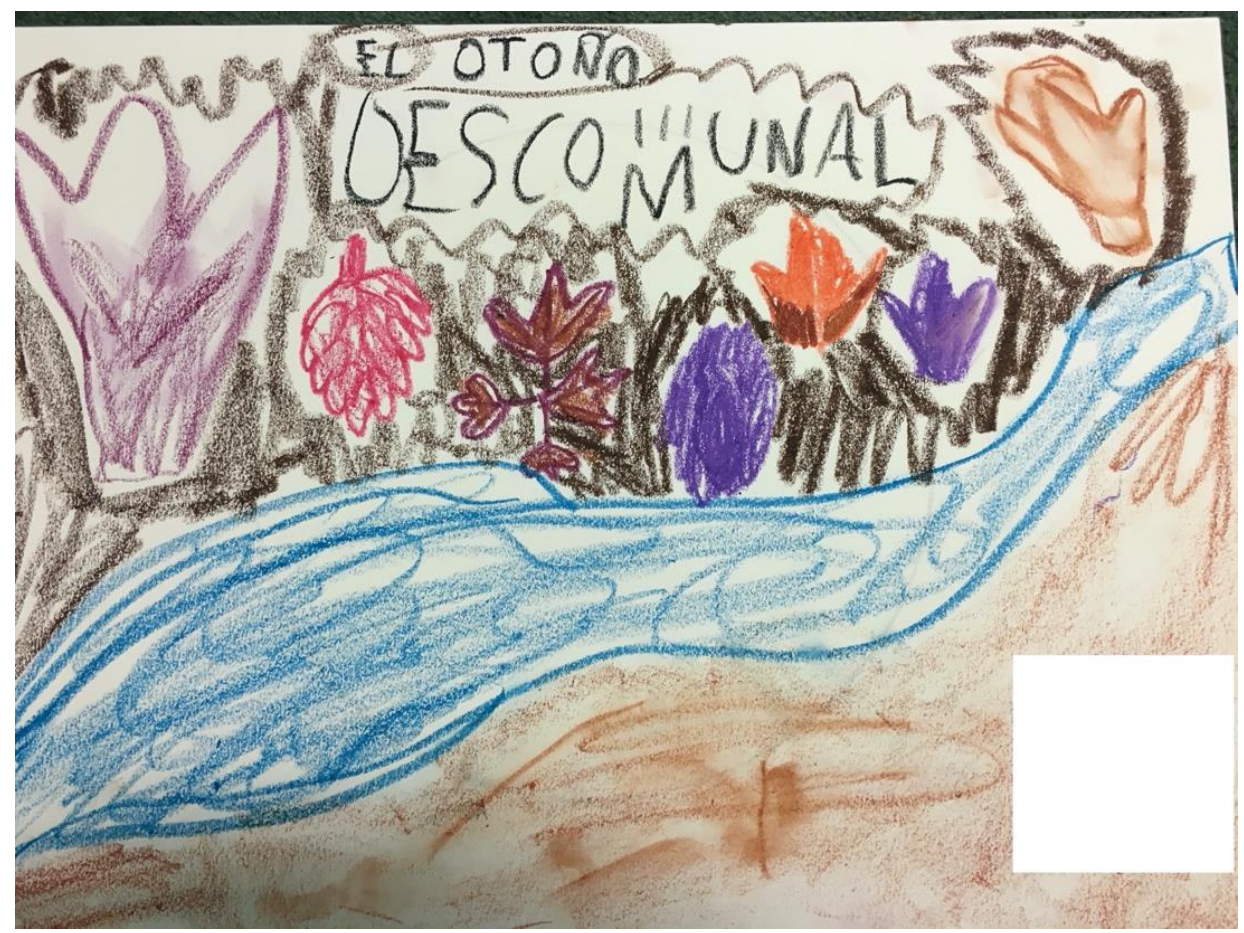

Figura 8. Mandala de N, Sesión 5. 04/04/2017. 
Otro mandala que sirve de ejemplo para complementar la información relacionada con la competencia de conciencia emocional es el de la segunda sesión de "I1", de 8 años de edad y sin diagnóstico de TDAH (Figura 9). En esta sesión, "I1" se muestra muy consciente de que quería conectar con el miedo, aunque desde un punto de vista relacionado con la curiosidad, el divertimento y el descubrimiento personal, demostrando capacidad de autopercepción y conciencia emocional. El dibujo, unido a las sensaciones que producía la música, refleja la identificación y conexión de dos de las emociones básicas principales: la alegría y el miedo:

Esta sesión ha sido interesantísima. (...) [C]uando le pregunto qué le quiere pedir a la música, dice que quiere sentir miedo. Esto llama mucho mi atención, ya que el miedo suele ser una emoción un poco delicada. Le pregunto por qué quiere hacer eso y dice que esta emoción le hace reírse a veces, y le apetece mucho sentir eso en la música. (...) Es increíble observar la reacción de su cuerpo cuando comienza la música (al principio es muy oscura): se tapa los ojos, se cubre la cabeza con el jersey y se balancea levemente, en posición y actitud de indefensión, como si tuviese la necesidad de protegerse de algo. (...) Ella misma explica que ha dibujado un paisaje de alegría por los momentos en los que la música (cito textualmente) "tintineaba". Se ha divertido mucho y se va muy contenta.

(Diario de investigación, Sesión 2 de I1)

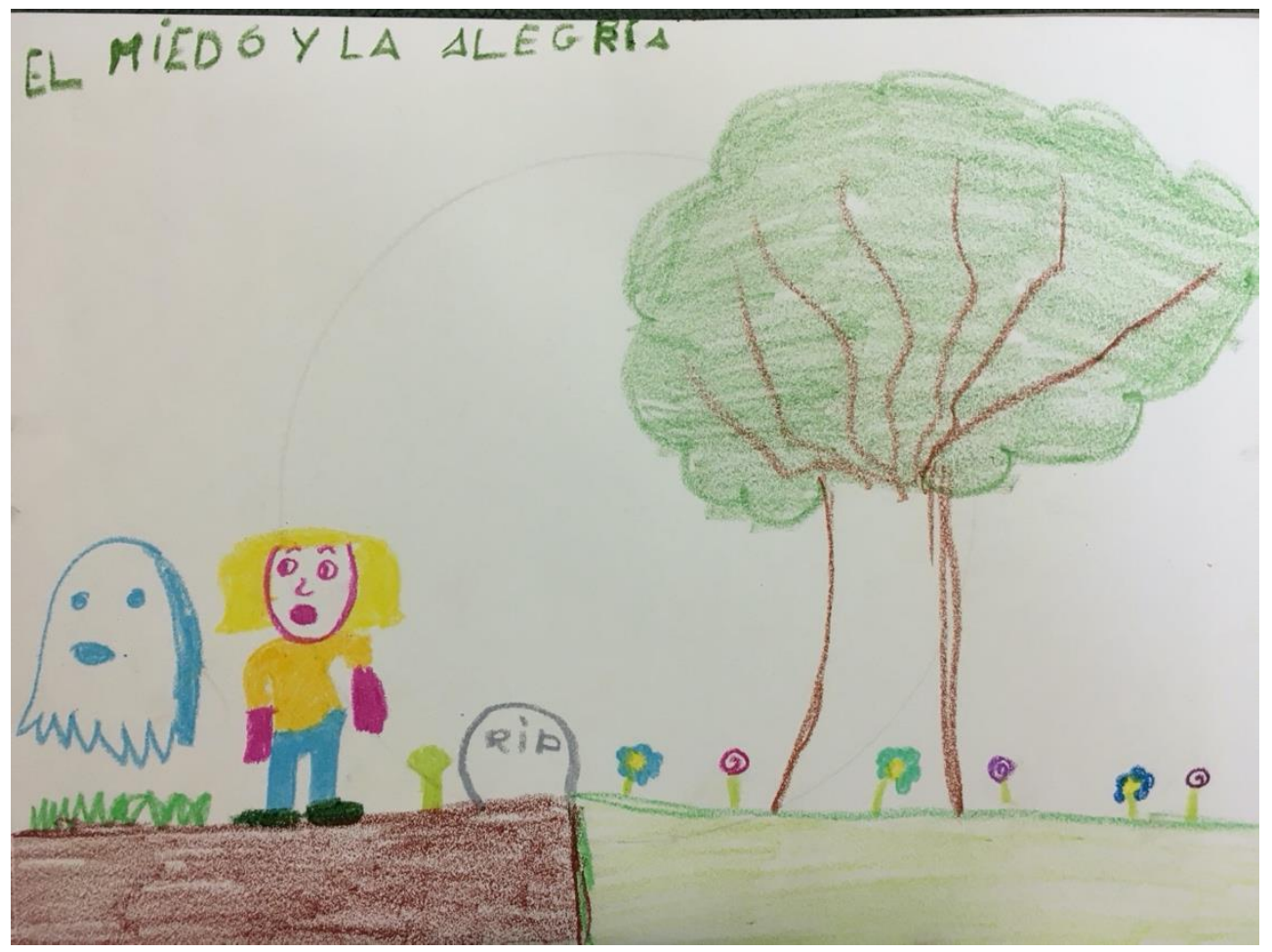

Figura 9. Mandala de I1, Sesión 2. 16/03/2017. 
En este caso, además es posible contrastar lo ocurrido en esta sesión en concreto con la información proporcionada por su madre antes y después de la intervención, quien, como se puede apreciar, muestra interés por la intervención, así como por la Musicoterapia, y expresa la necesidad de que su hija trabaje más a nivel emocional:

¿Qué por qué me llamó la atención la propuesta? En parte, por ayudar en una investigación, o sea, por empatía, porque soy una persona colaboradora. Y yo, si me llaman para un proyecto de robótica, pues no me llama tanto la atención, pero un proyecto como este, con el arte y la música, sí que me llama la atención y pueden ayudar mucho a las personas. Las terapias, yo pienso, que no son solo para tratar casos problemáticos, las terapias ayudan mucho a las personas a lo largo de la vida. Entonces, me pareció una oportunidad para que mi hija explore más sus emociones, maneje otros lenguajes y conviva con otras personas con otras casuísticas, ¿no?

(Entrevista a madre de I1, antes de la intervención)

Ha conectado también mucho con el miedo, hacía muchas cosas de miedo... (...) pero también con cosas muy alegres; sin embargo, con la ira, nada, no ha hecho cosas con ira... (...) Sí, la tristeza con el miedo, algo ha hecho...

(Entrevista a madre de I1, después de la intervención)

Por otra parte, al realizar la prueba de Wilcoxon para comparar el punto de vista del investigador principal con la opinión de las familias de los niños participantes, nos encontramos con que las diferencias de valores no son estadísticamente significativas para un n.d.c. del 5\% ( $\mathrm{Z}=-, 28 ; \mathrm{p}>, 05)$, tal y como se puede comprobar en la Tabla 18. Teniendo en cuenta el valor de las medias, se puede asumir, por lo tanto, que el investigador principal y las familias participantes, coinciden en la opinión de que la conciencia emocional es alta al finalizar la intervención, tal y como se ha podido apreciar al leer las citas textuales mostradas en relación con esta categoría de investigación.

Tabla 18

Punto de vista del investigador y de las familias respecto a la conciencia emocional después de la intervención

\begin{tabular}{lccccc} 
& Media & Mediana & D. T. & Z & Sig. \\
\hline Punto de vista del investigador & 5,00 & 5,00 &, 87 & & \\
Punto de vista de las familias & 5,11 & 5,00 &, 78 &,- 28 &, 78 \\
& & & & &
\end{tabular}

Fuente: Elaboración propia. 


\subsection{Regulación emocional}

Dentro de la escala EODE, el valor cuantitativo referido a la regulación emocional hace alusión a la capacidad mostrada por parte de los niños participantes para relajarse, pedir ayuda y/o encontrar solución a los problemas. Desde un punto de vista cualitativo se han tomado en consideración estos valores literalmente y, además, se ha considerado la capacidad de expresar o compartir las emociones, teniendo en cuenta que en muchas situaciones guarda una relación directa con el hecho de pedir ayuda y con la capacidad de gestionar problemas y saber encontrar soluciones de forma funcional. En la Tabla 19 se puede apreciar una breve definición de la categoría cualitativa empleada para tal fin, designada como EODE2_RE.

Tabla 19

Categoría cualitativa para el análisis textual de regulación emocional

\begin{tabular}{|c|c|c|c|c|}
\hline Nombre & Citas & Definición & Cuándo se usa (ejemplo) & $\begin{array}{c}\text { Cuándo no se usa } \\
\text { (ejemplo) }\end{array}$ \\
\hline EODE2_RE & 302 & $\begin{array}{l}\text { Citas textuales en las } \\
\text { que se alude a la capaci- } \\
\text { dad para relajarse, pedir } \\
\text { ayuda y/o encontrar so- } \\
\text { lución a los problemas. } \\
\text { También se refiere a la } \\
\text { capacidad para compar- } \\
\text { tir o expresar emocio- } \\
\text { nes. }\end{array}$ & $\begin{array}{l}\text { "Porque es lo que decías tú el } \\
\text { otro día, si lo que ayudáis es a } \\
\text { que se expresen... mi hijo es } \\
\text { una bomba, es un niño pre- } \\
\text { cioso, pero muchas veces, } \\
\text { tiene muchas cosas de rabia, } \\
\text { de furia, pues que le salen por } \\
\text { esa sensación de malestar que } \\
\text { le provoca todo un poco." }\end{array}$ & $\begin{array}{l}\text { "Y eso yo entiendo, } \\
\text { que es una dificultad } \\
\text { de adultos lo que le } \\
\text { pasa. Y es que, a ve- } \\
\text { ces, te parecen las co- } \\
\text { sas tan evidentes y te } \\
\text { has esforzado tanto en } \\
\text { que las entienda..." }\end{array}$ \\
\hline
\end{tabular}

Fuente: Elaboración propia.

Es necesario tener en cuenta, en este punto, que se trata de la categoría que más cantidad de citas textuales ha recibido durante el proceso de análisis de datos cualitativos (302), es decir, de la información textual obtenida de las entrevistas a las familias y del diario de investigación, no solo de entre todas las categorías relativas a la escala de competencia emocional EODE, sino también de entre el resto de las categorías del estudio. Esto parece indicar que, a grandes rasgos, es el tema de mayor interés para las familias y para el investigador.

A la hora de hacer la comparación del valor de regulación emocional antes y después de la intervención nos encontramos con que, al igual que en el caso anterior, referido a la competencia de conciencia emocional, se han producido cambios estadísticamente significativos en cuanto a la regulación emocional para un n.d.c. del $5 \%(\mathrm{Z}=-2,45 ; \mathrm{p}<, 05)$, tal y como se puede observar en la Tabla 20. De hecho, teniendo en cuenta el valor de las medias antes y después de la intervención, podemos asumir que ha tenido lugar un aumento de la regulación emocional. 
Tabla 20

Regulación emocional antes y después de la intervención

Media Mediana D. T. $Z$ Z Sig.

\begin{tabular}{rrrrrr}
\hline Antes de la intervención & 3,56 & 3,00 & 1,74 & & \\
Después de la intervención & 6,11 & 6,00 & 1,27 & & \\
\hline
\end{tabular}

Fuente: Elaboración propia.

En relación con esta categoría se han dado casos realmente interesantes en los que los niños exponían un problema, normalmente asociado a algún tipo de necesidad emocional, y encontraban en la música y en la situación de terapia una respuesta a dicha necesidad. No obstante, en determinadas ocasiones no exponían ese problema o necesidad previamente (durante la conversación inicial, sino que surgía durante el momento de relajación, imaginación y escucha activa de la música. Veamos, en este caso, el mandala de la cuarta sesión de "D2", de 8 años de edad y sin diagnóstico de TDAH. Tal y como se puede observar en la Figura 10, este dibujo representa la tumba de una mascota que tuvo "D2", que había fallecido unos meses atrás y le había dado mucha pena. Él mismo lo explica después de haber realizado el dibujo:

D2 cada día me sorprende más. (...) El mandala que resulta es interesante y muy significativo para D2. Representa la tumba de su mascota Juan, una hormiga (o un saltamontes, según su madre) que trajo de una excursión el año pasado y que conservó con ilusión como mascota. Lógicamente, murió. En esta ocasión la música le ha recordado a Juan y dice que le pone triste que ya no esté porque le echa de menos, pero asegura que la música tenía una parte muy bonita y alegre que le ha ayudado a dejar atrás lo que ocurrió cuando murió su mascota. Dice que siempre se va a acordar de Juan. Creo que es una gran reflexión, muy profunda y madura, para un niño de 8 años. Dice que está triste, pero le alegra saber que siempre se va a acordar de él. Además, le invito a que se lleve el dibujo y lo añada a un libro que tiene guardado con fotos (y más información) de Juan. Le encanta esta idea, se va contento y relajado.

(Diario de investigación, Sesión 4 de D2) 


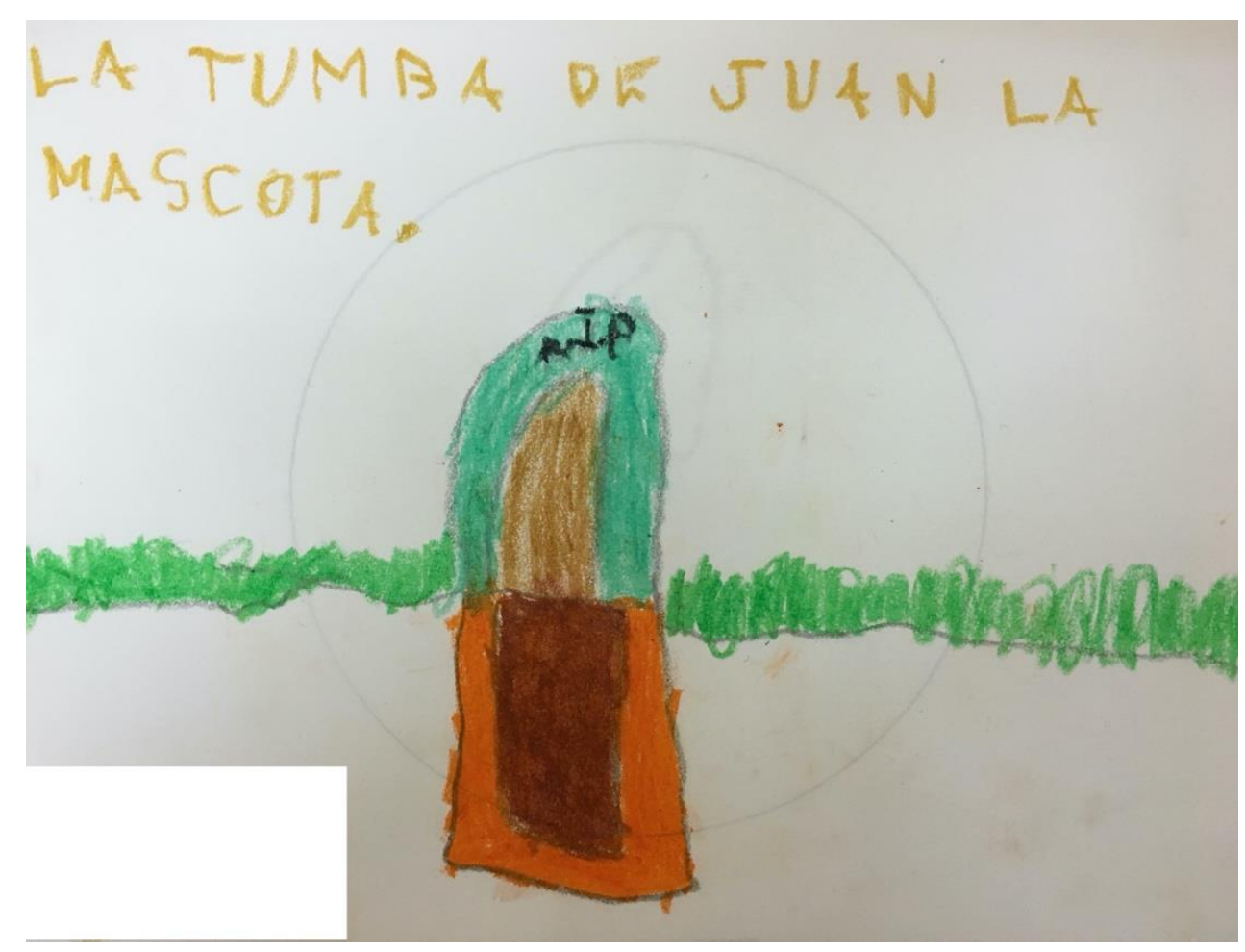

Figura 10. Mandala de D2, Sesión 4. 30/03/2017.

Esta sesión le sirvió a "D2" para resolver un conflicto emocional interno que estaba presente desde que tuvo lugar la muerte de esta mascota. Puede parecer un hecho aislado, o no muy significante, pero sin duda contenía la suficiente importancia como para que surgiese de forma espontánea durante la sesión. De hecho, surgió durante el momento de escucha activa, unida al proceso de imaginación con los ojos cerrados, por lo que se podría decir que emergió de forma inconsciente o involuntaria.

En relación con ello, otro caso que resulta de interés y relevancia es nuevamente el de "A", esta vez en su séptima sesión (primera sesión grupal), en la que vuelve a conectar con el recuerdo de su perro, que, como se indica en la transcripción de su primera sesión, falleció unos días antes del comienzo de la intervención, por lo que aparece representado en relación con la tristeza (Figura 6). En esta ocasión, vuelve a surgir este tema, pero ya no solo se conecta con la tristeza, sino también con la alegría (Figura 11):

A explica que se ha imaginado que estaba con su perro, que estaban en un pantano y que su perro se caía al agua. (...) A explica que con el dibujo se siente triste, porque echa de menos a su perro, y a la vez contenta, porque al escuchar la música, que le ha parecido alegre, se da cuenta de que tiene recuerdos bonitos con él.

(Diario de investigación, Sesión 7) 


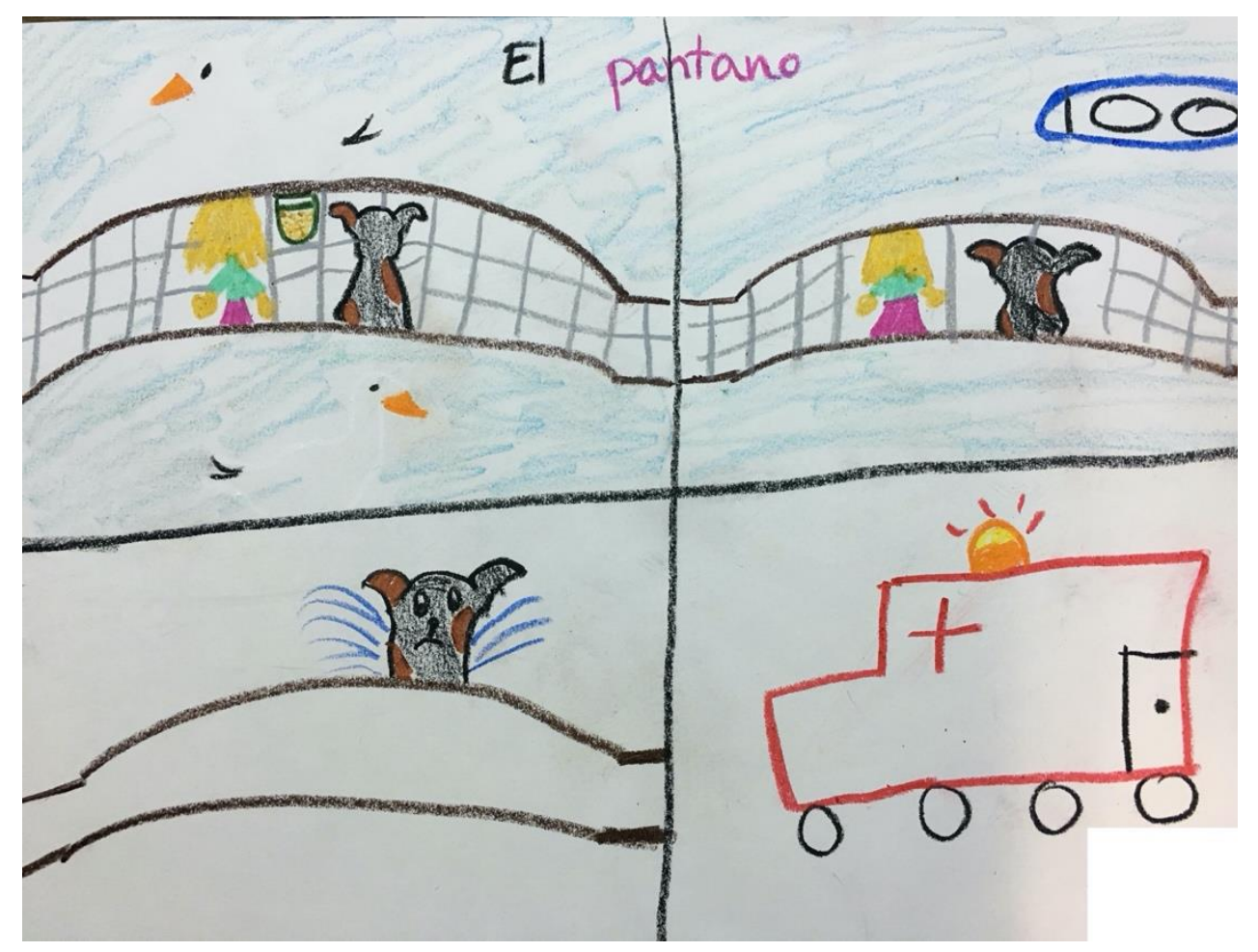

Figura 11. Mandala de A, Sesión 7. 04/05/2017.

Por lo tanto, este se trata de un hecho importante y conecta directamente con la situación personal de "A", tal y como explica su madre antes del comienzo de la intervención, así como después de su desarrollo:

Hemos tenido un rottweiler durante 10 años, cuando nació ella ya teníamos al perro, y cuando se murió el perro hace quince días estuvo una semana llorando por las esquinas... (...) Además, era un perro buenísimo. Es de raza peligrosa y si te muerde, te arranca la cabeza, pero con las niñas, buenísimo. Y ella, cuando murió el perro, lo pasó muy mal.

(Entrevista a madre de A, antes de la intervención)

Y, claro, estuvo una semana llorando, que se acordaba del perro..., claro, es que la gustan mucho los animales, por eso te digo que es muy sensible, pero el exteriorizar eso, ya es más difícil. (...) Luego, al final, ya lo asimiló, pero los primeros días, fueron terribles... (...) Hizo un dibujo de este tema, no sé si fue el primero o el segundo. (Entrevista a madre de A, después de la intervención)

En este caso, esto resulta de especial relevancia, ya que, en la entrevista realizada a su madre después de la intervención, ella misma explica que A no está habituada a compartir cómo se siente o dar forma o salida a sus emociones: 
A nivel emocional, es una niña que tampoco lo exterioriza mucho. (...) Pero, de todas formas, es que no te cuenta nada, normalmente, aunque se la nota en la cara, en el aspecto, no en el habla, pero yo, muchas veces, con solo verla la cara ya sé que la pasa algo; pero ella se cierra y como que no me dice nada... Luego, a base de insistir, pues ya me cuenta algo, aunque más que contártelo, yo se lo noto en la cara.

(Entrevista a madre de A, después de la intervención)

Siguiendo el ejemplo de "A", esta actitud de expresión emocional se pudo observar en otras sesiones, como por ejemplo en su sexta sesión, en la que la música y la experiencia de Musicoterapia le ayudó a canalizar una situación emocional delicada en la que estuvo a punto de quedarse sin ir a una fiesta de cumpleaños de una amiga por un conflicto familiar. De alguna forma, la sesión le ayudó a dar respuesta emocional o salida al sentimiento que tenía respecto a este tema. El mandala resultantes de esta sesión (Figura 12) habla por sí solo:

[E]xplica que está enfadada porque por culpa de su hermana mediana casi se queda sin ir al cumpleaños de una amiga suya. (...) Ante esto dice que se siente enfadada y un poco triste, pero sobre todo enfadada. (...) Cuando le pregunto qué tipo de música le apetece escuchar, dice que quiere que sea música alegre, no triste, y que sea lenta. (...) Tal y como se puede apreciar, este [el mandala] muestra el momento el que se ha pegado con su hermana (esquina inferior izquierda), su madre enfadada, regañándolas (a la izquierda) y a sí misma imaginando el momento en el que se imaginaba a sus amigas en el cumpleaños de una de sus amigas sin ella. (...) Explica que en el momento en el que le dijeron que no iba a ir al cumpleaños de su amiga estaba muy triste. Como vemos, se trata de un mandala que tiene una carga emocional bastante significativa. De hecho, afirma que cuando estaba escuchando la música el primer sentimiento que le ha surgido ha sido la tristeza. Dice que la música le ha ayudado a estar más tranquila y un poco menos enfadada. Además, afirma que puede que meta la pata si ahora pega a su hermana otra vez. Dice que suele enfadarse con su madre, pero que en este momento no está enfadada, sino alegre. Al final de la música ha podido pensar que sí que va a ir al cumpleaños y eso le ha puesto alegre.

(Diario de investigación, Sesión 6 de A) 


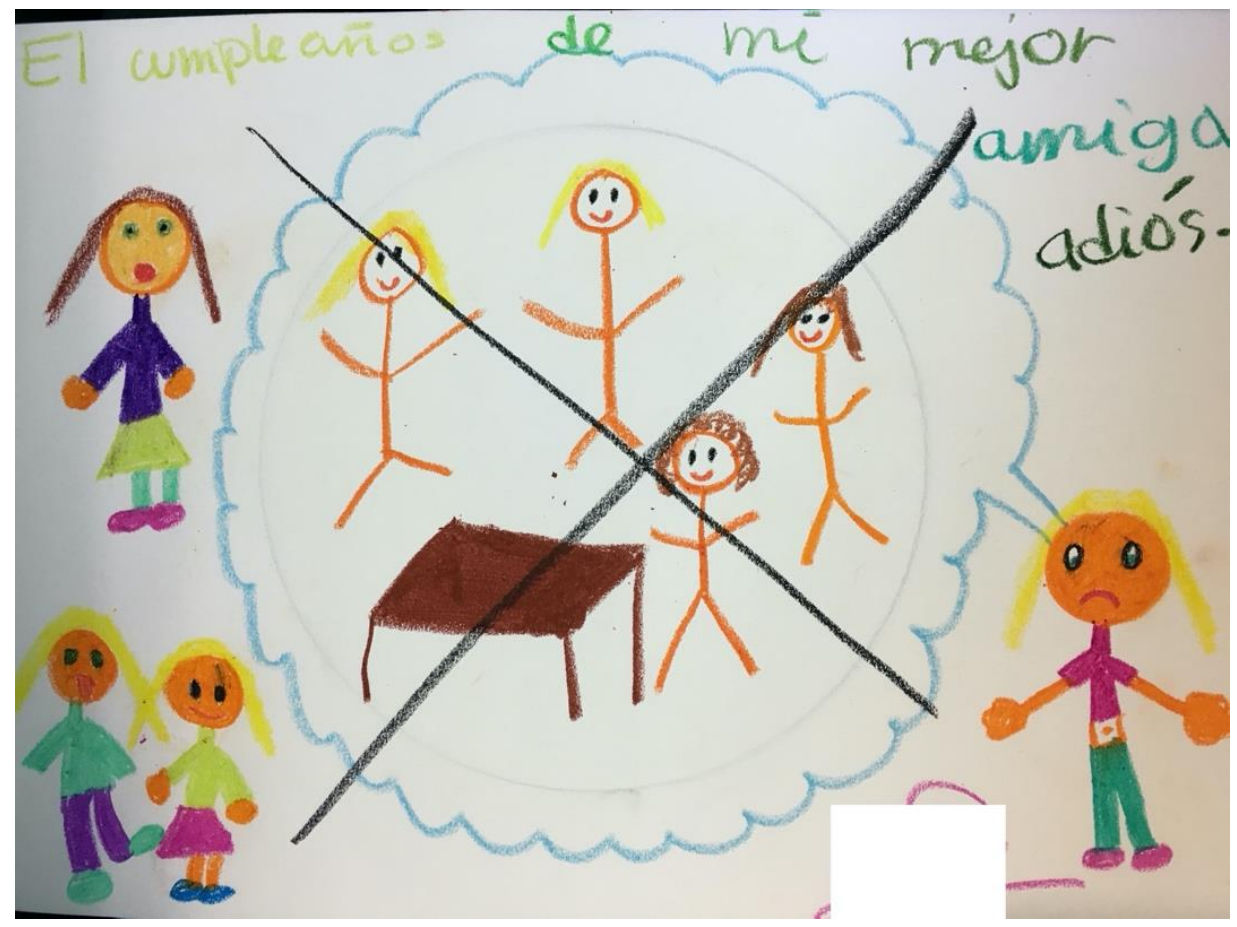

Figura 12. Mandala de A, Sesión 6. 20/04/2017.

En relación con esta sesión, en la entrevista de después de la intervención, la madre de "A" hace alusión a que tiene la sensación de que las sesiones le han ayudado a gestionar mejor las emociones, lo que ha repercutido positivamente en su actitud tanto en el colegio como en casa, especialmente en relación con su capacidad para relajarse:

Hombre, en clase, en el colegio, me han dicho que está mejor, no como antes que llamaba la atención, porque ella es la más graciosa, que se ríen con ella... En ese sentido yo creo que sí que lo controla más, lo ha intentado canalizar más, me lo han dicho los profesores que está mejor, aunque todavía la queda, pero bueno, se nota que ha mejorado en ese aspecto, que está más a lo suyo, en eso sí, sí que lo noto. (...) Bueno, en casa está algo más tranquila, discute menos, aunque sigue discutiendo, ya te lo he dicho..., está algo más tranquila porque, a lo mejor, en lugar de gritar más, pues se corta un poco, como que está más tranquila.

(Entrevista a madre de A, después de la intervención)

En el caso de "J2", por ejemplo, también se puede apreciar cierta evolución en cuanto a la capacidad para expresar las emociones, comparando la perspectiva de su madre antes y después de la intervención:

Sí, muy difícil para él. Le cuesta más trabajo expresar sus emociones, pero es un niño absolutamente emotivo, con una empatía tremenda, o sea, los dos. Vemos una película de esas tristes y se ponen a llorar los dos, les da una pena la película...

(Entrevista a madre de $\mathrm{J} 1$ y J2, antes de la intervención) 
Pues yo no sé si tendrá algo que ver o no, pero respecto hacia mi persona, emocionalmente, se ha abierto más, más receptivo al cariño, al contacto físico, a las caricias, más cariñoso, más amoroso, muchísimo más receptivo. No sé si tiene que ver con eso o con qué, pero sí que hemos trabajado mucho los dos a lo largo del curso a otros niveles...no sé, más receptivo, más cariñoso, más dándose cuenta de las cosas, con J1. (...) Pues me ha sorprendido que, bueno, él tiene su mundo, le han pasado muchas cosas, porque igual que tiene problemas para relacionarse con los demás, para abrirse, ha tenido problemas para contarme sus problemas y sus cosas... y ahora tiene más facilidad para contarme lo que le sucede. Por ejemplo, nunca se ha quejado de su hermano, nunca... sin embargo, hará como diez días o así me dijo que estaba harto de su hermano, que por qué él tenía que tener un hermano así y no un hermano normal. (...) Pero sí que ha sido capaz de decirme lo que sentía, de expresar lo que sentía, sí que ha sido capaz de expresarme eso. Y seguramente, eso lo llevará dentro de él años y ahora ha sido capaz de expresarlo, antes jamás me lo había dicho y el otro día me lo dijo. (Entrevista a madre de $\mathrm{J} 1$ y J2, después de la intervención)

Otro caso que sirve como buen ejemplo para representar el trabajo que se ha hecho durante la intervención para desarrollar esta competencia de regulación emocional es el de "I1", en este caso en su quinta sesión. En la conversación inicial comparte una situación personal que le hace estar triste, y se puede apreciar cómo, a través de la música y el dibujo, empleados dentro del contexto musicoterapéutico, gestiona y canaliza esta emoción (Figura 13):

Cuando hablamos sobre cómo quiere que sea la música, dice que quiere que le inspire tristeza, que ha sacado un seis en un examen de música y está triste por eso. Decide escuchar la música con los ojos cerrados, lo cual hace durante la reproducción de la pieza musical, relajadamente, sin problema. Cuando termina la música abre los ojos y busca el mandala y las ceras con la mirada. Se lo dejo y comienza a dibujar, prácticamente sin pensar. El mandala representa, como se puede ver, un funeral. (...) Las nubes están enfadadas porque creen que esa persona no tendría que haber muerto. Dice que al dibujarlo se ha sentido triste al imaginar que alguien a quien quieres ha muerto, que te sientes mal cuando algo así ha ocurrido. (...) Al finalizar la sesión dice que se siente bien (...). I1 muestra en todo momento una actitud positiva (...), sobre todo al observar el dibujo que ha realizado.

(Diario de investigación, Sesión 5 de I1) 


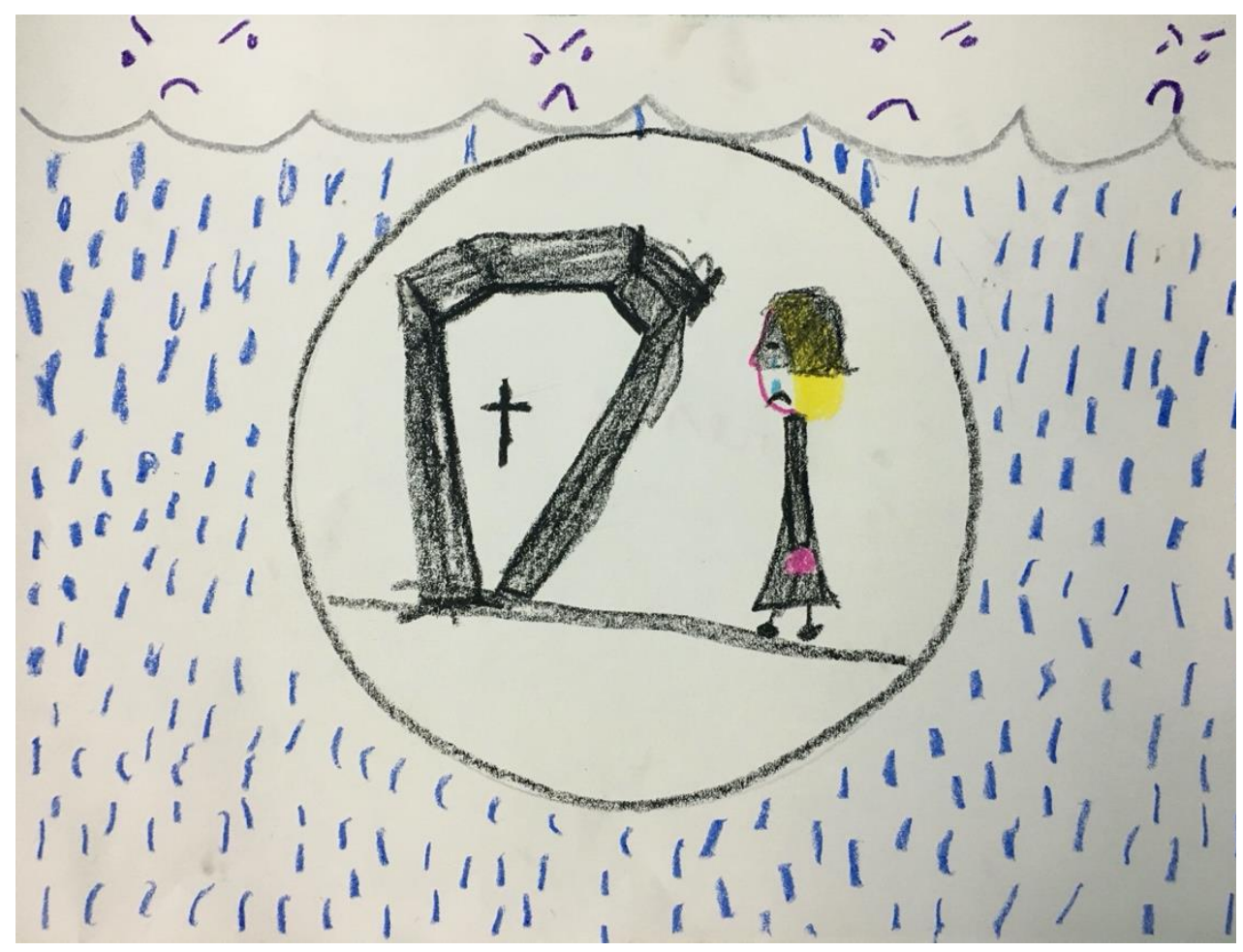

Figura 13. Mandala de I1, Sesión 5. 06/04/2017.

De hecho, el aumento de la capacidad de regulación emocional de "I1" se ha podido apreciar tanto en las sesiones realizadas como fuera de este contexto, al contrastar el punto de vista del investigador con el de su madre por medio de las entrevistas antes y después de la intervención:

Pues, mira, la tristeza sí que la tiene muy controlada, porque, por ejemplo, a veces, se pone a llorar porque se acuerda de su abuelo y de su bisabuela, eso sí que lo ha sentido mucho, porque eran las dos personas que se han muerto así, mientras ella estaba. Le ha dolido mucho y, a veces, se pone triste, porque dice que se acuerda mucho. Eso sí que lo tiene controlado, pero... emociones como la rabia $\mathrm{u}$ otras, no las exterioriza, la pena, la desilusión... Tiene un montón de emociones negativas que no acaba de mostrar, ¿sabes?

(Entrevista a madre de I1, antes de la intervención)

En general, yo sí he visto cambios en I1. (...) [Y]o creo que tiene más capacidad para mostrar emociones negativas, que antes no tenía, se metía así, como para adentro... Un día, que yo aluciné, que hablamos de la reválida, que les iban a hacer un examen... Y empezó a soltar sapos y culebras por la boca, quejándose de ello... I1 nunca ha sido así, sus enfados son más de irse a su cuarto, enrabietarse y llorar, pero el sacar esa rabia o esa ira... Pero muy bien, claro, porque esos sentimientos están y esas emociones están y si no se saca...

(Entrevista a madre de I1, después de la intervención) 
Volviendo al caso de "N", en su tercera sesión también tuvo lugar una situación en la que se podría considerar que se dio un proceso de gestión emocional. Demostrando una gran capacidad de conciencia y regulación emocional, "N" pidió que la música fuese triste, ya que, tal y como lo verbalizó al comienzo de la sesión, estaba viviendo una situación personal no muy agradable. El mandala resultante de esta sesión, que se puede apreciar en la Figura 14, y titulado "El mundo mega triste", habla por sí solo:

Hoy tiene muy claro el foco u objetivo de la sesión: quiere que la música le traslade a un mundo triste. El porqué reside en el hecho de que hemos dedicado otras dos sesiones a la alegría y a la imaginación, y es por esto que hoy se la quiere dedicar a la tristeza, aunque dice que no está triste. Sin embargo, en la charla inicial habla de varias situaciones de su vida que le entristecen. En relación con esto, su actitud al explicar por qué ha dibujado un mundo triste es muy interesante porque señala con mucha seguridad que no siempre le apetece estar alegre, que a veces necesita no estar tan contento, conectar un poco más con la tristeza. (...) [E]sta reflexión denota un nivel de autopercepción y de sensibilidad considerable y significativo. A la hora de hablar con su padre, él mismo reconoce, al igual que yo, que se ha asombrado con el dibujo de $\mathrm{N}$ y con la explicación que ha dado en relación con su deseo de dibujar algo más triste.

(Diario de investigación, Sesión 3 de N)

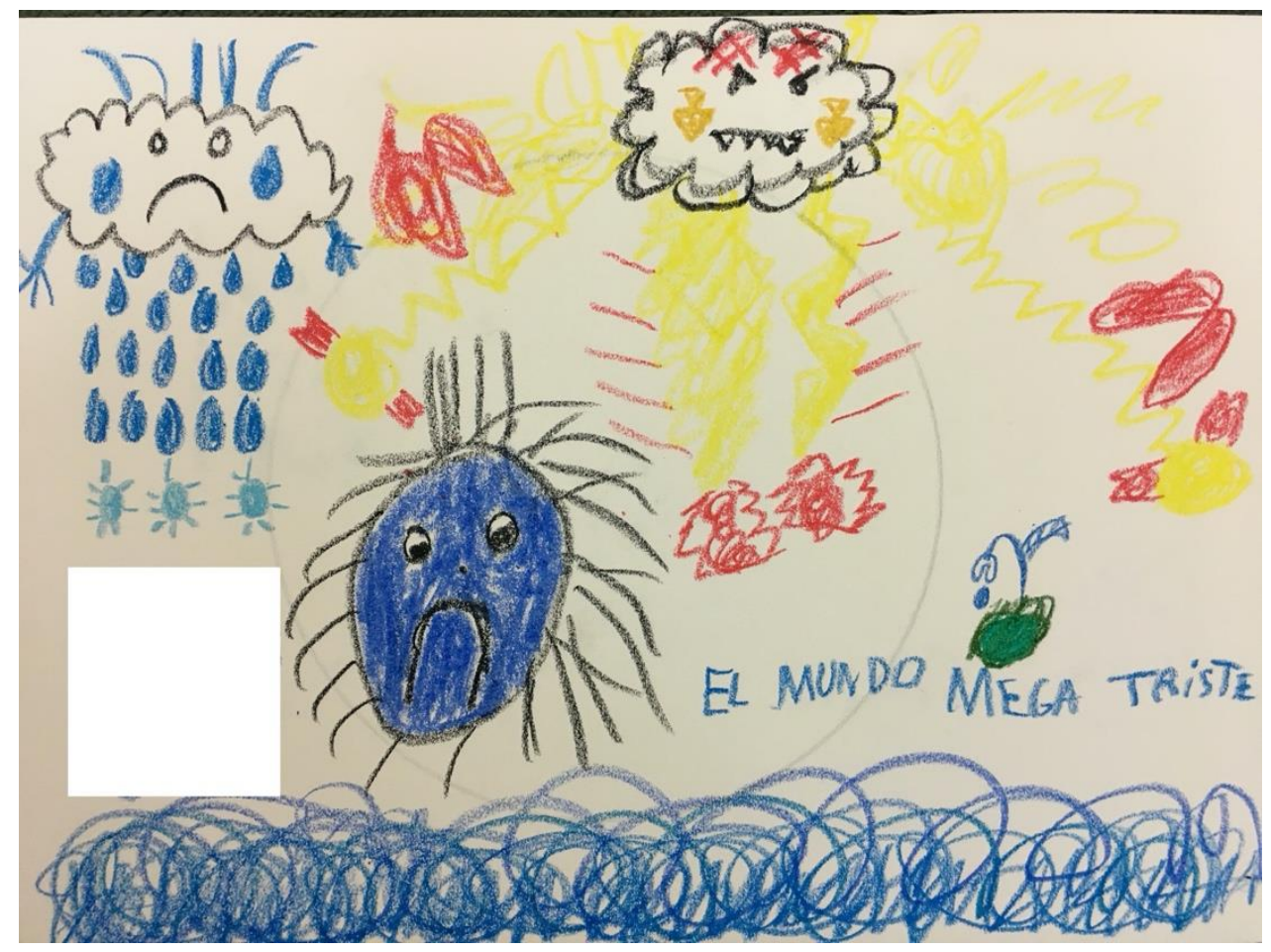

Figura 14. Mandala de N, Sesión 3. 22/03/2017. 
Como se puede observar en este extracto textual, obtenido del diario de investigación, la actitud de "N", así como la forma de verbalizar las razones que ha escogido para realizar un dibujo de este tipo, demuestra su competencia de regulación emocional, sobre todo al explicar que no siempre le apetece estar contento. Este hecho, que puede sorprender o, incluso, preocupar en algunos casos, a los adultos, en este contexto se entiende como una capacidad de gestión o regulación que permitió a " $\mathrm{N}$ " conectar con emociones o situaciones conflictivas a nivel emocional y canalizarlas hacia otro tipo de sensaciones como la tranquilidad, el bienestar o la alegría. Resulta interesante, en relación con ello, reflejar el punto de vista de sus padres respecto a lo que ocurrió este día, en la entrevista que se realizó después de la intervención:

\footnotetext{
Sí, yo creo que ese día vino un poco mosca a la sesión. Creo recordar que ese día yo pensé que algo había pasado [padre de N]. Sí, pero dentro de que era un mundo triste, yo el dibujo lo vi optimista, nada triste, no me pareció... [madre de N] (...) Estoy tratando yo de hacer memoria..., yo creo que ese día le habíamos regañado por algo y venía la cosa un poco complicada [padre de N].

(Entrevista a padres de N, después de la intervención)
}

Otro caso que resulta de especial interés en este punto es el de "M", de 10 años de edad y sin diagnóstico de TDAH. Tanto él como su hermano, "Y", viven actualmente en situación de familia de acogida. Son niños con una historia personal complicada, ya que viven en esta situación desde sus primeros meses de vida y, con 11 y 9 años de edad, respectivamente, han vivido ya con cuatro familias diferentes. Dadas estas circunstancias, y a pesar de que en este momento tienen cierta estabilidad proporcionada por la familia con la que están viviendo, es normal que existan ciertos conflictos emocionales a nivel interno o diferentes aspectos personales que están por resolver, como iremos viendo a lo largo de este capítulo.

Ya desde la primera sesión de la intervención, "M" hablaba sobre la delicada relación que tiene con algunos de sus compañeros de clase, explicando que en un momento dado le habían acorralado con intención de pegarle. A lo largo del desarrollo de la intervención continuaba surgiendo este tema, de tal modo que se convirtió en algo ciertamente recurrente y que se mostró, de forma significativa, en su cuarta sesión. En el mandala de esta sesión (Figura 15) se aprecia que hay un incendio, en el que claramente están muriendo personas, que "M" identifica meticulosamente con algunos compañeros de clase (los nombra uno por uno) y con su propio hermano, tal y como él mismo señala a la hora de compartir la explicación de su dibujo: 
Viene a la sesión muy serio y pensativo, como si hubiese algo que realmente le preocupa. Sigue hablando de la mala relación que tiene con sus compañeros de clase. En el mandala refleja un incendio y un edificio en llamas del que se está tirando gente para suicidarse. Lo que resulta impactante es preguntarle quién son esas personas y descubrir que, según afirma $\mathrm{M}$, son sus compañeros de clase y su hermano (el ángel). De hecho, los nombra uno por uno y explica meticulosamente por qué está cada uno donde está. Cuando le pregunto por qué les dibuja así me dice que les odia y me explica por qué unos se están suicidando y otros están directamente muertos. Aun así, él se representa a sí mismo en el coche de bomberos que aparece al lado del edificio, y a la altura de la segunda línea de ventanas pone una cama elástica, dividiendo así los que se pueden salvar (los que no odia tanto) de los que no (a los que odia profundamente y pone nombres y apellidos). (...) Dice que le ayuda más o menos hablar sobre esto y que le gusta venir a Musicoterapia. Parece que se va un poco más tranquilo tras haber hablado de esto.

(Diario de investigación, Sesión 4 de M)

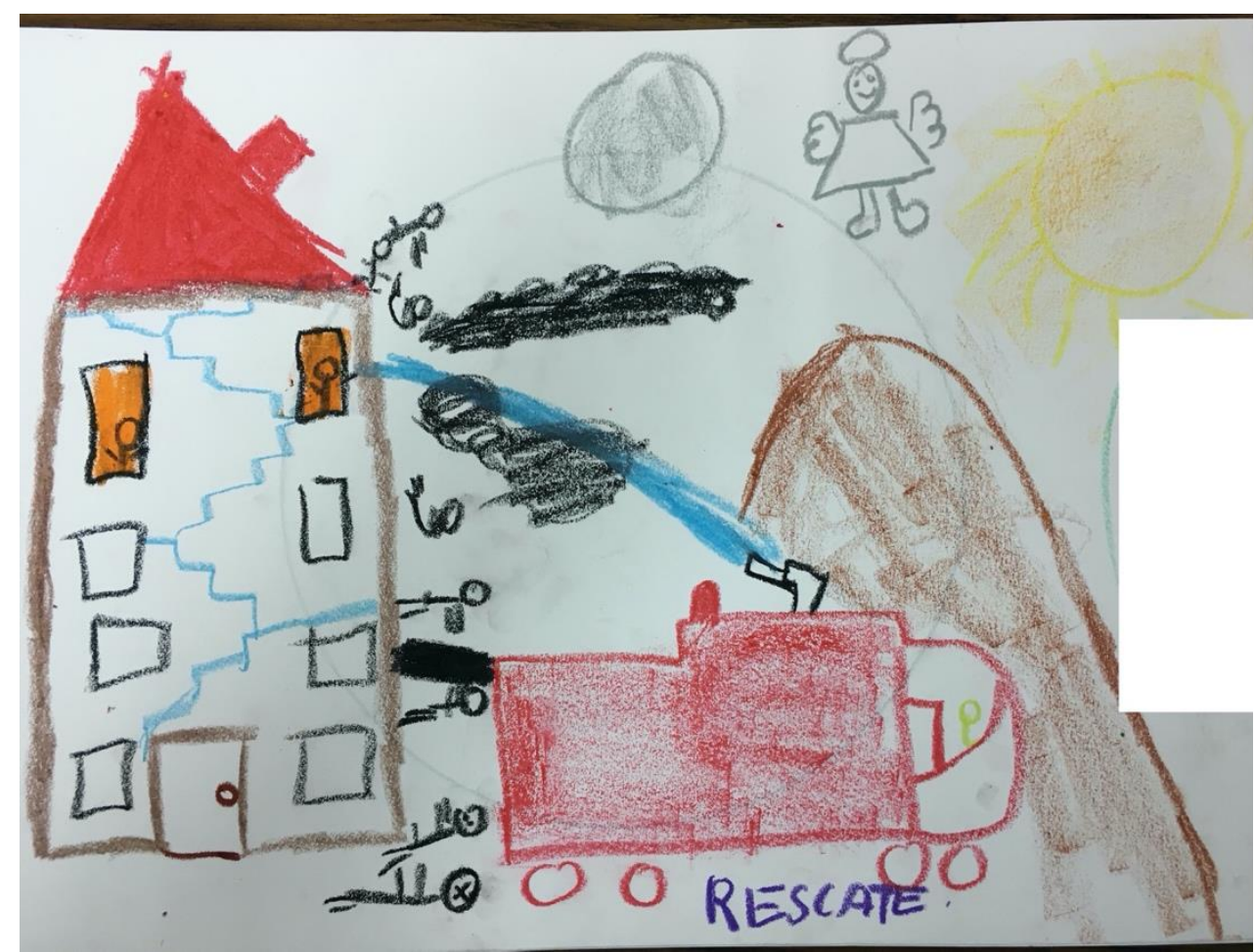

Figura 15. Mandala de M, Sesión 4. 30/03/2017.

En este sentido, da la sensación de que a " $M$ " le calmaba, en cierto sentido, ser consciente de que al venir contaba con un espacio y un momento para poder expresarse libremente, sabiendo que su discurso no recibía juicio, sino que era acogido y escuchado. De hecho, conforme se iban desarrollando las sesiones de Musicoterapia daba la impresión de que le estaban ayudando a 
regular su necesidad emocional, desde la primera sesión (en la que compartía lo que había ocurrido con sus compañeros) en adelante:

De hecho, en un momento de la conversación inicial habla sobre algo que sucedió en el colegio. Sus compañeros de clase le acorralaron y de algún modo le amenazaron. Se nota que es algo que le molesta, le duele, le entristece, le hace sentir miedo o algo similar, pero no muestra sus emociones. Se mantiene firme.

(Diario de investigación, Sesión 1 de M)

Aunque en la pre-sesión hablamos sobre los problemas que tiene con sus compañeros de clase, $\mathrm{M}$ vuelve a mostrar su parte más humana y emocional en la sesión. Parece que estas sesiones le sirven para recurrir a la música como vía de escape, dar rienda suelta a la imaginación y dedicar tiempo a pensar y expresar sus sueños, es decir, las cosas que quiere hacer en su vida porque le hacen sentir contento y alegre. En este caso ha dibujado una escena de un cocinero afirmando que es él, que quiere ser así de mayor. Es probable que proporcionar un espacio donde $\mathrm{M}$ puede expresarse libremente a nivel emocional esté repercutiendo positivamente en su día a día. Al terminar la sesión muestra una actitud muy positiva y se va aparentemente muy tranquilo.

(Diario de investigación, Sesión 2 de M)

En esta sesión surge de nuevo el tema de los compañeros de clase de $\mathrm{M}$ y el momento en que le acorralaron con intención de (supuestamente) pegarle. Cuando habla de este tema cambia drásticamente tanto su expresión facial como su lenguaje no verbal, es decir, la postura que adopta. Se nota que es algo que le incomoda y le preocupa, aunque no lo exprese claramente ni deje ir sus sentimientos. Una vez más (...) esta sesión le sirve como vía de escape hacia su imaginación, sus sueños y sus deseos. Habla entusiasmado del mandala en el que ha plasmado una situación de concierto formada por un pianista y un cantante, y muestra mucha alegría en el momento de ponerles un nombre. (...) Afirma que se siente mucho más alegre y tranquilo después de la sesión.

(Diario de investigación, Sesión 3 de M)

En relación con esta información extraída del diario de investigación, nótese cómo se puede apreciar la diferencia a nivel emocional entre el mandala mostrado previamente, correspondiente a la cuarta sesión (Figura 15) con el de la segunda sesión (Figura 16) que está más relacionado con la imaginación de "M" y la expresión de sus sueños, deseos y sensaciones positivas: 
Dicho lo cual, siguiendo el proceso de "M", se puede observar que, aparentemente, expresar sus sensaciones o compartir sus problemas libremente, desde la primera sesión, le ha llevado a poder expresar ese sentimiento de odio que sentía hacia sus compañeros de clase, en la cuarta sesión. En este sentido, lo que permite la gestión y regulación emocional, dentro del contexto terapéutico proporcionado, es canalizar este tipo de sensaciones conflictivas hacia la situación de Musicoterapia o, más en concreto, hacia la libre expresión a través del mandala.

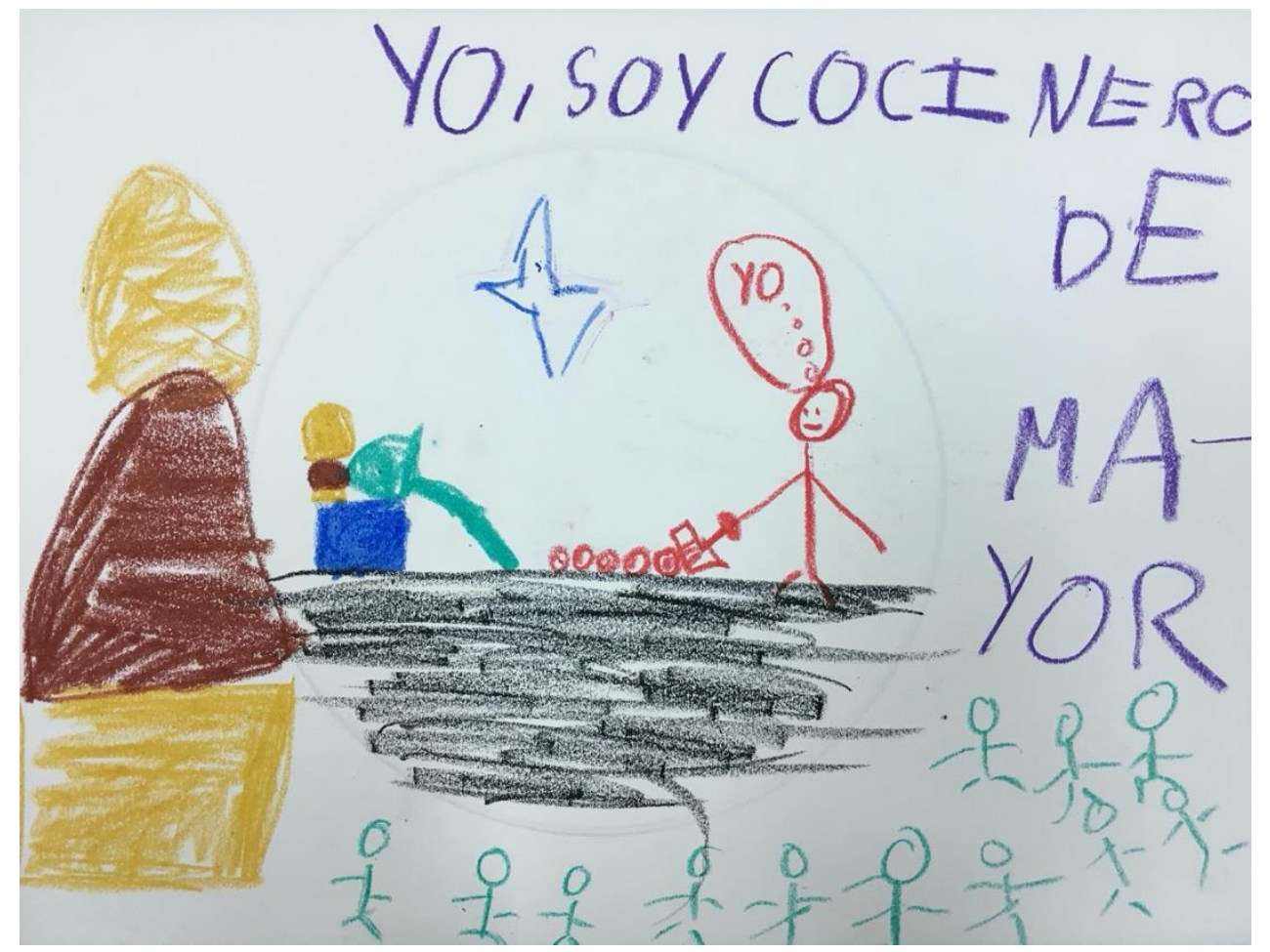

Figura 16. Mandala de M, Sesión 2. 16/03/2017.

Igualmente, la madre de "M" corrobora este hecho al afirmar en la entrevista de después de la intervención que se ha notado que las sesiones le han ayudado a desarrollar la capacidad de expresarse desde un punto de vista emocional en el contexto familiar:

Sí, sí, pero yo creo que esto ha ayudado bastante, en casa ha cambiado también su actitud y ya sí te cuenta cosas. (...) ¿Últimamente? Hombre, sí que te cuenta, te cuenta más cosas, lo que ha estado haciendo si ha estado con su amigo, o vienen a casa y cogen el wifi, no les importa que vea lo que están haciendo o que oigamos lo que hablan... En ese sentido es menos reservado que antes, ahora, a lo mejor, no se van a su habitación, sino que se quedan en el patio y les puedes oír. Y, además, sí que expresa si algo le gusta o si quiere 
algo o lo que ha hecho en el cole... y, sobre todo, si han tenido cambios, por ejemplo, han tenido una profesora distinta a la del año pasado... y parece que sí, que tiene más confianza y lo lleva mejor con esta profesora nueva... Te lo dice, que está mejor con ella, que normalmente no contaba nada.

(Entrevista a madre de Y y M, después de la intervención)

Teniendo en cuenta estos ejemplos, así como la información extraída del diario de investigación y las entrevistas realizadas, cabe señalar, antes de cerrar esta categoría de investigación, que el punto de vista del investigador principal y el de las familias, en relación con la competencia de regulación emocional, no difiere de forma estadísticamente significativa para un n.d.c. del 5\% $(Z=-0,12 ; p>, 05)$, tal y como se puede observar en la Tabla 21 . De hecho, se puede apreciar que los valores de media son exactamente iguales.

\section{Tabla 21}

Punto de vista del investigador y de las familias respecto a la regulación emocional después de la intervención

Media Mediana D. T. $Z$ Sig.

\begin{tabular}{lllllll}
\hline Punto de vista del investigador & 6,11 & 6,00 & 1,27 & & \\
Punto de vista de las familias & 6,11 & 6,00 & 1,62 & & \\
\hline
\end{tabular}

Fuente: Elaboración propia. 


\subsection{Autonomía emocional}

El valor cuantitativo que se refiere a la autonomía emocional dentro de la escala EODE hace alusión a la capacidad de los niños participantes a la hora de reconocer sus cualidades físicas, académicas y personales. Desde el punto de vista cualitativo se han tomado en consideración estos valores, extrapolando estos datos a la observación durante las sesiones. Así, se ha prestado atención al modo en que los participantes en la investigación se relacionaban con la situación de terapia y consigo mismos en lo que se refiere a la percepción de sus propias cualidades. En la Tabla 22 se puede observar una breve definición de la categoría enunciada desde un punto de vista cualitativo para obtener y analizar dicha información. Esta categoría queda enunciada como EODE3_AE.

Tabla 22

Categoría cualitativa para el análisis textual de autonomía emocional

\begin{tabular}{|c|c|c|c|c|}
\hline Nombre & Citas & Definición & Cuándo se usa (ejemplo) & $\begin{array}{c}\text { Cuándo no se usa } \\
\text { (ejemplo) }\end{array}$ \\
\hline EODE3_AE & 92 & $\begin{array}{l}\text { Citas textuales en las } \\
\text { que se alude a la capaci- } \\
\text { dad para reconocer cua- } \\
\text { lidades físicas, académi- } \\
\text { cas y personales en uno } \\
\text { mismo. }\end{array}$ & $\begin{array}{l}\text { "Y digo, jolín, pero cuando lo ve } \\
\text { entero hecho ya no quiere hacer } \\
\text { otro, porque dice que esto le ha } \\
\text { sobrepasado, que ya no le mande } \\
\text { más y cuando lo ve todo hecho } \\
\text { entero, no se ve capaz, pero si va } \\
\text { por pasitos, pues sí. Yo con él lo } \\
\text { tengo que hacer todo pasito a pa- } \\
\text { sito, primero esto, luego esto } \\
\text { otro... y cuando lo ve entero dice } \\
\text { que imposible, que eso no puede } \\
\text { hacerlo." }\end{array}$ & $\begin{array}{l}\text { "Mira, yo desde } \\
\text { que empezó en in- } \\
\text { fantil, yo ya sabía } \\
\text { que el niño tenía } \\
\text { problemas de } \\
\text { aprendizaje, claro, } \\
\text { es un niño que } \\
\text { también empezó } \\
\text { más tarde a ha- } \\
\text { blar..." }\end{array}$ \\
\hline
\end{tabular}

Fuente: Elaboración propia.

En relación con ello, dada la naturaleza del estudio, así como de la intervención musicoterapéutica, que parte de la generación de un espacio de seguridad y bienestar con el objetivo de promover momentos de expresión libre emocional, se considera necesario aclarar que para esta categoría ha sido más complicado contrastar la información obtenida de forma cualitativa con los datos cuantitativos. El motivo de esto reside en el hecho de que la sesiones no iban directamente orientadas a valorar algunas de las cualidades mencionadas, si bien es cierto que pudieron surgir en diferentes situaciones a lo largo del proceso de intervención. 
De hecho, en el momento de comparar el valor inicial de la autonomía emocional con su valor después del desarrollo de la intervención, nos encontramos con que se han producido cambios estadísticamente significativos para un n.d.c. del 5\% ( $\mathrm{Z}=-2,69 ; \mathrm{p}<, 05)$. Si tenemos en cuenta esto, junto con la comparación de los valores antes y después de la intervención, podemos asumir que se ha producido ligeramente un aumento de la capacidad de autonomía emocional, como se puede observar en la Tabla 23.

Tabla 23

Autonomía emocional antes y después de la intervención

Media Mediana D. T. $\quad Z$ Sig.

\begin{tabular}{ccccccc}
\hline Antes de la intervención & 4,44 & 5,00 & 1,51 & & \\
Después de la intervención & 6,56 & 7,00 & 1,67 & & \\
\hline
\end{tabular}

Fuente: Elaboración propia.

Si bien es cierto, como se ha señalado, que se ha obtenido menos información cualitativa para esta categoría en comparación con otras (resultando un total de 88 citas textuales), es necesario considerar también algunos ejemplos en los que se ha visto reflejada la evolución de la capacidad de autonomía emocional, especialmente en algunos casos.

Por ejemplo, en el caso de "N", en su sexta sesión se puede observar cómo relacionó el contenido de la sesión con contenido personal directamente conectado con sus cualidades físicas a la hora de jugar al fútbol (véase Figura 17). Además, es una sesión en la que igualmente reconoce sus cualidades académicas:

$\mathrm{Al}$ igual que en otras sesiones, me habla de algunos de sus hobbies con entusiasmo, y me dice alegre que ha sacado muy buenas notas en el colegio, lo cual denota que reconoce sus cualidades académicas. (...) Ha dibujado un partido de fútbol con todos los detalles, los cuales explica tranquilamente. El componente emocional más significativo del mandala, más allá del hecho de que el fútbol le divierte, es que ha dibujado a su amigo, quien, junto con otro amigo, que también aparece representado en el dibujo, es su mejor amigo. Al terminar la sesión dice que tiene muchas ganas de jugar al fútbol, que es lo que va a hacer cuando se vaya, se muestra contento.

(Diario de investigación, Sesión 6 de N) 


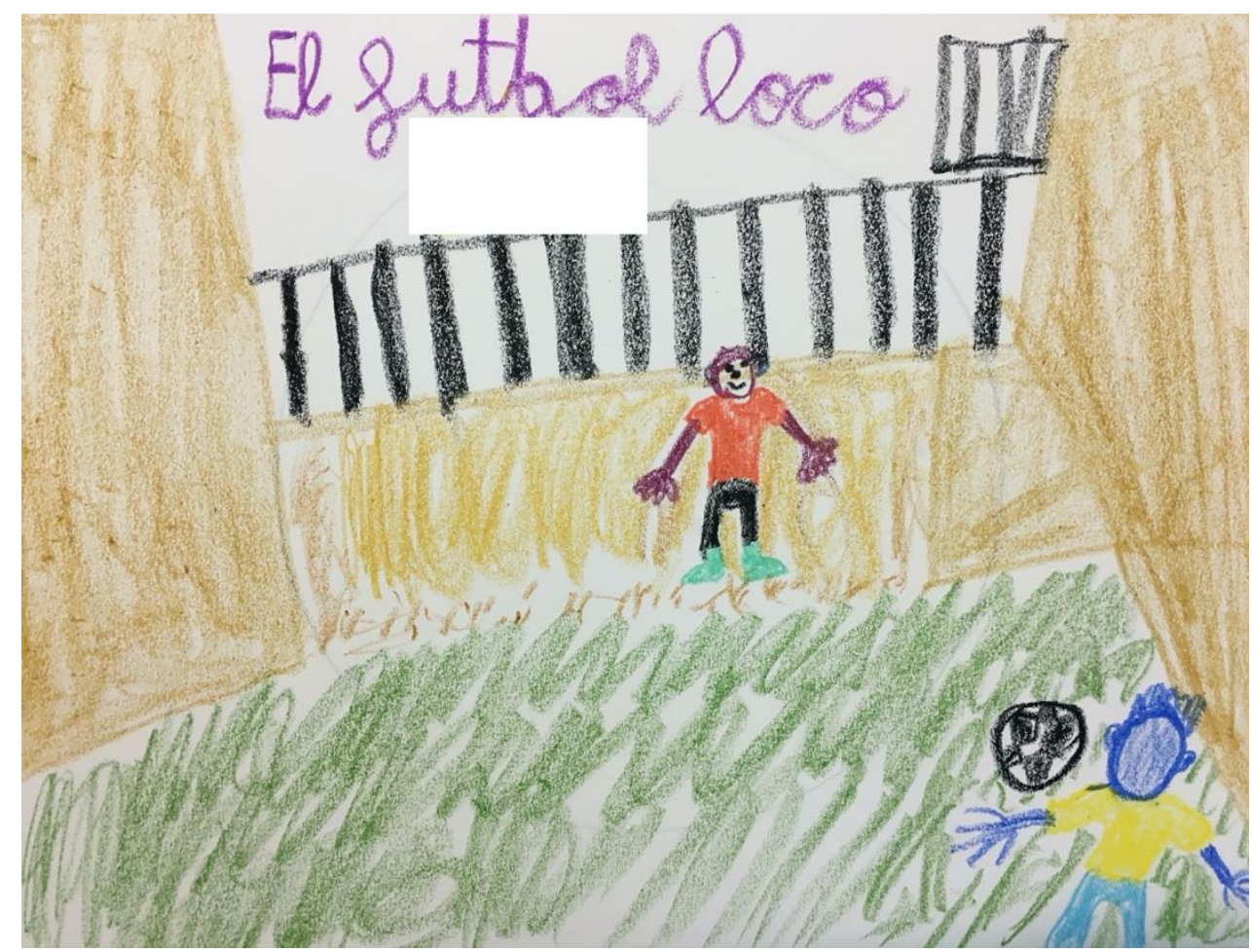

Figura 17. Mandala de N, Sesión 6. 11/04/2017.

Igualmente, a la hora de contrastar la información cualitativa nos encontramos con algunas situaciones y testimonios por parte de las familias que nos ayudan a valorar de qué forma se ha producido este incremento de la capacidad de autonomía emocional. El primer ejemplo, de hecho, en relación con el caso de "N":

Mira, A, un día se lo dijo a su madre y ella me lo dijo a mí, delante de él, que qué bien pintaba N. Y como son niños a los que normalmente no se les reconoce lo que hacen bien, pues cuando sí se les reconoce algo, a él le puede subir la autoestima, el hecho de que la gente reconozca lo que hace bien. (...) Es como en el colegio, que se le da muy bien la papiroflexia, y hay niños que se lo reconocen y le piden que les haga cosas. Y eso a él le viene muy bien, el que la gente reconozca que hace cosas bien, porque como siempre es al revés, casi todo el mundo le destaca lo negativo..., a él le gusta oír que le digan las cosas que hace bien. Y con esto ha tenido esa oportunidad de sacar lo que llevaba dentro y luego el que haya un grupo de gente, aunque sea pequeño, que se lo reconoce.

(Entrevista a madre y padre de N, después de la intervención) 
Sin embargo, lo del dibujo le ha gustado menos. Además, viendo a otros niños que lo hacen muy bien, pues él como que se queda retraído, como mirando, como diciendo que él no puede. Y de ahí vienen sus arrebatos y sus cosas, pero mira, también tiene sus momentos de victoria, como el último día que dibujó muy bien los meteoritos, que decía él.

(Entrevista a madre de F, después de la intervención)

Pues porque ya no dice: "Yo no sé hacer esto, yo no voy a poder, ¿sabes? Él se pone con las tareas, que es en general, con todo lo que hace, pero yo con las tareas, es donde más se lo he notado... Mira, físicamente, no es muy hábil, no sé cómo decirte...(...) Pero, sí, en cuanto a las tareas, yo le veo mejor... A ver, a lo mejor, es un proceso de todo..., que aquí está bien, que va siendo un poco más mayor, es bastante inmaduro, que a lo largo de todo el curso ha ido llevando una rutina. Mira, el sábado, por ejemplo, que ya tenía hechas las tareas del viernes, me dijo que se iba a poner a estudiar un poco, para ya tenerlo estudiado para el día siguiente y fue él solo, sin decirle nada... Y, claro, también ve que se lo valoran y cuando ven que te valoran las cosas que haces, pues lo quieres hacer bien... (Entrevista a madre de D2, después de la intervención)

De hecho, a pesar de que la información cualitativa para contrastar esta categoría sea más escasa, si comparamos el valor de EODE3_AE desde el punto de vista del investigador con el punto de vista de las familias, podemos considerar que las dos perspectivas son prácticamente iguales (Tabla 24) de forma estadísticamente significativa para un n.d.c. del 5\% ( $\mathrm{Z}=, 00 ; \mathrm{p}>, 05)$. Esto quiere decir que tanto el investigador principal como las familias están de acuerdo en la opinión de que la capacidad de autonomía emocional de los niños participantes se ha visto incrementada a lo largo del proceso de intervención.

\section{Tabla 24}

Punto de vista del investigador y de las familias respecto a la autonomía emocional después de la intervención

Media Mediana $\quad$ D. T. $\quad$ Z Sig.

\begin{tabular}{ccccccc}
\hline Punto de vista del investigador & 6,56 & 7,00 & 1,67 & & \\
& & 7,00 & 1,00 \\
Punto de vista de las familias & 6,56 & 7,00 & 1,88 & & \\
\hline
\end{tabular}

Fuente: Elaboración propia. 


\subsection{Competencia social}

Dentro de la escala EODE, el valor cuantitativo que se refiere a la competencia social está relacionado con la capacidad de los niños participantes en la investigación para pedir permiso, dar las gracias y pedir perdón. A la hora de contrastar los datos cuantitativos con la información textual cualitativa obtenida de las sesiones, se tienen en cuenta estos enunciados y, además, se considera y observa de qué forma la intervención da pie a una mejora de los procesos de relación social, no solo entre los compañeros sino también con el musicoterapeuta y otros adultos como pueden ser los padres y profesores de los niños. En la Tabla 25 se recoge una breve definición de esta categoría cualitativa, designada como EODE4_CS, así como el número total de citas recogidas y dos ejemplos sobre cuándo se utiliza y cuándo no se utiliza esta categoría.

Tabla 25

Categoría cualitativa para el análisis textual de competencia social

\begin{tabular}{|c|c|c|c|c|}
\hline Nombre & Citas & Definición & Cuándo se usa (ejemplo) & Cuándo no se usa (ejemplo) \\
\hline EODE4_CS & 110 & $\begin{array}{l}\text { Citas textuales en } \\
\text { las que se alude a la } \\
\text { capacidad para pe- } \\
\text { dir permiso, dar las } \\
\text { gracias y pedir per- } \\
\text { dón. También re- } \\
\text { fleja la repercusión } \\
\text { de la intervención } \\
\text { en la forma de rela- } \\
\text { ción social de los } \\
\text { niños. }\end{array}$ & $\begin{array}{l}\text { "Y el mayor, pues no, por- } \\
\text { que como ha tenido proble- } \\
\text { mas de autoestima, pues no } \\
\text { se relaciona fácilmente, es } \\
\text { un buen niño, tiene sus ami- } \\
\text { gos, se porta muy bien, pero } \\
\text { le cuesta mucho relacio- } \\
\text { narse con los demás. Como } \\
\text { es más tranquilo, el resto de } \\
\text { los niños, en vez de meterle } \\
\text { en su grupo, pues no le } \\
\text { quieren." }\end{array}$ & $\begin{array}{l}\text { "Yo sobre todo lo enfoco en } \\
\text { el deporte, para que desgaste } \\
\text { energía, bueno, en general, } \\
\text { actividades que le supongan } \\
\text { un gasto de energía. Es en } \\
\text { esas actividades en las que } \\
\text { más ocupadas tiene las tar- } \\
\text { des. Y yo sé que para él es un } \\
\text { desahogo, pero bueno... tam- } \\
\text { poco..." }\end{array}$ \\
\hline
\end{tabular}

Fuente: Elaboración propia.

Para analizar la información referida a esta categoría desde un punto de vista cualitativo, durante la primera parte de la intervención, correspondiente a las sesiones individuales, fue de utilidad prestar mucha atención a la forma en que los niños se relacionaban con el musicoterapeuta, así como tener muy en cuenta los testimonios por parte de padres y madres en relación con su actitud respecto a otros compañeros y adultos en otros contextos fuera de la situación de terapia (colegio, casa, tiempo de ocio, etc.).

Por otra parte, como cabía esperar, esta categoría se hizo mucho más presente en la segunda parte del estudio, relacionada con las sesiones grupales. En este sentido, si bien es cierto que en algunos grupos la situación de terapia con compañeros produjo cierto desajuste en la rutina y en el comportamiento de algunos de los niños participantes en la intervención, dio lugar a una clara 
mejora de la competencia social, especialmente en algunos de los casos, como veremos a continuación con algunos ejemplos.

De hecho, a la hora de comparar los resultados cuantitativos referidos al valor de competencia social, nos encontramos con que se ha producido un aumento estadísticamente significativo de esta capacidad en la mayor parte de los casos para un n.d.c. del 5\% ( $\mathrm{Z}=-2,76 ; \mathrm{p}<, 05)$, como se puede observar en la Tabla 26 al comparar las medias antes y después de la intervención llevada a cabo.

Tabla 26

Competencia social antes y después de la intervención

Media Mediana D. T. $\quad$ Z $\quad$ Sig.

\begin{tabular}{ccccccc}
\hline Antes de la intervención & 4,78 & 5,00 & 1,56 & & \\
Después de la intervención & 6,11 & 6,00 & 1,45 & & \\
\hline
\end{tabular}

Fuente: Elaboración propia.

Uno de los ejemplos que nos sirve para ilustrar y contrastar estos resultados desde un punto de vista cualitativo es el de "F", de 7 años de edad, adoptado y con diagnóstico de TDAH. Ya desde un primer momento, en la sesión 1, se pudo observar cómo se mostraba reacio ante la idea de participar en la situación de Musicoterapia, escuchar música, dibujar, etc. De hecho, su madre dio esta información a la hora de llevarle a la primera sesión. Con ello, la relación establecida con el musicoterapeuta, así como con el resto de niños al inicio de las sesiones grupales, estaba marcada por la desconfianza y cierta incomodidad, sobre todo al principio de la intervención.

Sin embargo, a lo largo del proceso se pudo observar como esta competencia social empezaba a desarrollarse por medio de la cimentación del vínculo terapéutico, por una parte, y de la relación entre iguales, por otra. Esto se puede considerar, en primer lugar, teniendo en cuenta la tercera sesión de "F", que supuso un punto de inflexión para el resto del proceso terapéutico. En esta sesión, del hecho de ser reacio a la situación de terapia y la relación con el musicoterapeuta, pasó a explorar su necesidad emocional desde un punto de vista más auténtico, a través del juego simbólico, e incluso a realizar la actividad de dibujar de forma conjunta, dando lugar a un mandala que funcionó como hilo conductor para las siguientes sesiones individuales (Figura 18). La vivencia relatada en esta sesión se ve contrastada, igualmente, con el punto de vista de su madre en la entrevista después de la intervención: 
Esta dinámica ha dado como resultado el dibujo de un mapa del tesoro en el que se recogen distintos obstáculos que hay que ir superando, y que está formado por dos partes: el mandala de $\mathrm{F}$ y el mío. De esta forma, lo más importante de la sesión de hoy ha sido la utilización del juego simbólico de aventuras como hilo conductor de la sesión y el hecho de haber dibujado un mapa de forma cooperativa, de tal modo que hagan falta los dos mandalas para poder completar el camino hacia el tesoro. [E]l hecho de dibujar el mapa del tesoro entre los dos fortalece el vínculo y estrecha la confianza. De hecho, él mismo sigue afirmando que quiere que lo guarde en secreto, lo que denota un nivel de confianza significativo. [Q]ue F vea en la situación de musicoterapia un espacio seguro donde puede expresarse libremente es un hecho que sienta las bases para que se pueda producir un proceso terapéutico.

(Diario de investigación, Sesión 3 de F)

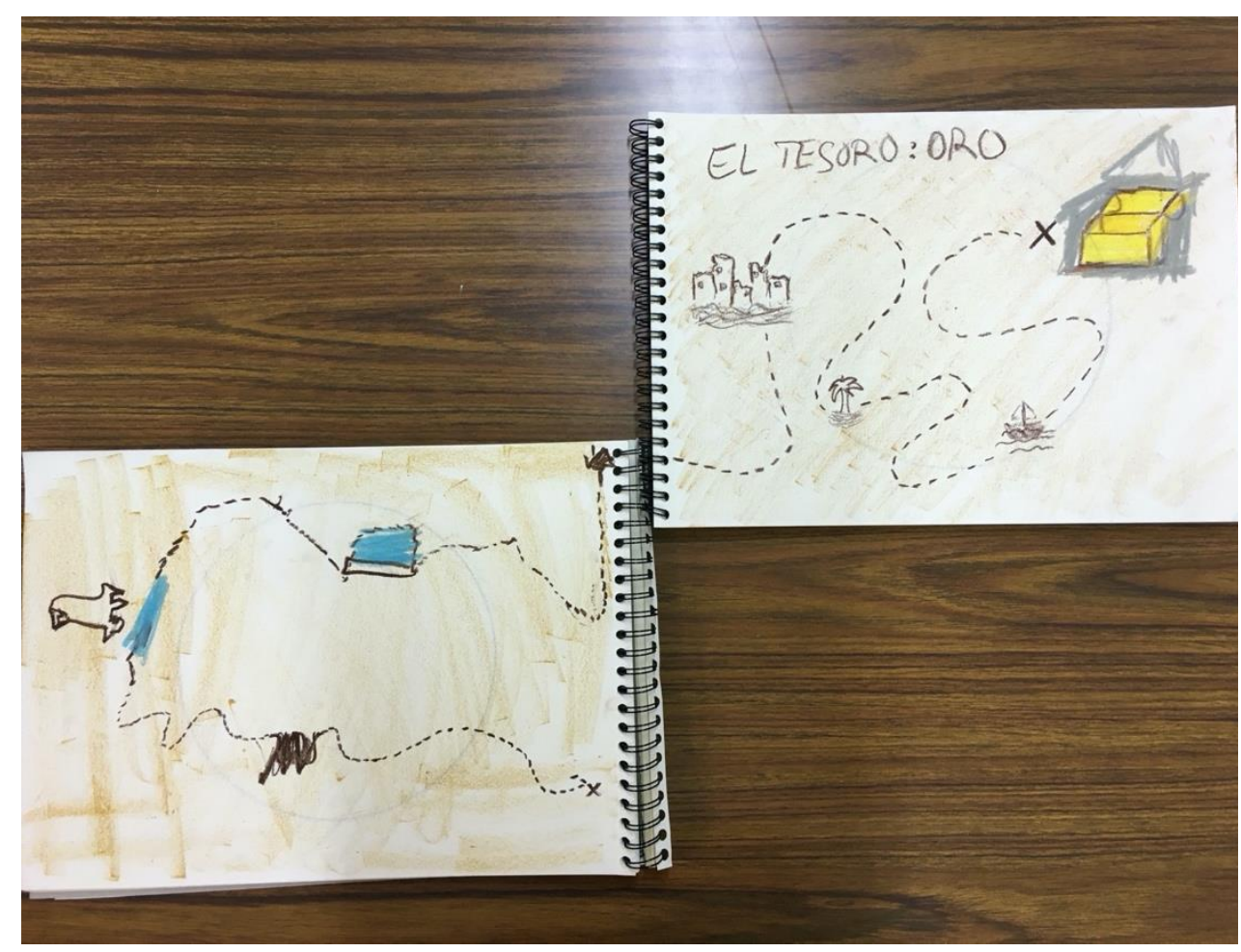

Figura 18. Mandala de F, Sesión 3. 20/03/2017.

Pues toda la historia que vivía con los juegos que hacías de pintar el mapa del tesoro, para él ha sido como vivir una aventura... Y es que, además, con la música él se mete mucho. Yo creo que le ha gustado y que le ha venido muy bien.

(Entrevista a madre de F, después de la intervención) 
En relación con ello, respecto a las sesiones grupales, tanto el investigador principal como la madre de " $F$ " pudieron observar que su capacidad de relación social se vio ciertamente desarrollada, especialmente por la conexión que se producía con "D2" y en relación con el incremento de cierto sentido de conciencia o responsabilidad social:

$[\mathrm{N}]$ o es un niño al que invitarían a su cumpleaños, muchos de ellos... Mira que bien se lleva con D2 y el otro día vino muy afectado a casa porque D2 ya no iba a ser su amigo; y al preguntarle por qué me dijo que le ha dicho que dice muchas palabrotas y muchos insultos y que le ha dicho que o deja de decir esas cosas o va a dejar de ser su amigo. Y yo se lo tuve que explicar: "Te lo llevo diciendo mucho tiempo, que no se puede hablar así, que no se pueden decir palabrotas, que puedes molestar a los demás. (...) El otro día, viniendo de D2, le dolió mucho, así que mira, a lo mejor ahí hemos ganado algo. (...) En otro momento, lo de D2, no me lo hubiera contado y en esta ocasión sí, le ha llegado fuerte, pero por la conexión tan buena que han hecho en la clase. Ellos van juntos al cole, bueno, juntos, pero separados... Y ahora han coincidido en esto [en las sesiones de Musicoterapia] y como es muy amigo de sus amigos...

(Entrevista a madre de F, después de la intervención)

Por otra parte, la madre de "I1" hace alusión a su actitud en cuanto a la relación social con sus compañeros antes de la intervención, y señala los cambios que ha podido percibir en ella una vez ha finalizado la intervención musicoterapéutica a raíz de las sesiones grupales:

Me da la sensación de que es porque es una persona un poco dominada, por así decirlo, sumisa. Y eso le hace ser una niña muy bien mandada, muy obediente, enseguida que le pides algo, te lo hace de mil amores... (...) Y lo que yo la veo, de lo poco que la he visto relacionarse con niños de su clase, se relaciona muy a la defensiva, con sus iguales; a lo mejor, al hablar contigo es una niña encantadora, pero en cuanto un niño de su edad la dice algo, reacciona muy a la defensiva. "¿Qué tienes ahí?" "Pues nada que te importe” Entonces, yo sí que he intentado hablar con ella: "No, I, es que, si les hablas así, no te van a tratar bien, porque si una persona te habla mal, no vas a querer hablar con ella". Entonces, intenta hablar mejor, le digo que la gente no lo hace por hacerte ningún mal, pero eso, creemos, que va un poco también en lo que ha ido recibiendo en el otro colegio.

(Entrevista a madre de I1, antes de la intervención) 
[M]uy buena sintonía con los compañeros, yo creo que también le ha ayudado, porque como iba con compañeros, por ejemplo, con F..., a D2 sí que le conocía y tenía mucho vínculo con él, porque D2 se cambió con ella a este colegio..., se conocen desde los tres años. Pero, por ejemplo, con F, yo creo que tiene ahora más relación, más vínculo, porque han hecho esto juntos..., habla mucho de Y... y me parece que ella no le da importancia, no sé si no se da cuenta, de que hay gente con una problemática..., ella cuenta anécdotas de sus compañeros..., pero no dice mucho más, a pesar de que yo creo que ella sí que es consciente de que en este trabajo hay gente con problemas, con TDA..., ¿es TDA?

(Entrevista a madre de I1, después de la intervención)

Igualmente, la madre de " $\mathrm{A}$ " reflexiona en la entrevista antes de la intervención en cuanto a la capacidad de relación social, y compara con lo que observa después de la intervención:

Lo que yo me estoy dando cuenta, desde siempre, es que es muy charlatana en clase... La motivación, lo que me han dicho los profesores, porque ella está en quinto, me explican los profesores, que de los cuarenta minutos que dura una clase, ella utiliza o rinde diez minutos, porque el resto del tiempo o está haciendo bromas, o está mirando por la ventana o interrumpe las clases..., o sea, se dispersa, no se centra, bueno, como cualquier niña, que le da pereza o que es muy aburrido... (...) Y el profesor le hace llamadas de atención, a veces da contestaciones de una niña... Que tiene que tener respecto al profesor.

(Entrevista a madre de A, antes de la intervención)

En cuanto a las clases, venía contenta, le han gustado, tiene todos los dibujos en el armario, aunque tampoco me ha contado nada; el caso es que habla mucho, porque habla por los codos, pero si tú no le preguntas, no te cuenta nada, si se lo preguntas, te lo cuenta, pero si no, no. En los estudios ha mejorado y en el comportamiento también, supongo que tendrá algo que ver...

(Entrevista a madre de A, después de la intervención)

El padre de "Y" y "M", en la entrevista antes de la intervención, alude a la dificultad que supone reeducar en cuanto a algunos principios morales que repercuten directamente en la calidad de las relaciones sociales (recordemos que ambos son niños de acogida). Su madre, después de la intervención, también reflexiona sobre los efectos que ha podido tener la Musicoterapia en cuanto a la relación social de sus hijos con sus compañeros, especialmente aludiendo al desarrollo de las sesiones grupales: 
Tiene unos ciertos vicios, los principios morales y todas estas cosas, que se ponen los primeros años de vida, si no se siembran bien, pues luego es difícil... Ese problema no lo tiene Y, porque ha sido separado antes de la familia y se ha sembrado eso mejor, pero él al ser dos años mayor, pues... cada ver que dice una verdad se le cae un brazo, también le gusta ser algo amigo de lo ajeno..., estamos trabajando con él esas historias.

(Entrevista a padre de Y y M, antes de la intervención)

Como balance general..., les he visto contentos, han venido contentos y como había chicos que conocían del cole, pues eso les ha ayudado a encontrarse en el colegio de otra manera. Fíjate, yo creo que ha ayudado también a esa relación en el cole, fuera del cole, en el parque, yo creo que les ha ayudado, tanto a M como a Y. (...) Y con el otro chaval, (...) este hiperactivo, que estuve hablando con el padre que llevaba medicación..., en ese sentido yo le he visto mejor [a "M"], que me parece curioso, que van juntos, pero no tenían tanta relación y ahora suelen quedar para ir juntos al colegio o lo que sea. ["Y"] Sale a jugar en el parque, con sus amigos y tiene mejor relación con ellos, no les impone, no les insulta, intenta colaborar con todos..., yo le veo que están más contentos... y los padres se dan cuenta del cambio... (...) El contacto con los chicos, que quieran ir con él a darse una vuelta con la bici..., no ha sido algo normal antes. O que los padres dejen a los amigos venirse a casa con él...

(Entrevista a madre de Y y M, después de la intervención)

De hecho, si comparamos el valor total del punto de vista del investigador principal con el de las familias después de la intervención, al aplicar la prueba de Wilcoxon, nos encontramos con que la diferencia no es estadísticamente significativa para un n.d.c. del 5\% ( $\mathrm{Z}=-1,20 ; \mathrm{p}>, 05)$, como se puede apreciar en la Tabla 27.

Tabla 27

Punto de vista del investigador y de las familias respecto a la competencia social después de la intervención

Media Mediana D. T. $\mathrm{Z}$ Sig.

\begin{tabular}{lllllll}
\hline Punto de vista del investigador & 6,11 & 6,00 & 1,45 & & \\
Punto de vista de las familias & 6,89 & 8,00 & 1,90 & & \\
\hline
\end{tabular}

Fuente: Elaboración propia. 


\subsection{Competencia de vida y bienestar}

Teniendo en cuenta de nuevo la escala EODE, el valor referido a la competencia de vida y bienestar desde un punto de vista cuantitativo hace alusión principalmente a si los niños muestran una actitud positiva, así como a su capacidad creativa. Desde una perspectiva cualitativa, se han tomado en consideración estos valores de forma literal, y además se ha tenido en cuenta valorar si la actitud positiva guarda relación solo con las sesiones de Musicoterapia o si, por el contrario, va más allá y repercute en la realidad personal, familiar y social de los participantes. De igual forma, se trata de valorar si la creatividad se ha visto desarrollada no solo en las sesiones de Musicoterapia, sino también en la vida cotidiana de los participantes. En la Tabla 28 se puede apreciar una breve definición de la categoría cualitativa empleada para tal fin, designada como EODE5_CVB.

Tabla 28

Categoría cualitativa para el análisis textual de competencia de vida y bienestar

\begin{tabular}{|c|c|c|c|c|}
\hline Nombre & Citas & Definición & Cuándo se usa (ejemplo) & $\begin{array}{c}\text { Cuándo no se usa } \\
\text { (ejemplo) }\end{array}$ \\
\hline EODE5_CVB & 217 & $\begin{array}{l}\text { Citas textuales en las } \\
\text { que se alude a muestra } \\
\text { de una actitud positiva y } \\
\text { a la capacidad creativa. } \\
\text { También hace alusión a } \\
\text { cómo se han desarro- } \\
\text { llado estos dos factores } \\
\text { a lo largo de la interven- } \\
\text { ción. }\end{array}$ & $\begin{array}{l}\text { "N ha experimentado un cam- } \\
\text { bio sustancial en la segunda se- } \\
\text { sión en comparación con la an- } \\
\text { terior. De antemano, antes de } \\
\text { entrar su madre me ha dicho } \\
\text { que el último día se fue encan- } \\
\text { tado, que había disfrutado mu- } \\
\text { cho y que estaba deseando vol- } \\
\text { ver a hacer la siguiente se- } \\
\text { sión." }\end{array}$ & $\begin{array}{l}\text { "Pero, sobre todo, } \\
\text { que preste atención, } \\
\text { no sólo diez minu- } \\
\text { tos, sino que tiene } \\
\text { que estar centrada, } \\
\text { que tenga un poco } \\
\text { de organización, } \\
\text { que no se organiza." }\end{array}$ \\
\hline
\end{tabular}

Fuente: Elaboración propia.

Junto con la categoría de regulación emocional, la categoría de competencia de vida y bienestar ha sido la categoría con más citas textuales extraídas (217) a la hora de realizar el análisis de la información textual. Por lo tanto, es necesario destacar que ha resultado ser un aspecto muy relevante durante el proceso de intervención, especialmente en algunos casos en concreto, como pasamos a explicar en líneas subsecuentes. 
En lo que se refiere al análisis cuantitativo respecto a este valor de competencia de vida y bienestar, con el objetivo de contrastar si se han producido cambios, podemos afirmar que sí, ya que al comparar los valores obtenidos antes y después de la intervención nos encontramos con una variación estadísticamente significativa para un n.d.c. del $5 \%(\mathrm{Z}=-2,68 ; \mathrm{p}<, 05)$, como se puede apreciar en la Tabla 29. De hecho, si observamos y comparamos el valor de las medias antes y después de la intervención podemos afirmar que se ha producido un aumento de la competencia de vida y bienestar.

Tabla 29

Competencia de vida y bienestar antes y después de la intervención

\begin{tabular}{rrrrrr} 
& Media & Mediana & D. T. & $\mathbf{Z}$ & Sig. \\
\hline Antes de la intervención & 2,56 & 3,00 & 1,13 & & \\
Después de la intervención & 5,67 & 6,00 &, 70 & & \\
\hline
\end{tabular}

Fuente: Elaboración propia.

Sirva de ejemplo el caso de "Y", quien en las sesiones habitualmente dibujaba escenas relacionadas con guerras, realmente violentas y alejadas de toda realidad. De hecho, él mismo verbalizaba en muchos casos que estaba tratando de representar escenas reales de su vida diaria, en las que luchaba contra enemigos muy dispares o incluso contra sus propios compañeros de clase. Llegaba a compartir que se había enfrentado a decenas de contrincantes, incluso cientos, lo que muestra una clara representación que se podría considerar, cuanto menos, fruto de la imaginación de un niño de 9 años como él. Lo importante de este hecho es que a través de estos dibujos y el modo de hablar sobre ello estaba demostrando una de sus formas de comprender el mundo y relacionarse: a través de la violencia. Algunos ejemplos de estos mandalas son las Figuras 19 y 20. 


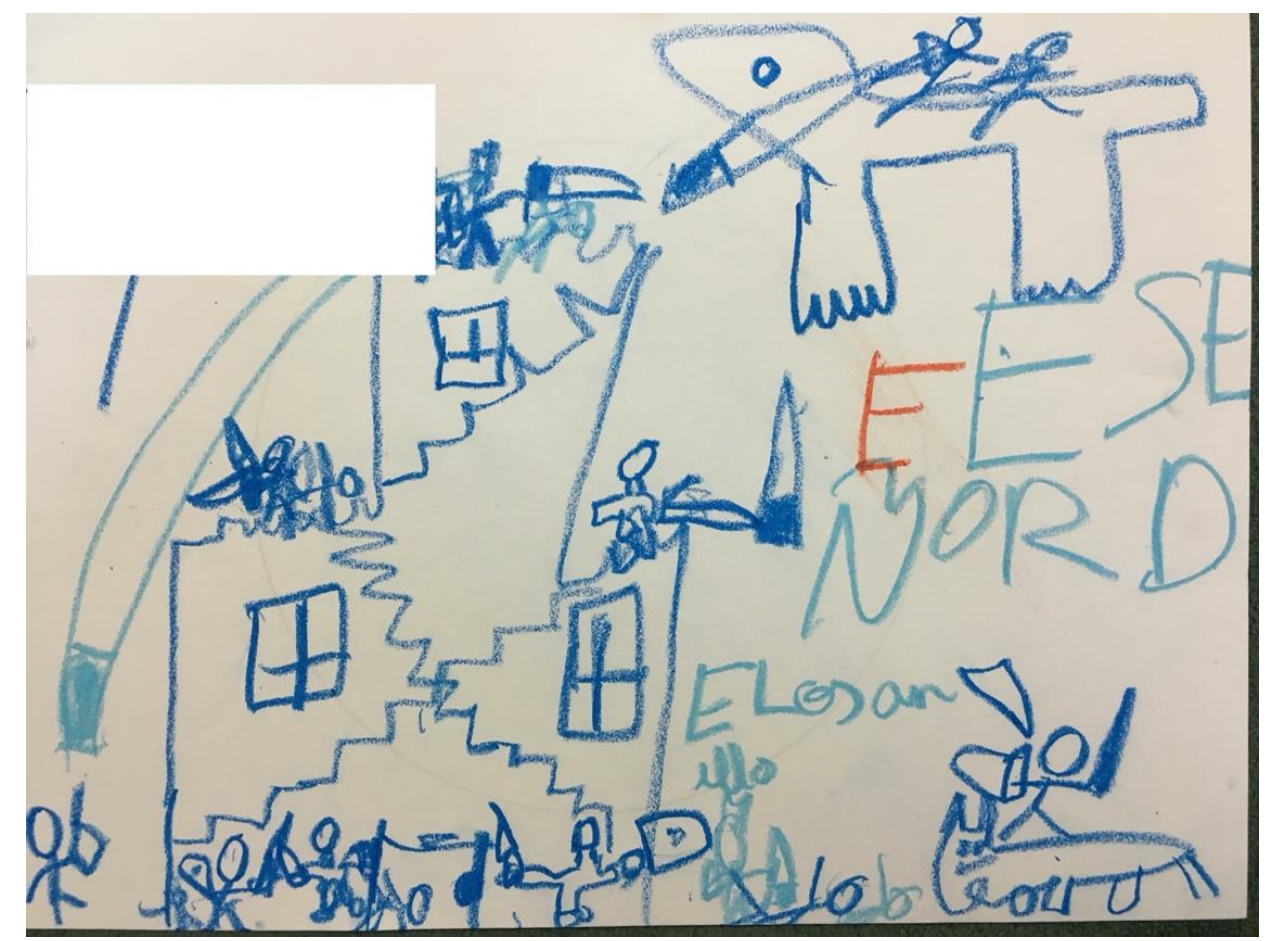

Figura 19. Mandala de Y, Sesión 2. 16/03/2017.

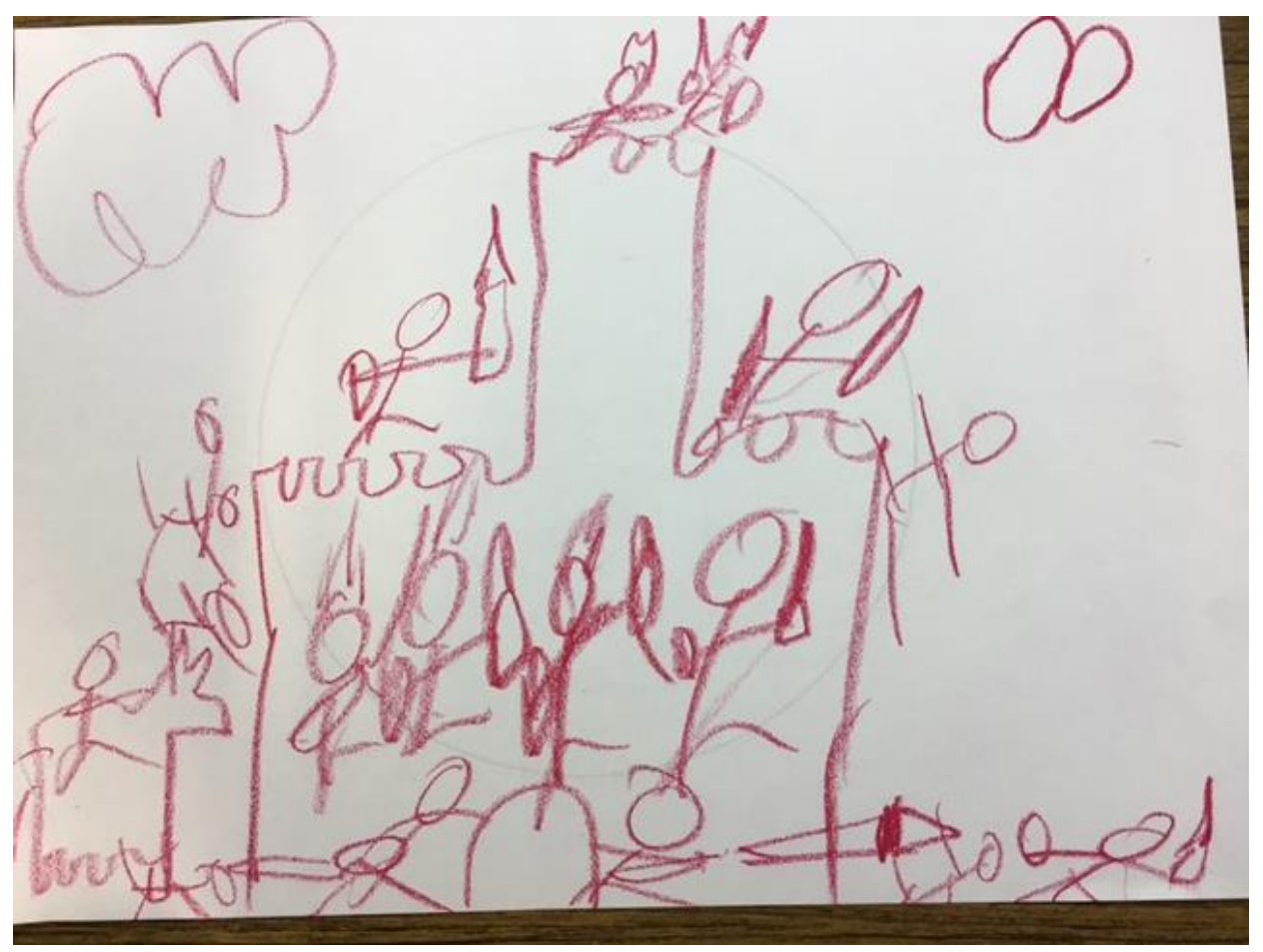

Figura 20. Mandala de Y, Sesión 3. 23/03/2017. 
Sin embargo, en la última sesión de la intervención musicoterapéutica (sexta sesión grupal) "Y" mostró una parte de sí mismo que no se había mostrado en sesiones anteriores. Hizo un mandala que demuestra un cambio de actitud bastante considerable, lo cual se puede apreciar en la Figura 21 y en el extracto del diario de investigación que se presenta a continuación:

Cuando la música termina, se aleja de su dibujo para decir algo sobre la música y, cuando vuelve y ve lo que ha hecho, se sorprende y él mismo verbaliza: “¡Hala! ¿Lo he hecho yo?”. Sus compañeros también preguntan, asombrados, si lo ha hecho él. Y está realmente asombrado y comparte sonriendo: "No sé cómo me ha salido tan bien". Lo que acaba de hacer marca realmente una diferencia en comparación con el resto de sesiones, en las que los mandalas seguían habitualmente una misma línea temática (guerras, muerte, violencia, etc.). En esta ocasión, Y ha dibujado un sol que realmente le gusta y que dice que es muy bonito. Cuando se lo enseña a sus compañeros se muestra muy contento y les pregunta si les gusta. Sin duda la actitud que muestra es distinta a la que tiene en otras sesiones, ya que en este momento considera que lo que ha dibujado es de verdad importante, lo da valor y quiere y espera que sus compañeros también reconozcan ese valor.

(Diario de investigación, Sesión 12 de Y)

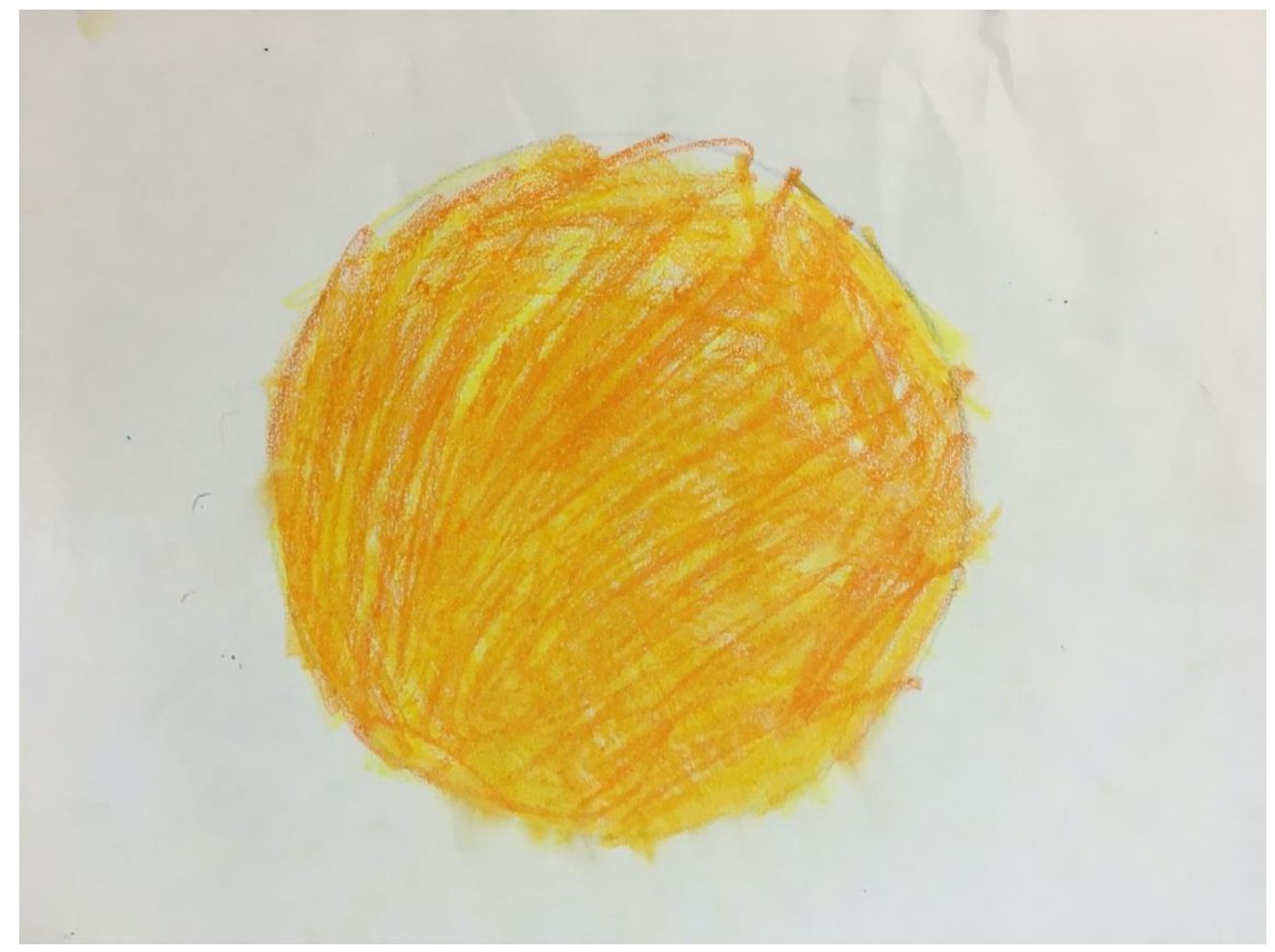

Figura 21. Mandala de Y, Sesión 12. 08/06/2017. 
Igualmente, su madre explica en la entrevista realizada después de la intervención que ella también se ha dado cuenta de cómo se ha producido este cambio, como se puede observar en esta cita textual extraída de dicha entrevista:

Como balance general..., les he visto contentos, han venido contentos y como había chicos que conocían del cole, pues eso les ha ayudado a encontrarse en el colegio de otra manera. Fíjate, yo creo que ha ayudado también a esa relación en el cole, fuera del cole, en el parque, yo creo que les ha ayudado, tanto a M como a Y. Y no tiene problemas para buscar amigos, pero sí que tiene más problemas con la relación, de cómo les trata. M, en cambio, sí que tiene más problemas de hacer amigos en el grupo, pero, vamos, en general, yo creo que muy bien. (...) Han ido cambiando de peleas a otras cosas, que es lo que me ha parecido curioso, que ya no tenga esa necesidad de dibujar peleas. (...) ¡Uy! ¿Un sol o algo así? (...) Sí, es que es como muy redondo y no se sale, como teniendo mucho control de no salirse de algo...

(Entrevista a madre de Y y M, después de la intervención)

De hecho, es necesario señalar en este punto que la perspectiva del investigador principal después de la intervención respecto a si se han dado cambios en la competencia de vida y bienestar no se diferencia de la opinión de las familias, afirmación que podemos asumir al comprobar que las medias obtenidas no difieren de forma estadísticamente significativa para un n.d.c. del 5\% (Z=1,65; p>,05), como se puede apreciar en la Tabla 30.

Tabla 30

Punto de vista del investigador y de las familias respecto a la competencia de vida y bienestar después de la intervención

Media Mediana D. T. $\quad Z$ Sig.

\begin{tabular}{lllllll}
\hline Punto de vista del investigador & 5,67 & 6,00 &, 71 & & \\
& & & & $-1,65$ &, 10 \\
Punto de vista de las familias & 4,78 & 5,00 &, 97 & & \\
\hline
\end{tabular}

Fuente: Elaboración propia. 
Otro ejemplo en el que se puede apreciar esta muestra de una actitud positiva, así como el desarrollo de la creatividad, lo encontramos en el caso de "D2", cuya madre destacaba en la entrevista después de la intervención lo que había observado a lo largo de todo el proceso en comparación con lo que compartía en la entrevista antes de la intervención:

Sí, [dibuja] amigos o gente que ha visto en la piscina de no sé dónde. Y si le dices que porqué ha hecho dice y te dice, pues porque sí, entonces me mata. Pero, ¿por qué? Pues porque me gusta... Hombre, a mí me gustaría que me dijera, pues he dibujado esto por tal o por cual..., por esto otro, porque aquí hay no sé qué...Porque digo yo que él en su interior lo ha dibujado por algo.

(Entrevista a madre de D2, antes de la intervención)

A mí me ha parecido bien, a él le ha gustado mucho venir, ha venido muy contento y he visto que dentro desarrollaba mucho la creatividad, con los dibujos..., del primer dibujo que hizo a los últimos..., como que al principio estaba más cohibido al dibujar y luego mejor. (...) [É]l estaba encantado de venir y le gustaba. (...) [E]n los dibujos; por ejemplo, el del otro día, el del monstruo..., yo sé que es capaz de dibujar cosas, pero en casa prefiere el ordenador, me dice: "Déjame el ordenador para ver cómo se dibuja un coche de carreras". Y yo le digo que no, que lo dibuje él. Es como que le cuesta, no es que sea vago, pero le cuesta pensar qué quiere dibujar o qué quiere hacer...y, en cambio, aquí, yo le veo que los hace mejor. Por eso te preguntaba que si lo había dibujado él solo, porque me sorprendía, porque en casa no lo hace así de bien, aunque tiene días, hay días que hace las cosas muy bien y otros días que hace cuatro palotes y ya está, se acabó. Le digo que tiene que ser más creativo y dice que no se le ocurre nada.

(Entrevista a madre de D2, después de la intervención)

El monstruo al que se refiere la madre de "D2" en esta cita extraída de la entrevista después de la intervención, apareció en el mandala que dibujó en la sesión número 11 (Figura 22):

De esta sesión resulta uno de los mandalas más originales y sorprendentes que D2 ha dibujado a lo largo del proceso de intervención. Él mismo explica con detalle todas las partes del monstruo, así como sus cualidades, como, por ejemplo, que tiene un poder infinito que se muestra en los colores marrón y dorado. Al explicarlo se muestra entusiasmado y completamente centrado en lo que cuenta sobre el dibujo.

(Diario de investigación, Sesión 11 de D2) 


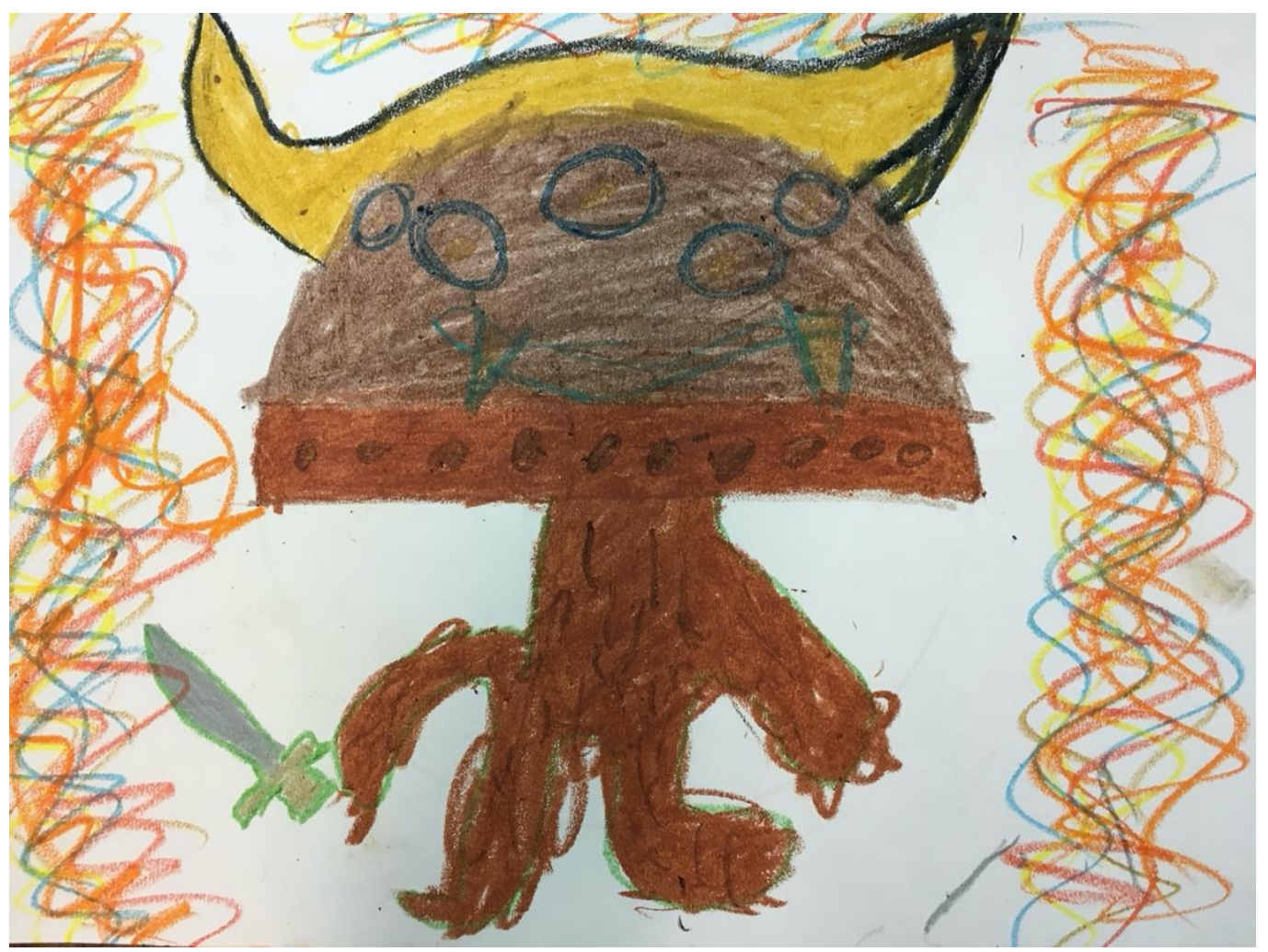

Figura 22. Mandala de D2, Sesión 11. 01/06/2017.

También resulta de interés el caso de "J2", quien desde un primer momento mostró una gran capacidad creativa en las sesiones a la hora de dibujar. Si bien es cierto que probablemente las sesiones no le hayan hecho evolucionar mucho más en esta capacidad, ya que desde un primer momento esto se hizo claramente palpable, en las sesiones se le veía centrado y atento a lo que explicaba, y en esto sí se puede ver una evolución. De entre todos los mandalas realizados a lo largo del proceso, sirve como ejemplo el de su quinta sesión (Figura 23), en el que dibuja una nave espacial, especialmente por la perspectiva que utiliza al visualizar y dibujar este objeto desde arriba:

Lo que más resalta y sorprende de algunos dibujos de J2, como este y el de la tercera sesión, es que refleja el punto de vista superior, es decir, como si se estuviese viendo como un plano desde arriba. No es muy común que los niños plasmen esta perspectiva y esto denota la gran creatividad e imaginación que tiene J2, que vuelve a demostrar en esta sesión. Está entusiasmado a la hora de hablar de su nueva creación.

(Diario de investigación, Sesión 5 de J2) 


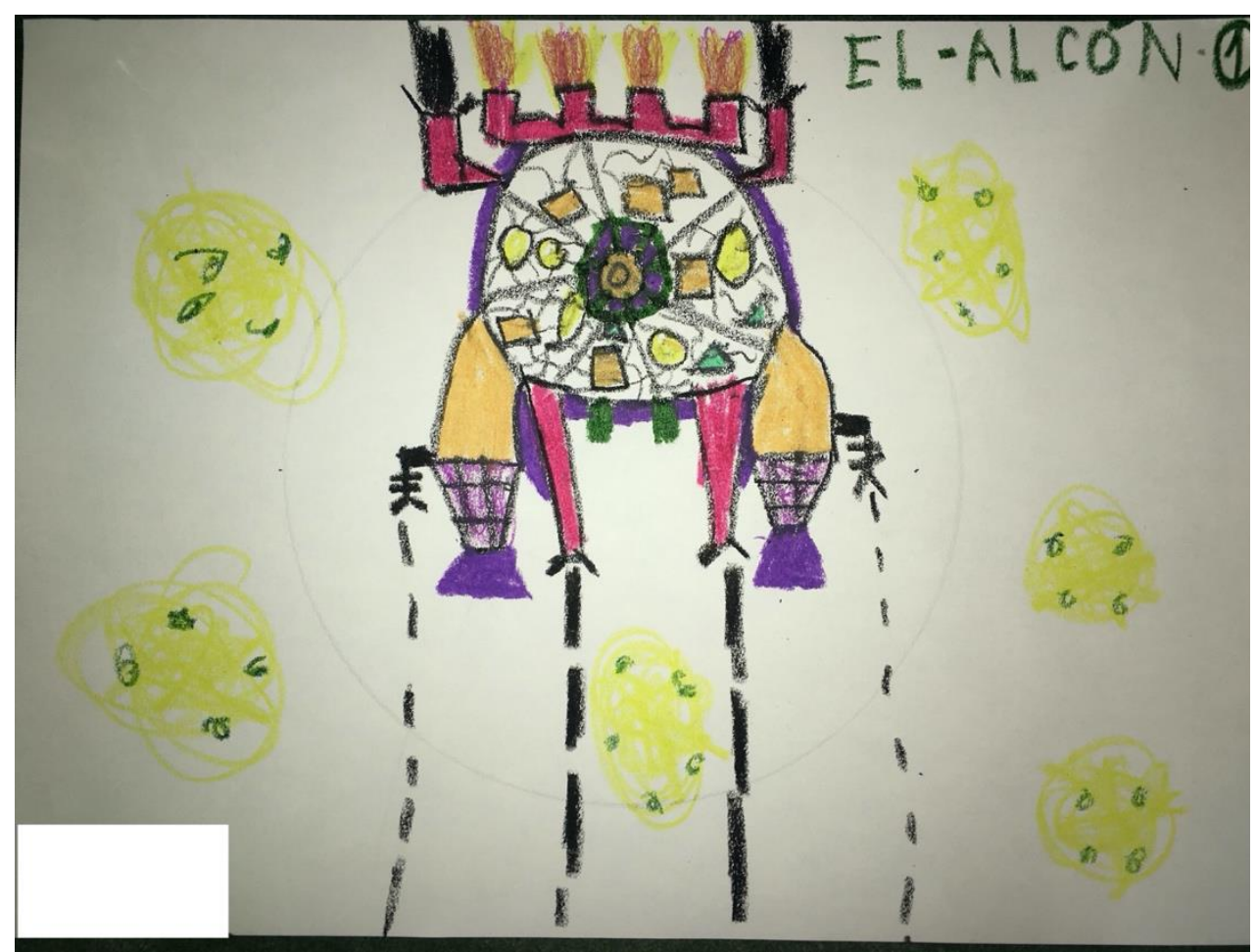

Figura 23. Mandala de J2, Sesión 5. 04/04/2017.

Además, tal y como explica su madre, es posible que las sesiones no le hayan ayudado a desarrollar más su capacidad creativa, pero sí a reforzar y enriquecer su mundo interior y, con ello, a sentirse más realizado, lo cual puede haber repercutido en otro tipo de ámbitos como el académico, el social, etc.:

Es que él tiene un mundo tan rico... No me ha sorprendido, porque si tú vinieras a mi casa y vieras las cosas que hace, por ejemplo, con su plastilina y su pasta de modelar, es que te quedas tonto, porque es que me hace unas cosas... que es tremendo. Y unas construcciones... le compro los legos más difíciles y les hace, que yo me vuelvo loca con las instrucciones, pues él los hace, los tiene una temporada en su habitación y luego, los deshace y crea su mundo interior con ellos. Y me hace unas construcciones... que yo me quedo alucinada. (...) $[Y]$ o creo que le ha gustado mucho, le ha llenado mucho... ya sabes, las personas cuando encontramos algo que nos gusta, que nos llena, nos sentimos motivados y eso hace que todo funcione mejor: las relaciones con sus padres, con sus compañeros, su nivel académico... yo creo que eso hace que todo eso mejore, bueno como nos pasa a los demás.

(Entrevista a madre de $\mathrm{J} 1$ y $\mathbf{J} 2$, después de la intervención) 
Otro ejemplo que se puede asociar a esta categoría, en relación con la muestra de creatividad en las sesiones, corresponde a "I1", quien realiza en su sexta sesión un mandala original, lleno de color, técnica, significado y expresividad (Figura 24). En la entrevista a su madre después de la intervención, ella también afirma que "I1" ha venido muy contenta a las sesiones, lo cual ha repercutido directamente en su actitud positiva:

Ella sí que estaba muy a gusto, de hecho, le ha dado mucha pena que se acabase. (...) Es que está en una época que también pinta mucho... y sí, han cambiado mucho. Decía que este le recordaba a la magia, por la canción que escuchó..., pero esa forma de rodear es muy bonita, así, como haciendo un sueño, a lo mejor... Son recursos que antes no tenía, que es lo que te decía, que está en una época muy de modelo iconográfico, no de investigar ella, sino de aprender..., los ojos se hacen así, la boca así..., copiar truquillos. (...) Que eso es lo que iba a decir yo, que lo que sí hay es como una tendencia a los cuatro espacios, pero no sé, ¿tú les dices algo de que tienen que verlo así? [No, no, nada, yo no les digo nada, solo que pinten cómo se sienten...] iQué gracia!

(Entrevista a madre de I1, después de la intervención)

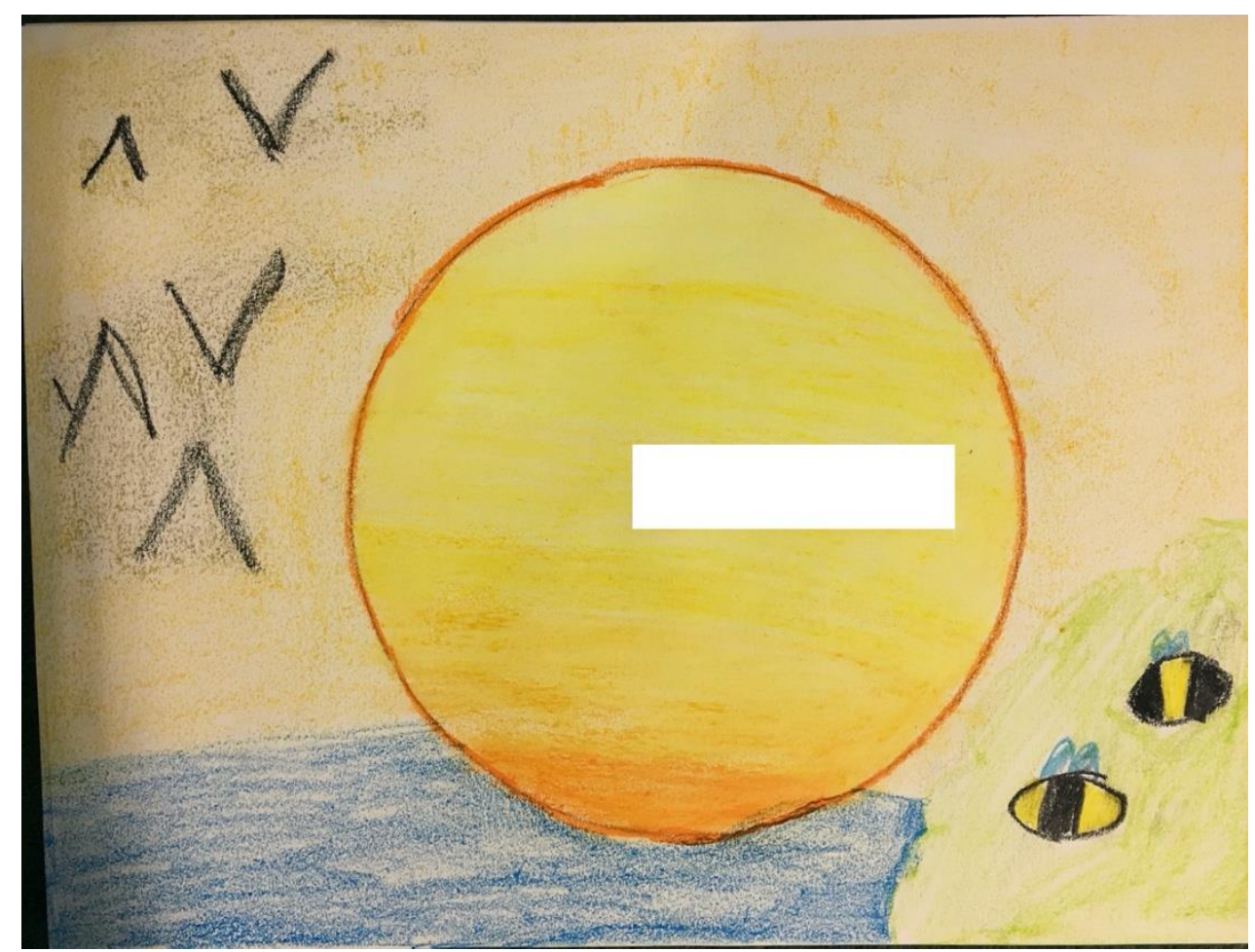

Figura 24. Mandala de I1, Sesión 6. 20/04/2017. 
Como se puede apreciar, el resultado es un mandala original, lleno de creatividad y con bastante complejidad en cuanto a la técnica empleada. Dice que la música le recordaba al momento del día en el que el sol se esconde, junto a los pájaros, el mar y unas abejas. Dice que cuando ve el dibujo se siente tranquila, que cuando está tranquila no se agobia, y que ella normalmente está tranquila. Además, relaciona la temática del dibujo con un libro que está leyendo en la asignatura de lengua. Se va de la sesión tranquila y contenta, le enseña el dibujo a su padre.

(Diario de investigación, Sesión 5 de I1)

Por último, antes de finalizar la presentación de resultados relativos a esta categoría de investigación, cabe mencionar de nuevo el caso de " $\mathrm{N}$ ", en el que también se ha podido apreciar una muestra del desarrollo de la creatividad desde el comienzo de la intervención en adelante. Esto lo podemos observar al comparar algunos de los mandalas que se han presentado previamente ( $\mathrm{Fi}$ guras 7,8 y 14) con el que se muestra a continuación, que corresponde con su primera sesión (Figura 25). En esta primera sesión, lo que podemos observar es una diferencia en comparación con las otras. Igualmente, se puede apreciar que ya desde un primer momento mostraba una actitud positiva de cara a la intervención:

Él mismo decide escuchar la música con los ojos cerrados, con tranquilidad, sentado. Sonríe y asiente disimuladamente mientras lo hace. (...) [L]e ha costado decidir qué iba a dibujar. En el mandala dibuja unas flores, llenas de color y de fuerza, que, según afirma él mismo, le hacen sentir bien, le producen alegría y le ponen muy contento.

(Diario de investigación, Sesión 1 de N)

Igualmente, sus padres refuerzan, en la entrevista después de la intervención, el hecho de que " $\mathrm{N}$ " ha disfrutado viniendo a las sesiones, mostrando una actitud positiva en todo momento, compartiendo distintos momentos del proceso en los que esto se ha manifestado a través de distintas situaciones y comentarios por parte de él:

Pues eso, te contaba la experiencia que había tenido ese día... Un día nos dijo: "Yo creo que a Alberto le caigo bien, porque se ríe mucho conmigo" (Ríen los tres). (...) Y nos dice: "Es que es muy buen chaval". (...) No, lo que está claro es que él ha estado muy a gusto, se le nota además enseguida cuando en una actividad está a gusto o no... Normalmente, cuando le dices cualquier cosa, que no va al parque y tal, te planta una batalla tremenda, pero en esos días, pues no...

(Entrevista a madre y padre de N, después de la intervención) 
También hacen referencia al desarrollo de su creatividad, de nuevo aportando ejemplos concretos de lo que han ido observando a lo largo del proceso de intervención:

Pues mira, a mí, los dibujos me han sorprendido mucho. (...) Siempre ha sido creativo, pero sí que es verdad...(...) Es que los dibujos que ha hecho son muy expresivos y que te explicaba lo que ha querido plasmar ahí, o ha plasmado cosas que él tenía en la cabeza o ideas suyas... Que de otra manera, igual no las había sacado, eso es cierto. Es lo que te iba a decir, que él siempre ha sido muy creativo, pero el venir a estas sesiones le ha dado la oportunidad de sacarlo, porque si no, él posiblemente, no coge un boli o un lápiz y se pone a pintar. Y de esta manera, él ha tenido la oportunidad de sacar eso que él tenía dentro y de hacer esos dibujos, que al mismo tiempo, como eran dibujos que a él le gustaban y a nosotros nos han gustado, pues también eso le sube un poco la autoestima.

(Entrevista a madre y padre de N, después de la intervención)

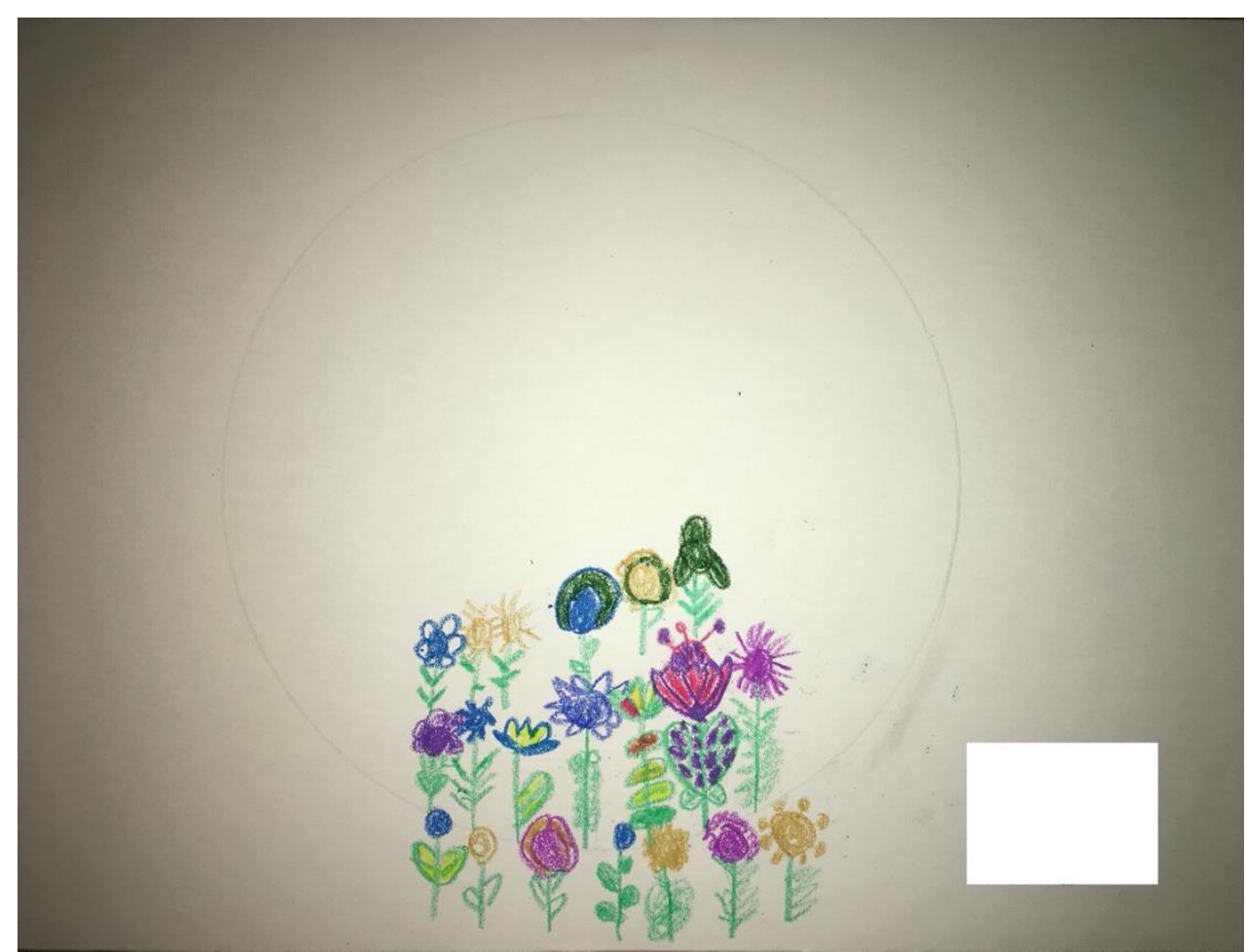

Figura 25. Mandala de N, Sesión 1. 08/03/2017. 


\section{REPERCUSIÓN DE LA INTERVENCIÓN RESPECTO A LAS CARACTERÍSTICAS PROPIAS DEL TDAH}

\subsection{Hiperactividad e impulsividad}

Tomando en consideración en este caso la escala EDAH, diseñada para la evaluación de conductas propias del TDAH, tal y como se ha explicado previamente, el valor cuantitativo que corresponde a la hiperactividad y la impulsividad se determina en base a la muestra de conductas tales como el exceso de inquietud motora, la exigencia de satisfacción inmediata a las demandas, la molestia hacia otros niños, el movimiento constante e intranquilo y la impulsividad e irritabilidad del niño en cuestión. Desde un punto de vista cualitativo, se han tenido en cuenta estos ítems a la hora de observar las conductas mostradas en las sesiones con el objetivo de valorar si ha tenido lugar una evolución respecto a la muestra de hiperactividad e impulsividad en los casos de niños con diagnóstico de TDAH que han participado en el estudio. En la Tabla 31 se puede apreciar una breve definición de la categoría cualitativa empleada para tal fin, designada como EDAH1_HI.

A la hora de analizar este valor de hiperactividad e impulsividad desde un punto de vista cuantitativo, con el objetivo de valorar si se han producido cambios relevantes al comparar el comienzo y el final de la intervención, nos encontramos con que dichos cambios se han producido de manera estadísticamente significativa para un n.d.c. del $5 \%(\mathrm{Z}=-2,03 ; \mathrm{p}<, 05)$, tal y como se puede apreciar en la Tabla 32. Además, si comparamos los valores de las medias de hiperactividad e impulsividad antes y después de la intervención, podemos observar que la muestra de este tipo de conductas ha disminuido.

Tabla 31.

Categoría cualitativa para el análisis textual de hiperactividad e impulsividad

\begin{tabular}{|c|c|c|c|c|}
\hline Nombre & Citas & Definición & Cuándo se usa (ejemplo) & $\begin{array}{c}\text { Cuándo no se usa } \\
\text { (ejemplo) }\end{array}$ \\
\hline EDAH1_HI & 122 & $\begin{array}{l}\text { Citas textuales en las } \\
\text { que se alude a la mues- } \\
\text { tra de conductas hiper- } \\
\text { activas e impulsivas, así } \\
\text { como al proceso de evo- } \\
\text { lución de los niños en lo } \\
\text { que se refiere a este tipo } \\
\text { de conductas. }\end{array}$ & $\begin{array}{l}\text { "Claro, porque con un amigo } \\
\text { suyo este se emociona y él, en } \\
\text { lugar de decirle: ¿qué tal, ma- } \\
\text { jete? pues va y le da un empu- } \\
\text { jón. Pero él no lo hace con } \\
\text { mala intención, es pura im- } \\
\text { pulsividad, es muy impulsivo. } \\
\text { Entonces, es muy difícil..." }\end{array}$ & $\begin{array}{l}\text { "Les encanta pintar } \\
\text { también, todo el día es- } \\
\text { tán las pinturas ro- } \\
\text { dando por casa... y es } \\
\text { que les gusta mucho. } \\
\text { Cuando dijiste lo de los } \\
\text { mandala, pues a éstos } \\
\text { les encanta..." }\end{array}$ \\
\hline
\end{tabular}

Fuente: Elaboración propia. 
Tabla 32

Hiperactividad e impulsividad antes y después de la intervención

Media Mediana D. T. Z Sig.

\begin{tabular}{ccccccc}
\hline Antes de la intervención & 9,80 & 14,00 & 5,85 & & \\
Después de la intervención & 5,20 & 3,00 & 4,92 & & \\
\hline
\end{tabular}

Fuente: Elaboración propia.

Teniendo en cuenta estos datos, y con el objetivo de contrastarlos con la experiencia e información obtenida desde el punto de vista cualitativo a la hora de llevar a cabo la intervención, hay algunos ejemplos que representan el cambio de conductas hiperactivas e impulsivas en los casos de niños diagnosticados de TDAH.

Un ejemplo que llama especialmente la atención es el de "F", en cuyo caso se puede observar una clara evolución respecto a la muestra de este tipo de conductas. En su primera sesión, "F" se muestra tímido, pregunta constantemente lo que tiene que hacer y cómo tiene que dibujar, como si estuviese más pendiente de lo que se espera de él que de lo que realmente quiere expresar. De hecho, el resultado de esta primera sesión es un dibujo contenido, que sigue el contorno del círculo interno del mandala. Al observarlo da la sensación de que se ha limitado a seguir la línea del círculo porque sea lo que pensase que hay que hacer, casi como si se tratase de una tarea del colegio (Figura 26).

Parecía que estaba dibujando de forma racional, rodeando el contorno del círculo con un bolígrafo que ha traído, como si eso fuese lo que se esperaba de él, lo que "había que hacer". Esto lo he pensado, sobre todo, porque ha empezado a pasar páginas, ha visto que había más círculos, y ha preguntado si los tenía que hacer todos. Además, ha utilizado su propio bolígrafo en lugar de las ceras de colores que yo le he propuesto, lo que puede denotar que él se siente más seguro y tranquilo al utilizar su propio bolígrafo, algo que ya es conocido para él. En un primer momento, me da la sensación de que está actuando como se supone que debe de comportarse, no realmente como quiere expresarse. Sin embargo, a la hora de explicar el dibujo ha dicho que es la luna llena, que no le ha dado tiempo a terminarlo, que tiene que seguir al próximo día.

(Diario de investigación, Sesión 1 de F) 


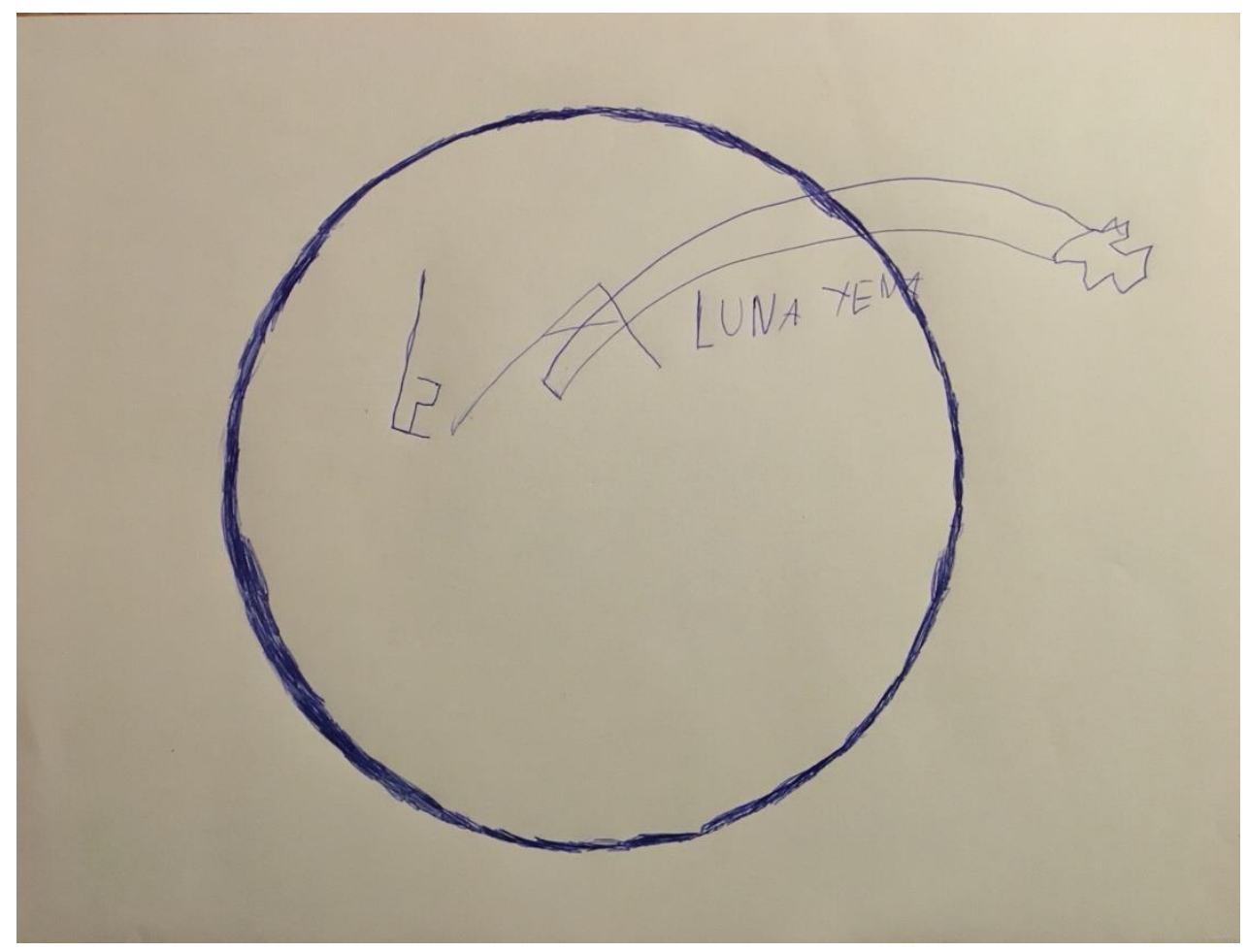

Figura 26. Mandala de F, Sesión 1. 06/03/2017.

A la hora de contrastar esta experiencia con el punto de vista de su madre después de la intervención, ella coincide con la opinión de que es muy probable que se sintiese de esta manera a la hora de llevar a cabo la tarea de dibujar:

Pobrecillo, es que en la vida diaria es lo que hace..., él no sabe lo que tiene que hacer. Yo creo que él se pone en la situación de ver lo que se espera de él y hace lo que hace porque él piensa que debe ser eso lo que está bien. Y piensa que lo de la otra manera, lo que él piensa, seguro que está mal.

(Entrevista a madre de F, después de la intervención)

Partiendo de esto, cuando empezamos a hablar sobre lo que se ha ido haciendo durante las sesiones, así como del proceso que ha seguido " $F$ " a lo largo de la intervención musicoterapéutica, su madre reflexiona sobre lo que podía aportar a su hijo el hecho de tener libertad para expresarse durante este proceso:

[M]e parece maravilloso, solo por ese hecho, merece la pena todo esto. A lo mejor, nosotros es que somos muy perfeccionistas, queremos que haga las cosas de una manera o de otra y, a lo mejor, le cortamos mucho también de expresarse, de ser como es él, porque a veces, cuando se expresa, sale por peteneras, muchas veces...

(Entrevista a madre de F, después de la intervención) 
Después de esta primera experiencia, si acompañamos el proceso de evolución de "F", podemos observar cómo en la siguiente sesión su actitud y la forma de llevar a cabo los dibujos cambiaron significativamente con respecto a la primera sesión. Después de venir a la sesión con una agitación y actividad considerables, nos encontramos con que, por medio de la libre expresión a través del dibujo y con el acompañamiento de la música, "F" encuentra una forma de dar salida a esta agitación física y al sentimiento de enfado que traía a la sesión (tal y como él lo expresó):

[V]iene a la sesión alborotado, emocionado, contento, nervioso, agitado. Su madre me lo dice antes de que comencemos. Sin embargo, lo primero que dice es que tiene muchas ganas de escuchar música y de pintar (recordemos que en la información previa sobre F constaba que no le gustaba pintar). (...) Se produce un cambio sustancial en esta sesión respecto a la sesión anterior a la hora de hacer los dibujos. Muestra algo de agitación física a la hora de escuchar música. (...) [S]e puede observar cómo se acompasa la velocidad y la fuerza de su brazo con el carácter de la música. Cuando termina dice que su mano está cansada, que ha dibujado una luna roja de África que le gusta y le hace sentir bien y alegre, que allí puede disfrutar. [T] $]$ niendo en cuenta la intensidad de los dibujos, pienso que la actividad le ha ayudado a dar salida a esa constante energía y necesidad de movimiento. De hecho, afirma que venía un poco enfadado y ahora se va contento, lo cual es un cambio muy importante. (...) Incluso se le ve más calmado al terminar la sesión. (...) Llega a la sesión alborotado, no se sienta y no deja de moverse por la sala, pero termina sentado en el suelo hablando con calma y tranquilidad. (...) Al salir de la sesión su madre me dice que no sabe qué ocurre en esta sala, pero que su hijo se fue encantado de la sesión y vuelve con muchas ganas de continuar haciendo cosas. Lo que más le asombra es que $\mathrm{F}$ diga que le encanta pintar.

(Diario de investigación, Sesión 2 de F)

En esta sesión "F" mostró una parte diferente de conexión y de necesidad de expresión emocional en comparación con la primera sesión. En esta ocasión él supo claramente que lo primero que quería hacer era completar el mandala de la sesión anterior ("La Luna Yena", Figura 27) para, a continuación, dibujar "La luna menguante", según lo expresó él mismo, con una clara intención de expresión e incluso un significado claro (Figura 28). 


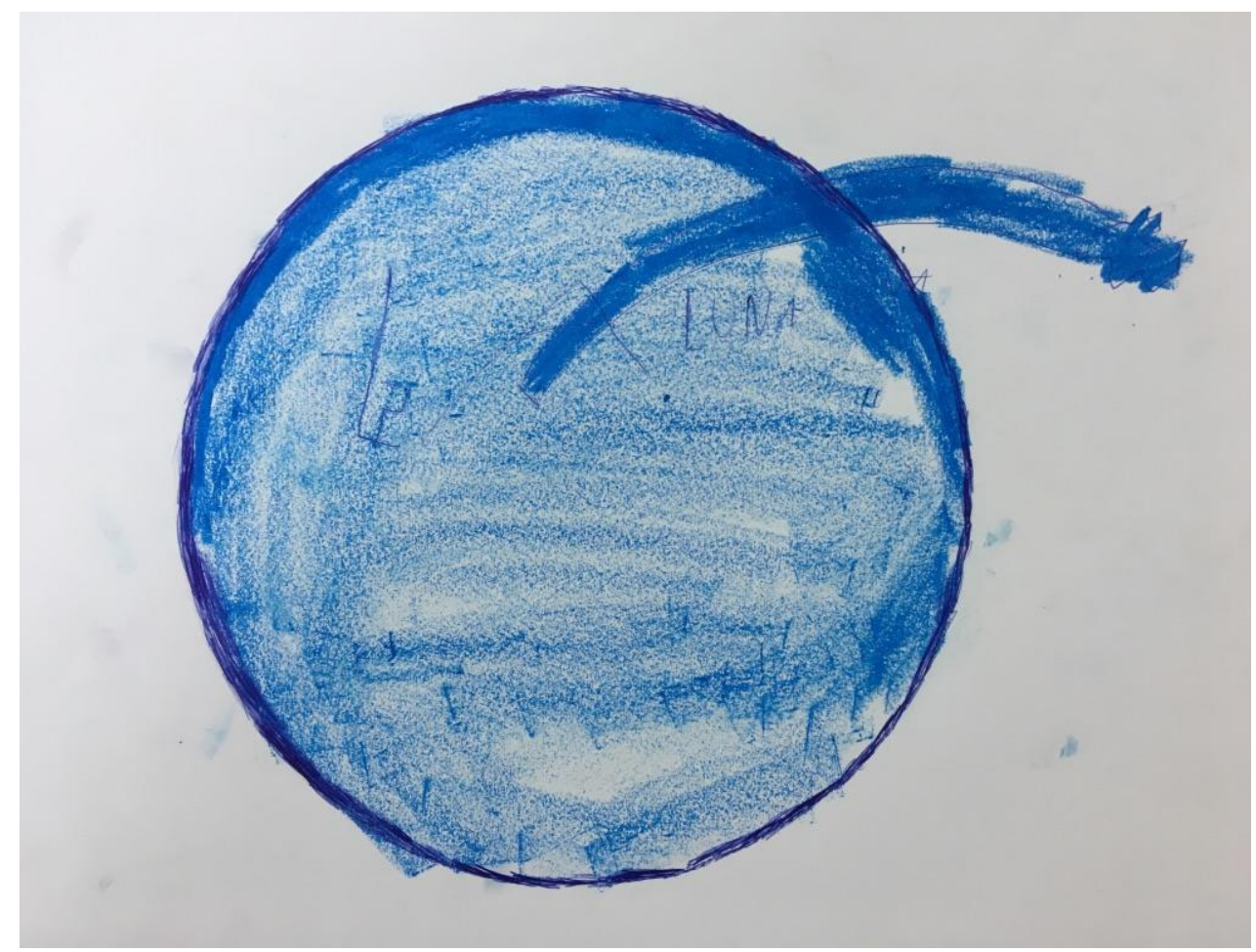

Figura 27. Mandala de F, Sesión 2. 13/03/2017.

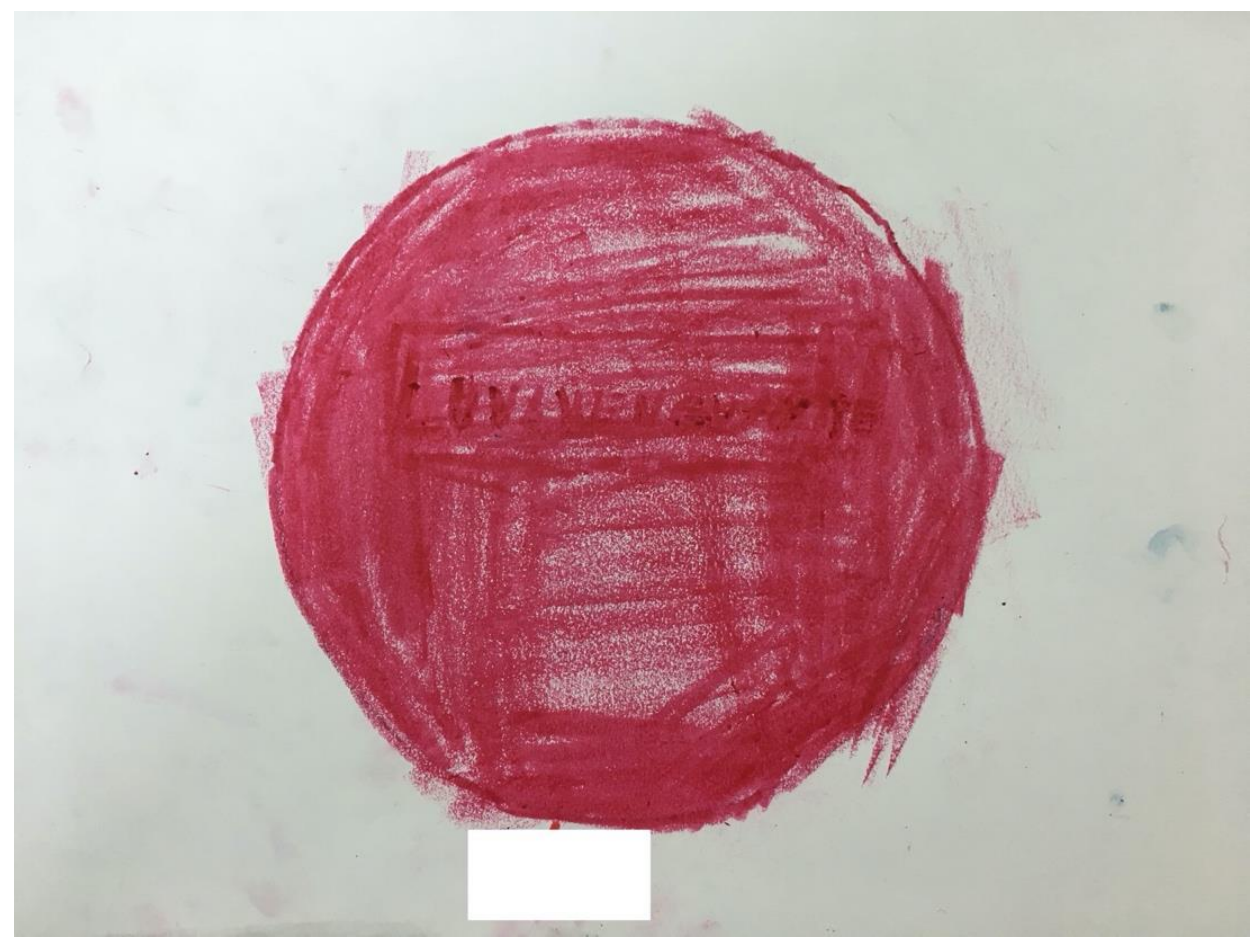

Figura 28. Mandala de F, Sesión 2. 13/03/2017. 
Lo que llama la atención de " $F$ " es que a la hora de incorporarse a la investigación fuese presentado como un caso en el que la hiperactividad y la impulsividad se representaban de forma incontrolada y exagerada. Partiendo de esta base, y a través de las siguientes sesiones, "F" comenzó a conectar con el proceso de intervención, hasta que en su cuarta sesión se hizo visible esta muestra de conductas hiperactivas e impulsivas. Llegó a la sesión con mucha actividad y hablando con energía sobre lo que quería explorar ese día. El resultado se puede apreciar en el mandala (Figura 29) y en la siguiente cita textual extraída del diario de investigación. Lo más importante de esta sesión es el cambio que se produjo en su actitud al comparar cómo llegaba con cómo se marchó tras haber realizado la escucha de música y el dibujo:

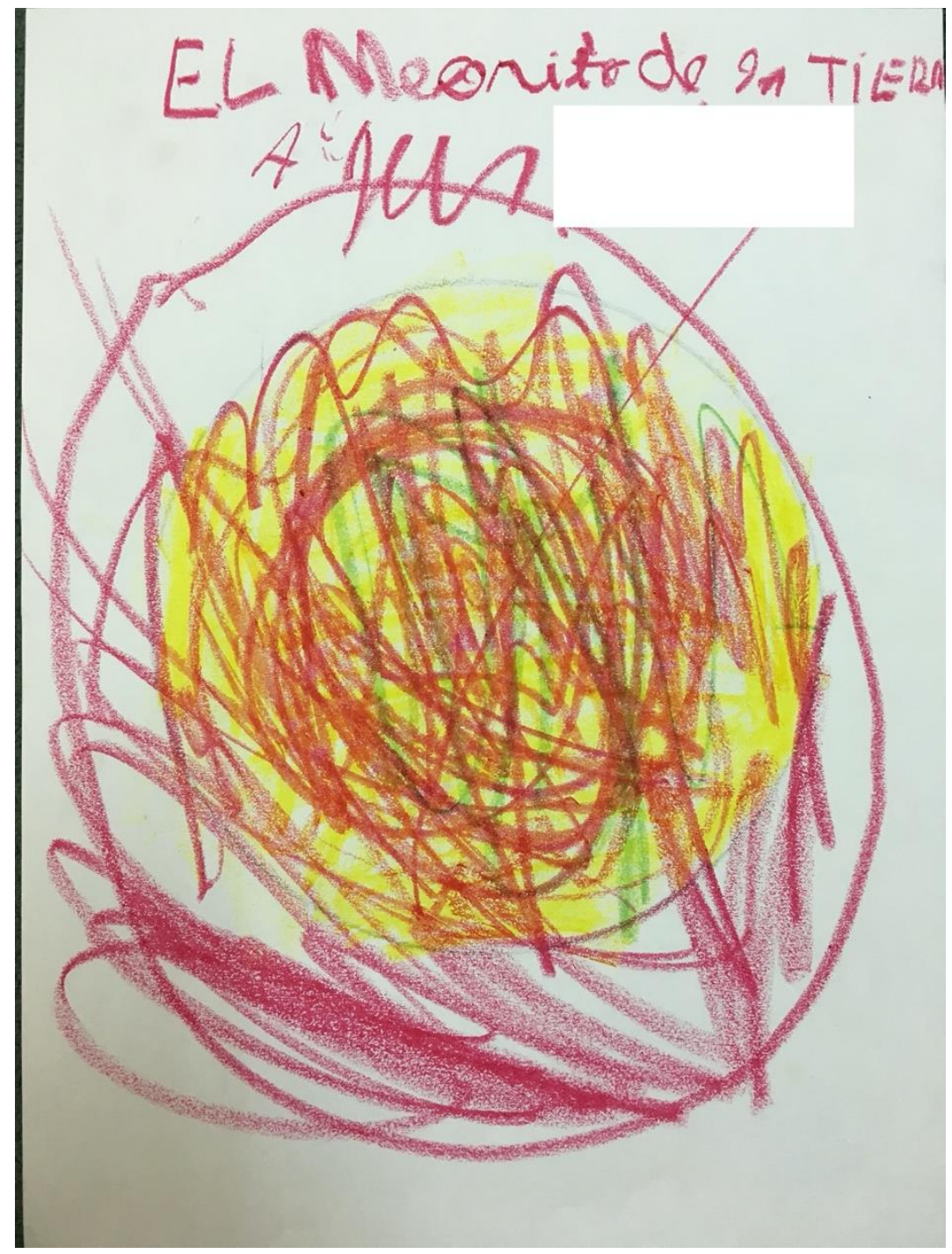

Figura 29. Mandala de F, Sesión 4. 27/03/2017. 
El resultado de la sesión de hoy es increíble, sobre todo si tenemos en cuenta que antes de comenzar con la intervención partíamos de la base de que a F no le gustaba dibujar. En este mandala, que representa un meteorito cayendo y explotando sobre la tierra, podemos apreciar perfectamente que contiene mucha energía e, incluso, cierto sentimiento de enfado, tanto en los colores escogidos como en la forma de los trazos, cargados de fuerza. De algún modo esto le ha servido para canalizar su energía. Parece que esto es lo que refleja $\mathrm{F}$ al sentir que puede expresarse libremente. (...) Después de hacer el dibujo y escuchar la segunda obra, mucho más calmada, la actitud de $\mathrm{F}$ se muestra muy distinta en comparación con el comienzo de la sesión. Termina mucho más calmado, tranquilo, incluso habla algo menos fuerte que al comienzo.

(Diario de investigación, Sesión 4 de F)

Durante la entrevista a su madre después de la intervención, a la hora de visualizar y comentar esta experiencia junto con el mandala resultante, ella misma reflexiona sobre los hechos que pueden llevar a " $F$ " a expresarse de esta forma:

$[\mathrm{N}] \mathrm{o}$ es el hecho de tener que dibujar que se haya puesto agresivo, no, sino que él tiene una vivencia interior con mucha ansiedad, con mucho estrés y es una manera de sacar eso que él tiene dentro, pero de su propia percepción, de sus nervios..., es un niño que tiene una vida interior bastante fuerte, pero no se atreve a sacarla. (...) Tiene la autoestima muy baja y él lucha por hacer las cosas bien, pero le cuesta tanto que le agota mucho, va dando altibajos. (...) Pues es que puede ser por su falta de expresión, que no sabe cómo expresarlo y para él es eso, porque no sabe expresar todo lo que siente y lo hace así, de esa manera. Ese es su mundo.

(Entrevista a madre de F, después de la intervención)

En relación con estas palabras, su madre alude al hecho de que las sesiones de Musicoterapia, junto con el trabajo por medio de formas de expresión distintas, pudieron ayudar a "F" a expresar sentimientos profundos desde su mundo interior y desde un punto de vista diferente al rutinario, lo cual puede repercutir en una mejora respecto a la capacidad de gestión y expresión emocional: 
No, nada, él lo que dice te lo suelta a la cara. No se calla, no, él lo que siente, lo habla, donde otros niños se callarían, él no, él lo suelta, no se calla. Él no entiende la situación de embarazo que lo que él diga le puede crear a otras personas. Y, claro, contigo, como eres una persona muy serena y muy tranquila, pues le contagias eso. Él actúa conforme a lo que tiene al lado y yo eso lo veo. (...) Yo estoy convencida que esto le va a sanar, de manera inconsciente, aunque él no lo sepa, pero de alguna manera le va impregnando y le viene bien. Entonces, entre unas cosas y otras, iremos saliendo adelante así.

(Entrevista a madre de F, después de la intervención)

De entre los niños con diagnóstico de TDAH participantes en el estudio, otro ejemplo que resulta relevante para contrastar los resultados obtenidos en lo referido a las conductas hiperactivas e impulsivas es el caso de "J1", de 8 años de edad. Ya desde un primer momento se podían observar claramente este tipo de conductas al comenzar la intervención. Sin embargo, también resultó interesante apreciar su actitud positiva de cara a la sesión, así como su respuesta a la dinámica y a la música planteadas, tal y como se muestra en la siguiente cita textual, extraída del diario de investigación:

Tiene muestras claras de inquietud e hiperactividad. (...) Es muy creativo y activo, le encanta la música y se mueve al ritmo mientras piensa qué dibujar. Tiene mucha energía que, en cuanto empieza a pintar, se canaliza de alguna manera, cesa el movimiento corporal (a modo de estereotipias) y se centra en la tarea de dibujar lo que está imaginando y sintiendo. (...) Se ha divertido mucho y, por lo que parece, su energía se ha conducido hacia la actividad de pintar, ya que después de esto su movimiento corporal, que en un primer momento era constante, se ha disminuido considerablemente.

(Diario de investigación, Sesión 1 de J1)

El resultado de esta primera sesión son los músicos de la orquesta, a quienes (según él mismo afirma) se ha imaginado tocando mientras escuchaba la música. Esto denota cierta capacidad para mantener la atención en la tarea que se está realizando. En la Figura 30 se puede apreciar este dibujo, que se muestra para observar cómo es el trazo, marcado y energético en toda la composición, lo cual nos puede llevar a entender la fuerza que "J1" empleó a la hora de hacerlo. 


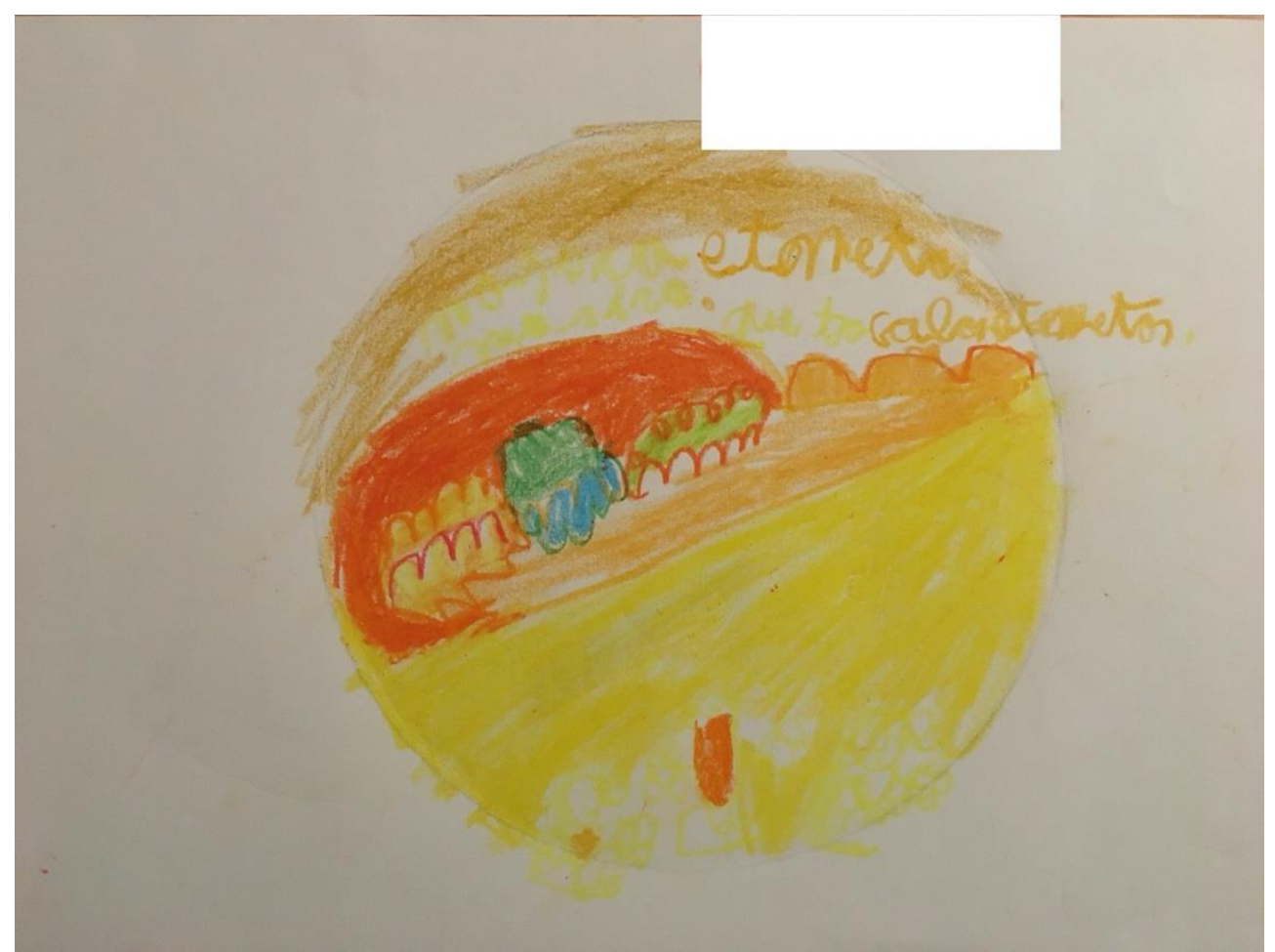

Figura 30. Mandala de J1, Sesión 1. 09/03/2017.

Si se muestra este mandala también es para que se pueda comparar este resultado con el de la cuarta sesión, en la que se pudo notar de forma significativa un cambio considerable en relación con la disminución de la actividad física, así como una evolución respecto a la temática de los dibujos (véase Figura 31), que hasta ese momento habían tratado sobre temas muy parecidos y siempre relacionados con la música:

Poco a poco vamos abriendo perspectivas y posibilidades imaginativas y de expresión en la mente de J1. Recordemos que hacía dibujos monotemáticos, todos relacionados con escenarios, músicos o artistas. Sin embargo, en esta sesión escucha la música con los ojos cerrados durante más tiempo, centrando cada vez más su atención en la actividad y en su propia imaginación. Así, sigue rompiendo los esquemas previos y da un paso más hacia la creatividad y dibuja a "El gigante Peteoooo" en su mandala. En el dibujo se puede apreciar que sigue utilizando la misma gama de amarillos y naranjas predominantemente, pero introduce otros colores, como el azul, el verde, el rojo y el negro para remarcar el contorno y que quede así claro cómo es el gigante, por lo que hay una intención expresiva clara. (...) J1 es capaz de hablar con más calma y de cerrar los ojos durante algo de tiempo para escuchar la música antes de dibujar, cosa que al principio no hacía.

(Diario de investigación, Sesión 4 de J1) 


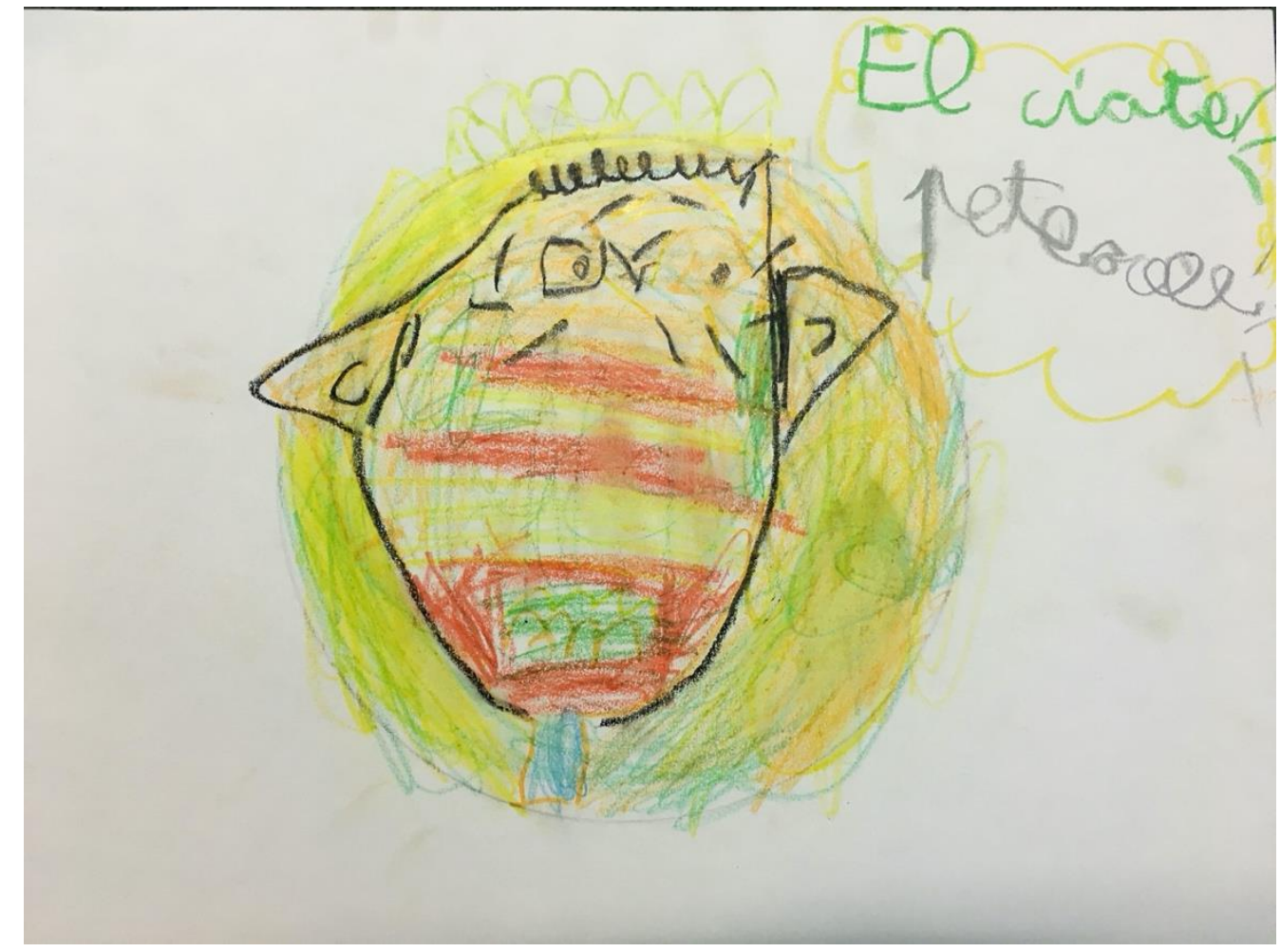

Figura 31. Mandala de J1, Sesión 1. 09/03/2017.

Teniendo en cuenta estas dos sesiones, y en relación con esta capacidad para escuchar la música de forma relajada y con los ojos cerrados, al considerar el proceso de "J1" desde un punto de vista global nos encontramos con que ha ido incrementando esta capacidad a lo largo de las sesiones:

De igual modo que en la sesión anterior, en esta ocasión escucha la música durante algunos segundos para, rápidamente, abrirlos y empezar a dibujar, lo cual denota esa falta de capacidad para estar tranquilo y relajado, y muestra el grado de actividad física con el que habitualmente se desenvuelve.

(Diario de investigación, Sesión 2 de J1)

[E]s la primera vez que escucha música con los ojos cerrados, aunque los abre de vez en cuando. Tal vez por esto ocurre que el dibujo cambia ligeramente, tanto de temática como de gama de colores. El mandala es similar al de otras sesiones, pero introduce nuevos colores, como el azul y el verde, muy distintos a los que utiliza habitualmente.

(Diario de investigación, Sesión 3 de J1) 
Lo más interesante de esta sesión es que realiza la escucha activa con los ojos cerrados, centrando y manteniendo la atención en la música durante más tiempo que en la sesión anterior. Cada vez es más capaz de pararse a escuchar con calma y centrarse en dar rienda suelta a su imaginación.

(Diario de investigación, Sesión 5 de J1)

Se pasea a gatas por el espacio, no cesa su movimiento constante. (...) En esta sesión J1 logra escuchar la música con los ojos cerrados durante tres minutos. (...) Curiosamente, y en contraposición a lo ocurrido en otras sesiones, en este momento J1 dedica tiempo y se emplea cuidadosamente en realizar el dibujo, prestando atención y cuidando los detalles, es decir, sin prisas, que es, como he podido observar, como lo hacía en otras sesiones. Incluso cuando la música ha terminado, termina perfilando los últimos detalles del mandala en silencio, sin articular palabra, concentrado en la tarea. (...) Se va contento y aparentemente más relajado que al principio de la sesión. Presenta menos actividad física y menos actividad verbal.

(Diario de investigación, Sesión 6 de J1)

Es posible contrastar esta información con el punto de vista de su madre por medio de la entrevista realizada después de la intervención. Hablando sobre la hiperactividad y la impulsividad de "J1" comparando el comienzo de la intervención con el final, su madre afirma que tanto ella como su padre notaron una disminución de ese tipo de conductas, tanto a la hora de salir de las sesiones, como tiempo después en casa:

Pues, mira, como un guante, salía de las sesiones individuales, se montaba en el coche y... él acostumbra a preguntar montón de cosas... Pues ahora no, cuando salía de las sesiones individuales se montaba en el coche y estaba súper relajado, muy tranquilo. Yo creo que eso le calmaba mucho. (...) Mucho, mucho, de hecho, llegábamos a casa y llegaba mi marido a cenar y le veía muy bien, no era solo una percepción mía, su padre también se lo ha notado, que ha salido fenomenal, súper tranquilo, yo creo que también, al estar él tranquilo consigo mismo, el poder centrarse a hacer una cosa, hace que se sienta más realizado, eso le da confianza... Vamos, muy bien. (Entrevista a madre de J1, después de la intervención) 
Por otra parte, el caso de "Y" es también representativo para esta categoría de análisis de la información. En el momento de conocerle lo primero que llamó especialmente la atención fue la cantidad de movimiento y actividad física que tenía de cara a la sesión, en la que preguntaba constantemente qué íbamos a hacer, por qué estaba ahí, mirando a todas partes de la habitación:

[E]levada actividad corporal y mental (no deja de moverse en la silla y dice cosas sin parar, sin mucha relación entre unas oraciones y otras). (...) [P]regunta constantemente qué vamos a hacer sin dejar de mirar a todas partes de la sala, con mucha inquietud y con una aparente sensación de desconfianza, como si no supiese lo que puede ocurrir y sintiese miedo a lo desconocido. También tiene una actitud de curiosidad y exploración del espacio. En ningún momento cesa esta actividad, ni durante la conversación inicial, ni durante la escucha de la música, ni durante la realización del mandala. (...) Ese estado de constante actividad física y verbal no cesa en ningún momento a lo largo de la sesión. (...) Por otra parte, su modo de firmar (llena un folio entero solo con su nombre) es una muestra clara de su alto nivel de actividad y energía. De hecho, seguro que habría hecho otro dibujo si nos hubiese dado tiempo.

(Diario de investigación, Sesión 1 de Y)

Teniendo en cuenta el proceso que "Y" ha vivido, lo que es necesario considerar en este punto es que ha ido disminuyendo su actitud de constante actividad física y aparente inquietud emocional conforme se iba avanzando en el desarrollo de las sesiones de la intervención. Recordemos en relación a esto la temática de los mandalas de sus primeras sesiones (Figuras 19 y 20) en comparación con la última sesión de la intervención (sesión 12, Figura 21), mostrados anteriormente en este capítulo. Esta misma evolución se puede percibir por medio de la experiencia relatada en el diario de investigación, especialmente en la tercera sesión, en la que su actitud comienza a cambiar considerablemente:

Me pregunto si hablar y dibujar sobre guerra le está sirviendo de algo, pero creo que es muy importante que tenga un espacio seguro donde pueda reflejar y expresar, precisamente tanto verbal como no verbalmente, esta agresividad. De hecho, lo más interesante y significativo de la sesión de hoy es que después de hacer el dibujo me ha empezado a contar su historia familiar personal (...). Me explica que su hermano $\mathrm{M}$ y él han vivido ya con cuatro familias (recordemos que son niños de acogida) y que han pasado por muchos sitios. Al preguntarle cómo se siente él con todo lo que ha pasado y con la situación que está viviendo en la actualidad es capaz de reconocer que no le gusta, que se siente triste. (...) Durante esta segunda parte 
de la sesión he podido notar, igualmente, que cuando comparte esta información personal se muestra más tranquilo (al menos más tranquilo que como vino en la primera sesión) y que es capaz de mantener la atención en la conversación, sin desviarse del tema, ni mostrar un pensamiento desorganizado, ni decir cosas que no tienen nada que ver con la conversación, como ocurre en otros momentos.

(Diario de investigación, Sesión 3 de Y)

Además, tomando en consideración esta experiencia de la tercera sesión, se puede apreciar una relación entre la regulación emocional y la disminución de las conductas hiperactivas e impulsivas, así como del pensamiento desorganizado. De alguna manera, es posible que el hecho de poder hablar con confianza de su historia personal ayudó a "Y" a estar más tranquilo en situación de terapia.

Durante esta explicación se muestra muy inquieto, con mucha energía y actividad física (como no podía ser de otra manera). (...) Así, creo que la sesión le sirve como un espacio donde puede hablar sobre esto libremente y expresar libremente sus emociones (...) sin recibir ningún juicio, castigo o bronca. Ciertamente se va de la habitación más relajado y alegre, como si se hubiese quedado más tranquilo al haber podido compartir lo que ha pasado (o haber dado rienda suelta a su imaginación).

(Diario de investigación, Sesión 4 de Y)

La actitud de $\mathrm{Y}$ va cambiando gradualmente con cada sesión que hacemos. Se le nota más tranquilo, tiene menos actividad motora y no habla con tanta frecuencia ni con tanta velocidad. (...) [C]ambio sustancial y significativo en su forma de percibir, ya que siente lo que ocurre en la música de forma distinta, con más profundidad y mucha más calma.

(Diario de investigación, Sesión 5 de Y)

La música comienza y la escucha con los ojos abiertos, pero sentado en la silla tranquilamente. Se pone el jersey en la cabeza al principio. Escucha la música sin apenas hablar, sentado, hasta que comienza a dibujar, mientras la música sigue sonando. Si comparamos este momento de la sesión con el inicio, el nivel de actividad y energía física que presenta Y se ha disminuido considerablemente. Es capaz de hacer preguntas, esperar la respuesta y esperar su turno para intervenir. Se va de la sesión tranquilo y contento.

(Diario de investigación, Sesión 6 de Y) 
Al contrastar esta información con la madre de "Y" después de la intervención, coincide con la opinión de que le ha visto más relajado a raíz de lo que hemos trabajado en las sesiones:

A Y le he visto más relajado y como no viéndose tan raro, que yo creo que se veía un poco raro, como muy señalado. (...) Sí, claro, como que siempre es el señalado, como el que arma jaleo, el que da guerra...Mira, durante parte del curso ha estado controlado por la profesora, trabajando allí, en su mesa, para que no molestara, para que no dijese nada..., y claro, ahora se ha visto que no es él solo el que arma el jaleo, que hay otros que también la lían de vez en cuando.

(Entrevista a madre de Y, después de la intervención)

Por último, es necesario señalar que, al comparar las medias entre el punto de vista del investigador con la perspectiva de las tutoras de los niños diagnosticados de TDAH participantes en la investigación, los valores no distan de forma estadísticamente significativa para un n.d.c. del 5\% ( $\mathrm{Z}=-0,37 ; \mathrm{p}>, 05)$. Esto nos indica que la opinión del investigador principal apenas dista de la opinión de las tutoras a la hora de contrastar la información después de la intervención (Tabla 33).

Al considerar el hecho de que las conductas hiperactivas e impulsivas se hayan visto disminuidas a raíz de la intervención, esta comparación, junto con la idea de que las medias apenas distan en cuanto al valor resultante, supone un buen apunte a la hora de contrastar la información obtenida de la investigación con los datos obtenidos del entorno educativo de los niños participantes más cercano.

Tabla 33

Punto de vista del investigador y de las tutoras respecto a la hiperactividad e impulsividad después de la intervención

Media Mediana D. T. $Z$ Sig.

\begin{tabular}{llllll}
\hline Punto de vista del investigador & 5,20 & 3,00 & 4,92 & & \\
& & & &,- 37 &, 71 \\
Punto de vista de las tutoras & 6,80 & 6,00 & 5,26 & & \\
\hline
\end{tabular}

Fuente: Elaboración propia. 


\subsection{Déficit de atención}

Teniendo en cuenta de nuevo la escala de evaluación de conductas EDAH, pasamos a analizar el valor cuantitativo que recoge la información relativa al déficit de atención en los casos de los niños participantes con diagnóstico de TDAH. Este valor se basa, desde un punto de vista cuantitativo, en la muestra de conductas tales como que estos niños se distraigan fácilmente o muestren escasa atención, que dé la sensación de que están en las nubes, como ensimismados, que dejen por terminar las tareas que empiezan, que sus esfuerzos se frustren fácilmente (sean inconstantes) y que tengan dificultades de aprendizaje escolar.

Desde un punto de vista cualitativo, además de tener en cuenta estos ítems se ha tratado de valorar si la capacidad de mantenimiento de la atención y la concentración se han visto desarrolladas a lo largo del proceso de intervención, no solo en la situación de terapia, sino también en otras situaciones, como en casa o el contexto educativo. En la Tabla 34 se puede apreciar una breve definición, así como el número total de citas extraídas y un ejemplo de la utilización de esta categoría en el proceso de análisis de los datos.

Tabla 34

Categoría cualitativa para el análisis textual de inatención

\begin{tabular}{|c|c|c|c|c|}
\hline Nombre & Citas & Definición & Cuándo se usa (ejemplo) & Cuándo no se usa (ejemplo) \\
\hline EDAH2_A & 52 & $\begin{array}{l}\text { Citas textuales en las } \\
\text { que se alude a la } \\
\text { muestra de conductas } \\
\text { relacionadas con la di- } \\
\text { ficultad para centrar } \\
\text { y/o mantener la aten- } \\
\text { ción, así como al pro- } \\
\text { ceso de evolución de } \\
\text { los niños en este sen- } \\
\text { tido. }\end{array}$ & $\begin{array}{l}\text { "Sí, su día a día es así, con } \\
\text { su pensamiento, son ciclos } \\
\text { muy cortos en los que él } \\
\text { trabaja su concentración. } \\
\text { Y aunque a nosotros nos } \\
\text { parezcan cortísimos, para } \\
\text { él son lo suficientes." }\end{array}$ & $\begin{array}{l}\text { "O sea, lo que él dice es que } \\
\text { si yo quiero estar con él, es- } \\
\text { toy, pero si no, no hace falta. } \\
\text { Él quiere que esté con él, por- } \\
\text { que sí que lo desea, pero no } \\
\text { quiere ser un estorbo. Y como } \\
\text { ha vivido muchas cosas, yo } \\
\text { creo que tiene esos proble- } \\
\text { mas." }\end{array}$ \\
\hline
\end{tabular}

Fuente: Elaboración propia.

Con el objetivo de contrastar si se han producido cambios significativos en lo que se refiere al valor total del grado de déficit de atención, al realizar la prueba de Wilcoxon para comparar este valor antes y después de la intervención, nos encontramos con que se ha producido una disminución estadísticamente significativa para un n.d.c. del $5 \%(Z=-2,03 ; p<, 05)$, como se puede apreciar en la Tabla 35. Tomando en consideración este análisis de datos cuantitativos, podemos considerar que la muestra de conductas de inatención ha disminuido. 
Tabla 35

Inatención antes y después de la intervención

Media Mediana D. T. $\mathrm{Z}$ Sig.

\begin{tabular}{lllllll}
\hline Antes de la intervención & 11,20 & 11,00 & 1,30 & & \\
Después de la intervención & 2,80 & 3,00 & 1,79 & & \\
\hline
\end{tabular}

Fuente: Elaboración propia.

Por otra parte, y con el objetivo de contrastar estos datos cuantitativos con los datos textuales extraídos tanto del diario de investigación como de las entrevistas antes y después de la intervención, podemos tener en cuenta, en primer lugar, los testimonios de algunas de las madres de los niños diagnosticados de TDAH, antes y después de la intervención, así como la experiencia durante el desarrollo de las sesiones de Musicoterapia:

Pero, por ejemplo, cuando nos ponemos a hacer deberes o a estudiar, es que se le ve que le viene el agotamiento, es una cosa con la que él no puede. (...) Y bueno, a nivel de comportamiento, se suele portar bien, sí, se porta bien. El niño, mucha gente nos dice: un niño más... Si tú le llevas donde quieres y como quieres, el niño tiene un comportamiento muy bueno y tal, pero claro, el problema llega a la hora de la concentración, del estudio, en ponerse a la tarea... (...) Hombre, cuando ya se pone a hacer los deberes, ya ahí te cambia el cuento, porque le cuesta concentrarse. (...) Bueno, sí que nos han dicho que se despista mucho en clase, que le ven que se va, que no se concentra, que le haría falta concentrarse un poco más.

(Entrevista a madre y padre de N, antes de la intervención)

$\mathrm{Al}$ igual que en otras sesiones, $\mathrm{N}$ emplea tiempo, paciencia y dedicación en hacer un buen dibujo, prestando toda la atención en todo momento (mantiene esta atención en hacer el dibujo durante quince minutos, sin distraerse en ningún momento).

(Diario de investigación, Sesión 6 de N)

No, desde luego, la segunda evaluación ha sido buenísima, ha estado súper centrado y ha obtenido mejores resultados. En relación a lo que ha trabajado y las notas que ha sacado, pues mejor. Y los profesores le han reconocido lo que ha hecho... (...) vamos, que en general le hemos notado, yo por lo menos, más centrado y más..., una evolución con respecto a los años de atrás.

(Entrevista a madre y padre de $\mathrm{N}$, después de la intervención) 
Entonces, la información que recibimos es la de que tenía TDAH y, pues, no va bien en el colegio, ha repetido y la información de la otra madre de acogida, pues que no se puede estar quieto, que se mete con todo el mundo, etc.

(Entrevista a padre de Y y M, antes de la intervención)

Sí, sí, ha coincidido que los jueves solían ir a clase para hacer las tareas con una profesora y, claro, él no podía y por eso en casa teníamos que hacerlas. Y él insistía en hacerlas para luego, al terminarlas, poder salir. Y como más centrado... (...) Después, después [de la sesión de Musicoterapia]. (...) Sí, pero luego salía y sí que se centraba, o sea, que yo veía que lo que hacía aquí dentro le venía bien, le había que dejar su espacio para que se relaje o para que se desfogue y luego ya... (...) A ver, en conjunto, yo creo que se le ha notado... bueno ya veremos las notas, aunque eso a mí no me preocupa demasiado, pero sí que se le ha notado, me ha parecido interesante lo que hicieras.

(Entrevista a madre de Y y M, después de la intervención)

Uno de los ejemplos que sirve para representar esta disminución del grado de inatención es el de J2. A la hora de trabajar con él a través de la Musicoterapia, se pudo observar cómo su capacidad de mantenimiento de la atención y concentración iban aumentando conforme se iban desarrollando las sesiones. Con la ayuda de las siguientes citas textuales, extraídas del diario de investigación, se puede apreciar el proceso de evolución de J2. En la tercera sesión, se puede observar un momento significativo de cambio en cuanto a su capacidad de atención en relación con la forma de expresarse:

$\mathrm{J} 2$ tiene muy poca energía aparentemente, escaso movimiento corporal, ninguna muestra de hiperactividad ni impulsividad, ni muestras de conducta inadecuadas, pero sí le cuesta formar oraciones de manera fluida y natural. En este sentido, se dan muestras claras de un déficit de atención bastante acentuado.

(Diario de investigación, Sesión 1 de J2)

Dibuja una nave de guerra futurista llena de invenciones y utilidades nunca vistas. Una vez más puedo observar cómo mejora su capacidad de expresión oral después de la escucha a la hora de hablar de su gran obra, centrando y manteniendo la atención en su discurso. Se muestra orgulloso, motivado y entusiasmado.

(Diario de investigación, Sesión 4 de J2) 
Lo más interesante del caso de J2 es cómo se expresa después de la escucha activa, a la hora de explicar lo que ha dibujado, en comparación con cómo se comunica en la conversación inicial. Cuando habla de lo que ha dibujado (que es una ciudad futurista provista de recursos, soluciones y medidas mucho más avanzadas que las actuales) cambia su actitud y su expresión facial (llena de alegría), se muestra entusiasmado, se expresa con fluidez, de forma mucho más clara y con estructuras sintácticas bien construidas. De hecho, a la hora de hablar de emociones también matiza de forma significativa. Por ejemplo, dice que está feliz, o muy contento, cuando al inicio de la sesión afirma que está simplemente bien.

(Diario de investigación, Sesión 3 de J2)

Si observamos el mandala que resulta de esta sesión (Figura 32) podemos apreciar el grado de meticulosidad, cuidado y atención que $\mathrm{J} 2$ pone a la hora de dibujar. Esta información se puede contrastar, además, con la opinión de su madre después de la intervención:

Bueno, sus resultados académicos han ido bastante bien, sí que es verdad que estas últimas semanas que ya no había sesiones ha ido peor, pero yo creo que por cansancio, por calor, se le han juntado todos los exámenes, exámenes prácticamente todas las semanas y él como que se ha relajado un poco, pero su tutora está muy contenta con él, porque ha tenido una evolución a lo largo del curso estupenda. Ahora, pues se ha relajado, la última semana se ha relajado un poco de clase. Pero yo creo que sí le ha ayudado a concentrarse, yo creo que se refugia en el dibujo porque es su mundo interior. Cuando se aísla y no quiere oír a su hermano, ni los problemas de su hermano ni a su madre, pues él se pone con sus dibujos, en su mundo, les trabaja y les construye... no es como el resto de los niños, que hacen un dibujo y ya está hecho el dibujo. Él no, él los trabaja, como si fuera una obra importante para él, va trabajando al detalle... [Referido a J2]

(Entrevista a madre de $\mathrm{J} 1$ y J2, después de la intervención) 


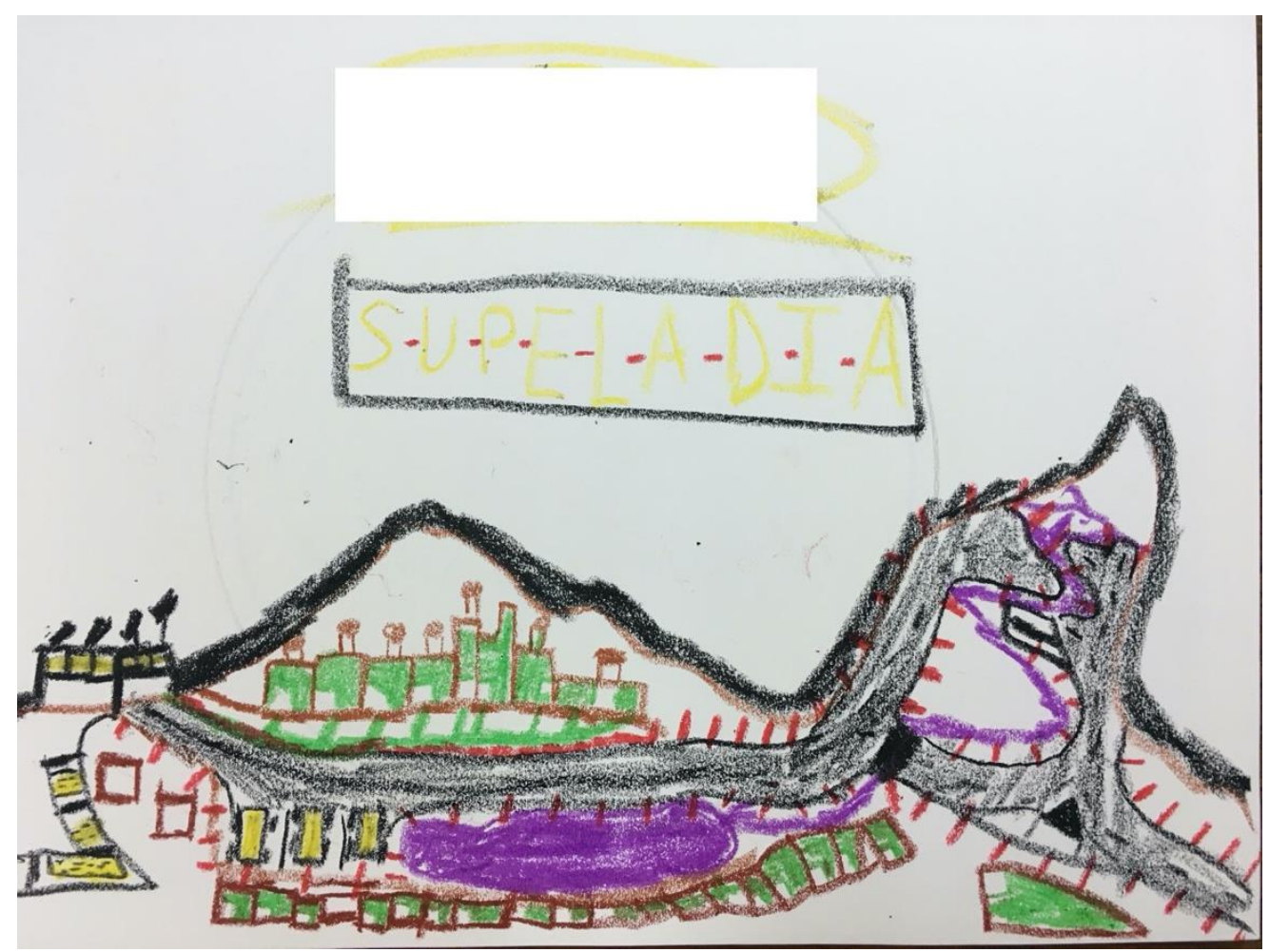

Figura 32. Mandala de J2, Sesión 3. 21/03/2017.

Por otra parte, a lo largo del proceso de intervención se puede observar, en distintas sesiones, cómo esta capacidad de mantenimiento de la atención se ve desarrollada a través de las actividades realizadas:

Igualmente, en el momento de hacer el dibujo concentra toda su atención y mantiene la concentración para obtener el mejor resultado posible. De hecho, su madre me dice que está alucinando con los dibujos que está haciendo últimamente, que nunca había sido tan creativo y le está encantando que esto esté surgiendo en él.

(Diario de investigación, Sesión 5 de J1)

Por lo que se puede observar, esta sesión le ha servido, una vez más, para dar rienda suelta a su imaginación y canalizar a través del dibujo su gran cantidad de actividad física. Además, el hecho de que en esta ocasión haya utilizado un solo color y que haya completado el dibujo en poco tiempo nos indica que ha sido capaz de centrar la atención rápidamente para concretar y completar la tarea. Recordemos que en la primera sesión tardó mucho tiempo en hacer "simplemente" un contorno con boli, así que esto nos indica que se está mostrando más resolutivo, tanto a la hora de decidir lo que quiere dibujar como en la forma de hacerlo.

(Diario de investigación, Sesión 5 de F) 
Por último, antes de cerrar esta categoría de investigación, es necesario considerar si la perspectiva del investigador principal se corresponde con el punto de vista de las tutoras de los niños participantes con diagnóstico de TDAH después de la realización de la intervención musicoterapéutica.

A la hora de realizar la prueba de Wilcoxon, nos encontramos con que los valores totales de este punto de vista distan de forma estadísticamente significativa para un n.d.c. del 5\% ( $\mathrm{Z}=-2,02 ; \mathrm{p}<, 05)$, tal y como se puede observar en la Tabla 36. Esto quiere decir que el punto de vista del investigador principal y de las tutoras de los niños con diagnóstico de TDAH es diferente de forma estadísticamente significativa.

Tabla 36

Punto de vista del investigador y de las tutoras respecto a la inatención después de la intervención

\begin{tabular}{cccccc} 
& Media & Mediana & D. T. & Z & Sig. \\
\hline Punto de vista del investigador & 2,80 & 3,00 & 1,79 & & \\
Punto de vista de las tutoras & 9,20 & 10,00 & 3,96 & & \\
\hline
\end{tabular}

Fuente: Elaboración propia.

Esto, que solo ha ocurrido en esta categoría de investigación, puede deberse a que los cambios que se pueden observar en las sesiones de Musicoterapia no se hayan visto extrapolados a la situación académica y el día a día de los niños con diagnóstico de TDAH.

También puede suponer que en las sesiones de Musicoterapia se llevaban a cabo actividades que resultaban en sí mismas motivadoras para los niños y que, por lo tanto, no requerían de una capacidad de atención tal que pudiera compararse con la que se necesita para realizar tareas escolares.

Sin embargo, durante las sesiones sí se pudo apreciar una evolución de la capacidad de atención y mantenimiento de la concentración (como se puede observar en la Tabla 35), y los testimonios de las familias en las entrevistas después de la intervención corroboran esta evolución. Por lo tanto, lo más probable es que este cambio se hiciese palpable en las sesiones y en el día a día de los niños, y no tanto en el entorno escolar. 


\subsection{Trastorno de conducta}

Tomando una vez más como referencia la escala de evaluación de conductas EDAH, en este último apartado pasamos a analizar el valor cuantitativo que se refiere a la muestra de comportamientos relacionados con el trastorno de conducta. Recordemos que los factores que hacen alusión a este valor de la escala guardan relación con momentos en los que los niños diagnosticados de TDAH gritan a menudo en situaciones inadecuadas, contestan con facilidad (siendo irrespetuoso y arrogante), tienen explosiones impredecibles de mal genio, discuten y pelean por cualquier cosa, son mal aceptados por el grupo, les falta el sentido de la regla (del "juego limpio"), niegan sus errores o echan la culpa a otros, se llevan mal con la mayoría de sus compañeros, tienen dificultad para las actividades cooperativas y aceptan mal las indicaciones del profesor.

Desde un punto de vista cualitativo, se han tenido en cuenta estos factores a la hora de observar las conductas de los niños con diagnóstico de TDAH, y además se ha tratado de valorar si la intervención de Musicoterapia llevada a cabo ha disminuido la muestra de comportamientos que puedan considerarse relacionados con trastornos de conducta. De esta forma, mediante las conversaciones durante y después de la intervención con las familias y con las tutoras, se ha tratado de considerado si los pasos conseguidos en las sesiones se han visto extrapolados de alguna forma a otras situaciones, como la vida cotidiana en casa y el contexto escolar. Esta categoría de investigación queda designada como EDAH3_TC, y en la Tabla 37 puede observarse su definición, así como el número de citas extraídas y su modo de empleo a la hora de analizar la información textual cualitativa.

Tabla 37

Categoría cualitativa para el análisis textual de trastorno de conducta

\begin{tabular}{|c|c|c|c|c|}
\hline Nombre & Citas & Definición & Cuándo se usa (ejemplo) & $\begin{array}{l}\text { Cuándo no se usa } \\
\text { (ejemplo) }\end{array}$ \\
\hline EDAH3_TC & 60 & $\begin{array}{l}\text { Citas textuales en las } \\
\text { que se alude a la } \\
\text { muestra de compor- } \\
\text { tamientos relaciona- } \\
\text { dos con trastorno de } \\
\text { conducta, así como } \\
\text { al proceso de evolu- } \\
\text { ción de los niños con } \\
\text { diagnóstico de } \\
\text { TDAH en este sen- } \\
\text { tido. }\end{array}$ & $\begin{array}{l}\text { "Y entonces...una vez que estuvi- } \\
\text { mos fuera quince días mi mujer y } \\
\text { yo, en Venezuela, que se casaba } \\
\text { mi hijo biológico, estuvieron los } \\
\text { chicos con mi hermana y, tam- } \\
\text { bién, le dejaban ir solo al parque, } \\
\text { hasta que un día le estaban espe- } \\
\text { rando todos los padres para decir- } \\
\text { les que les estaba insultando, di- } \\
\text { ciendo tacos... y entonces, ya no } \\
\text { le dejaron ir solo y ya iban con él } \\
\text { siempre." }\end{array}$ & $\begin{array}{l}\text { "No, jamás, me lo ha } \\
\text { dicho como hará } \\
\text { quince días... sé que } \\
\text { ese es un tema que le } \\
\text { habrá rondado por la } \\
\text { cabeza mucho tiempo. } \\
\text { Si te lo ha dicho a ti es } \\
\text { porque ha cogido un } \\
\text { grado de confianza } \\
\text { grande, porque si no, } \\
\text { no te lo dice."'šlp. }\end{array}$ \\
\hline
\end{tabular}

Fuente: Elaboración propia. 
Dicho lo cual, con el objetivo de valorar si se ha producido una disminución de la muestra del trastorno de conducta, a la hora de realizar la prueba de Wilcoxon para los valores totales de este factor antes y después de la intervención, nos encontramos con una diferencia estadísticamente significativa entre estos dos valores para un n.d.c. del $5 \%(Z=-2,03 ; p<, 05)$, como se puede observar en la Tabla 38. Si tenemos en cuenta el valor total de este factor antes y después de la intervención, podemos considerar que se ha producido esta disminución de la muestra de comportamientos relacionados con trastorno de conducta.

Tabla 38

Trastorno de conducta antes y después de la intervención

Media Mediana D. T. $Z$ S Sig.

\begin{tabular}{rcccccc}
\hline Antes de la intervención & 16,40 & 13,00 & 6,11 & & \\
Después de la intervención & 5,40 & 2,00 & 6,43 & & \\
\hline
\end{tabular}

Fuente: Elaboración propia.

Uno de los ejemplos más claros al respecto es el de "N", ya que, tal y como afirmaban sus padres, tenían problemas en casa en lo que se refería a la relación con su hermana, especialmente teniendo en cuenta la casuística al estar diagnosticado de TDAH. A raíz de la intervención de Musicoterapia, sus padres fueron testigos de cómo la actitud de "N", relacionada con el trastorno de conducta cambió de forma significativa, especialmente los días en los que acudía a las sesiones. Las siguientes citas textuales, extraídas tanto del diario de investigación como de las entrevistas realizadas a sus padres antes y después de la intervención, muestran la situación inicial, la situación durante el proceso y el resultado final:

O sea, él se levanta como un torbellino, dando voces, no hace caso a nada, bueno, no es que no haga caso, es que no puede evitarlo, que no puede controlarlo, con la risa esa tonta, retador, luchador, bueno, es que es terrible, quinchando a su hermana... Y cuando le damos la medicación, al cabo de un rato, se ve que le va haciendo efecto, se va directamente a hacer su cama, se prepara la mochila, si se da cuenta que se ha pasado antes, te pide perdón, porque él se da cuenta. Él nos dice: "lo siento mamá, es que no lo controlo". (...) Bueno, y también está medicado y cuando se le pasa el efecto de la medicación, pues también se le nota, que se pone más pesado, se pone más machacón con su hermana.

(Entrevista a madre y padre de N, antes de la intervención) 
Su padre comparte conmigo que tanto él como su mujer se están percatando de que $\mathrm{N}$ está más tranquilo, más cordial, más educado, más amable e incluso más cariñoso (con su hermana, por ejemplo, a quien le ofrece contarle el cuento de buenas noches) después de las sesiones de musicoterapia. Que los padres hagan este tipo de observaciones y se percaten de que el hecho de acudir a musicoterapia está resultando ser beneficioso para $\mathrm{N}$ es algo destacable y denota que se están produciendo cambios positivos en el hogar después de solo tres sesiones de intervención.

(Diario de investigación, Sesión 3 de N)

Estaba como más relajado, más receptivo, como que te contaba las cosas de otra manera... (...) Y como más tranquilo, porque normalmente si le preguntas cómo está o qué tal, te dice: "bien" ... y ya está, pero esos días, estaba más dispuesto a escuchar, a hablar más tranquilamente... Se le notaba otra cosa. Incluso los días que tenía que estudiar, se le notaba más relajadito. (...) Sí, se le notaba con otra actitud mucho menos conflictiva, menos de entrar al enfrentamiento. (...) El mayor problema que tenemos con él es, pues eso, que es muy retador, que no se conforma con cualquier cosa, tú le dices algo y no te dice que sí a la primera, siempre te tiene que rebatir... Es como que está siempre dispuesto al conflicto; por eso, es lo que te hemos dicho, que cuando salía de aquí [de las sesiones de Musicoterapia], iba como menos dado a ese conflicto y era más capaz de escucharte relajado, de razonar un poco más las cosas, según tú se las estás diciendo. (...) Y luego, pues lo que te hemos dicho, notábamos que algo funcionaba o que algo cambiaba después de las sesiones, pero luego el resto de los días, había muy pocos cambios con respecto a antes, como que se había pasado al día siguiente el efecto Musicoterapia. (...) Así que eso, a esperar al día siguiente. Cada día que veníamos aquí, lo que te hemos comentado, que él estaba bien, notábamos buenas vibraciones y al niño le gustaba venir.

(Entrevista a madre y padre de N, después de la intervención)

De hecho, algo que llama la atención del caso de "N" en las sesiones grupales es que es el que menos problema tiene para tumbarse y relajarse, mientras que son sus compañeros de grupo quienes no dejan de hablar en el momento previos a la escucha musical. Sus padres, en la entrevista realizada después de la intervención, explican también que les sorprendió gratamente que su hijo saliese relajado y contento de las sesiones grupales, durante las cuales le veían igualmente muy sociable: 
En el momento de escuchar la música, cuando se apaga la luz, resulta sorprendente que $\mathrm{N}$ cierra los ojos y se relaja sin ningún problema para escuchar la música, mientras que $\mathrm{A}$ y $\mathrm{M}$ no cierran los ojos y les cuesta dejar de hablar, relajarse y simplemente escuchar la música. De hecho, no dejan de hablar y están molestando a $\mathrm{N}$. Cuando empieza la música sí que guardan silencio y se paran a escuchar. $\mathrm{N}$ permanece durante toda la escucha musical, que dura 17 minutos, con los ojos cerrados, tumbado y relajado.

(Diario de investigación, Sesión 7 de N)

Yo creo que bien, él salía contento también. De hecho yo le pregunté qué tal en las sesiones de grupo y me dijo que muy bien también... Porque me podía haber dicho que le gustaba más cuando iba él solo, pero no, él salía contento también. Como había asimilado que unas eran individuales y otras en grupo, pues muy bien.

(Entrevista a madre y padre de N, después de la intervención)

Por otra parte, en el caso de "J1", uno de los ejemplos más claros en relación con la presencia de conductas hiperactivas e impulsivas, su madre explica, en la entrevista después de la intervención, que le nota más reflexivo cuando se da cuenta de que ha hecho algo mal, y afirmando que es capaz de recapacitar y pedir perdón:

Mira, lo que sí he notado yo estos meses es que... mira, él es muy impulsivo, ¿vale? Entonces, cuando él hace una cosa que está mal, cuando la está haciendo no se da cuenta de que lo que está haciendo está mal, por su impulsividad, pero sí que luego reconoce y le duele y sufre al darse cuenta de que ha hecho algo que estaba mal. Incluso, se pone a llorar, sin yo regañarle, se pone a llorar, porque él reconoce que lo ha hecho mal y eso antes no lo hacía. Entonces, él sí que ha profundizado un poco en ese aspecto, no sé eso cómo podemos ponerlo, eso antes no lo hacía y ahora sí que lo hace. B.: Pues eso antes, no lo tenía y ahora sí. No sé cómo llamarlo ni definirlo... B.: Sí, sí que se da cuenta y reflexiona, que antes no reflexionaba... ahora reflexiona y se da cuenta, promete que no lo va a volver a hacer, aunque luego vuelva a hacerlo, pero reflexionar, sí, reflexiona.

(Entrevista a madre de $\mathrm{J} 1$ y J2, después de la intervención) 
Igualmente, en el caso de "Y", que es uno de los ejemplos más claros de muestra de conductas conflictivas determinadas situaciones, especialmente en la relación con sus compañeros de clase y amigos del parque, se puede apreciar una evolución:

Por otra parte, como es muy activo, muy activo, le gusta mucho siempre el juego de peleas y eso tiene un problema, que los juegos de peleas siempre terminan mal, porque cuando uno da un poquito más fuerte, al final se enfadan. Juega mucho con su hermano al juego de peleas y siempre termina llorando él, pues porque su hermano es más mayor. Pero por mucho que le digas que no juegue a las peleas, pues es a lo que él quiere jugar. (...) Al parque, de vez en cuando le dejamos que vaya solo al parque, aunque estemos nosotros cerca, le dejemos que esté solo en el parque, jugando con los chicos o lo que sea. A veces, le hemos castigado sin ir al parque solo, porque, pues...yo tengo perro y estoy en la parte de abajo del parque y de repente oyes a alguien que está diciendo palabrotas, tan grandes que no me caben en la boca... y es que en cuanto le oí, ya sé quién es... y bajo para abajo y les estaba llamando de todo, a los padres y a los niños...

(Entrevista a padre de Y y M, antes de la intervención)

Sorprendentemente, a Y se le nota bastante relajado en comparación con otras sesiones. En esta ocasión es capaz de estar tranquilo, sentado y hablando con sus compañeros sobre distintas cosas de su vida cotidiana. A la hora de escuchar la música, está realmente atento (aunque en ningún momento cierra los ojos para escucharla) y se mueve por el espacio, compartiendo la experiencia con sus compañeros.

(Diario de investigación, Sesión 12 de Y)

Sí, como más cordial... Hombre, desde luego, se nota otra actitud. Bueno, ya veremos el verano que no vas a estar, si se revoluciona le tendré que poner música... (...) Sale a jugar en el parque, con sus amigos y tiene mejor relación con ellos, no les impone, no les insulta, intenta colaborar con todos..., yo le veo que están más contentos... y los padres se dan cuenta del cambio...

(Entrevista a madre de Y y M, después de la intervención)

Por último, para cerrar esta categoría de investigación y, con ello, este capítulo de análisis de datos, solo queda valorar si el punto de vista del investigador principal dista o es similar al de las tutoras de los niños participantes con diagnóstico de TDAH después de la intervención. 
Para ello, una vez más se ha llevado a cabo la prueba de Wilcoxon para comparar los valores después de la intervención, dando como resultado que no se diferencian de forma estadísticamente significativa para un n.d.c. del 5\% ( $\mathrm{Z}=$ 0,94; $p>, 05$ ), como se puede apreciar en la Tabla 39. Esto quiere decir que el punto de vista del investigador principal y de las tutoras coinciden de forma estadísticamente significativa.

Tabla 39

Punto de vista del investigador y de las tutoras respecto a trastorno de conducta después de la intervención

Media Mediana D. T. $Z$ S Sig.

\begin{tabular}{lllllll}
\hline Punto de vista del investigador & 5,40 & 2,00 & 6,43 & & \\
Punto de vista de las tutoras & 9,40 & 5,00 & 11,93 & & \\
\hline
\end{tabular}

Fuente: Elaboración propia. 

CAPÍTULO VII. DISCUSIÓN DE LOS RESULTADOS DE INVESTIGACIÓN 

A la hora de considerar este capítulo de discusión de los resultados, se han tenido en cuenta no solo las categorías de investigación tratadas y contrastadas en el proceso de análisis de los datos mostrado en el capítulo anterior, sino también el hecho de que la propia viabilidad de la intervención basada en técnicas de música e imagen para TDAH debe ser contrastada, ya que se trata de una forma de intervención que (basándonos en las evidencias científicas previas) no ha sido explorada previamente.

\section{REPERCUSIÓN DE LA INTERVENCIÓN MUSICOTERAPÉUTICA A NIVEL EMOCIONAL}

En primer lugar, cabe destacar que la intervención llevada a cabo ha resultado ser beneficiosa para atender y resolver necesidades físicas y psicológicas de los niños participantes, especialmente las relacionadas con las emociones, la afectividad y los vínculos relacionales (Blasco y Sanjosé, 2000). Esto demuestra, una vez más, que la Musicoterapia ayuda a gestionar determinados asuntos psicológicos, lo cual es algo que ha sido comprobado y contrastado a lo largo de toda la historia de la humanidad (Betés, 2000).

En nuestro trabajo, hemos podido comprobar que una intervención basada en técnicas específicas de música e imagen ha repercutido de forma positiva en la capacidad de gestión emocional de un grupo de niños de entre 7 y 11 años de edad. La música ha servido como objeto proyectivo emocional (Bonny, 1986; Bush, 1995), es decir, como reflejo de las necesidades emocionales que los niños presentaban cada día de sesión.

En relación con la competencia de conciencia emocional (EODE1_CE), las sesiones de Musicoterapia han ayudado a los niños a ser más capaces de reconocer e identificar tanto sus propias emociones como las de sus compañeros. Esto demuestra que las dinámicas relacionadas con ejercicios de imaginación y escucha activa de música repercuten de forma positiva en el desarrollo de un mayor nivel de autoconciencia y de la capacidad para atender a las necesidades no solo personales, sino también de grupo (Powell, 2007).

Por otra parte, en lo que se refiere a la capacidad de regulación emocional (EODE2_RE), en todos los casos la música ha servido, en alguna o en varias sesiones, para alcanzar momentos de relajación y de calma (Clark, 2002; Grocke y Wigram, 2011; Powell, 2007), así como para aumentar la capacidad para verbalizar los problemas y necesidades emocionales y encontrar solución o respuesta ante ellos (Colegrove et al., 2019; Kang, 2017; Wigram et al., 
2011). En otras palabras, en todos los casos, en algún momento de la intervención se ha podido observar cómo las sesiones de Musicoterapia han ayudado a los niños a canalizar emociones que estaban latentes en su mundo interior, pero que no encontraban una forma de expresión.

La competencia de autonomía emocional (EODE3_AE) se ha visto desarrollada para todos los casos del estudio, especialmente en relación con el aumento de la autoestima (Roy, 1996) y con la confianza y seguridad derivada del sentimiento de pertenencia a un grupo (Borling \& Miller, 2007), es decir, en relación con el reconocimiento de las cualidades personales respecto a uno mismo y con respecto al grupo de iguales.

Respecto a la categoría de competencia social (EODE4_CS), podemos afirmar que las sesiones han servido para mejorar las habilidades relacionadas con la capacidad de relación social entre los niños (Benenzon, 2011; Lacárcel, 2006). También se ha podido observar la importancia de la relación personal y el desarrollo del vínculo terapéutico establecido con el musicoterapeuta, ya que las habilidades sociales de los niños se desarrollaban más conforme esta se iba cimentando. En este sentido, el papel y la responsabilidad del musicoterapeuta, así como el grado de compromiso adquirido de cara a las personas con quienes trabaja, son fundamentales a la hora de guiar el proceso terapéutico (Ferrari, 2013).

Por último, en lo que se refiere al desarrollo de la competencia de vida y bienestar (EODE5_CVB) se ha observado que las sesiones han repercutido de forma significativa en el desarrollo y aumento de la creatividad en todos los casos del estudio. En este sentido, el empleo de música académica ha marcado la diferencia, ya que llama la atención de los niños y les ayuda a conectar con su imaginación y a estimular su capacidad de evocación (Roy, 1996).

De hecho, las actividades relacionadas con la imaginación y la evocación de imágenes en base a una selección musical previamente seleccionada, que son las que se han empleado en nuestro estudio, son algunas de las dinámicas de Musicoterapia que mejor funcionan para el desarrollo de la creatividad (Grocke y Wigram, 2011). Por otra parte, la expresión a través del dibujo constituye una vía natural y espontánea de desarrollo para la creatividad, especialmente en los niños, que exploran habitualmente nuevas formas de comunicación no verbal (Fosati y Segurado, 2014). 


\section{REPERCUSIÓN DE LA INTERVENCIÓN MUSICOTERAPÉUTICA RESPECTO A LAS CARACTERÍSTICAS PROPIAS DEL TDAH}

Mediante el presente estudio hemos podido comprobar que la Musicoterapia ha repercutido de forma positiva en la disminución de las conductas propias del TDAH en un grupo de niños con este diagnóstico (Acebes-de Pablo y Carabias-Galindo, 2016; Acebes-de Pablo y Giráldez-Hayes, 2019; Briseño, 2019; Jackson, 2003; Peñalba, 2010; Rickson, 2006; Wigram et al., 2011). Por otra parte, este estudio también demuestra, como explicaremos a continuación, que, a pesar de que los métodos receptivos de intervención en $\mathrm{Mu}$ sicoterapia no son muy empleados en casos de TDAH (Jackson, 2003), las técnicas de música e imagen han resultado ser un acierto para la expresión y regulación física y emocional de los niños con diagnóstico de TDAH los que se ha trabajado en el estudio.

En lo que se refiere a la muestra de conductas hiperactivas e impulsivas (primera categoría de investigación en relación con el TDAH: EDAH1_HI), la repercusión de la intervención ha mostrado una disminución en la muestra de este tipo de conductas. Se ha podido observar, en concreto, que determinados ejercicios de escucha activa, relacionados siempre con procesos de evocación e imaginación, han ayudado a los niños a desarrollar un mayor nivel de autonocimiento que les ha permitido alcanzar momentos de relajación con mayor facilidad (Grocke y Wigram, 2011; Llamas, 2014).

De hecho, se ha podido observar cómo en algunos casos, en los que la capacidad de control de las conductas hiperactivas e impulsivas está relacionada con la competencia de regulación emocional, la música les ha ayudado a desarrollar la habilidad de expresarse con mayor facilidad y alcanzar así una mayor estabilidad emocional (Rickson, 2006; Wiebe, 2007), repercutiendo así, de forma positiva, respecto a la disminución de la hiperactividad y la impulsividad.

Por otra parte, respecto a la categoría de investigación referida al déficit de atención (EDAH2_A), se ha observado que la presencia de la música como nuevo estímulo ha supuesto una motivación en sí misma para todos los niños con diagnóstico de TDAH participantes en el estudio, lo cual se traduce, en primera instancia, en que ha supuesto una ayuda de base para focalizar la atención en la tarea que se está desarrollando en cada momento (Acebes-de Pablo y Giráldez-Hayes, 2019; Alonso y Bermell, 2008; Álvarez, 2004). Además, las sesiones han producido un aumento gradual de la capacidad de man- 
tener la concentración en una determinada actividad (Dewi et al., 2015; García-Huidobro, 2015) y una mejora en la capacidad de procesamiento cognitivo para todos los casos (Benzon, 2009; Briseño, 2019; Slater \& Tate, 2018).

Respecto a la tercera categoría de investigación referida al TDAH y, en concreto, a la muestra de trastornos de conducta (EDAH3_TC), la intervención ha repercutido en una mejora de la actitud respecto a las relaciones sociales entre los niños con diagnóstico de TDAH y sus compañeros, familia o profesores. En este caso, las sesiones individuales sirven para encontrar un equilibrio entre la muestra de conductas disruptivas y la actitud social de cara a la relación con su entorno más cercano (Peñalba, 2010). Además, la mejora de la capacidad de regulación en relación con la canalización por medio del dibujo, ha repercutido en una mejora de la capacidad de relación social de los niños (Henley, 1998, 1999).

Esto nos lleva a considerar que las técnicas de música e imagen, como método específico dentro del ámbito de la Musicoterapia, pueden ser empleadas como una intervención no farmacológica en casos de TDAH. Además, a pesar de que en algunos estudios previos se sugiere la necesidad de que esta intervención (al igual que otras terapias denominadas alternativas) se lleve a cabo solo de forma complementaria (García-González, 2014), se ha comprobado que se puede desarrollar tanto de forma principal como de forma complementaria, en función de las necesidades que presente cada caso concreto con el que se esté trabajando.

\section{LAS TÉCNICAS DE MÚSICA E IMAGEN COMO MÉTODO DE INTERVENCIÓN PARA NIÑOS CON Y SIN DIAGNÓSTICO DE TDAH}

Teniendo en cuenta que uno de los principales objetivos de esta investigación es valorar la viabilidad de la aplicación de las técnicas de música e imagen en casos de niños con y sin diagnóstico de TDAH de entre 7 y 11 años de edad, en primer lugar, considerando el proceso de discusión llevado a cabo hasta este punto, se puede aceptar la viabilidad y efectividad de esta intervención para el colectivo concreto con el que se ha llevado a cabo.

En concreto, se ha podido comprobar que el tiempo empleado en las sesiones individuales (aproximadamente $30 \mathrm{~min}$ ) y grupales (aproximadamente 40 min) es el adecuado para que se facilite el mantenimiento de los procesos de atención de los niños y que puedan tener lugar la expresión y exploración emocional sin que se pierda esa atención (Roy, 1996; Wesley, 2002). 
El método de intervención empleado, basado en técnicas de música e imagen (Summer, 2010), tiene ciertas similitudes con las técnicas de Relajación de Música e Imagen (MIR) y Viaje de Música e Imagen (MIJ) (Gimeno, 2015), pero sin duda se presenta como un método cuyo diseño y forma de aplicación difiere de métodos y técnicas previos debido a la propia naturaleza de los niños con diagnóstico de TDAH. Debido a ello, ha surgido la necesidad de adaptar algunas técnicas o formas de proceder anteriores al colectivo con el que se estaba trabajando.

En lo que se refiere al papel que ha desempeñado la música en las sesiones, lo primero que es necesario destacar es que ha servido para sintonizar con el estado anímico y la energía que los niños traían al espacio de terapia (Bruscia, 1998, 2014) y, con ello, a favorecer la verbalización y la expresión de las necesidades emocionales presentes en ese momento (Colegrove et al., 2019; Kang, 2017; Llamas, 2014; Wigram et al., 2011). Se podría decir, de hecho, que la música ha cumplido el papel de co-terapeuta para el que fue introducida en un origen en la forma del modelo original (Bonny, 1986). En todos los casos y en determinados momentos de la intervención, la escucha de música ha repercutido en la disminución del estrés y la ansiedad en distintas situaciones que los niños estuviesen viviendo (Grocke y Wigram, 2011; Kim \& Stegemann, 2016). Además, se ha podido observar cómo la realización de los mandalas ha ayudado a los niños con diagnóstico de TDAH a tener mayor capacidad de autocontrol en relación con las conductas hiperactivas e impulsivas, así como a desarrollar la capacidad de expresión emocional y creatividad (Castaño y Ortiz, 2019).

En relación con ello, la realización de un dibujo o mandala después de cada sesión ha favorecido en gran medida los procesos de expresión emocional, sobre todo en algunos casos en los que los niños no eran capaces de expresar con fluidez y, en cambio, podían hablar de sus emociones a través de sus dibujos con mucha facilidad (Bush, 1995; Quinlan et al., 2015; Vilá, 2015). De hecho, se notaba cómo los mandalas representaban los sentimientos, la capacidad perceptiva y la dimensión social de los niños (Lowenfeld y Brittain, 1980), así como su relación directa con el entorno más cercano (Fosati y Segurado, 2014; Henley, 1998, 1999). En algunos casos, incluso, se podía observar que los mandalas han representado no solo el carácter del niño o la niña en un momento puntual de elaboración de los mismos, sino también el proceso de evolución desde el inicio de la intervención hasta el final. Es decir, que de alguna forma los mandalas representan el camino de la experiencia vivida a través de las sesiones de Musicoterapia (Shamdasani, 2012). 
En definitiva, las técnicas de música e imagen han demostrado ser una intervención musicoterapéutica eficaz para el trabajo con niños de entre 7 y 11 años con y sin diagnóstico de TDAH, especialmente para favorecer el desarrollo de la imaginación y de la creatividad (Summer, 2010), así como para facilitar los procesos de conciencia, gestión y expresión emocional de diversas formas (Powell, 2007). Además, como se ha mostrado en el apartado anterior del presente capítulo, esta intervención también ha repercutido de forma positiva en la muestra de características y conductas asociadas a casos de TDAH. 




\section{CHAPTER VII. DISCUSSION OF RESEARCH RESULTS}



This discussion of the results considers not only the investigative categories discussed and contrasted during the data analysis in the previous chapter, but also the viability of music and imagery techniques of intervention for ADHD. That viability must be assessed because (on the basis of the scientific evidence seen earlier) the method has never before been tried for this disorder.

\section{EMOTIONAL IMPACT OF MUSIC THERAPY}

To begin with, it should be noted that the intervention proved beneficial in treating and resolving the physical and psychological needs of the children involved - particularly those connected to emotions, affect and relationships (Blasco \& Sanjosé, 2000). This demonstrates, once again, that music therapy is useful in managing specific psychological disorders, as it has been found to be many times throughout human history (Betés, 2000).

Our study found that music and imagery techniques had a positive impact on the emotional management capabilities of a group of children aged between 7 and 12. Music was used as an object of emotional projection (Bonny, 1986; Bush, 1995) - i.e. as a reflection of the children's emotional needs on each day.

With regard to emotional awareness (EODE1_CE), the music therapy helped the children to become better able to recognise and identify their own and others' emotions. This indicates that the dynamics of the imagination and active listening exercises had a positive impact, helping the subjects develop greater self-awareness and ability to serve the needs both of individuals and of the group (Powell, 2007).

In relation to emotional regulation (EODE2_RE), in all cases, in at least one session, the music helped each child to achieve relaxation and calm (Clark, 2002; Grocke \& Wigram, 2011; Powell, 2007). It was found to improve their ability to verbalise their problems and emotional needs, and to find a solution to those problems or a response to those needs (Colegrove et al., 2019; Kang, 2017; Wigram et al., 2011). In other words, in all cases, at a certain point during the intervention, it became evident that the music therapy had helped the children channel latent emotions from their internal universe, which they had previously been unable to express.

Emotional independence (EODE3_AE) was seen to develop in all the children studied. This is particularly true in terms of increased self-esteem (Roy, 1996), and of the confidence and security stemming from the feeling of belonging to a group (Borling \& Miller, 2007) - in relation to recognition of personal qualities both in themselves and in a group of their peers. 
In relation to the category of social skills (EODE4_CS), the sessions demonstrably helped improve the children's ability for social interaction amongst themselves (Benenzon, 2011; Lacárcel, 2006). We were also able to observe the importance of personal relationships and the development of the therapeutic relationship forged with the music therapist: the children's social skills began to progress more rapidly as that relationship became more concrete. In this sense, the music therapist's own role and responsibility, and the degree of their commitment to the patients with whom they work, are crucial in being able to steer the therapy process (Ferrari, 2013).

Finally, in terms of developing life skills and wellbeing (EODE5_CVB), the sessions plainly had a major impact in developing and enhancing creativity in all the children studied. In that sense, the use of classical music made a marked difference, as it attracts the children's attention, helping them to connect with their imaginations and stimulating their evocation ability (Roy, 1996).

In fact, activities connected with imagination and evocation of images by a preselected collection of music, such as those employed in our study, are among the dynamics in music therapy which are most effective in developing creativity in the subjects (Grocke \& Wigram, 2011). In addition, expression through drawing is a natural and spontaneous outlet for developing creativity - especially in children, who are constantly exploring new forms of nonverbal communication (Fosati \& Segurado, 2014).

\section{IMPACT OF MUSIC THERAPY ON THE DISTINGUISHING TRAITS OF ADHD}

Through this study, we were able to demonstrate that music therapy had a positive impact on the decrease of ADHD behaviours within a group of diagnosed children (Acebes-de Pablo \& Carabias-Galindo, 2016; Acebes-de Pablo \& Giráldez-Hayes, 2019; Briseño, 2019; Jackson, 2003; Peñalba, 2010; Rickson, 2006; Wigram et al., 2011). Furthermore, the study shows that (as we shall explain later on) though receptive means of intervention in music therapy are rarely used in cases of ADHD (Jackson, 2003), music and imagery techniques proved extremely beneficial for the ADHD-diagnosed children's physical and emotional expression and regulation. 
With respect to hyperactive and impulsive behaviour (the first investigative category in relation to ADHD: EDAH1_HI), the intervention was shown to reduce manifestations of such behaviour. In concrete terms, we observed that certain active listening exercises, always relating to the processes of evocation and imagination, helped the children develop greater self-awareness, allowing them to relax more easily (Grocke \& Wigram, 2011; Llamas, 2014).

In fact, our observation in certain cases, where the ability to control hyperactive and impulsive behaviour is related to the capacity of emotional regulation, was that the music helped the children develop the ability to express themselves more easily and, thereby, achieve greater emotional stability (Rickson, 2006; Wiebe, 2007). This had a positive impact, reducing hyperactivity and impulsiveness.

With respect to attention deficit as an investigative category (EDAH2_A), it was observed that the music, as a new stimulus, acted as a motivating factor, in itself, for the ADHD-diagnosed children. Consequently, in the first instance, it served as a fundamental aid in focusing their attention on the task at hand at any given time (Acebes-de Pablo \& Giráldez-Hayes, 2019; Alonso \& Bermell, 2008; Álvarez, 2004). In addition, the sessions produced a gradual improvement in the children's ability to concentrate on a given activity (Dewi et al., 2015; García-Huidobro, 2015), and improved their cognitive processing capability in all cases (Benzon, 2009; Briseño, 2019; Slater \& Tate, 2018).

With regard to the third investigative category pertaining to ADHD, and specifically to the manifestation of behavioural disorders (EDAH3_TC), the intervention led to improved attitudes in terms of social relations between the ADHD children, their classmates, family members and teachers. In this case, the individual sessions helped to establish a balance between disruptive behaviour and the child's social attitude towards those closest to him/her (Peñalba, 2010). In addition, the improvement in ability to self-regulate, connected with channelling emotions through drawing, also improved the children's social interactional skills (Henley, 1998, 1999).

This leads us to believe that music and imagery techniques, as a specific method within music therapy, can be used as a non-pharmacological treatment in cases of ADHD. Furthermore, though some earlier studies suggest that such intervention (much like other so-called alternative therapies) only be exercised to complement other, more mainstream forms of therapy (García-González, 2014), our findings show it can be used either as the main therapeutic tool or as a complementary method, depending on the specific needs in each individual case. 


\section{MUSIC AND IMAGERY TECHNIQUES AS A METHOD OF INTERVENTION FOR CHILDREN WITH AND WITHOUT AN ADHD DIAGNOSIS}

One of the main aims of this research is to show the viability of music and imagery techniques to treat children, with or without a formal diagnosis of ADHD, between 7 and 12 years of age. To begin with, considering the foregoing discussion, we can agree that this approach was viable, and effective, for the specific group of patients who took part in this study.

In concrete terms, we found that the length of each individual session (30 minutes approx.) and group session (40 minutes approx.) was appropriate in helping to maintain the children's attention processes, and allowing them to explore and express their emotions without their attention wandering (Roy, 1996; Wesley, 2002).

The intervention method used, based on music and imagery techniques (Summer, 2010), is similar, in some respects, to the Music Imagery Relaxation (MIR) and Music Imagery Journey (MIJ) (Gimeno, 2015). However, there can be no doubt that the design and application of this method differ from those of previous techniques by virtue of the very nature of ADHD-diagnosed children. Given the characteristics of the condition, it was necessary to adapt certain approaches from earlier studies to suit the group of people with whom we were working.

As to the role of music in the sessions, firstly, it helped tune in to the motivation and energy the children brought to the sessions (Bruscia, 1998, 2014), and thus helped encourage them to verbalise and express their emotional needs at the time (Colegrove et al., 2019; Kang, 2017; Llamas, 2014; Wigram et al., 2011). In fact, the music could be said to act as a co-therapist; indeed, that was its purpose when originally introduced in Bonny's (1986) model. In all cases, at specific points during the intervention, listening to music helped lower stress levels and anxiety in a range of life situations that the children were experiencing (Grocke \& Wigram, 2011; Kim \& Stegemann, 2016). In addition, we observe how drawing mandalas helped the ADHD children develop greater self-control in relation to hyperactivity and impulsiveness, and develop the capacity for emotional expression and creativity (Castaño \& Ortiz, 2019). 
In relation to this point, doing a drawing or a mandala after each session greatly aided the processes of emotional expression, particularly in some cases, where the children were unable to express themselves fluently, but were able to speak easily about their emotions expressed through their drawings (Bush, 1995; Quinlan et al., 2015; Vilá, 2015). It was noted that the mandalas represented the children's feelings, perceptive abilities and social skills (Lowenfeld \& Brittain, 1980), and their direct relationship with their immediate environment (Fosati \& Segurado, 2014; Henley, 1998, 1999). In some cases, the mandalas could be seen to represent not only the child's character at the time, but also the evolutionary process from the start to the end of the programme. That is to say, in some ways, the mandalas represent the path of the children's experience through the music therapy sessions (Shamdasani, 2012).

Ultimately, music and imagery techniques have proved to be an effective music-therapeutic tool for work with children between 7 and 12, with and without an ADHD diagnosis - especially in encouraging the development of imagination and creativity (Summer, 2010), and facilitating the processes of emotional awareness, management and expression in a variety of ways (Powell, 2007). Furthermore, as demonstrated in the previous section, this intervention had a positive impact on the traits and behaviours associated with ADHD. 

CAPÍTULO VII. CONCLUSIONES 



\section{CONCLUSIONES}

\subsection{Contraste de las hipótesis del estudio}

\subsubsection{Contraste de la Hipótesis 1 del estudio}

Si consideramos la primera hipótesis de nuestro estudio, H1.- La Musicoterapia, por medio de técnicas específicas de música e imagen, repercute de forma positiva en el nivel de competencia emocional de niños con y sin diagnóstico de TDAH de entre 7 y 11 años de edad, podemos aceptar dicha afirmación, ya que se ha podido comprobar que la intervención ha dado lugar a cambios positivos en la capacidad de competencia emocional de los niños participantes.

Más en concreto, en lo referido a la primera sub-hipótesis, H1.1.- Las técnicas de música e imagen aumentan el nivel de conciencia emocional de niños con y sin diagnóstico de TDAH, teniendo en cuenta los resultados obtenidos y la discusión realizada previamente, podemos afirmar que la intervención ha producido cambios significativos en la capacidad de conciencia emocional. Los niños participantes han demostrado tener más habilidad para reconocer sus propias emociones y las de los demás después de las sesiones. Además, se ha podido observar un incremento de la empatía en varios casos, lo cual está directamente relacionado con esta capacidad de conciencia emocional.

Por su parte, respecto a la segunda sub-hipótesis, H1.2.- Las técnicas de música e imagen aumentan la capacidad de regulación emocional de niños con y sin diagnóstico de TDAH, puede ser aceptada, ya que, tal y como se ha visto reflejado en el capítulo de análisis de datos, se ha podido observar una mejora significativa en la capacidad de regulación emocional por parte de todos los niños participantes en el estudio. En muchos casos las sesiones les sirvieron para encontrar una respuesta y una forma de expresión ante necesidades emocionales que tenían desde hacía tiempo, lo que queda reflejado en el capítulo de análisis de datos y en muchos de los mandalas realizados.

Respecto a la H1.3.- Las técnicas de música e imagen aumentan el nivel de autonomía emocional de niños con y sin diagnóstico de TDAH, se puede aceptar que la intervención ha tenido repercusiones positivas en este aspecto. En concreto, se han observado cambios en la actitud respecto al reconocimiento por parte los niños participantes hacia sus cualidades físicas (practicar deportes, pintar, etc.), académicas (concentración para los exámenes, gestión de las tareas, etc.) y personales (muestra de empatía, compañerismo, etc.). 
La cuarta sub-hipótesis, H1.4.- Las técnicas de música e imagen aumentan la competencia social de niños con y sin diagnóstico de TDAH, se acepta, ya que se ha observado este aumento en la competencia social en todos los casos de una forma significativa. Los niños participantes mostraron una mejora en su capacidad para relacionarse con el entorno en contextos como las sesiones de Musicoterapia, las situaciones familiares, la escuela o los momentos de ocio.

Por último, en lo que respecta a la quinta sub-hipótesis H1.5.- Las técnicas de música e imagen aumentan la competencia de vida y bienestar de niños con y sin diagnóstico de TDAH, se ha podido comprobar que la intervención ha estimulado de forma positiva la actitud receptiva y proactiva de los niños participantes en el estudio, incluyendo la de aquellos que al principio se mostraban más introvertidos o reservados a la hora de participar en las sesiones. Además, se ha visto desarrollada de forma significativa la creatividad en la mayor parte de los casos, siendo de especial interés aquellos en los que se observó una mayor evolución. Dentro de esta sub-hipótesis también consideramos las sensaciones de bienestar, relajación y tranquilidad que producían las sesiones de Musicoterapia.

\subsubsection{Contraste de la Hipótesis 2 del estudio}

La segunda hipótesis de nuestro estudio, H2. La Musicoterapia, por medio de técnicas específicas de música e imagen, reduce las muestras de déficit de atención, hiperactividad, impulsividad y trastorno de conducta en casos de niños con diagnóstico de TDAH de entre 7 y 11 años de edad, es aceptada de acuerdo con los resultados obtenidos tras el proceso de análisis de los datos y la discusión realizada al respecto. Las tres sub-hipótesis planteadas previamente nos ayudan a comprobar esta hipótesis de forma más concreta, fijando la atención en cada uno de los aspectos que es necesario considerar en relación con la muestra de conductas asociadas al TDAH, como veremos a continuación.

En primer lugar, la sub-hipótesis H2.1.- Las técnicas de música e imagen reducen el déficit de atención en casos de niños con diagnóstico de TDAH, es aceptada porque se pudo observar un incremento significativo de la capacidad de centrar de atención y mantener la concentración en todos los casos de niños con diagnóstico de TDAH participantes en el estudio. En algunos casos, de hecho, fue interesante observar cómo los tiempos de atención ante la escucha de música y el dibujo del mandala iban aumentando poco a poco conforme se iba desarrollando la intervención. En otros casos, por ejemplo, las sesiones ayudaban a los niños a prestar mayor atención de forma consciente a su estado anímico y sus necesidades emocionales. 
Por otra parte, respecto a la segunda sub-hipótesis H2.2.- Las técnicas de música e imagen reducen la muestra de conductas hiperactivas e impulsivas en casos de niños con diagnóstico de TDAH, es igualmente aceptada, ya que se obtuvo una disminución significativa de estas muestras de conducta en todos los casos. En relación con ello, lo más importante era observar cómo la muestra de conductas hiperactivas e impulsivas cambiaba en la propia sesión, comparando la actitud de los niños al comienzo y al final de la misma. Ya se ha hablado previamente de cómo en algunos casos los niños llegaban a la sesión con mucha actividad física y con mucha energía a la hora de hablar, y terminaban dibujando de forma calmada y hablando prácticamente susurrando. De hecho, esta experiencia era a menudo contrastada con el punto de vista de las familias cuando decían que sus hijos estaban mucho más tranquilos en casa después de las sesiones de Musicoterapia.

Por último, en lo que respecta a la tercera sub-hipótesis H2.3.- Las técnicas de música e imagen reducen el nivel de trastorno de conducta en casos de niños con diagnóstico de TDAH, también es aceptada de acuerdo con los resultados obtenidos. En este caso, lo más significativo era escuchar a las familias compartir que las sesiones ayudaban a sus hijos a mantener una relación más calmada y cordial en el entorno familiar, especialmente a la hora de tratar con hermanos o hermanas. También se pudo observar el proceso de evolución que vivieron los niños sobre todo en lo que se refiere a las sesiones grupales, en las que al principio resultaba difícil el trato con algunos compañeros y, a medida que iba avanzando la intervención, se iban mejorando las relaciones sociales entre iguales.

\subsection{Conclusiones relacionadas con los objetivos del estudio}

Respecto al objetivo 1. Valorar la Musicoterapia y, en concreto, las técnicas de música e imagen, como medio para favorecer la expresión emocional en niños sin diagnóstico de TDAH de entre 7 y 11 años de edad, se puede considerar que el método empleado ha resultado ser efectivo para mejorar esta capacidad de conexión y expresión emocional de la que hablamos. En primer lugar, los resultados obtenidos y mostrados mediante el análisis de datos y la comprobación de las hipótesis son positivos. A lo largo del proceso de intervención se pudo observar cómo los niños iban desarrollando esta capacidad de compartir y expresar sus necesidades a nivel emocional, incluso en aquellos casos en los que en las primeras sesiones se mostraban más reacios o tímidos ante este tipo de procesos. 
De hecho, se pudo comprobar cómo en algunas situaciones concretas, en las que resultaba complicado que los niños expresasen verbalmente cómo se sentían, se trabajaba directamente con la escucha de la música y con el dibujo del mandala, es decir, con la expresión no verbal, lo cual daba paso después a una mayor facilidad y fluidez a la hora de hablar sobre los procesos emocionales. En casos así, la música ayudaba a establecer una conexión emocional directa con el estado anímico de los niños, y el dibujo ayudaba a expresar de forma sutil, no verbal y no invasiva su mundo interior para después poder hablar sobre ello.

Respecto al objetivo 2. Considerar la Musicoterapia y, en concreto, las técnicas de música e imagen, como intervención no farmacológica en casos de niños con diagnóstico de TDAH de entre 7 y 11 años de edad, al igual que en el objetivo anterior, se pudieron observar las repercusiones positivas de la intervención para los niños con diagnóstico de TDAH. En estos casos se observó cómo la situación de terapia se presentaba como un entorno seguro y de confianza, en el que ellos iban notando poco a poco, conforme se iba desarrollando el proceso, que podían compartir sus preocupaciones, intrigas, gustos y aficiones de forma natural y espontánea.

Además, en lo que se refiere a las características propias del TDAH, la Musicoterapia, y más en concreto las selecciones musicales escogidas en cada momento, les ha servido en varios casos para conectar con su necesidad de movimiento y encontrar una forma de canalizarla hacia la actividad que estábamos llevando a cabo. Igualmente se observó cómo la escucha activa de música ayudaba a mantener procesos de concentración y de estimulación de la creatividad y la imaginación.

Respecto al objetivo 3. Explorar las posibilidades del mandala como objeto de proyección y expresión emocional en casos de niños con y sin diagnóstico de TDAH, podemos observar, como se puede apreciar en el capítulo de análisis de datos, de qué forma la realización de mandalas ha servido a los niños de ayuda como vía de expresión emocional. En algunos casos, la creación de un dibujo hacía que conectasen con su mundo interior de forma imaginativa y creativa. En otros casos, realizar esta tarea ayudaba a reflejar necesidades emocionales latentes que por medio de la palabra sería más complicado expresar o compartir. Igualmente, ha ayudado a obtener información de utilidad para el proceso terapéutico, por ejemplo, al mostrar de forma tácita conflictos acontecidos en el contexto académico o de ocio de los niños participantes. 
Por último, en relación con el objetivo 4. Conocer la relación entre el tipo de música empleada y la respuesta emocional de niños con y sin diagnóstico de $T D A H$, se pudo observar que la música ayudaba a los participantes a conectar con su estado anímico y su necesidad emocional, incluso en algunos casos en los que no lo podían verbalizar antes de realizar el ejercicio de escucha. De esta forma, la música escogida permitía que la conexión emocional se produjese de forma natural y espontánea. Igualmente, si en algún momento la música no encajaba con la necesidad emocional, los niños tenían la libertad de expresarlo para poder cambiar a otra selección que se adaptase mejor a las circunstancias. En definitiva, cuando la música encajaba con el estado emocional la conversación y la sesión se desarrollaban de forma fluida y natural tras el ejercicio de escucha activa.

Por último, en lo que respecta al objetivo 5. Valorar la repercusión que tiene la intervención musicoterapéutica en otros contextos de la vida de los niños, tales como la familia, la escuela o los momentos de ocio, se ha podido comprobar, por medio del testimonio de las familias participantes, que la intervención ha tenido efectos positivos en la actitud de los niños en otros momentos diferentes a las sesiones de Musicoterapia, como las situaciones cotidianas y propias de la rutina en su casa. De hecho, algunos padres y madres participantes señalaban que notaban estos cambios de forma especial justo después de la sesión y en días subsecuentes, manifestando que sus hijos mostraban una actitud más calmada y dialogante hacia ellos y hacia sus hermanos, por ejemplo. Si bien es cierto, por otra parte, que notaban que estos efectos positivos no perduraban en el tiempo a lo largo de la semana, es decir, a lo largo de la sesión.

En cuanto a la forma de relacionarse de los niños participantes en el ambiente académico, las familias compartían a lo largo del desarrollo de las sesiones que notaban cierta mejoría en la actitud que mostraban de cara a los profesores o en lo referido a la ejecución de las tareas de clase. Además, en el caso de los niños con diagnóstico de TDAH, después de la intervención se contrastó el punto de vista del investigador principal respecto a la muestra de conductas asociadas al trastorno con el punto de vista de las maestras tutoras, dando como resultado que no existían diferencias significativas, excepto en el caso del déficit de atención, respecto al cual las maestras tutoras no notaron cambios significativos. 


\section{LIMITACIONES Y FUTURAS LÍNEAS DE TRABAJO}

Si bien es cierto que este trabajo se encuadra dentro de un diseño mixto de triangulación concurrente y que, como tal, sigue la estructura, indicaciones y fases de dicho diseño, a continuación se exponen algunas consideraciones que pueden ayudar a profundizar a través de posibles líneas de investigación en el futuro, tanto desde un punto de vista cuantitativo como cualitativo.

\subsection{Ampliación del alcance de los resultados cuantitativos}

En primer lugar, consideramos que, si el objetivo fuese generalizar las hipótesis de la intervención llevada a cabo, sería necesario aumentar considerablemente la muestra de participantes. De esta forma sería posible extrapolar los resultados obtenidos a la hora de llevar a cabo el trabajo de campo al total de la población con la que se está trabajando (en nuestro caso, población infantil de entre 7 y 11 años con y sin diagnóstico de TDAH). Igualmente, el hecho de trabajar con una muestra mixta también supondría una limitación a la hora de generalizar y extrapolar los resultados al total de la población de estudio. En este sentido, sería recomendable establecer criterios de inclusión más acotados a la hora de seleccionar a los participantes para trabajar con una población más específica.

Asimismo, para tal fin sería imprescindible disponer de un grupo control que permitiese contrastar de forma objetiva si los efectos producidos por la $\mathrm{Mu}$ sicoterapia han tenido lugar por las características propias del método aplicado o, por el contrario, se deben al mero hecho de haber llevado a cabo una intervención. Eliminaríamos de esta forma la duda sobre si se ha llevado a cabo el conocido Efecto Hawthorne, según el cual se considera que las personas pueden cambiar de forma activa su conducta al ser conscientes de que están formando parte de un estudio.

Por otra parte, consideramos necesario señalar que existe la posibilidad de que el hecho de que en este estudio el investigador principal fuese, al mismo tiempo, el musicoterapeuta que llevó a cabo la intervención puede haber influido en la obtención objetiva de los resultados de la investigación. Aunque dentro del enfoque cualitativo es común en determinadas ocasiones que el investigador principal forme parte directamente de la realidad que está estudiando, en el caso de las investigaciones experimentales se considera que este hecho puede afectar a la objetividad de un estudio. Aun así, contar con el testimonio de las familias y de las profesoras tutoras fue la principal razón para triangular y contrastar la información obtenida directamente por el investigador principal. 


\subsection{Profundización en la información cualitativa emergente}

Por último, durante la fase de obtención de información, especialmente en las entrevistas semiestructuradas, surgieron diferentes temas que dieron lugar a categorías emergentes cualitativas que sería conveniente seguir trabajando en estudios futuros. El hecho de que surjan estos temas de conversación nos indica que son aspectos de la vida de los niños, de la realidad educativa, o de la presencia de la Musicoterapia en nuestra sociedad, que están en el pensamiento de las personas participantes y, por lo tanto, que tienen importancia para la realidad social con la que se está trabajando.

La razón por la que estas categorías emergentes no fueron incluidas en el proceso de análisis de datos es que no podían ser contrastadas de acuerdo con el método mixto que fue empleado, en el que la triangulación metodológica se lleva a cabo principalmente comparando la información obtenida y analizada mediante técnicas cualitativas y cuantitativas.

Se incluye una breve descripción de cada una de estas categorías en la Tabla 40. Si bien es cierto que algunas de ellas guardan una relación directa con las categorías principales de la investigación, otras pertenecen a un discurso que se aleja de los objetivos del estudio, pero que sin duda tiene importancia para las personas participantes. Por ejemplo, las categorías que se refieren a la importancia de la música (MT_M), del mandala (MT_D) o del vínculo terapéutico (MT_VT) en el proceso de evolución de las sesiones de Musicoterapia, ha aportado información relevante que se cruza con información importante para contrastar los datos obtenidos, pero a menudo generaba dudas y curiosidad a las familias y se hablaba más sobre ello en las entrevistas semiestructuradas.

Sin embargo, en el caso de otras categorías, por ejemplo, las relacionadas directamente con el concepto y la situación actual del TDAH, habitualmente se generaban conversaciones de debate bastante comunes, especialmente relacionadas con la prescripción farmacológica (TDAH_F), el proceso de diagnóstico (TDAH_D) y las necesidades emocionales (TDAH_NE) y la situación académica (TDAH_SA) de los niños con diagnóstico de TDAH. En cualquier caso, se hizo evidente que las madres y los padres participantes tenían una necesidad lógica y recurrente de hablar sobre su situación familiar personal y sobre la situación general relacionada con la consideración de este trastorno en nuestro país. Todos estos temas de conversación o debate guardan relación directa con el capítulo relativo a las controversias del TDAH desarrollado previamente en trabajo de investigación. 
Es por ello por lo que resultaría de interés para la continuación de este estudio aumentar la exploración y profundización de estas categorías en futuras líneas de investigación de corte cualitativo. Sería interesante, por ejemplo, organizar grupos de discusión en los que se representasen las diferentes partes implicadas en el conocimiento e intervención respecto al TDAH (profesores, psicólogos, maestros, musicoterapeutas, pedagogos, psiquiatras, etc.). Además, sería interesante plantear futuras intervenciones interdisciplinares en las que se estableciese una comunicación directa y continua entre los distintos profesionales que participasen en ella, con el fin de observar y analizar el objeto de estudio desde diferentes puntos de vista.

Por último, sería interesante profundizar de forma más detallada y sistemática en cómo unas selecciones musicales u otras pueden conectar en mayor o menor medida con los estados emocionales de las personas que participan en las sesiones de Musicoterapia.

Tabla 40.

Categorías emergentes durante la fase de obtención de información

\begin{tabular}{|c|c|}
\hline $\begin{array}{l}\text { Nombre de } \\
\text { la categoría }\end{array}$ & Breve definición \\
\hline MT & $\begin{array}{l}\text { Presentación del concepto de la Musicoterapia con relación a lo que esto } \\
\text { implica (presencia de la disciplina en sociedad, definición, experiencias } \\
\text { previas con ella, etc.). }\end{array}$ \\
\hline MT_D & Importancia y papel del mandala en las sesiones de Musicoterapia. \\
\hline MT_M & Importancia y papel de la música en las sesiones de Musicoterapia. \\
\hline MT_VT & $\begin{array}{l}\text { Presencia e importancia del vínculo terapéutico en el proceso de inter- } \\
\text { vención musicoterapéutica. }\end{array}$ \\
\hline SF & Situación y ambiente familiar de las personas participantes en el estudio. \\
\hline RF & $\begin{array}{l}\text { Repercusión de la intervención en la situación y el ambiente familiar de } \\
\text { las personas participantes en el estudio. }\end{array}$ \\
\hline SA & $\begin{array}{l}\text { Información relacionada con la situación académica de los niños partici- } \\
\text { pantes. }\end{array}$ \\
\hline TA & $\begin{array}{l}\text { Información que surgía de forma emergente en relación con determina- } \\
\text { das terapias alternativas. }\end{array}$ \\
\hline TDAH & $\begin{array}{l}\text { Información relacionada con el concepto, la definición y la situación ac- } \\
\text { tual del TDAH en términos generales. }\end{array}$ \\
\hline TDAH_D & $\begin{array}{l}\text { Todo tipo de información relacionada con el proceso de diagnóstico del } \\
\text { TDAH. }\end{array}$ \\
\hline TDAH_F & $\begin{array}{l}\text { Todo tipo de información relacionada con la prescripción farmacológica } \\
\text { para TDAH (experiencia de las familias, opiniones, etc.). }\end{array}$ \\
\hline TDAH_NE & $\begin{array}{l}\text { Información relacionada con las necesidades emocionales que habitual- } \\
\text { mente tienen los niños con diagnóstico de TDAH. }\end{array}$ \\
\hline TDAH_SA & $\begin{array}{l}\text { Información relacionada con la situación académica y las dificultades } \\
\text { que habitualmente tienen los niños con diagnóstico de TDAH en la es- } \\
\text { cuela, más en concreto en relación con su progreso académico. }\end{array}$ \\
\hline
\end{tabular}

Fuente: elaboración propia. 


\subsection{Continuar investigando: Musicoterapia y TDAH}

A lo largo de estos últimos años hemos explorado la posibilidad de aplicar la Musicoterapia en un contexto educativo con casos específicos de TDAH (Acebes-de Pablo y Carabias-Galindo, 2016) y hemos profundizado en cómo esta disciplina puede contribuir en el trabajo con casos de TDAH mediante procesos de intervención continuados en el tiempo (Acebes-de Pablo y Giráldez-Hayes, 2019).

Ahora, a través de esta investigación, se presenta un método de trabajo para casos de TDAH que apenas había sido explorado previamente: las técnicas específicas de música e imagen. De hecho, durante el proceso de diseño de la intervención, y a lo largo del desarrollo de esta, en diversos momentos era necesario repensar y adaptar la forma de trabajar para que fuese acorde a las necesidades que los niños con este diagnóstico suelen presentar.

Así, como se ha explicado previamente en el capítulo de descripción del método empleado, en ocasiones era necesario que los niños atendiesen a la música con los ojos cerrados, o puede ser que necesitasen dibujar mientras la música sonaba, o es posible que su necesidad fuese la de moverse enérgicamente junto con el ritmo y la melodía para dar respuesta a su gran actividad física. En cualquier caso, siempre iba en función de las características de cada niño y de sus circunstancias personales (grado de déficit de atención o de hiperactividad, medicación que estuviesen tomando en ese momento, etc.).

Por lo tanto, y teniendo en cuenta que se han ido desarrollando diferentes métodos específicos debido a la emergente necesidad de adaptar el Modelo Bonny de Imagen Guiada con Música (BMGIM) a determinados contextos, se presenta la posibilidad de que este proceso de intervención tome la forma de un método específico. Al igual que los métodos de Relajación de Música e Imagen (MIR) y Viaje de Música e Imagen (MIJ), expuestos previamente, este tendrá unas características muy concretas para su aplicación en casos de niños con diagnóstico de TDAH, y se plantea la continuación con este trabajo para que adquiera más solidez y sistematización en el futuro.

\section{CONSIDERACIONES FINALES}

Por todo lo expuesto en los capítulos de análisis de datos, discusión de resultados, y este capítulo final de conclusiones, consideramos que a través de esta investigación se presenta un método de intervención en Musicoterapia, basado en técnicas de música e imagen, que puede seguir siendo explorado en futuras investigaciones y trabajos de intervención de diversa índole. 
Después de casi siete años trabajando en este tema de investigación, relacionado directamente con el TDAH como objeto de estudio, supone para mí un gran paso completar esta tesis doctoral como cierre de una de las etapas que considero más importantes en mi vida. Sin duda ha sido un periodo en el que ha habido mucho aprendizaje y crecimiento personal.

Se trata de un estudio que tiene implicaciones para el conjunto de profesionales musicoterapeutas que contribuyen al desarrollo de esta disciplina en nuestro país día tras día. El camino hacia el reconocimiento de esta profesión no es sencillo, y es por medio de la investigación y del trabajo diario en la práctica e intervención directa que tantos compañeros hacen, que sea posible estar cada día más cerca de lograr que la Musicoterapia adquiera la visibilidad y reconocimiento que merece. Esta tesis doctoral puede dar ideas para seguir investigando e innovando dentro del campo de conocimiento de nuestra disciplina, así como recursos de técnicas receptivas para aplicar a la práctica musicoterapéutica.

Igualmente, esta investigación pretende ser una ayuda para docentes y otros profesionales implicados en la intervención en casos de TDAH, como psicólogos, musicoterapeutas, pedagogos, etc. Espero que sirva para obtener ideas y guiar la reflexión sobre la práctica docente o clínica en relación con la profundización en la comprensión del trastorno y las diferentes formas de trabajar con casos de este tipo.

Por último, y sin ánimo de plantear siquiera que un punto de vista personal pueda tener más presencia o importancia que el conjunto de resultados obtenidos en este estudio, me gustaría concluir con una humilde reflexión.

A lo largo de estos años, en los que mi línea de investigación se ha vinculado directamente al estudio del desarrollo infantil, he podido observar, tratando con niños y con personas adultas a través de mi trabajo como musicoterapeuta, que el tipo de educación y trato recibido en los primeros años de vida repercute de forma significativa en la etapa adulta de cualquier persona.

En casos de intervención en la etapa infantil, he escuchado en diversas situaciones cómo el entorno condiciona en mayor o menor medida el pensamiento y la autoconciencia de niños y niñas al afirmar que son malos estudiantes, tontos, insoportables u otras expresiones menos delicadas.

En casos de trabajo con adultos, he acompañado procesos de desarrollo personal en los que aun en la etapa de la madurez para algunas personas era enormemente difícil gestionar sentimientos enfrentados y relacionarse con sus progenitores de forma adulta debido a sucesos acontecidos en la infancia. 
Para finalizar, ilustraré esta idea con una cita de Pearson (1992) en la que creo que se establece de forma interesante y acertada una analogía entre la obra literaria Pinocho y la experiencia vivida tanto en la etapa de desarrollo infantil como en procesos de crecimiento personal en la etapa adulta:

\section{Volverse real}

En Pinocho, Gepetto anhela tener un hijo y talla el muñeco Pinocho de un bloque de madera. Luego aparece el Hada y le otorga al muñeco la capacidad de moverse a voluntad. Gepetto y el Hada juntos (...) pueden contribuir a hacer un muñeco que se porte bien, pero sólo [sic] Pinocho puede ganarse el derecho a ser real.

Al principio es un muñequito "bueno" y hace todo lo que debe. Su primer signo de independencia es un acto de desobediencia y traición a Gepetto, el Hada y el grillito que encarna su conciencia. Se escapa con su amigote a la Isla del Placer. (...)

Pinocho desciende a las profundidades de la instintiva búsqueda de placer, pero escapa en el último momento cuando se da cuenta de que él y sus amigos se están convirtiendo en asnos. Esta experiencia desorientadora sacude a Pinocho de tal modo que comienza a percibir el mundo de otra manera.

La iniciación de Pinocho en los misterios tiene cuatro pasos. Primero ve al Hada y descubre que posee el potencial para convertirse en un "niño real". Esta es la llamada a la misión. Segundo, se da permiso para experimentar las cualidades de su Sombra y la destrucción que provocan. (...) Finalmente, el hada lo convierte en un niño real porque se lo ha ganado: ha experimentado la vida. Ha sufrido. Ha aprendido a ver con ojos más penetrantes y, consecuentemente, ha aprendido a diferenciar entre diversiones baratas y verdadero placer, y ha ganado la capacidad de amar genuinamente. También ha aprendido a hacerse responsable de sus actos sin debilitarse con sentimiento de culpa o vergüenza. En resumen, se ha vuelto real. (pp. 57-58)

En definitiva, Pinocho, como cualquier otro niño, comprende de forma instintiva la realidad de lo que supone expresarse en el mundo como lo que necesita ser (no como lo que se espera de él) y este es el camino que le lleva a ser real, es decir, a encontrar su forma de existir en el mundo y de relacionarse 
en la sociedad en la que vivimos. Si a un niño (con o sin diagnóstico o características propias de TDAH) se le enseña desde pequeño y de forma continuada que se porta mal constantemente o que es un niño malo (ellos mismos lo verbalizan, y es sorprendente la cantidad de veces que he escuchado esto en sus propias palabras) vivirán con ese estigma, con esa sensación de no ser suficientemente buenos para nadie en ninguna circunstancia. Además, en muchos casos asumirán inevitablemente que la respuesta para ser una persona más sociable, tranquila y productiva es estar sujeto a una prescripción farmacológica para así estar en sintonía con el modelo de persona más aceptado socialmente (metafóricamente, como hizo Gepetto al modelar a Pinocho).

Los niños merecen ser respetados, queridos y valorados por lo que son en su esencia, y no por lo que el entorno espera que sean. Hagamos, por tanto, ejercicio de conciencia y humildad, hacia la actitud que adoptamos y las decisiones que tomamos ante las distintas situaciones de crianza y educación de las que somos partícipes y en las que tenemos en gran parte una responsabilidad directa, ya sea desde un punto de vista personal, profesional o social. 


CHAPTER VIII. CONCLUSIONS 



\section{CONCLUSIONS}

\subsection{Assessment of study hypotheses}

\subsubsection{Assessment of study Hypothesis 1}

The first hypothesis in our study, H1.- Music therapy, using specific music and imagery techniques, has a positive impact on emotional skills in children aged 7-11, with or without a diagnosis of ADHD, can be accepted as true: the intervention demonstrably produced positive changes in the children's emotional capabilities.

More specifically, let us look at the first sub-hypothesis, H1.1.- Music and imagery techniques improve the emotional competence of children with and without a diagnosis of ADHD. Considering the results and the discussion thereof, the intervention was seen to significantly enhance the children's capacity for emotional awareness. At the end of the sessions, the participants demonstrated a greater ability to recognise their own and others' emotions. Also, in a number of cases, the children showed increased empathy, which is directly related to that capacity for emotional awareness.

We can accept the second sub-hypothesis, H1.2.- Music and imagery techniques improve the capacity for emotional regulation of children with and without a diagnosis of ADHD. As reflected in the data analysis, a major improvement in emotional regulation was observed in all the study participants. In many cases, the sessions helped the children to find answers and a way of expressing emotional needs that had long lain latent. This is reflected in the data analysis, and in many of the mandalas the children drew.

Looking now at sub-hypothesis H1.3.- Music and imagery techniques improve the emotional independence of children with and without a diagnosis of $A D H D$, the intervention did indeed produce positive results in this respect. Specifically, the participants' attitudes changed in terms of recognising their own physical abilities (practising sports, painting, etc.), academic qualities (concentrating in exams, managing tasks, etc.) and personal traits (displaying empathy, companionship, etc.).

The fourth sub-hypothesis, H1.4.- Music and imagery techniques improve the social skills of children with and without a diagnosis of ADHD, can be accepted: we observed significantly improved social skills in all cases. The children demonstrated increased ability to relate to their surroundings in contexts including the music therapy sessions, family life, school and leisure time. 
Finally, we come to the fifth sub-hypothesis, H1.5.- Music and imagery techniques improve the life skills and wellbeing of children with and without a diagnosis of $A D H D$. The intervention positively stimulated the children's receptive and proactive attitudes - even in those who, at the beginning, were most introverted or reserved in participating in the sessions. In addition, we saw greatly increased creativity in most cases; here, the children in whom the greatest change is apparent are particularly interesting. This sub-hypothesis also covers the feelings of wellbeing, relaxation and tranquillity that the music therapy sessions brought about.

\subsubsection{Assessment of study Hypothesis 2}

The second study hypothesis, H2. Music therapy, using specific music and imagery techniques, reduces symptoms of attention deficit, hyperactivity, impulsiveness and behavioural disorders in cases of children aged 7-11 diagnosed with $A D H D$, is held to be true, in view of the data analysis results and discussion. Using the three sub-hypotheses, we can verify this hypothesis in a more concrete fashion, focusing in turn on each aspect that needs to be considered in relation to behaviour associated with ADHD, as we shall see below.

To begin with, sub-hypothesis H2.1.- Music and imagery techniques reduce attention deficit in children diagnosed with ADHD, is accepted: in all ADHDdiagnosed children taking part, we observed a significant increase in their ability to focus and maintain concentration. In fact, in some cases, it was interesting to observe how the children's attention spans when listening to music and drawing mandalas gradually increased as the intervention went on. In other cases, for example, the sessions helped the children to consciously acknowledge their state of mind and their emotional needs.

Sub-hypothesis H2.2.- Music and imagery techniques reduce hyperactive and impulsive behaviour in children with a diagnosis of ADHD is also accepted, as a significant reduction in such behaviour was seen in all cases. The most salient observation was how hyperactivity and impulsiveness changed even within the span of each session, when we compare the children's attitudes at the start and end of the session. We have already seen how, in some cases, the children came into the sessions extremely physically active and with a great deal of energy when talking, but by the end, were drawing calmly and speaking in barely more than a whisper. Indeed, this experience often correlates with the viewpoints of the children's families, who reported that the children were much calmer at home after the music therapy sessions. 
Finally, the third sub-hypothesis H2.3.- Music and imagery techniques reduce behavioural disorders in ADHD-diagnosed children, is also held to be true, in view of the results. In this case, the most significant thing was the families' testimony that the sessions were helping their children to maintain calmer and more cordial relationships at home, especially when interacting with their siblings. The children's own transition process was also apparent - especially in the group sessions where they initially found it difficult to interact with some of their peers but, as the programme progressed, social relations visibly improved.

\subsection{Conclusions regarding the study objectives}

With regard to objective 1. Assessing the value of music therapy and, specifically, music and imagery techniques, as a means of promoting emotional expression in children aged 7-11 without an ADHD diagnosis, the method was indeed effective in improving the children's ability to connect and express themselves. To begin with, the results were positive, as set out in the data analysis and hypothesis assessments. Throughout the intervention, the children were discernibly developing that ability to share and express their emotional needs - even those who, in the early sessions, were most reluctant or shy about engaging in such processes.

In fact, in certain situations, where the children had difficulty verbally expressing how they were feeling, we worked through listening to music and drawing mandalas - that is, through non-verbal expression. This approach eased friction and created greater fluidity when they were talking about their emotional processes, later on. In such cases, the music helped connect directly to the children's state of mind, and the drawing helped them to express their inner selves in a subtle, non-verbal, non-invasive way, which in turn helped them to talk about it.

Let us now look at objective 2. Considering music therapy and, specifically, music and imagery techniques, as a non-pharmacological means of intervention for ADHD-diagnosed children aged 7-11. As with the first objective, the positive impact of the intervention on the ADHD-diagnosed children was plain to see. The therapy presented a secure, safe environment, and as the process continued, the children gradually realised they could safely share their concerns, curiosities, likes and tastes naturally and spontaneously.

Furthermore, in relation to typical ADHD traits, music therapy - and, more specifically, the selections of music chosen at different times - often helped the children to connect with their need to move around, and channel it into 
the activity at hand. We also observed how active listening helped sustain concentration and stimulate creativity and imagination.

With regard to objective 3. Investigating the possibilities offered by mandalas as an object of projection and emotional expression for children with and without a diagnosis of $A D H D$, the data analysis shows how drawing mandalas served as a means of emotional expression for the children. In some cases, by drawing, they were able to connect with their inner world in an imaginative, creative way. In other cases, this activity helped reflect latent emotional needs that would have been harder to express or share verbally. In addition, it yielded information that was useful for the therapeutic process - for example, by tacitly reflecting conflicts that the children had encountered at school, or in their leisure times.

Regarding objective 4. Elucidating the relationship between the type of music used and the emotional response from children with and without a diagnosis of $A D H D$, it was apparent that the music helped participants to connect to their own state of mind and emotional needs - even where, in certain cases, they were unable to verbalise those needs before listening. Thus, the chosen music helped the emotional connection to form naturally and spontaneously. Additionally, if, at any time, the music did not fit with their emotional needs, the children were free to say so, and ask for it to be changed to a more suitable selection. Ultimately, when the music fitted with their emotional state, the conversation and session ran fluidly and naturally after the active listening.

Finally, with respect to objective 5. Assessing the impact of music therapy intervention in other areas of the children's lives, such as family time, school and leisure, the testimony from the families shows that the intervention had positive effects on the children's attitudes beyond the music therapy sessions, such as day-to-day situations and household routines. In fact, several of the parents said they were particularly aware of these changes just after the session and in the days following. They report that the children were calmer and more willing to talk to their parents and siblings, for example. On the other hand, it should be noted that these positive effects did not endure throughout the week.

As regards relationships at school, as the programme progressed, the families reported a certain improvement in the children's attitudes to their teachers, or to tasks set in class. In addition, with ADHD-diagnosed children, after the intervention, the lead researcher's perspective was compared to that of the children's teachers, regarding behaviour associated with ADHD. The two opinions matched quite closely, except with respect to attention deficit, where the teachers did not see any significant change. 


\section{LIMITATIONS AND AVENUES FOR FUTURE RESEARCH}

This work is part of a mixed concurrent triangulation design, and as such, is bound by the structure, prescriptions and phases of that design. Below are considerations that would be helpful in going further, through possible future research, both quantitative and qualitative.

\subsection{Extending the scope of the quantitative results}

We believe that, in order to generalise the hypotheses from this study to apply more broadly, the number of participants needs to be considerably increased. In doing so, the results obtained in fieldwork could be extrapolated to the whole target population (in our case, children aged 7-11, with or without an ADHD diagnosis). Working with a mixed sample would also be a limitation when generalising and extrapolating the results more broadly. Thus, it would be advisable to establish more limited inclusion criteria when choosing the participants to work with a more specific population.

In addition, for this purpose, a control group is crucial, to objectively determine whether the effects of the music therapy are attributable to the properties of the applied method, or due merely to the fact of conducting an intervention. This approach would eliminate the possibility of the so-called Hawthorne Effect, whereby people actively modify their behaviour because they are aware of being test subjects.

Another possibility must be noted. The lead researcher in this study was also the music therapist on the ground, which may have had a bearing on the objectivity of the results in the investigation. With qualitative studies, it is not uncommon for the lead researcher to be part of the real-life situation being investigated. However, in the case of experimental investigations, it is believed that such has the potential to impact the study's objectivity. Nonetheless, the data gathered directly by the lead researcher can be triangulated and compared against the testimonials from the families and teachers, in the present case.

\subsection{Delving deeper into the emerging qualitative information}

Finally, during the data-harvesting phase, especially in the semi-structured interviews, a range of topics came up. With these, we were able to construct a series of qualitative categories, on which it would be helpful to focus in future studies. By virtue of the fact that these topics came up during the conversation, they are genuine aspects of the children's lives, of their reality at school, or of the presence of music therapy in our society. These issues are 
on the participants' minds, and therefore, they are important factors in the social reality with which we are dealing.

The reason why these categories were not included in the data-analysis process is that they cannot be subjected to rigorous comparison, as required by the mixed method employed here. Methodological triangulation, in this study, was done mainly by comparing the information obtained and analysed using qualitative and quantitative techniques.

Each of these categories is briefly described in Table 41 . Some relate directly to the main themes of the research. Others are part of a discourse that is removed from the objectives of this research, but is indubitably important for the participants. For example, the categories relating to the importance of the music (MT_M), the mandalas (MT_D) or the therapeutic relationship (MT_VT) in the evolution of the music therapy sessions provided relevant information, cross-referenced with important information to contrast data obtained, but often gave rise to doubt and curiosity for the families. These topics were discussed in greater depth in the semi-structured interviews.

However, with other categories - e.g. those directly relating to the concept and the current situation of ADHD sufferers - the debate tended to go in fairly common directions, especially in connection with pharmacological prescription (TDAH_F), the diagnostic process (TDAH_D), the emotional needs (TDAH_NE) and the academic situation (TDAH_SA) of ADHD-diagnosed children. In any case, it became evident that the parents in the study had a logical and recurrent need to talk about their family situation, and about the general situation with consideration of ADHD in Spain. All these topics are directly connected to the earlier chapter on the controversial issues surrounding ADHD.

Hence, in future qualitative studies, it would be beneficial to widen and deepen the exploration of these categories. It would be interesting, for example, to organise discussion groups including representatives of all the different parties involved in knowledge and intervention in relation to ADHD (primary- and secondary-school teachers, psychologists, music therapists, psychiatrists, etc.). In addition, it would be interesting to organise interdisciplinary interventions involving direct and continuous communication amongst the various professionals taking part, to observe and analyse the subject from multiple angles.

Finally, it would be interesting to delve, more deeply and systematically, into how certain musical selections can connect, to a greater or lesser degree, with the emotional states of people undergoing music therapy. 
Table 41

Categories that emerged during the information-gathering stage

\begin{tabular}{|c|c|}
\hline Category & Brief definition \\
\hline MT & $\begin{array}{l}\text { Introduction to the concept of music therapy in terms of what it involves } \\
\text { (the presence of the discipline in society, its definition, prior experience } \\
\text { with it, etc.). }\end{array}$ \\
\hline MT_D & Importance and role of mandalas in the music therapy sessions. \\
\hline MT_M & Importance and role of music in the music therapy sessions. \\
\hline MT_VT & $\begin{array}{l}\text { Presence and importance of a therapeutic connection in the process of } \\
\text { music therapy. }\end{array}$ \\
\hline SF & Family situation and environment surrounding the participants. \\
\hline RF & $\begin{array}{l}\text { Impact of the intervention on the family situation and environment sur- } \\
\text { rounding the participants. }\end{array}$ \\
\hline SA & Information about the academic situation of the participants. \\
\hline TA & $\begin{array}{l}\text { Information that spontaneously emerged in relation to specific alternative } \\
\text { therapies. }\end{array}$ \\
\hline EDAH & $\begin{array}{l}\text { Information relating to the concept, definition and present general situa- } \\
\text { tion surrounding ADHD. }\end{array}$ \\
\hline EDAH_D & All manner of information relating to the process of ADHD diagnosis. \\
\hline EDAH_F & $\begin{array}{l}\text { All manner of information relating to pharmacological prescriptions for } \\
\text { ADHD (families' experiences, opinions, etc.). }\end{array}$ \\
\hline EDAH_NE & $\begin{array}{l}\text { Information relating to the usual emotional needs of children with } \\
\text { ADHD. }\end{array}$ \\
\hline EDAH_SA & $\begin{array}{l}\text { Information relating to the academic situation and difficulties typically } \\
\text { encountered by ADHD-diagnosed children at school - more specifically, } \\
\text { relating to their academic progress. }\end{array}$ \\
\hline
\end{tabular}

Source: compiled by the author.

\subsection{Further investigation: Music therapy and ADHD}

In recent years, we have investigated the possibility of applying music therapy in an educational context with specific cases of ADHD (Acebes-de Pablo \& Carabias-Galindo, 2016), and how music therapy can help in ADHD cases by extended interventions (Acebes-de Pablo \& Giráldez-Hayes, 2019).

The current investigation presents a working method to address ADHD cases which has barely been explored up until now: specific music and imagery techniques. In fact, during the process of designing the intervention, and throughout its conduction, it was necessary on multiple occasions to rethink and adapt our way of working to fit the needs that ADHD-diagnosed children tend to exhibit. 
Thus, as explained in the methodology chapter, it was sometimes necessary for the children to listen to the music with their eyes closed, or to draw whilst the music was playing; at times, they may have needed to move energetically in time with the rhythm and melody to release their physical energy. In any case, the approach was always tailored to each child's characteristics and personal circumstances (their level of attention deficit or hyperactivity, medication they were taking at the time, and so forth).

Thus, different specific methods were devised in view of the need to adapt the Bonny Method of Guided Imagery and Music (BMGIM) to specific contexts. In light of this adaptability, there is the possibility for the intervention process to crystallise into a targeted method. Much like the Music Imagery Relaxation (MIR) and Music Imagery Journey (MIJ) techniques discussed earlier, such a method would have very specific characteristics, geared towards children with diagnosed ADHD. We propose to continue this work in the future, to enhance the solidarity and systematic nature of the method.

\section{FINAL CONSIDERATIONS}

In view of all the findings from the data analysis, discussion and this concluding chapter, I believe this investigation presents a valid intervention method for music therapy, based on music and imagery techniques, which can be built upon through future research and interventions of various types.

After nearly seven years working on this research topic, relating directly to ADHD, the completion of this doctoral thesis marks the closing of what has been one of the most important chapters of my life. During that time, I have learnt a great deal, and experienced vast personal growth.

This study has implications for all professional music therapists helping, day by day, to develop the discipline in my native Spain. The path to broad recognition for this profession is not an easy one. However, through research and daily work in practice and direct intervention, colleagues bring the visibility and recognition which the discipline deserves ever closer. I hope this thesis may provide ideas on the basis of which to continue researching and innovating in our field, and resources for techniques that apply readily to music therapy. 
In addition, this study is intended to be of help to teachers and other professionals involved in intervention in cases of ADHD - psychologists, music therapists, educators, etc. I hope it serves as a source of ideas and orients their thinking about educational or clinical practice, deepening the understanding of the disorder, and the different ways of working with such cases.

Finally, whilst the practical results obtained in this study inevitably carry more weight that a personal perspective, I would like to conclude with a humble reflection.

Over the course of these past seven years, when my research was directly connected with the study of child development, in dealing with both children and adults through my work as a music therapist, I have been able to observe the major impact that the type of education and treatment received during early life have on people's adult lives.

In interventions during childhood, I have heard many times how the environment, to a greater or lesser extent, conditions children's thinking and selfimage, if they are persistently told that they are bad students, stupid, intolerable or other, less polite expressions.

Working with adults, I have witnessed processes of personal development where, some patients had enormous difficulty in managing their emotions and relating to their parents on an adult level, because of events in their childhood.

In closing, I wish to illustrate this idea with a quote from Pearson (1992), which I believe draws an interesting and accurate analogy between the tale of Pinocchio and our experiences of real life, in terms both of child development and personal growth in adulthood:

\section{Becoming Real}

In Pinocchio, Gepetto longs for a son and carves the puppet Pinocchio out of a block of wood. Then the Blue Fairy appears and grants the puppet the capacity to move on his own. Together, Gepetto and the Blue Fairy (...) can make a well behaved puppet, but only Pinocchio can earn the right to be real.

At first, he is a "good" little puppet and does everything he is supposed to do. His first sign of independence is an act of disobedience and betrayal of Gepetto, the Blue Fairy, and his little cricket conscience. He goes off with the rowdy Lampwick to Pleasure Island. (...) 
Pinocchio descends into the depths of instinctual pleasure seeking, but escapes just in time when he recognizes that he and his friends are turning into donkeys. This disorienting experience so shocks Pinocchio that he begins to see the world very differently.

Pinocchio's initiation into the mysteries has four parts. First, he sees the Blue Fairy and learns that he has the potential to become a "real boy". This is the call to the quest. Second, he allows himself to experience his own shadow qualities and the destruction they cause. (...) Finally, upon his return, the Blue Fairy turns him into a real boy because he has earned it: $\mathrm{He}$ has experienced life. He has suffered. He has learned to see with wiser eyes, and therefore to differentiate base pleasures from real bliss, and he has gained a capacity for genuine love. And he has learned to take responsibility for his actions without being debilitated by shame or regret. He has, in short, become real. (p. 60)

Ultimately, Pinocchio, like any other child, has an instinctive understanding of what it truly takes to express himself in the world in terms of what he needs to be (rather than what others expect of him). This journey helps him become real - that is, to find his own way of existing in the world and relating to others in society. If a child (with or without a diagnosis or traits specific to ADHD) is taught continually and from an early age that he is constantly behaving badly or she is a bad child (the children themselves will verbalise this, and it is astonishing how often I have heard children express these ideas in their own words), they will live with that stigma - that feeling of not being good enough for anybody, in any circumstances. In addition, they will frequently assume that pharmacological intervention is the way to become more sociable, easy-going and productive, to fit in with the most widely accepted social model (metaphorically, as Geppetto did when he made Pinocchio).

Children deserve to be respected, loved and valued for what they truly are not for what those around them expect them to be. With this in mind, we need to exercise awareness and humility in terms of our attitudes and decisions in the various nurturing and educational scenarios. We are active participants in these scenarios, and as such, bear a large portion of direct responsibility personal, professional or social. 




\section{REFERENCIAS BIBLIOGRÁFICAS}

Acebes-de Pablo, A. y Carabias-Galindo, D. (2016). El alumnado de primaria con Trastorno por Déficit de Atención/Hiperactividad (TDAH): la Musicoterapia como herramienta integradora dentro del contexto del aula de música. Revista Electrónica de LEEME, 38, 1-16.

Acebes-de Pablo, A. y Giráldez-Hayes, A. (2019). El papel de la Musicoterapia y las terapias alternativas en el tratamiento del TDAH: un estudio exploratorio. Medicina Naturista, 13(1), 15-20.

Aguilar-Cárceles, M. M. (2014). El trastorno por déficit de atención e hiperactividad (TDAH): aspectos jurídico-penales, psicológicos y criminológicos. Madrid: Dykinson.

Aguilar-Millastre, C. (2014). TDAH y dificultades de aprendizaje: guía para padres y educadores. Valencia: Diálogo.

Ainscow, M. y Miles, S. (2009). Desarrollando sistemas de Educación Inclusiva: ¿Cómo podemos hacer progresar las políticas? En C. Giné, D. Duran, J. Font y E. Miquel (coords.), La educación inclusiva. De la exclusión a la plena participación de todo el alumnado (pp. 161-170). Barcelona: Horsori Editorial.

Alonso, V. y Bermell, M. A. (2008). La música como instrumento de evaluación con niños hiperactivos. Boletín de Psicología, 93, 79-97. Recuperado de http://www.uv.es/seoane/boletin/previos/N93-5.pdf

Álvarez, I. (2004). Los beneficios de la música en el tratamiento de la hiperactividad. Filomúsica: Revista de publicación en Internet, 51. Recuperado de http://www.filomusica.com/filo51/hiperactivo.html

Alvin, J. (1967). Musicoterapia. Buenos aires: Paidós.

Alvin, J. (1971). La musicoterapia en los niños autistas. En R. O. Benenzon, Musicoterapia y Educación (pp. 103-112). Buenos Aires: Paidós.

Amador, J. A., Forns., M. y Gonzàlez, M. (2010). Trastorno por déficit de atención con hiperactividad. Madrid: Síntesis. 
American Psychiatric Association (2014). Manual diagnóstico y estadístico de los trastornos mentales. [Diagnostic and Statistical Manual of Mental Disorders] ( $5^{\mathrm{a}}$ ed.). Buenos Aires [etc.]: Editorial Médica Panamericana.

American Psychological Association (2010). Manual de publicaciones de la American Psychological Association. [Publication Manual of the American Psychological Association, Sixth Edition] (3 $3^{\mathrm{a} e d .) . ~ M e ́ x i c o: ~}$ Manual moderno.

Arnaiz, P. (2003). Educación inclusiva: una escuela para todos. Málaga: Ediciones Aljibe.

Arrufat, C. (2017). ¿Magia y TDAH? Padres y maestros, 370, 50-54. doi: pym.i370.y2017.008

Barba, J. J. (2013). La investigación cualitativa en educación en los comienzos del siglo XXI. En M. Díaz y A. Giráldez (coords.), La investigación cualitativa en educación musical (pp. 23-38). Barcelona: Graó.

Barkley, R. A. (1997). Behavioral Inhibition, Sustained Attention, and Executive Functions: Constructing a Unifying Theory of ADHD. Psychological Bulletin, 121(1), 65-94. doi: 10.1037/0033-2909.121.1.65

Barkley, R. A. (1999). Niños hiperactivos: cómo comprender y atender sus necesidades especiales. Barcelona: Paidós.

Barkley, R. A. (2008). El manejo del TDAH en el aula: estrategias para el éxito. En VV. AA., Hiperactivos: estrategias y técnicas para ayudarlos en casa y en la escuela (pp. 38-82). Madrid: LoQueNoExiste.

Barton, L. (2011). La investigación en la educación inclusiva y la difusión de la investigación sobre discapacidad. Revista Interuniversitaria de Formación del Profesorado, 25(1), 63-76. Recuperado de http://www.redalyc.org/articulo.oa?id=27419147004

Beck, B. D., Messel, C., Meyer, S. L., Cordtz, T. O., Sogaard, U., Simonsen, E., \& Moe, T. (2018). Feasibility of trauma-focused Guided Imagery and Music with adult refugees diagnosed with PTDS: A pilot study. Nordic Journal of Music Therapy, 27(1), 67-86. doi: 10.1080/08098131.2017.1286368 
Benasayag, L. (2009a). Deconstrucción neurológica del llamado "ADDH". En L. Benasayag (comp.), TDAH: niños con déficit de atención e hiperactividad: ¿una patología de mercado? Una mirada alternativa con enfoque multidisciplinario (pp. 13-34). Humanes de Madrid (Madrid): CEP.

Benasayag, L. (2009b). Una visión alternativa para el tratamiento del llamado ADDH. En L. Benasayag (comp.), TDAH: niños con déficit de atención e hiperactividad: ¿una patología de mercado? Una mirada alternativa con enfoque multidisciplinario (pp. 209-236). Humanes de Madrid (Madrid): CEP.

Benasayag, L. y Ferreyra, G. E. (2009). “ADDH”: Diagnósticos diferenciales, tratamiento y casuística. En L. Benasayag (comp.), TDAH: niños con déficit de atención e hiperactividad: ¿una patología de mercado? Una mirada alternativa con enfoque multidisciplinario (pp. 107-131). Humanes de Madrid (Madrid): CEP.

Benenzon, R. O. (1971). Musicoterapia y Educación. Buenos Aires: Paidós.

Benenzon, R. O. (2011). Musicoterapia. De la teoría a la práctica (2ª ed.). Barcelona: Paidós Ibérica S.A.

Benzon, W. L. (2009). Music and the Prevention and Amelioration of ADHD: A Theoretical Perspective. Social Science Research Network (SSRN), 1-24. Recuperado de https://papers.ssrn.com/sol3/papers.cfm?abstract_id $=1527090$

Betés, M. (2000). Bases históricas del uso terapéutico de la música. En M. Betés (comp.), Fundamentos de musicoterapia (pp. 23-36). Madrid: Morata.

Bianchi, E. (2012). Problematizando la noción de trastorno en el TDAH e influencia del manual DSM. Revista Latinoamericana de Ciencias Sociales, Niñez y Juventud, 10(2), 1012-1038. Recuperado de http://dialnet.unirioja.es/servlet/articulo?codigo $=4023862$

Bignone, I. M., Serrate, M. y Diez, R. A. (2009). Fármacovigilancia de las drogas usadas en niños con diagnóstico de ADD/H o ADHD. En L. Benasayag (comp.), TDAH: niños con déficit de atención e hiperactividad: ¿una patología de mercado? Una mirada alternativa con enfoque multidisciplinario (pp. 173-207). Humanes de Madrid (Madrid): CEP. 
Blake, R. L. (1994). Vietnam Veterans with Post Traumatic Stress Disorder: Finding from a Music and Imagery Project. Journal of the Association for Music and Imagery, 3, 5-17.

Blasco, F. y Sanjosé, L. V. (2000). Música y afectividad: La música como medio de exploración de las emociones humanas. En M. Betés (comp.), Fundamentos de musicoterapia (pp. 150-173). Madrid: Morata.

Bogdan. R., \& Biklen, S. (2003). Qualitative research for education: an introduction to theories and methods. New York: Allyn \& Bacon.

Bonny, H. L. (1986). Music and Healing. Music Therapy, 6(1), 3-12. Recuperado de https://bit.ly/2NJm6pH

Bonny, H. L., y Savary, L. M. (1994). La música y su mente. Madrid: EDAF.

Borling, J.E., \& Miller, R.G. (2007). Conscious Drumming: Drumming from the Heart. In B. Matney (Ed.), Tataku: The use of percussion in music therapy (pp. 226-232). Denton, TX: Sarsen Publishers.

Bosco, J. (2000). Danza, movimiento y terapia. En M. Betés (comp.), Fundamentos de musicoterapia (pp. 102-109). Madrid: Morata.

Briseño, A. J. (2019). La influencia de la musicoterapia en la mejora de niveles de atención y percepción de alumnado escolarizado entre 6 y 8 años con diagnóstico de TDAH. Una propuesta de intervención. Revista de Investigación en Musicoterapia, 3, 86-107. doi: 10.15366/rim2019.3.006

Bruscia, K. E. (1996). Definiendo musicoterapia. Salamanca: Amarú Ediciones.

Bruscia, K. E. (2002a). A psychodynamic orientation to the Bonny Method. In K. E. Bruscia, \& D. E. Grocke (eds.), Guided Imagery and Music: The Bonny Method and beyond (pp. 225-243). Gilsum, NH: Barcelona Publishers.

Bruscia, K. E. (2002b). The Boundaries of Guided Imagery and Music (GIM) and the Bonny Method. In K. E. Bruscia, \& D. E. Grocke (eds.), Guided Imagery and Music: The Bonny Method and beyond (pp. 3761). Gilsum, NH: Barcelona Publishers. 
Bruscia, K. E. (2007). Musicoterapia. Métodos y prácticas. Ciudad de México: Pax México.

Bruscia, K. E. (2010). Modelos de improvisación en musicoterapia. VitoriaGasteiz: AgrupArte Producciones.

Burns, D. S., \& Masko, M. K. (2016). Combining interpretivist with objectivist methods in explanatory sequential designs. In B. L. Wheeler, \& K. M. Murphy (Eds.), Music Therapy Research (3 ${ }^{\text {rd }}$ Ed.) (pp. 19931209). Dallas: Barcelona Publishers.

Bush, C. A. (1995). Healing Imagery and Music: Pathways to the Inner Self. United States: Rudra Press.

Casanova, M. A. (2011). De la educación especial a la educación inclusiva. Estado de la cuestión y retos pertinentes. CEE Participación Educativa, 18, 2-24. Recuperado de https://goo.g1/3j4R9E

Castaño, M. F. y Ortiz, T. F. (2019). Efecto del arte terapia con la técnica del mandala en niños con déficit de atención con hiperactividad (Trabajo Fin de Grado Psicología). Recuperado de http://45.5.172.45/handle/10819/7039

Catalá-López, F., Peiró, S., Ridao, M., Sanfélix-Gimeno, G., Gènova-Maleras, R., \& Catalá, M. A. (2012). Prevalence of attention deficit hyperactivity disorder among children and adolescents in Spain: a systematic review and meta-analysis of epidemiological studies. BMC Psychiatry, 12(168), 1-13. doi: 10.1186/1471-244X-12-168

Cavas, M. (2006). Tratamiento farmacológico del trastorno por déficit de atención/hiperactividad. En J. F. Guerrero (coord.), Creatividad, ingenio e hiperconcentración: las ventajas de ser hiperactivo (TDAH) (pp. 125-135). Archidona (Málaga): Aljibe.

Clark, M. F. (2002). Evolution of the Bonny Method of Guided Imagery and Music (BMGIM). In K. E. Bruscia \& D. E. Grocke (eds.), Guided Imagery and Music: The Bonny Method and Beyond (pp. 5-27). Gilsum, NH: Barcelona Publishers.

Clarkson, G. (1995). Adapting a Guided Imagery and Music series for a nonverbal man with autism. Journal of the Association for Music and Imagery, 4, 121-138. 
Cohen, N. (2015). The Floating Leaf: Adapted Bonny Method Sessions for a Musician with Brain Damage. In D. E. Grocke, \& T. Moe, Guided Imagery and Music (GIM) and Music Imagery Methods for Individual and Group Therapy (pp. 141-152). London: Jessica Kingsley Publishers.

Colegrove, V. M., Havighurst, S. S., \& Kehoe, C. E. (2019). Emotion regulation during conflict interaction after a systemic music intervention: Understanding changes for parents with a trauma history and their adolescent. Nordinc Journal of Music Therapy, 28(5), 405-425. doi: 10.1080/08098131.2019.1616807

Corraliza, J. A. y Collado, S. (2011). La naturaleza cercana como moderadora del estrés infantil. Psicothema, 23(2), 221-226. Recuperado de http://www.unioviedo.es/reunido/index.php/PST/article/viewFile/9026/8890

Davis, W. B., Gfeller, K. E. y Thaut, M. H. (2012). Introducción a la musicoterapia: teoría y práctica. Barcelona: Boileau.

Dewi, E. K., Rusmawati, D., \& Ratnaningsih, I. Z. (2015). The Effect of Music and Motoric Movement Intervention to Increase Attention among Elementary School Studentsin Semarang Central Java. Procedia environmental Sciences, 23, 179-185. doi: 10.1016/j.proenv.2015.01.028

Echeita, G. (2011). El proceso de inclusión educativa en España. ¡Quien bien te quiere te hará llorar! CEE Participación Educativa, 18, 117-128. Recuperado de https://goo.g1/3j4R9E

Echeita, G. y Ainscow, M. (2011). La educación inclusiva como derecho. Marco de referencia y pautas de acción para el desarrollo de una revolución pendiente. Tejuelo, 12, 26-46. Recuperado de https://dialnet.unirioja.es/servlet/articulo?codigo $=3736956$

Elboj, C., Puigdellívol, I., Soler, M. y Valls, R. (2005). Comunidades de aprendizaje. Transformar la educación. Barcelona: Graó.

Fernández, M. A. (2018). El TDAH y los trastornos del neurodesarrollo: un viaje de las sombras a la luz en unos cuantos capítulos. Alcalá la Real: Formación Alcalá. 
Fernández-Batanero, J. M. (2008). Educación especial: Una aproximación a la investigación en el contexto español. Revista Mexicana de Investigación Educativa, 13(38), 945-968. Recuperado de https://goo.gl/v3vxp1

Franco, A. (2012). Temas controversiales en el TDAH. Revista latinoamericana de bioética, 12(2), 100-105. Recuperado de https://goo.gl/o616iT

Farré, A. y Narbona, J. (2013). EDAH. Escalas para la evaluación del trastorno por Déficit de Atención con Hiperactividad ( $7^{\mathrm{a}}$ Ed.). Madrid: TEA.

Ferrari, K. D. (2013). Musicoterapia: Aspectos de la sistematización y la evaluación de la práctica clínica. Buenos Aires: MTD Ediciones.

Filella-Guiu, G., Pérez-Escoda, N., Agulló, M. J. y Oriol, X. (2014). Resultados de la aplicación de un programa de educación emocional en Educación Primaria. Estudios Sobre Educación, 26, 125-147.

Flecha, R. y Puigvert, L. (2015). Las comunidades de aprendizaje: una apuesta por la igualdad educativa. Cultura para la esperanza: instrumento de análisis de la realidad, 99, 29-35. Recuperado de https://dialnet.unirioja.es/servlet/articulo?codigo=5179809

Flick, U. (2004). Introducción a la investigación cualitativa. Madrid: Morata.

Flick, U. (2014). El diseño de investigación cualitativa. Madrid: Morata.

Fosati, A. y Segurado, B. (2014). Expresión plástica y educación infantil. En J. Caja (coord.), La educación visual y plástica hoy ( $8^{a}$ reimp.) (pp. 81-122). Barcelona: Graó.

Fridman, R. (1997). La música para el niño por nacer. Salamanca: Amarú Ediciones.

Fugle, G. K. (2015). "The Rhythm that Scares the Monster". Music and Imagery for a Child with Complex Trauma after Child Abuse and Neglect. In D. E. Grocke, \& T. Moe, Guided Imagery and Music (GIM) and Music Imagery Methods for Individual and Group Therapy (pp. 52-62). London: Jessica Kingsley Publishers. 
Gallego, M. (2015). Educación emocional con y sin TDAH. Madrid: EOS.

Gálvez, J. J. (2010). Trastorno por Déficit de Atención con Hiperactividad (TDAH). Medicina Naturista, 4(1), 9-14. Recuperado de: http://dialnet.unirioja.es/servlet/articulo?codigo $=3142829$

García-Carrión, R., Racionero, S., Torrego-González, A. y García-Monge, A. (2013). Las comunidades de aprendizaje, un modelo transformador en Educación. En H. Rodríguez y L. Torrego (coords.), Educación inclusiva, equidad y derecho a la diferencia (pp. 141-157). Madrid: Wolters Kluwer España.

García-González, N. (2014). Programa de intervención educativa para alumnos de educación infantil con presencia sintomatológica de TDAH (Tesis Doctoral). Recuperado de https://cutt.ly/ehys3oO

García-Huidobro, F. (2015). Intervención Educativa Musical en niños con Dificultades de Atención (Tesis Doctoral). Recuperada de https://dialnet.unirioja.es/servlet/tesis?codigo $=117348$

Garrido-Landívar, E. (2017). 500 preguntas y respuestas sobre la hiperactividad (TDAH). Pamplona: Ediciones Eunate.

Gasalberti, D. (2006). Alternative Therapies for Children and Youth with Special Health Care Needs. Journal of Pediatric Health Care, 20, 133-136. doi:10.1016/j.pedhc.2005.12.015

Gerge, A., Pedersen, I. G., Gattino, G. S., \& Wärja, M. (2020). The body in the mind - Assessing the phenomenal self through paintings created by gynaecological cancer survivors. The Arts in Psychotherapy, 71. doi: 10.1016/j.aip.2020.101691

Gimeno, M. M. (2005). Orientación teórica del Método Bonny de Imaginación Guiada con Música (BMGIM) un método transformativo. Aloma: revista de psicología, ciències de l'educació i de l'esport, 16, 131-142.

Gimeno, M. M. (2010). The Effect of Music and Imagery to Induce Relaxation and Reduce Nausea and Emesis in Patients With Cancer Undergoing Chemotherapy Treatment. Music and Medicine, 2(3), 174-181. doi: 10.1177/1943862110374622 
Gimeno, M. M. (2015). MED-GIM Adaptations of the Bonny Method for Medical Patients. In D. E. Grocke, \& T. Moe, Guided Imagery and Music (GIM) and Music Imagery Methods for Individual and Group Therapy (pp. 178-188). London: Jessica Kingsley Publishers.

Gimeno-Sacristán, J. (2002). Hacerse cargo de la heterogeneidad. Cuadernos de Pedagogía, 311, 52-55. Recuperado de http://educar.unileon.es/Didactic/Temas/CdP31102.pdf

Giné, C. (2009). Aportaciones al concepto de inclusión. Aportación de los organismos internacionales. En C. Giné, D. Duran, J. Font y E. Miquel (coords.), La educación inclusiva. De la exclusión a la plena participación de todo el alumnado (pp. 13-24). Barcelona: Horsori Editorial.

Grof, S. (1999). La mente holotrópica (2 ${ }^{\mathrm{a}}$ Ed.). Barcelona: Kairós.

Grocke, D. y Wigram, T. (2011). Métodos receptivos en musicoterapia. Vitoria-Gasteiz: AgrupArte Producciones.

Guerrero, J. F. (2006). Yo soy dos y estoy en cada uno de los dos por completo: de San Agustín al gato de Schröndinger o las dos caras de la persona con hiperatividad (TDAH). En J. F. Guerrero (coord.), Creatividad, ingenio e hiperconcentración: las ventajas de ser hiperactivo (TDAH) (pp. 9-45). Málaga: Aljibe.

Guerrero, J. F. y Pérez, R. (2011). El alumnado con TDAH (hiperactividad) como colectivo en riesgo de exclusión social: propuestas de acción y mejora. Revista Ruedes

Guinot, J. (2013). Mitos y realidades sobre el TDAH. Hiperactividad y déficit de atención. Tarragona: Altaria.

Guirado, A. y Sepúlveda, L. (2012). El alumnado con necesidades educativas especiales. Una mirada histórica de la Educación Especial desde normativas legales. Revista Qurriculum, 25, 77-102. Recuperado de https://dialnet.unirioja.es/servlet/articulo?codigo=3943630

Hargreaves, D. (1998). Música y desarrollo psicológico. Barcelona: Graó. 
Harvey, E. A., Lugo-Candelas, E. I., \& Breaux, R. P. (2015). Longitudinal Changes in Individual Symptoms Across the Preschool Years in Children with ADHD. Journal of Clinical Child and Adolescent Psychology, 44(4), 580-594.

Henley, D. (1998). Art therapy in a socialization program for children with attention deficit hyperactivity disorder. American Journal of Art Therapy, 37(1), 2-12. Recuperado de https://cutt.ly/bhyoFG9

Henley, D. (1999). Facilitating socialization within a therapeutic camp setting for children with attention deficits utilizing the expressive therapies. American Journal of Art Therapy, 38(2), 40. Recuperado de https://cutt.ly/whyoJBS

Hernández-Ruiz, E. (2019). How is music processed? Tentative answers from cognitive neuroscience. Nordic Journal of Music Therapy, 28(4), 315332. doi: $10.1080 / 08098131.2019 .1587785$

Hernández-Sampieri, R., Fernández, C. y Baptista, P. (2014). Metodología de la investigación ( $6^{\mathrm{a}}$ ed.). México: McGraw-Hill.

Hertrampf, R. (2015). Group Music and Imagery (GrpMI) Therapy with Female Cancer Patients. In D. E. Grocke, \& T. Moe, Guided Imagery and Music (GIM) and Music Imagery Methods for Individual and Group Therapy (pp. 241-252). London: Jessica Kingsley Publishers.

Jackson, N. A. (2003). "A survey of Music Therapy Methods and Their Role in the Treatment of Early Elementary School Children with ADHD. Journal of Music Therapy, 40(4), 302-323.

Jaussi, M. L. (2006). Comunidades de aprendizaje. En VVAA, Transformando la escuela: comunidades de aprendizaje (pp. 29-34). Barcelona: Graó.

Kang, H. J. (2017). Supportive music and imagery with sandplay for child witnesses of domestic violence: A pilot study report. The Arts in Psychotherapy, 53, 72-79. doi: 10.1016/j.aip.2017.01.009

Kellogg, R. (1979). Análisis de la expresión plástica del preescolar. Madrid: Cincel. 
Kim, J., \& Stegemann, T. (2016). Music listening for children and adolescents in health care contexts: A systematic review. The Arts in Psychotherapy, 51, 72-85. doi: 10.1016/j.aip.2016.08.007

Khun, T. S. (1970). The Structure of Scientific Revolutions ( $2^{\text {nd }}$ Ed.). Chicago: University of Chicago.

Kvale, S. (2011). Las entrevistas en Investigación Cualitativa. Madrid: Morata.

Láez, M. C., Requejo, M., Silvano, J. J. y Velasco, M. C. (2011). Protocolo de Coordinación del trastorno por déficit de atención e hiperactividad. Valladolid: Gerencia Regional de Salud. Recuperado de https://cutt.ly/VhypnAO

Lacárcel, J. (1990). Musicoterapia en educación especial. Murcia: Universidad de Murcia.

Lacárcel, J. (2006). Importancia de los “arquetipos sonoros" en musicoterapia aplicada a niños con necesidades educativas especiales. Intervención en el alumnado con necesidades educativas especiales, 37, 1-8. Recuperado de https://bit.ly/38vQ3Dy

LaGasse, A. B., Manning, R. C. B., Crasta, J. E., Gavin, W. J., \& Davies, P. L. (2019). Assessing the Impact of Music Therapy on Sensory Gating and Attention in Children With Autism: A Pilot and Feasibility Study. Journal of Music Therapy, 56(3), 287-314. doi: 10.1093/jmt/thz008

Leblanc, A. (1987). The Development of Music Preference in Children. In J. C. Peery, I. W. Peery, \& T. W. Draper (Eds.), Music and Child Development (pp. 137-157). New York: Springer.

Lecumberri, M. M. (2016). Comprendiendo el TDAH. Alcalá la Real: Formación Alcalá.

Leivinson, C. A. (2005). Musicoterapia y Neurología. Música, terapia y comunicación: Revista de Musicoterapia, 25, 59-76. Recuperado de https://dialnet.unirioja.es/servlet/articulo?codigo $=3305548$

León-Guerrero, M. J. (2018). La inclusion educativa del alumnado con TDAH: rompiendo las barreras curriculares y organizativas en los centros escolares de Educación Primaria. Madrid: La Muralla. 
Lin, M. F., Hsu, M. C., Chang, H. J., Hsu, Y. Y., Chou, M. H., \& Crawford, P. (2010). Pivotal moments and changes in the Bonny Method of Guided Imagery and Music for patients with depression. Journal of clinical Nursing, 19, 1139-1148. doi: 10.1111/j.13652702.2009.03140.x

Llamas, J. C. (2014). Alumnos con TDAH y Musicoterapia: cómo trabajar en primaria para mejorar el desarrollo personal y escolar de estos niños. Artseduca, 8, 136-157. Recuperado de https://bit.ly/2ZDdUgu

Llopis, C. (2011). Aprendizaje cooperativo. Crítica, 972, 37-41. Recuperado de https://goo.gl/Rr3zDo

Lobato, X. (2001). Diversidad y educación. La escuela inclusiva y el fortalecimiento como estrategia de cambio. Barcelona: Paidós.

Lorenzo, A. e Ibarrola, B. (2000). Modelo humanista-transpersonal. En M. Betés (comp.), Fundamentos de musicoterapia (pp. 364-378). Madrid: Morata.

López, G. y Acuña, S. (2011). Aprendizaje cooperativo en el aula. Inventio, la génesis de la cultura universitaria en Morelos, 14, 28-37. Recuperado de https://bit.ly/2Av7k2T

López, V. M., Monjas, R. y Pérez, D. (2003). Buscando alternativas a la forma de entender y practicar la educación física escolar. Barcelona: INDE.

Louv, r. (2008). The Last Child in the Woods. Saving our children from Nature-Deficit Disorder. Chapel Hill, NC: Algonquin Books.

Louv, R. (2009). Do our kids have nature-deficit disorder? Educational Leadership, 67(4), 24-30. Recuperado de https://goo.gl/AQd4VJ

Lowenfeld, V. y Brittain, W. L. (1980). Desarrollo de la capacidad creadora ( $6^{\mathrm{a}}$ ed.). Buenos Aires: Kapelusz.

Lucas, M. (2013). Introducción a la musicoterapia. Madrid: Síntesis.

Machón, A. (2009). Los dibujos de los niños. Génesis y naturaleza de la representación gráfica. Un estudio evolutivo. Madrid: Cátedra. 
Magee, W. L. (2016). Combining objectivist with interpretivist methods in exploratory sequential designs. In B. L. Wheeler, \& K. M. Murphy (Eds.), Music Therapy Research (3 ${ }^{\text {rd }}$ Ed.) (pp. 1210-1220). Dallas: Barcelona Publishers.

Manterola, C., Quiroz, G., Salazar, P. y García, N. (2019). Metodología de los tipos y diseños de estudio más frecuentemente utilizados en investigación clínica. Revista Médica Clínica Las Condes, 30(1), 36-49. doi: 10.1016/j.rmclc.2018.11.005

March-Luján, V. A. (2017). Estudio del impacto de la intervención con una adaptación grupal del Método de Musicoterapia BMGIM en pacientes con enfermedad inflamatoria intestinal (Enfermedad de Crohn y Colitis Ulcerosa) (Tesis Doctoral). Recuperada de https://www.educacion.gob.es/teseo/mostrarSeleccion.do

Martí, P. (2000). Visión general y teoría de la musicoterapia. En M. Betés (comp.), Fundamentos de musicoterapia (pp. 287-305). Madrid: Morata.

Martín-Navarro, N. (2012). Caracterización y evolución del TDAH en la etapa adulta. Cuadernos de psiquiatría comunitaria, 11(2), 87-105. Recuperado de http://aen.es/wp-content/uploads/2014/06/cuaderno_psiquiatria_comunitaria_2_2012.pdf

Mateos, L. A. y San Romualdo, B. (2012). Musicoterapia y Trastorno por Déficit de Atención e Hiperactividad (TDAH). En M. Mercadal-Brotons y P. Martí, Música, Musicoterapia y Discapacidad (pp. 219-230). Badalona: Editorial Médica Jims.

McClain, F. J. (2000). Music Therapy Supervision: a Review of the Literature. En M. Forinash (ed.), Music Therapy Supervision (pp. 9-17). Gilsum, NH: Barcelona Publishers.

Mercadal-Brotons, M. (2000). Modelo conductista. En M. Betés (comp.), Fundamentos de musicoterapia (pp. 309-317). Madrid: Morata.

Montero, I. y León, O. G. (2002). Clasificación y descripción de las metodologías de investigación en Psicología. International Journal of Clinical and Health Psychology, 2(3), 503-508. Recuperado de https://www.redalyc.org/pdf/337/33720308.pdf 
Moore, R., \& Gillette. (1993). La nueva masculinidad: Rey, Guerrero, Mago y Amante. Barcelona: Paidós Ibérica.

Muller, B. (2014). Variations in Guided Imagery and Music: Taking a Closer Look. University Park: Barcelona Publishers.

Myers, C. S. (1922). Individual differences in listening to music. British Journal of Psychology, 13(1), 52-71.

Nizar, N. C. (2017). The Role of Psychological Intervention to Improve Attention ADHD Child. Advances in Social Science, Education and Humanities Research, 133, 113-117. doi: 10.2991/acpch-17.2018.51

Nordoff, P. \& Robbins, C. (1971). Therapy in Music for Handicapped Children. London: Victor Gollancz.

Pearson, C. S. (1992). Despertando los héroes interiores. Madrid: Mirach, S.A.

Pehk, A. (2015). TEAM-GIM: A Creative Group Method for Team Building Institutions and Organizations. In D. E. Grocke, \& T. Moe, Guided Imagery and Music (GIM) and Music Imagery Methods for Individual and Group Therapy (pp. 211-220). London: Jessica Kingsley Publishers.

Pelayo-Terán, J. M., Trabajo, P. y Zapico-Merayo, Y. (2012). Aspectos históricos y evolución del concepto de Trastorno por Déficit de Atención e Hiperactividad (TDAH): Mitos y realidades. Cuadernos de psiquiatría comunitaria, 11(2), 7-20. Recuperado de http://aen.es/wp-content/uploads/2014/06/cuaderno_psiquiatria_comunitaria_2_2012.pdf

Peñalba, A. (2010). Musicoterapia e hiperactividad. Revista Musical Catalana, 303, 4-6.

Pérez-Galán, R. (2009). La redefinición teórico-práctica del trastorno TDAH desde una perspectiva más comprensiva y positiva: de lo que fue a lo que debe ser. En L. Benasayag (comp.), TDAH: niños con déficit de atención e hiperactividad: ¿una patología de mercado? Una mirada alternativa con enfoque multidisciplinario (pp. 13-34). Humanes de Madrid (Madrid): CEP. 
Pérez-Gómez, A. I. (2002). Un aprendizaje diverso y relevante. Cuadernos de Pedagogía, 311, 66-70. Recuperado de http://educar.unileon.es/Didactic/Temas/CP311022.pdf

Poch, S. (2011). Compendio de Musicoterapia. I (2a Ed.). Barcelona: Herder.

Powell, L. T. (2007). Stories, Music, and Imagery. A Doorway to a Child's Self-Esteem. Tarentum: Word Association Publishers.

Priestley, M. (1994). Essays on Analytical Music Therapy. Phoenixville: Barcelona Publishers.

Pujolàs, P. (2012). Aulas inclusivas y aprendizaje cooperativo. Educatio Siglo XXI, 30(1), 89-112. Recuperado de http://revistas.um.es/educatio/article/view/149151/132141

Quinlan, R., Schweitzer, R. D., Khawaja, N., \& Griffin, J. (2015). Evaluation of a school-based creative arts therapy programme for adolescents from refugee backgrounds. The Arts in Psychotherapy, 47, 72-78. doi: 10.1016/j.aip.2015.09.006

Rekalde, I. y García, J. (2015). El aprendizaje basado en proyectos: un constante desafío. Innovación Educativa, 25, 219-234. Recuperado de http://www.usc.es/revistas/index.php/ie/article/view/2304

Rickson, D. J. (2006). Instructional and Improvisational Models of Music Therapy with Adolescents who have Attention Deficit Hyperactivity Disorder (ADHD): A Comparison on the effects of Motor Impulsivity. Journal of Music Therapy, 43(1), 39-62.

Ricoy, C. (2006). Contribución sobre los paradigmas de investigación. Educação. Revista do Centro de Educação, 31(1), 11-22. Recuperado de http://www.redalyc.org/pdf/1171/117117257002.pdf

Rodrigo, M. S. (2000). Música: terapia de música y sonido. Madrid: Musicalis.

Rodríguez-Fuentes, A. (2005). Investigación sobre necesidades educativas especiales: ¿qué y cómo investigar en Educación Especial? Electronic Journal of Research in Educational Psychology, 3(5), 97-111. Recuperado de http://www.investigacion-psicopedagogica.org/revista/articulos/5/espannol/Art_5_41.pdf 
Rodríguez-Gómez, G., Gil, J. y García, E. (1999). Metodología de la investigación cualitativa ( $2^{\mathrm{a}}$ ed.). Málaga: Aljibe.

Rodríguez, H., Torrego, L. y Flecha, R. (2013). Marco de referencia internacional y modelos emergentes en educación inclusiva. En H. Rodríguez y L. Torrego (coords.), Educación inclusiva, equidad y derecho a la diferencia (pp. 15-33). Madrid: Wolters Kluwer España.

Robb, S. L. et al. (2018). Reporting quality of music intervention research in healthcare: A systematic review. Complementary Therapies in Medicine, 38, 24-41. doi: 10.1016/j.ctim.2018.02.008

Roy, M. (1996). Guided Imagery and Music group experiences with adolescent girls in a high school setting. Journal of the Association for Music and Imagery, 5, 61-74.

Rubiales, J., Bakker, L. y Delgado, I D. (2011). Organización y planificación en niños con TDAH: evaluación y propuesta de un programa de estimulación. Cuadernos de Neuropsicología, 5(2), 145-161. Recuperado de http://www.cnps.cl/index.php/cnps/article/view/126/113

Ruiz, J. I. (2012). Metodología de la investigación cualitativa (5 ${ }^{\mathrm{a}}$ Ed.). Bilbao: Universidad de Deusto.

Santos-Guerra, M. A. (2002). Organizar la diversidad. Cuadernos de Pedagogía, 311, 76-80. Recuperado de https://cutt.ly/qhuXzEh

Shamdasani, S. (2012). Liber Novus: El libro rojo de C. G. Jung. En L. Pinkler y M. S. Costantini (Eds.), El libro rojo. Carl Gustav Jung (pp. 76-156). Buenos Aires: Elhilodariadna.

Short, A. E. (2007). Theme and variations on quietness: Relaxation-focused music and imagery in aged care. Australian Journal of Music Therapy, $18,39-61$.

Skaggs, R. (1997). Music-centered creative arts in a sex offender treatment program for male juveniles. Music Therapy Perspectives, 15(2), 7378.

Slater, J. L., \& Tate, M. C. (2018). Timing Deficits in ADHD: Insights From the Neuroscience of Musical Rhythm. Frontiers in Computational Neuroscience, 12(51). doi: 10.3389/fncom.2018.00051 
Stake, R. (1999). Investigación con estudio de casos (2a ed.). Madrid: Morata.

Stokes-Stearns, S. (2014). The Music of Paradox. Harmonizing Shadow and Light. Journal of the Association for Music and Imagery, 14, 75-104.

Summer, L. (2010). Music therapy and depression: Uncovering re- sources in music and imagery. In A. Meadows (Ed.), Developments in music therapy practices: Case study perspectives (pp. 486-500). Gilsum, NH: Barcelona Publishers.

Tarrida, J. (2000). Salud activa. Técnicas de diagnóstico y terapias alternativas. Barcelona: Plaza y Janés.

Taylor, S. J. y Bogdan, R. (2010). Introducción a los métodos cualitativos de investigación. La búsqueda de significados (13 ${ }^{\mathrm{a}}$ reimp.). Barcelona: Paidós.

Tójar, J. C. (2006). Investigación cualitativa: comprender y actuar. Madrid. La Muralla.

Torres, E. (2015). Group Music and Imagery (GMI) for Treating Fibromyalgia: Listening to Oneself as a Path of Opening and Transformation. In D. E. Grocke, \& T. Moe, Guided Imagery and Music (GIM) and Music Imagery Methods for Individual and Group Therapy (pp. 267276). London: Jessica Kingsley Publishers.

Ubieto, J. R. (2014). TDAH: hablar con el cuerpo. Barcelona: UOC.

UNESCO (1990). Declaración Mundial sobre Educación para Todos: Satisfacción de las Necesidades Básicas de Aprendizaje. Nueva York.

UNESCO (2005). Guidelines for inclusion: Ensuring Access to Education for All. París: UNESCO. Recuperado de http://unesdoc.unesco.org/images/0014/001402/140224e.pdf

Usher, R. y Bryant, L. (1992). La educación de adultos como teoría, práctica e investigación. Madrid: Morata.

Vaillancourt, G. (2009). Música y musicoterapia: su importancia en el desarrollo infantil. Madrid: Narcea, D.L. 
van der Kolk, B. (2015). El cuerpo lleva la cuenta: Cerebro, mente y cuerpo en la sanación del trauma. Barcelona: Eleftheria.

Vega, F. M. (2012). Protocolo de intervención en TDAH. Cuadernos de psiquiatría comunitaria, 11(2), 21-35. Recuperado de https://cutt.ly/1hyiDoA

Ventre, M. (2002). The individual form of the Bonny Method of Guided Imagery and Music (BMGIM). In K. E. Bruscia \& D. E. Grocke (eds.), Guided Imagery and Music: The Bonny Method and Beyond (pp. 2935). Gilsum, NH: Barcelona Publishers.

Vera, A. (2000). Introducción a la Psicología de la Música. En M. Betés (comp.), Fundamentos de musicoterapia (pp. 114-119). Madrid: Morata.

Verd, J. M. y Lozares, C. (2016). Introducción a la investigación cualitativa. Fases, métodos y técnicas. Madrid: Síntesis.

Verdú, F. T. (2018). OMS u OMC. Sobre las medicinas tradicionales y complementarias. Medicina Naturista, 12(1), 40-46. Recuperado de https://cutt.ly/Ihyhae1

Vergara, J. J. (2016). Aprendo porque quiero: el aprendizaje basado en proyectos $(A B P)$, paso a paso ( $2^{\text {a }}$ Ed.). Madrid: SM.

Viega, M. (2009). Body listening as a method of understanding a music program used in the Bonny Method of Guided Imagery and Music. Journal of the Association for Music and Imagery, 12, 1-27.

Vieillard, S., Peretz, I., Gosselin, N., Khalfa, S., Gagnon, L., \& Bouchard, B. (2008). Happy, Sad, Scary and Peaceful Musical Excerpts for Research on Emotions. Cognition and Emotion, 22, 750-752. Recuperado de https://cutt.ly/uhuXgle

Vilá, S. (2015). Improvisation, Guided Imagery and Music (GIM) and Mandala Drawing with an 11-Year-Old Girl. In D. E. Grocke, \& T. Moe, Guided Imagery and Music (GIM) and Music Imagery Methods for Individual and Group Therapy (pp. 43-52). London: Jessica Kingsley Publishers. 
Wheeler, B. L. (2016). Principles of Interpretivist Research. In B. L. Wheeler, $\&$ K. M. Murphy (Eds.), Music Therapy Research (3 ${ }^{\text {rd }}$ Ed.) (pp. 294314). Dallas: Barcelona Publishers.

Wiebe, J. E. (2007). ADHD, the Classroom and Music: A Case Study (Master Thesis). Recuperado de

http://ecommons.usask.ca/bitstream/handle/10388/etd-09162007165847/wiebe_j.pdf

Wigle-Justice, R., \& Kasayka, R. (1999). Guided Imagery and Music with cancer patients. In C. Dileo (Ed.), Music therapy and medicine: Theoretical and clinical applications (pp. 23-30). Silver Spring, MD: American Music Therapy Association.

Wigram, T., Pedersen, I. N. y Bonde, L. O. (2011). Guía completa de musicoterapia. Vitoria-Gasteiz: AgrupArte Producciones. 
